National Wildlife Health Center

\title{
Baylisascaris Larva Migrans
}

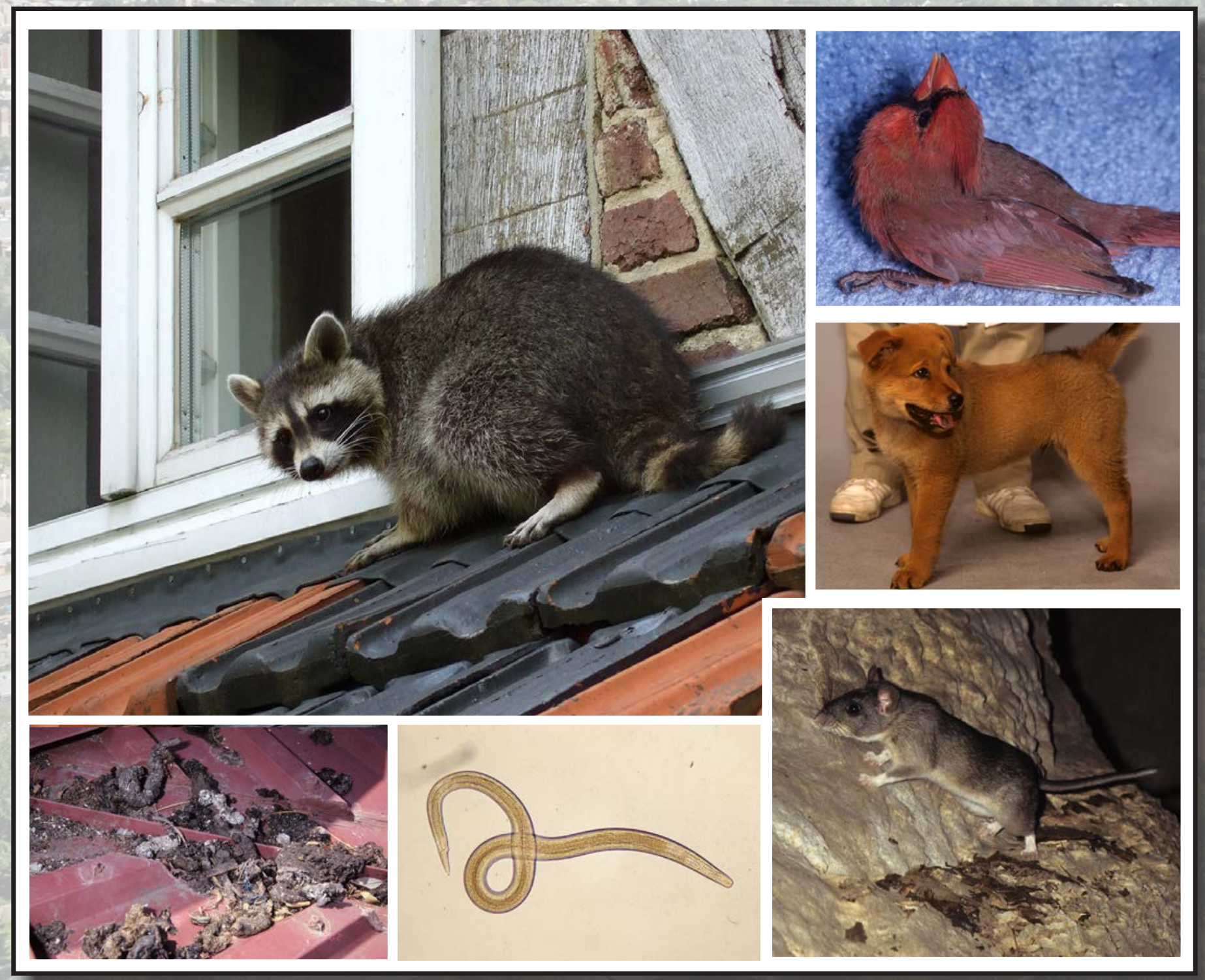

Circular 1412

U.S. Department of the Interior

U.S. Geological Survey 


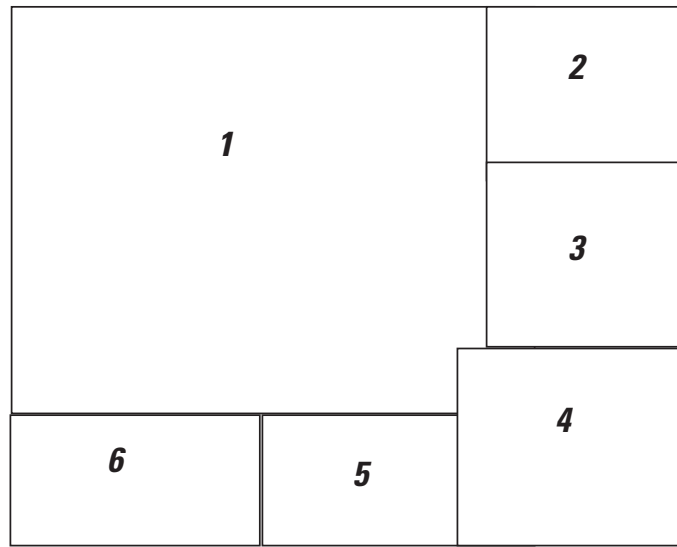

\section{Cover artwork:}

Background image: Chicago view with Chase Park in foreground, photo by YoChicago.com;

1. Common raccoon, Germany, photo by Carsten Volkwein;

2. Cardinal with neural larva migrans, photo by Kevin Kazacos and Sam Royer;

3. Young dog found to be infected with B. procyonis, photo by Sam Royer;

4. Allegheny woodrat in an Indiana cave, photo by Kevin Kazacos;

5. B. procyonis larva from brain squash of conure, photo by Kevin Kazacos and Sam Royer;

6. Raccoon latrine on rooftop, photo by William J. Murray. 


\section{Baylisascaris Larva Migrans}

By Kevin R. Kazacos

Edited by Rachel C. Abbott and Charles van Riper, III

USGS National Wildlife Health Center

Circular 1412

U.S. Department of the Interior

U.S. Geological Survey 


\title{
U.S. Department of the Interior SALLY JEWELL, Secretary
}

\author{
U.S. Geological Survey \\ Suzette M. Kimball, Director
}

U.S. Geological Survey, Reston, Virginia: 2016

For more information on the USGS —-the Federal source for science about the Earth, its natural and living resources, natural hazards, and the environment-visit http://www.usgs.gov or call 1-888-ASK-USGS.

For an overview of USGS information products, including maps, imagery, and publications, visit http://www.usgs.gov/pubprod/.

Any use of trade, firm, or product names is for descriptive purposes only and does not imply endorsement by the U.S. Government.

Although this information product, for the most part, is in the public domain, it also may contain copyrighted materials as noted in the text. Permission to reproduce copyrighted items must be secured from the copyright owner.

Suggested citation:

Kazacos, K.R., 2016, Baylisascaris Larva Migrans: U.S. Geological Survey Circular 1412, 122 p., 3 appendixes, http://dx.doi.org/10.3133/cir1412.

\section{Library of Congress Cataloging-in-Publication Data}

Names: Kazacos, Kevin R., author.

Title: Baylisascaris larva migrans / by Kevin R. Kazacos.

Description: Reston, Viriginia : United States Department of the Interior,

U.S. Geological Survey, 2016. | Series: U.S. Geological Survey circular ;

$$
1412
$$

Identifiers: LCCN 2016009973 | ISBN 9781411340299

Subjects: LCSH: Raccoons as carriers of disease. | Baylisascaris procyonis. |

Raccoon--Parasites.

Classification: LCC RA641.R15 K38 2016 | DDC 614.5/554--dc23

LC record available at https://Iccn.loc.gov/2016009973

ISSN 1067-084X (print)

ISSN 2330-5703 (online) 


\title{
Foreword
}

\author{
C. van Riper, III, R.C. Abbott, M. Friend, and C. Bunck
}

"Let both sides seek to invoke the wonders of science instead of its terrors. Together let us explore the stars, conquer the deserts, eradicate disease, tap the ocean depths, and encourage the arts and commerce."

John F. Kennedy, from his Presidential inaugural address on January 20, 1961

Disease emergence in wildlife since the late 1900s has been of unprecedented scope relative to geographic areas of occurrence, wildlife species affected, and the variety of pathogens involved (Friend, 2006; Daszak and others, 2000). This treatise on Baylisascaris larva migrans highlights the recent emergence of a zoonotic disease that over the past 35 years has evolved and progressed as both an animal and human disease. Like many new zoonotic diseases in humans in recent years, the emergence of baylisascariasis is a result of our densely populated, highly mobilized, and environmentally disrupted world. As towns and cities expand, and wildlife populations increase, the wild land-urban interface broadens and human associations with wildlife become increasingly frequent. With geographic distance and isolation no longer meaningful

barriers, the opportunities for once isolated diseases to spread have never been greater. Dealing with emerging diseases requires the ability to recognize pathogens when they first appear and to act appropriately. Because outbreaks often are evident in the nonhuman components of the environment before humans are affected, understanding our environment and associated "sentinel" wildlife is a prerequisite to protecting human health.

Increasingly, society is recognizing that parasitic zoonoses are an important component of emerging global infectious diseases (Daszak and Cunningham, 2002), not only for wildlife but for human populations. Because over 50 percent of the pathogens involved with human disease have had their origins in wild animal populations (Daszak and others, 2000; World Health Organization, 2004), there is more recognition than ever before of the need to better integrate the disciplines of human and animal health to address the phenomenon of infectious disease emergence and resurgence. Recognizing the need to document the present status of zoonotic diseases, the U.S. Geological Survey (USGS) instituted a series of USGS Circulars on emerging zoonotic diseases. This summary of baylisascariasis is the eighth in the series.

Zoonotic diseases, such as baylisascariasis, are receiving increasing attention as components of disease emergence and resurgence (Kazacos, 2001). Baylisascariasis is caused by the roundworm Baylisascaris procyonis and is one of the more recent zoonotic disease developments. This disease remains one of the least known and poorly understood zoonotic diseases, yet over the past several decades it has become widespread. It originated in wildlife species and is now well established as a human malady. Baylisascariasis is transmitted to humans via consumption of contaminated feces, and the role of wildlife (primarily raccoons) in this transmission process is becoming more clearly known and is outlined in this report. Currently, over 50 percent of the raccoons in the United States are infected, and a smaller percentage in Europe is infected. Because 
raccoons have been relocated from the United States to Europe and Asia, this zoonotic disease also causes problems in wildlife species across the globe as well as being a major cause of concern for human health. Future generations of humans will continue to be jeopardized by Baylisascaris infections in addition to many of the other zoonotic diseases that have emerged during the past century. Through monitoring Baylisascaris infection levels in wildlife populations, we will be better able to predict future human infection levels of this important zoonotic disease.

"In examining disease, we gain wisdom about anatomy and physiology and biology. In examining the person with disease, we gain wisdom about life."

\section{Oliver Sacks}

\section{References Cited}

Daszak, P., and Cunningham, A.A., 2002, Emerging infectious diseases: A key role for conservation medicine, in Aguirre, A.A., Ostfeld, R.S., House, C.A., Tabor, G.M., and Pearl, M.C., eds., Conservation medicine: Ecological health in practice: New York, Oxford University Press, p. 40-61.

Daszak, P., Cunningham, A.A., and Hyatt, A.D., 2000, Emerging infectious diseases of wildlife-Threats to biodiversity and human health: Science, v. 287, p. 443-449.

Friend, M., 2006, Disease emergence and reemergence: The wildlife-human connection: U.S. Geological Survey Circular 1285, $388 \mathrm{p}$.

Kazacos, K.R., 2001, Baylisascaris and related species, in Samuel, W.M., Pybus, M.J., and Kocan, A.A., eds., Parasitic diseases of wild mammals (2nd ed).: Ames, lowa State University Press, p. 301-341.

World Health Organization, 2004, Expert consensus, in Contruvo, J.A., Dufour, A., Rees, G., Bartram, J., Carr, R., Cliver, D.O., Craun, G.F., Fayer, R., and Gannon, V.P.J., eds., Waterborne zoonoses: Identification, causes and control: London, IWA Publishing, p. 3-16. 


\section{Contents}

Foreword ..............................................................................................................................

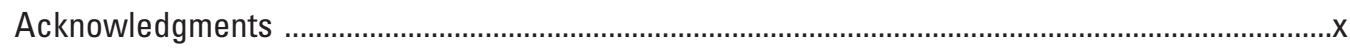

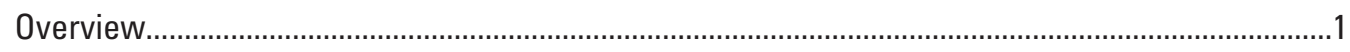

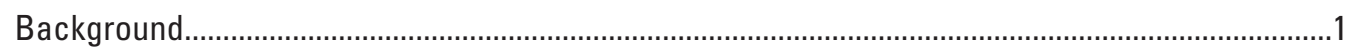

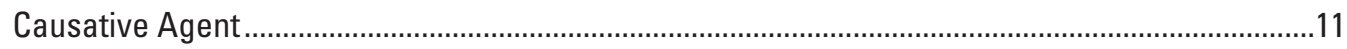

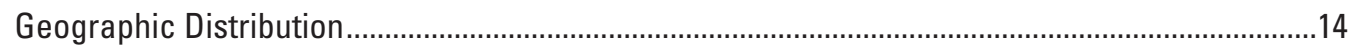

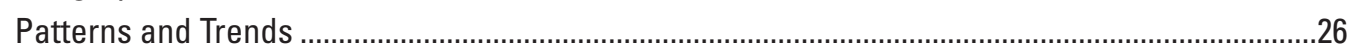

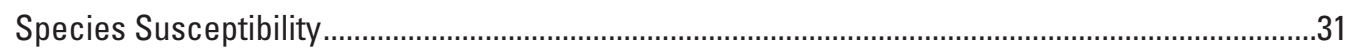

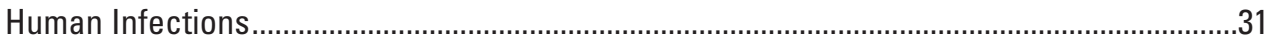

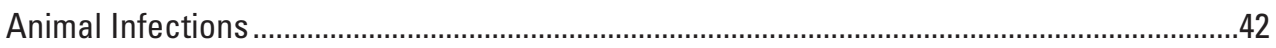

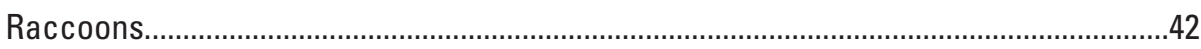

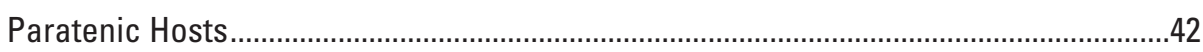

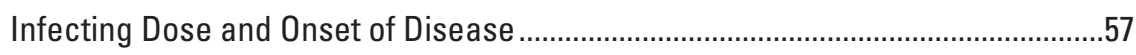

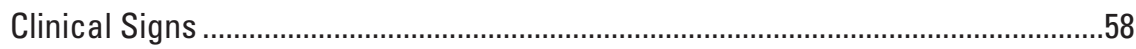

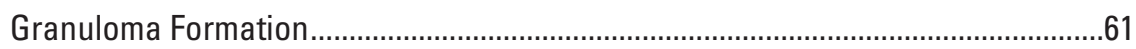

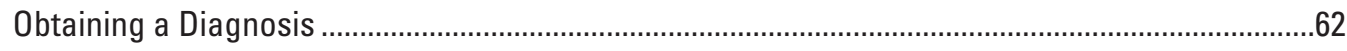

Disease Ecology

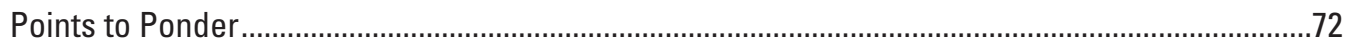

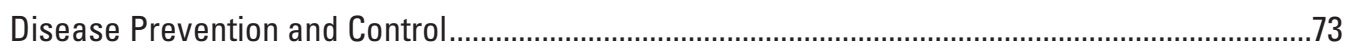

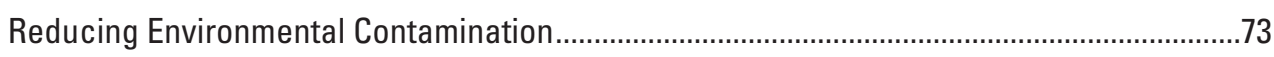

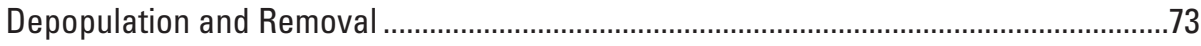

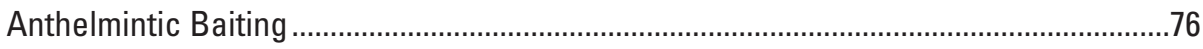

Preventing Contact with Contaminated Areas or Articles.......................................................76

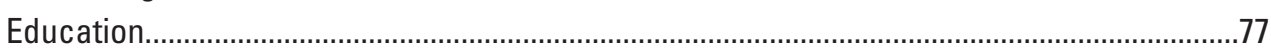

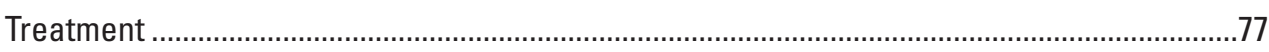

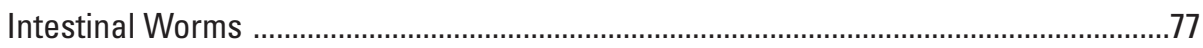

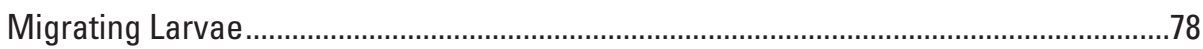

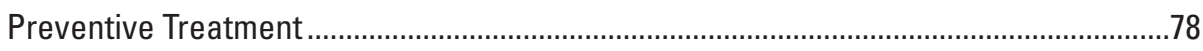

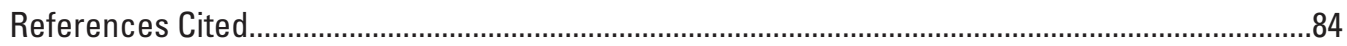

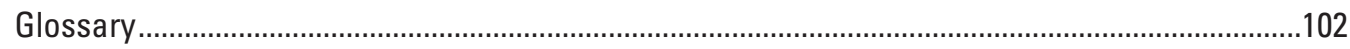

Appendix 1. Common and scientific names of animals cited ................................................110

Appendix 2. Cases of Baylisascaris neural larva migrans in pets ............................................117

Appendix 3. Cases of Baylisascaris neural larva migrans in animal facilities............................118 


\section{Topic Highlight Boxes}

A History of Baylisascaris Neural Larva Migrans .......................................................................

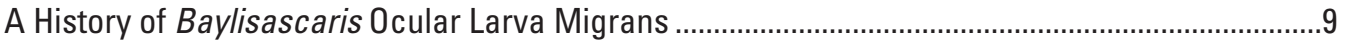

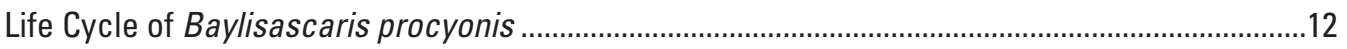

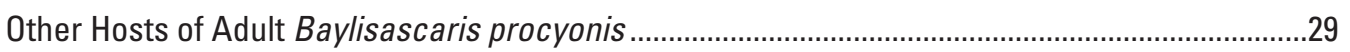

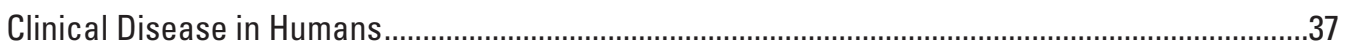

Diagnosis of Baylisascaris Neural Larva Migrans.....................................................................63

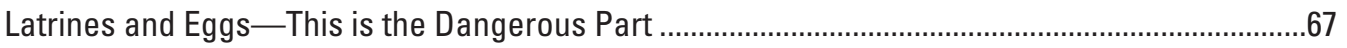

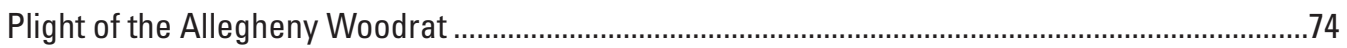

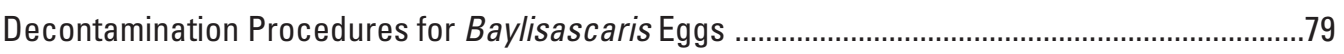

Coping with Baylisascaris Neural Larva Migrans-

From Individual People, to Wildlife Populations, to Organizations .......................................81

\section{Figures}

1. Photograph showing adult Baylisascaris procyonis roundworms from an

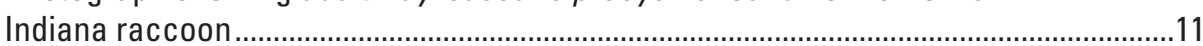

2. Photographs showing common raccoon.....................................................................14

3. Map showing distribution of the common raccoon in North and Central America ........15

4. Map showing distribution of the common raccoon in Europe.......................................15

5. Map showing distribution and general prevalence of Baylisascaris procyonis in

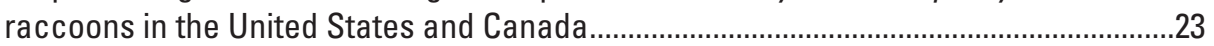

6. Map showing numbers and locations of animal cases and outbreaks of Baylisascaris larva migrans in the United States and Canada ......................................24

7. Map showing locations of human cases of Baylisascaris larva migrans in the

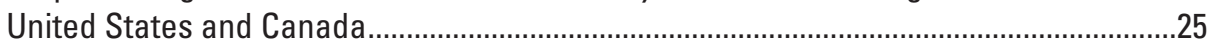

8. Diagram showing the life cycle of Baylisascaris procyonis ...........................................4

9. Photographs showing mammals affected with Baylisascaris procyonis neural larva migrans

10. Photographs showing the sequence of clinical neural larva migrans in a wild gray squirrel.

11. Photograph showing abnormal circling behavior of a mouse or vole in the snow along the Bighorn River near Worland, Wyoming, likely caused by Baylisascaris neural larva migrans

12. Photographs showing birds affected with Baylisascaris procyonis neural larva migrans

13. Photograph showing larval granulomas on the intestinal tract of a hamster with B. columnaris neural larva migrans.

14. Diagram showing areas near homes where humans and animals are at risk of contacting raccoon feces containing $B$. procyonis eggs. 


\section{Tables}

1. Mammals naturally and (or) experimentally affected by Baylisascaris neural larva migrans as of 2015

2. Birds naturally and (or) experimentally affected by Baylisascaris neural larva migrans as of 2015 .3

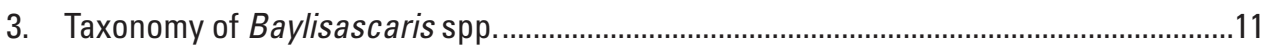

4. Baylisascaris species and their primary hosts............................................................11

5. Location, prevalence, and numbers of intestinal Baylisascaris procyonis in raccoons.

6. Location, type of infection, number of animals infected, and numbers of intestinal Baylisascaris procyonis, B. potosis, or Baylisascaris spp. in nonraccoon definitive

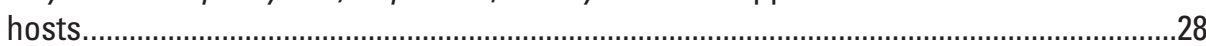

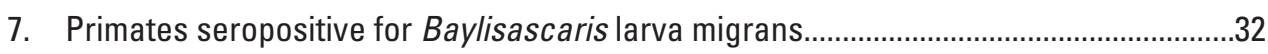

8. Cases of Baylisascaris neural larva migrans in humans ................................................34

9. Cases of Baylisascaris ocular larva migrans-diffuse unilateral subacute neuroretinitis in humans ............................................................................................. 40

10. Rodents with naturally occurring Baylisascaris neural larva migrans ............................44

11. Rabbits with naturally occurring Baylisascaris neural larva migrans ............................4

12. Carnivores with naturally occurring Baylisascaris neural larva migrans .......................48

13. Primates with naturally occurring Baylisascaris neural larva migrans ...........................49

14. Miscellaneous mammals with naturally occurring Baylisascaris neural larva

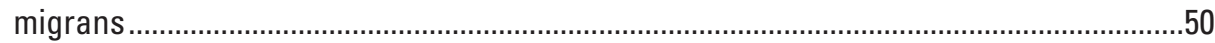

15. Gamebirds with naturally occurring Baylisascaris neural larva migrans. ......................50

16. Perching birds with naturally occurring Baylisascaris neural larva migrans..................51

17. Wading birds, shorebirds, diving birds, and waterfowl with naturally occurring Baylisascaris neural larva migrans .............................................................................

18. Parrots with naturally occurring Baylisascaris neural larva migrans .............................52

19. Flightless birds with naturally occurring Baylisascaris neural larva migrans .................53

20. Miscellaneous birds with naturally occurring Baylisascaris neural larva migrans .......54

21. Animals experimentally susceptible to Baylisascaris neural larva migrans.....................55

22. Clinical signs of Baylisascaris neural larva migrans in small mammals.........................58

23. Clinical signs of Baylisascaris neural larva migrans in birds.......................................60

24. Examples of locations of Baylisascaris larval granulomas in mammals ........................62 


\section{Conversion Factors}

International System of Units to Inch/Pound

\begin{tabular}{|c|c|c|}
\hline Multiply & By & To obtain \\
\hline \multicolumn{3}{|c|}{ Length } \\
\hline inch (in.) & 2.54 & centimeter $(\mathrm{cm})$ \\
\hline inch (in.) & 25.4 & millimeter (mm) \\
\hline mile (mi) & 1.609 & kilometer (km) \\
\hline
\end{tabular}

International System of Units to Inch/Pound

\begin{tabular}{lcc}
\hline \multicolumn{1}{c}{ Multiply } & By & To obtain \\
\hline centimeter (cm) & Length & \\
millimeter (mm) & 0.3937 & inch (in.) \\
\hline hectare (ha) & 0.03937 & inch (in.) \\
hectare (ha) & Area & acre \\
\hline gram (g) & 2.471 & square mile (mi $\left.{ }^{2}\right)$ \\
\hline
\end{tabular}

Temperature in degrees Celsius $\left({ }^{\circ} \mathrm{C}\right)$ may be converted to degrees Fahrenheit $\left({ }^{\circ} \mathrm{F}\right)$ as follows: ${ }^{\circ} \mathrm{F}=\left(1.8 x^{\circ} \mathrm{C}\right)+32$

Temperature in degrees Fahrenheit $\left({ }^{\circ} \mathrm{F}\right)$ may be converted to degrees Celsius $\left({ }^{\circ} \mathrm{C}\right)$ as follows: ${ }^{\circ} \mathrm{C}=\left({ }^{\circ} \mathrm{F}-32\right) / 1.8$

A micrometer $(\mu \mathrm{m})$ is a unit of measurement of the sizes of cells and bacteria. One micrometer is equal in length to one-thousandth of a millimeter.

Words shown in bold are defined in the glossary. 


\title{
Abbreviations
}

\author{
CDC Centers for Disease Control and Prevention \\ CNS Central nervous system \\ CSF Cerebrospinal fluid \\ DUSN Diffuse unilateral subacute neuroretinitis \\ ELISA Enzyme-linked immunosorbent assay \\ LM Larva migrans \\ MRI Magnetic resonance imaging \\ NLM Neural larva migrans \\ NWHC National Wildlife Health Center \\ OLM Ocular larva migrans \\ PI Postinfection \\ VLM Visceral larva migrans \\ USGS U.S. Geological Survey
}




\section{Acknowledgments}

This publication is based on many years of research, investigation, research collaboration, and assistance from many individuals spanning a wide variety of professions and disciplines. These include numerous veterinarians, physicians, pathologists, diagnosticians, wildlife and exotics biologists, public health officials, parasitology researchers, students, staff, animal owners, human patients and their families, and others I have worked with. I thank them all for their generosity, cooperation, diligence, and assistance in providing and sharing information, giving access to case and reference material, collecting and providing samples, processing specimens, and allowing us to learn more about this exceptionally interesting parasite. Without everyone's help, the extent of our progress would not have been possible, and it is sincerely appreciated. As with many things in life, my long association with Baylisascaris resulted from serendipity, based on a very interesting case that crossed my desk. Who would think that more than 35 years later I would still be working on it and that with the help of my numerous colleagues, we would gain such a great understanding of the importance of this devastating parasite? My sincere thanks to all.

Special thanks to Rachel C. Abbott for her editorial suggestions and assistance in the development and organization of this publication.

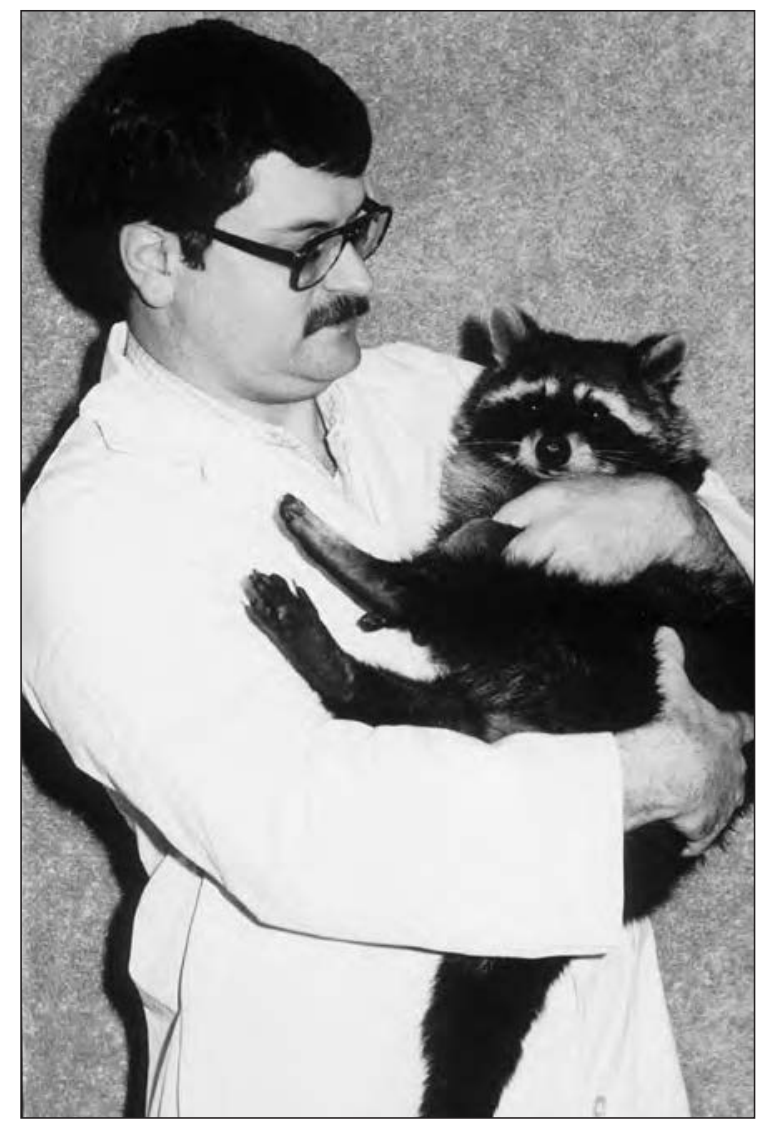

The author with a common raccoon. (Photo by Sam Royer) 


\title{
Baylisascaris Larva Migrans
}

\author{
By Kevin R. Kazacos ${ }^{1}$
}

“.....the experiments reported here suggest that B. procyonis should be considered dangerous to man until proved otherwise.” (Kazacos, Wirtz, and others, 1981)

“The evidence presented overwhelmingly supports the conclusion that this patient died of Baylisascaris eosinophilic meningoencephalitis.” (Huff and others, 1984)

\section{Synonyms}

Baylisascariasis, baylisascarosis, raccoon roundworm infection, raccoon ascarid infection, raccoon roundworm encephalitis, Waschbärenspulwurm Infektionen (German)

\section{Overview}

Baylisascaris procyonis, the common raccoon roundworm or ascarid, an intestinal parasite, is the most commonly recognized cause of clinical larva migrans (LM) in animals, a condition in which an immature parasitic worm or larva migrates in a host animal's tissues, causing obvious disease, but the larva does not develop to the adult stage. Infection with $B$. procyonis is best known as a cause of fatal or severe neurologic disease that results when the larvae invade the brain, the spinal cord, or both; this condition is known as neural larva migrans (NLM) and, historically, cerebrospinal nematodiasis. NLM has been seen in over 150 species of mammals and birds in North America and elsewhere (tables 1 and 2).

Baylisascariasis is a zoonotic disease, that is, one that is transmissible from animals to humans. In humans, Baylisascaris procyonis can cause damaging visceral (VLM), ocular (OLM), and neural larva migrans (Sorvillo and others, 2002; Murray and Kazacos, 2004; Gavin and others, 2005; Wise and others, 2005; Shafir and others, 2006; Saffra and others, 2010; Kazacos and others, 2013; Singaravelu and others, 2016). Due to the ubiquity of infected raccoons around humans, there is considerable human exposure and risk of infection with this parasite (Roussere and others, 2003; Page, Anchor, and others, 2009). In North America, Baylisascaris has gained notoriety

\footnotetext{
1. Professor Emeritus, Purdue University College of Veterinary Medicine
}

as a cause of eosinophilic meningoencephalitis mainly in children, and human cases are being increasingly recognized (Murray, 2004; Murray and Kazacos, 2004; Gavin and others, 2005; Perlman and others, 2010; Kazacos and others, 2013). The remarkable disease-producing capability of B. procyonis in animals and humans is one of the most significant aspects of the biology of ascarids (large roundworms) to come to light in recent years (Kazacos, 2001). Infection with B. procyonis has important health implications for a wide variety of freeranging and captive wildlife, zoo animals, domestic animals, as well as human beings, on both an individual and population level (Page, 2013). Other closely related ascarids, for example, $B$. columnaris of skunks and $B$. melis of badgers, are also potential causes of clinical larva migrans in animals and humans.

\section{Background}

Baylisascaris procyonis was first reported during the 1930s in raccoons in the New York Zoological Park (McClure, 1933) and on a fur farm in Minnesota (Olsen and Fenstermacher, 1938). At the time, the parasite was considered to be Ascaris columnaris, which had been previously described in skunks. It was later described as a distinct species (Ascaris procyonis) based on worms collected from raccoons in Poland (Stefański and Žarnowski, 1951). Subsequently, the parasite was renamed and included in the newly erected genus Baylisascaris (Sprent, 1968).

Within the last 60 or so years, and especially the last 35 , baylisascariasis has evolved and progressed as both an animal and human disease. In the late 1940s and early 1950s, Drs. Jack Tiner and John F.A. Sprent did considerable research on larval migration, larval distribution in mice, growth of the larvae, and central nervous system (CNS) disease capability, and compared the raccoon and skunk parasites to other carnivore ascarids that had similar somatic migration within the body tissues of paratenic (or transport) hosts (Tiner, 1949, 1951, 1952a,b, 1953a,b; Sprent, 1951, 1952a,b, 1953a,b, 1955). Their excellent early work set the stage for the clinical importance of Baylisascaris. A few naturally occurring cases and outbreaks of clinical NLM were described in the 1960 s and 1970s but, especially in early reports, the parasites involved were not conclusively identified. Concerning 
Table 2. Birds naturally and (or) experimentally affected by Baylisascaris neural larva migrans as of 2015.

[N, naturally susceptible; $\mathbf{E}$, experimentally infected]

\begin{tabular}{|c|c|c|}
\hline \multicolumn{3}{|c|}{ Domestic and wild gamebirds (11 species: all naturally susceptible, 1 experimentally infected) } \\
\hline Domestic chicken $(\mathbf{N}, \mathbf{E})$ & Chukar (N) & Ruffed grouse $(\mathbf{N})$ \\
\hline Common pheasant $(\mathbf{N})$ & Wild turkey (N) & Indian peafowl (N) \\
\hline Northern bobwhite $(\mathbf{N})$ & California quail (N) & Australian brush turkey (N) \\
\hline Rock partridge (N) & Helmeted guineafowl (N) & \\
\hline \multicolumn{3}{|c|}{ Perching birds (14 species: all naturally susceptible) } \\
\hline House sparrow $(\mathbf{N})$ & House finch $(\mathbf{N})$ & Canary (N) \\
\hline Bushtit (N) & Spotted towhee $(\mathbf{N})$ & Loggerhead shrike (N) \\
\hline California thrasher $(\mathbf{N})$ & Northern cardinal (N) & Northern mockingbird (N) \\
\hline American robin $(\mathbf{N})$ & European starling (N) & Blue jay (N) \\
\hline Western scrub jay $(\mathbf{N})$ & American crow (N) & \\
\hline \multicolumn{3}{|c|}{ Parrots (29 species: all naturally susceptible, 1 experimentally infected) } \\
\hline Budgerigar (N) & Blue-and-yellow macaw (N) & Scarlet macaw $(\mathbf{N})$ \\
\hline Red-and-green macaw (N) & Military macaw $(\mathbf{N})$ & Eastern rosella $(\mathbf{N})$ \\
\hline Blue-fronted Amazon (N) & Yellow-headed Amazon (N) & Yellow-naped Amazon (N) \\
\hline Cuban Amazon (N) & Red-crowned Amazon (N) & Thick-billed parrot (N) \\
\hline Burrowing parrot $(\mathbf{N})$ & African grey parrot $(\mathbf{N})$ & Blue-crowned parakeet (N) \\
\hline Orange-fronted parakeet (N) & Sun parakeet $(\mathbf{N})$ & Rosy-faced lovebird (N) \\
\hline Rainbow lorikeet (N) & Swainson’s lorikeet (N) & Yellow-backed lorikeet (N) \\
\hline Ornate lorikeet (N) & Marigold (Edward's) lorikeet (N) & Cockatiel (N, E) \\
\hline Galah cockatoo $(\mathbf{N})$ & Red-tailed black cockatoo (N) & Salmon-crested cockatoo $(\mathbf{N})$ \\
\hline White (umbrella) cockatoo (N) & $\begin{array}{l}\text { Hybrid of blue-and-yellow } \\
\text { and scarlet macaw (N) }\end{array}$ & \\
\hline \multicolumn{3}{|c|}{ Pigeons and doves (3 species: all naturally susceptible) } \\
\hline Rock pigeon $(\mathbf{N})$ & Mourning dove (N) & Diamond dove $(\mathbf{N})$ \\
\hline \multicolumn{3}{|c|}{ Woodpeckers (1 species: naturally susceptible) } \\
\hline \multicolumn{3}{|l|}{ Northern flicker $(\mathbf{N})$} \\
\hline \multicolumn{3}{|c|}{ Roadrunners (1 species: naturally susceptible) } \\
\hline \multicolumn{3}{|l|}{ Greater roadrunner $(\mathbf{N})$} \\
\hline \multicolumn{3}{|c|}{ Mousebirds (2 species: both naturally susceptible) } \\
\hline Speckled mousebird (N) & Blue-naped mousebird (N) & \\
\hline \multicolumn{3}{|c|}{ Hornbills and Hoopoe (1 species: naturally susceptible) } \\
\hline \multicolumn{3}{|l|}{ Northern red-billed hornbill (N) } \\
\hline \multicolumn{3}{|c|}{ Owls (1 species: naturally susceptible) } \\
\hline \multicolumn{3}{|l|}{ Barn owl (N) } \\
\hline \multicolumn{3}{|c|}{ Wading birds and waterfowl (6 species: 5 naturally susceptible, 1 experimentally infected) } \\
\hline Black-crowned night heron (N) & Sanderling (N) & Inca tern $(\mathbf{N})$ \\
\hline Mallard X (N) & Domestic duck (E) & Crested screamer $(\mathbf{N})$ \\
\hline \multicolumn{3}{|c|}{ Flightless birds (3 species: all naturally susceptible) } \\
\hline Emu $(\mathbf{N})$ & Ostrich (N) & Greater rhea $(\mathbf{N})$ \\
\hline
\end{tabular}


paratenic hosts of Baylisascaris, such as small mammals and birds, these used to be called intermediate hosts (Kazacos, 1983a, 1986, 2001); however, larval development, specifically a larval molt to a subsequent stage, has never been found in them (D.D. Bowman, written commun., 2015), indicating that no required or essential development takes place, so they instead should be called paratenic hosts.

Additional research at the Purdue University College of Veterinary Medicine in the 1980s indicated that B. procyonis was highly pathogenic and dangerous, as it killed nearly every animal species and individual that was infected, including primates (Kazacos, 1981; Kazacos, Wirtz, and others, 1981; Kazacos, Vestre, and Kazacos, 1984; Wirtz, 1981, 1982; Kazacos and Wirtz, 1983). Surprisingly, fewer natural cases than expected were recognized, given the parasite's ability to cause disease (pathogenicity) and its widespread occurrence in raccoons. However, the diagnosis was most likely missed because of a diagnostic focus on rabies. Every year in the United States and Canada, thousands of rodents and rabbits suffering from nervous system disease were (and still are) submitted to diagnostic laboratories or health departments, but they were primarily tested as rabies suspects, not for Baylisascaris (Fitzpatrick and others, 2014). As one would expect, almost all (99 percent) of these animals were negative for rabies, which begged the question as to what they were actually suffering from. Unfortunately, the brain and other tissues were then unavailable for further testing. When similar animals were examined for Baylisascaris larvae and other causes, NLM was found to be a common and widespread cause of their neurologic disease (Richter and Kradel, 1964; Swerczek and Helmboldt, 1970; Fleming and Caslick, 1978; Kazacos, Appel, and Thacker, 1981; Roth and others, 1982). These diagnoses and documentation of many other cases (for example, Richardson and others, 1980; Reed and others, 1981; Koch and Rapp, 1981; Kazacos, 1982; Kazacos and others, 1982; Kazacos, Winterfield, and Thacker, 1982; Kazacos, Reed, and others, 1983, Kazacos, Reed, and Thacker, 1986; Kazacos, Fitzgerald, and Reed, 1991; Larson and Greve, 1983; Myers and others, 1983; Dixon and others, 1988; Thomas, 1988; Medway and others, 1989; Sanford, 1991; Kwiecien and others, 1993) prompted a reconsideration of diagnostic protocols for such animals in laboratories across North America, with Baylisascaris NLM given much stronger consideration. In addition, considerable research was initiated on the prevalence and natural ecology of Baylisascaris, including how it is maintained and transmitted in nature.

The significant zoonotic potential of $B$. procyonis was recognized early on, and studies of the infection in two species of nonhuman primates were conducted (Kazacos, Wirtz, and others, 1981; Kazacos, Vestre, and Kazacos, 1984; Kazacos and others, 1985). The infecting doses were relatively low and easily transmittable to young children, which further put the zoonotic risk of $B$. procyonis into perspective. During this time, cases of human OLM and NLM were identified, and the NLM cases conclusively linked to B. procyonis from raccoons (Raymond and others, 1978; Gass and Braunstein, 1983; Huff and others, 1984; Fox and others, 1985). As would be expected for a previously unknown human disease, other earlier cases in humans that matched a probable diagnosis of baylisascariasis were identified in the literature, and these are now considered to be additional human cases of Baylisascaris NLM and OLM, including one from Europe (Parsons, 1952; Schrott, 1961; Anderson and others, 1975).

Since the 1970s, the parasite has been increasingly identified as a cause of animal and human disease. Over 2,400 cases of raccoon roundworm encephalitis in animals and 25 cases in humans have been published or reported (Kazacos, 2001; Kazacos, Gavin, and others, 2002; Schultz, 2002; Murray and Kazacos, 2004; Cheney, 2005; Chris, 2005; Gavin and others, 2005; Shafir and others, 2006; Pai and others, 2007; Reilly, 2008; Chun and others, 2009; Hajek and others, 2009; Kelly and others, 2009, 2012; Moore, 2009; Mehta and others, 2010; Perlman and others, 2010; Ciarlini and others, 2011; Hung and others, 2012; Haider and others, 2012; Kazacos and others, 2013) (table 8), and additional cases of animal and human NLM as well as numerous cases of covert or subclinical infection as determined through serology have also been identified (Cunningham and others, 1994; Brinkman and others, 2003; K.R. Kazacos, unpub. data, 1995-2010). In addition, the parasite has progressed from a questioned cause of human eye disease to a well-known cause of human OLM and the primary cause of the large nematode variant of the ocular syndrome, diffuse unilateral subacute neuroretinitis (DUSN). 


\section{A History of Baylisascaris Neural Larva Migrans}

The stage was set for Baylisascaris to enter the scene as an agent of animal and human disease when two pioneering parasitologists, Dr. Jack D. Tiner and Dr. John F. A. Sprent, began examining the biology of larval migration due to these parasites in the late 1940s and early 1950s (see references ). It was their research that showed B. procyonis and $B$. columnaris larvae aggressively migrate through somatic tissues and tend to cause severe clinical central nervous system disease (neural larva migrans, NLM) in paratenic hosts. Dr. Tiner worked primarily with $B$. procyonis of raccoons and Dr. Sprent with B. columnaris of skunks, which previously were considered the same or similar species from the two respective hosts. They also worked with other species, such as $B$. melis of badgers, $B$. transfuga of bears, $B$. devosi of weasels, and B. tasmaniensis of Tasmanian devils. Their work was meticulous, intriguing, and sometimes downright scary. Indeed, a graduate student roommate of Dr. Tiner was quite concerned about what Jack was working on, since his mice would circle, fall over, and die of nervous system disease. And then there were the wild house mice in the lab building that also came down with it, apparently having gotten into some of the egg-laden peanut butter used to infect the experimental mice. The other students tended to give Jack and his animals a wide berth.

Tiner's and Sprent's work showed differences in the pathogenicities of the raccoon and skunk ascarids and a greater disparity between these two species and the bear, weasel, dog, and cat ascarids as causes of clinical NLM. They found that Baylisascaris of raccoons and skunks are aggressive migrators whose larvae enter the tissues of mice and other rodents soon after oral infection with infective eggs. As part of this migration, small numbers (approximately 5-7 percent) of larvae enter the brain, but because of their rapid growth and aggressiveness, they produce considerable damage to the brain, resulting in clinical disease (Tiner, 1953b; Sprent, 1955). The raccoon ascarid was about 20 times more pathogenic than the skunk ascarid, whose larvae were walled off more readily by the host and thus were better tolerated; however, the skunk roundworm could still produce similar brain disease in some mice. Tiner (1953a,b) also found that the badger roundworm (B. melis) was a particularly pathogenic species in causing NLM, and Sprent (1952a, 1953a,b, 1955) showed that the ascarids of bears, weasels, and dogs were not nearly as pathogenic as the others. Based on the experimental work of Tiner and Sprent, another famous parasitologist, Dr. Paul Beaver, first alluded to the zoonotic potential of Baylisascaris and included these parasites in his discussion of larva migrans and paratenesis (Beaver, 1969). In addition to studying migration and neural pathogenicity, Tiner first noted the relevance of B. procyonis as a cause of natural disease in animal populations and studied the parasite in squirrels in Illinois woodlots. Tiner estimated that $B$. procyonis was responsible for as much as 5 percent of natural rodent mortality in woodlots where raccoons were common (Tiner, 1954). Despite the excellent early research of these two scientists, many still viewed these parasites as interesting curiosities, and the widespread importance of Baylisascaris as disease agents would remain hidden until later.

Three cases or outbreaks of naturally occurring clinical NLM due to Baylisascaris were described in the 1960s and a dozen more in the 1970s, in woodchucks, squirrels, long-tailed chinchillas, beavers, nutria, rabbits, and several avian species (Richter and Kradel, 1964; Kelly and Innes, 1966; Fritz and others, 1968; Swerczek and Helmbolt, 1970; Schueler, 1973; Church and others, 1975; Dade and others, 1975, 1977; Nettles and others, 1975; Helfer and Dickinson, 1976; Jacobson and others, 1976; Fleming and Caslick, 1978; Sass and Gorgacz, 1978; Winterfield and Thacker, 1978; Fleming and others, 1979). Again, they were viewed for the most part as pathogenic curiosities, and in early cases, the identification of the parasite and the source of the infection were both lacking. Sprent (1968) had described the new genus Baylisascaris and listed the known species, but it took some time for this to become widely known. Later papers indicated more strongly the broader importance of the parasites in causing larger clinical outbreaks (Dade and others, 1975, 1977; Nettles and others, 1975; Jacobson and others, 1976).

In 1979, the owner of a poultry operation in central Indiana was steadily losing birds to rapidly progressive central nervous system (CNS) disease: 115 birds in the first week, 66 in the second, 109 in the third, etc.

(A). Birds were submitted to the Indiana Animal Disease Diagnostic Laboratory, but the cause was undetermined.

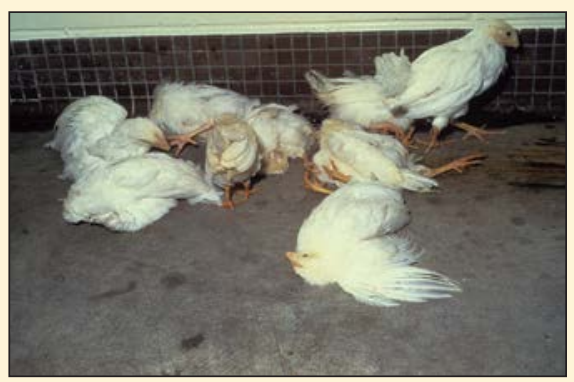

A. Chickens suffering from Baylisascaris neural larva migrans. (Photo by Sam Royer) 


\section{A History of Baylisascaris Neural Larva Migrans}

Viral encephalitis was a possibility because the birds had not been vaccinated against Newcastle disease. However, histological examination of brain tissue revealed lesions that looked like something had migrated through the brain. Upon examining sequential thin sections of the brains of several birds, multicellular parasites were found in the brain tissue and were identified as large ascarid larvae $(B)$.

Living larvae were isolated from the brains of other birds by using a Baermann funnel $(C)$. The parasites were identified as larvae of Baylisascaris, most likely B. procyonis.

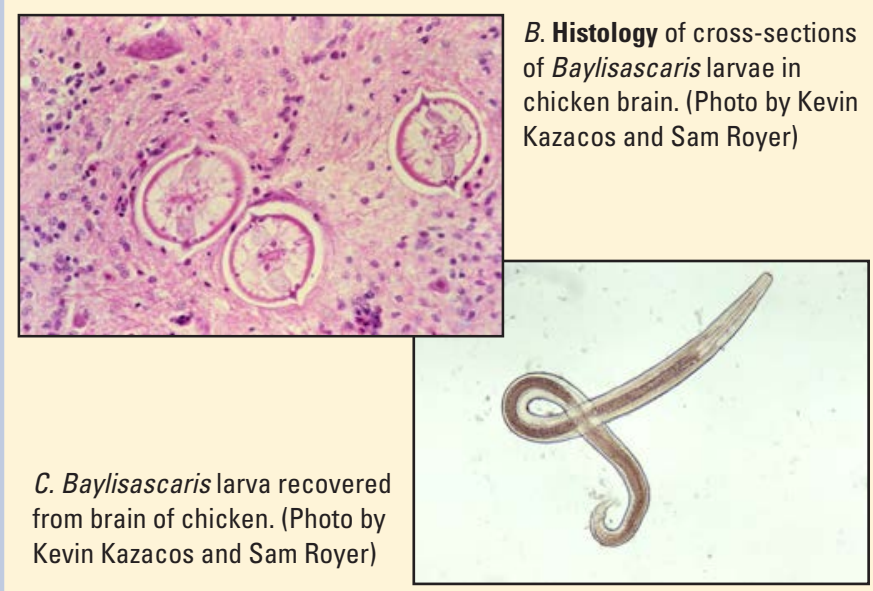

The owner continued to lose birds, although fatalities were decreasing by the sixth week. The birds were housed in a total confinement building, with little human and no animal traffic into the poultry house. The owner was presented with a list of carnivores (dogs, cats, raccoons, skunks, weasels, foxes, coyotes, and bears), and asked if there might be any contact with any of them. He immediately picked out raccoons, and said he had a terrible problem with them denning and defecating in his straw loft $(D, E)$. This was the same straw he had unwittingly used as litter in his poultry house, revealing how the birds were becoming infected. B. procyonis eggs were identified in the raccoon feces from the straw loft, and the owner was advised to 1) not use any more of the contaminated straw, 2) remove the birds and carefully clean out all of the material from the poultry house and straw loft and burn it, and 3) prevent any further raccoon incursions and contamination. He did this right away; losses essentially ceased by the end of the seventh week, and subsequent groups of birds did not become infected. In total, the owner lost 622 birds over the 7 -week period, and until recently this remained the largest outbreak of Baylisascaris encephalitis ever recorded (Richardson and others, 1980).
One and a half years later, similar lesions and parasites were seen in bobwhites with neurologic disease $(F)$. The bobwhites were from a group of 85 that had access to a 12-by-24 foot dirt pen in which three baby raccoons had been housed previously for three months $(G)$. In short order, all of the birds died from CNS disease (Reed and others, 1981). Subsequent investigation indicated that even though the raccoons were lightly infected with Baylisascaris, they were shedding 1,300-5,400 eggs per gram of feces and had contaminated the pen with an estimated 155,593,800 eggs (Kazacos, 1982), ensuring the death of all of the birds from NLM. Indeed, Tiner and Sprent had shown that a single larva in the brain of a small rodent was fatal.

Within two years of the original outbreak, several additional cases were identified: a woodchuck submitted as a rabies suspect, a brushturkey from the Indianapolis Zoo, an emu (with $B$. columnaris), and domestic rabbits suffering high mortality (again, contaminated straw was the source) (Kazacos, Appel, and Thacker, 1981; Kazacos, Kazacos, and others, 1982; Kazacos, Winterfield, and Thacker, 1982; Kazacos and others, 1983). Mice, hamsters, rats, gray squirrels, chickens, ducks, ferrets, a chipmunk, woodchucks, least weasel, squirrel monkeys, and crab-eating macaques were experimentally infected with $B$. procyonis eggs $(H, I)$, and nearly all died with severe CNS disease (Kazacos, 1981, 1983a; Wirtz, 1982; Kazacos and Wirtz, 1983; Kazacos, Wirtz, and others, 1981; Kazacos, Vestre, Kazacos, and Raymond, 1984; Kazacos, Vestre, and Kazacos, 1984; Kazacos and others, 1985; Kazacos and Kazacos, 1984, Kazacos, E.A., and Kazacos, K.R.,1988).

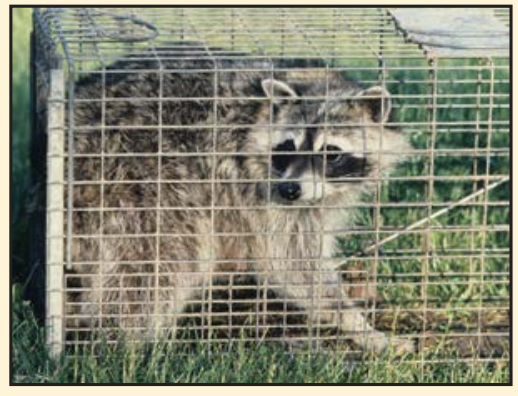

$D$. Raccoon trapped from barn. (Photo by

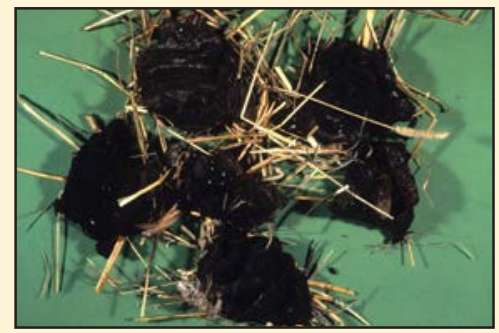

E. Raccoon feces recovered from straw loft of barn. (Photo by Kevin Kazacos and Sam Royer)

\section{Kevin Kazacos)}




\section{A History of Baylisascaris Neural Larva Migrans}

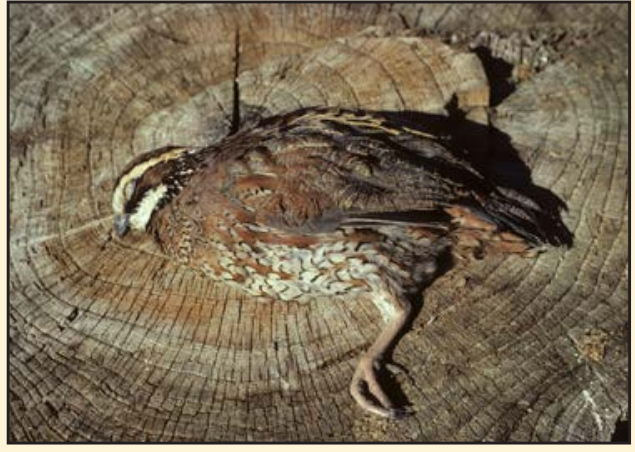

F. Bobwhite with Baylisascaris neural larva migrans. (Photo by Kevin Kazacos)

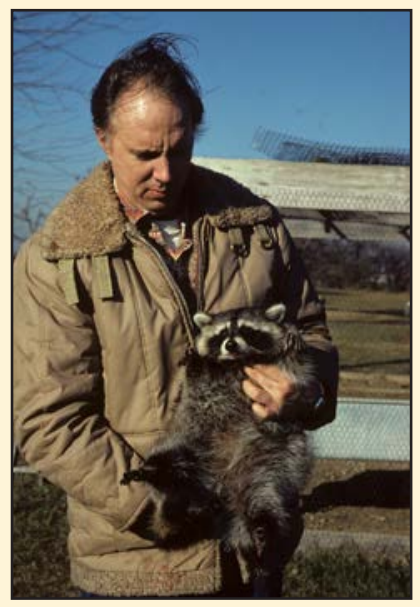

G. Pet raccoon linked to outbreak of Baylisascaris neural larva migrans in bobwhites. (Photo by Kevin Kazacos)

Research using squirrel monkeys and crab-eating macaques provided important insights into the pathogenicity of the parasite in primates and thus potentially in humans (Kazacos, Wirtz, and others, 1981; Kazacos, Vestre, and Kazacos, 1984; Kazacos and others, 1985). All of these primates died from CNS disease, and the parasites had migrated extensively throughout muscle and connective tissue, the brain, and the eyes, proving the probable danger of $B$. procyonis to humans. In addition to data on NLM, the macaques provided great insight into clinical Baylisascaris ocular larva migrans (OLM).

In early 1983, a child in Pennsylvania died of eosinophilic meningoencephalitis and larvae in his tissues were identified as Baylisascaris, for the first time ever in a human (Huff and others, 1984) $(J)$. Cases of human OLM and diffuse unilateral subacute neuroretinitis (DUSN) were also attributed to Baylisascaris (Raymond and others, 1978; Gass and Braunstein, 1983; Kazacos, Vestre, Kazacos, and Raymond, 1984; Kazacos, Vestre, and Kazacos, 1984; Kazacos and others, 1985). Based on rapidly accumulating evidence,

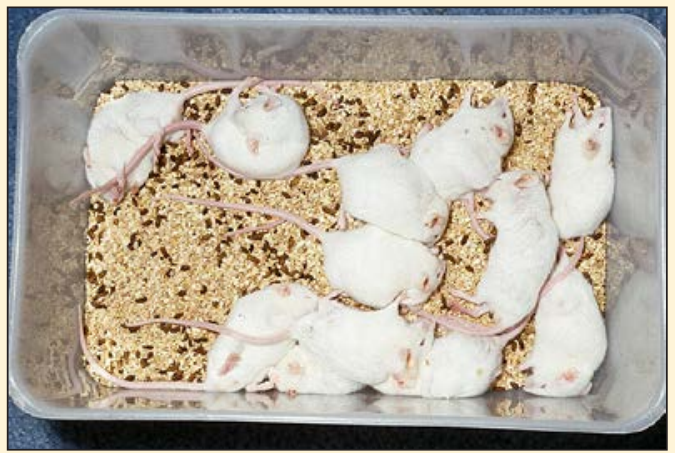

H. Mice with Baylisascaris neural larva migrans, ten days after experimental infection with B. procyonis eggs. (Photo by Kevin Kazacos and Sam Royer)

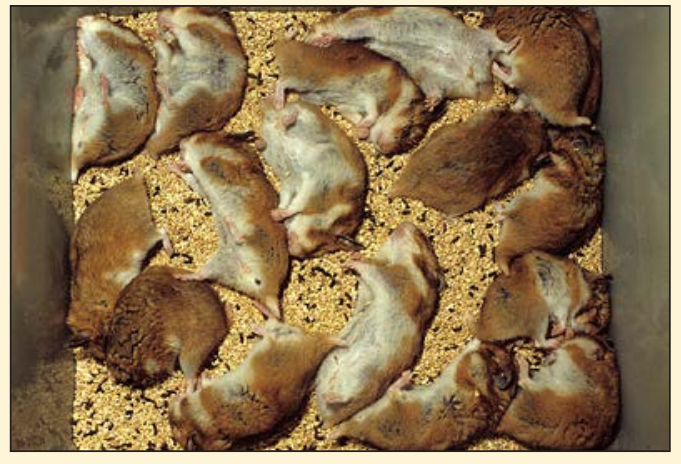

I. Hamsters with Baylisascaris neural larva migrans, ten days after experimental infection with $B$. procyonis eggs. (Photo by Kevin Kazacos and Sam Royer)

B. procyonis was described as a cause of both animal and human disease (Kazacos, 1983a), and shortly thereafter the parasite was identified as the cause of death of a second child, in Illinois $(K, L)$ (Fox and others, 1985). All state and territorial public health agencies and laboratory directors in the country were strongly warned in a letter about $B$. procyonis and its probable zoonotic importance in human beings (Kazacos, 1984). In a short time, B. procyonis had been identified conclusively for the first time in humans, identified in additional cases of NLM, implicated as a cause of human OLM and DUSN, and received much deserved national attention as a newly recognized human pathogen. Based mainly on Baylisascaris, but also including other parasites, neural larva migrans was introduced as a new type of larva migrans in 1994-95 (Cunningham and others, 1994; Kazacos, 1995; Kazacos and Boyce, 1989, 1995) and has been well accepted. Baylisascaris is now recognized internationally as a cause of animal and human disease and 


\section{A History of Baylisascaris Neural Larva Migrans}

is routinely considered in cases of eosinophilic meningoencephalitis and OLM-DUSN in humans in North America, Europe, and Asia. Twenty-five cases of Baylisascaris NLM in humans have been published or reported (table 8), over a dozen additional cases are also known, and over a hundred seropositive individuals have been identified (table 7) (K.R. Kazacos, unpub. data, 1995-2010; Brinkman and others, 2003; Dangoudoubiyam and Kazacos, 2009; Dangoudoubiyam and others, 2011; Rascoe and others, 2013). Excellent serologic tests have been developed for this infection and are in current use in at least two national laboratories (United States and Canada). Now when infection with Baylisascaris is suspected, serologic confirmation of infection is usually sought without delay and aggressive treatment is initiated promptly. This has and will continue to make an important difference in the lives of those affected by this parasite.
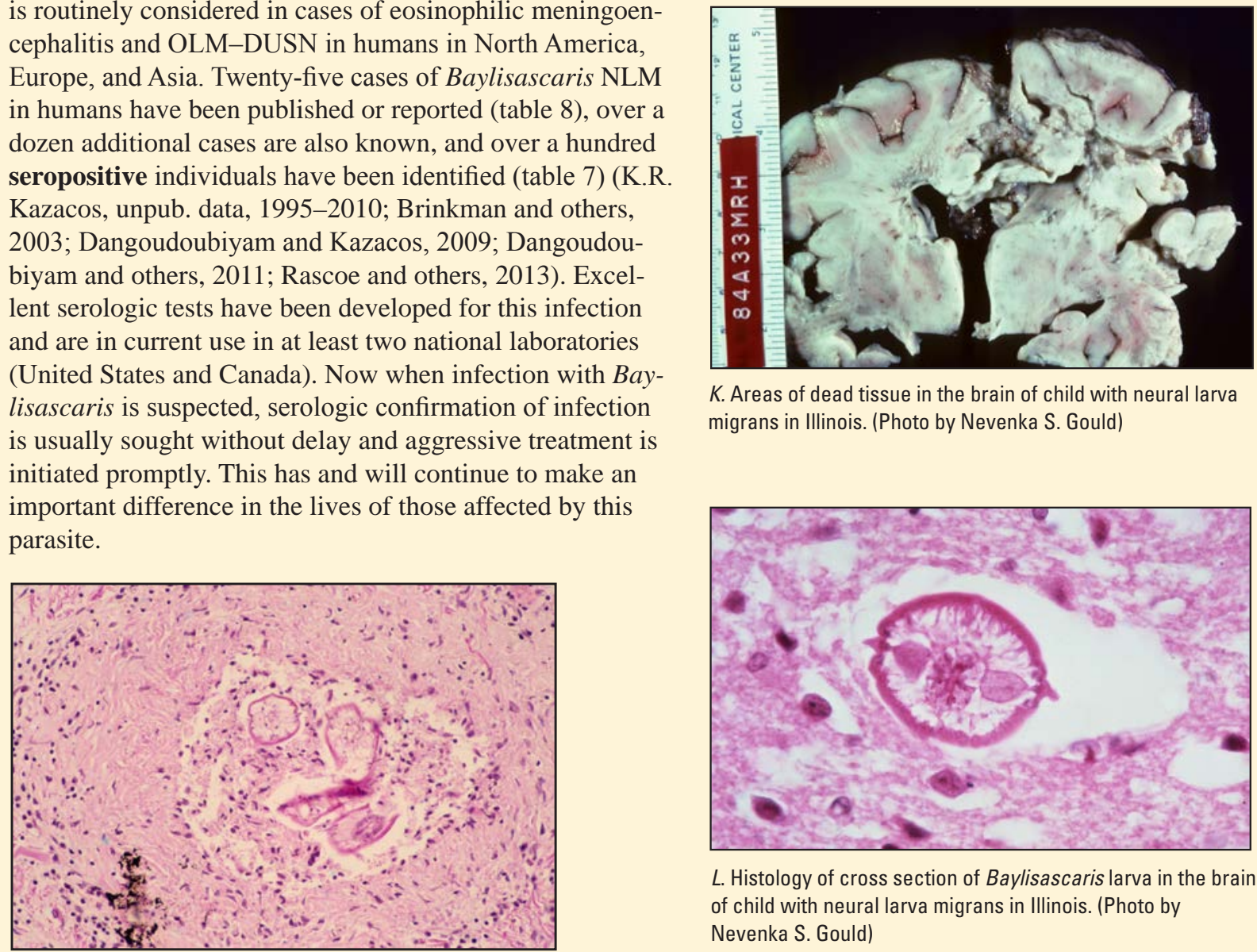

$K$. Areas of dead tissue in the brain of child with neural larva migrans in Illinois. (Photo by Nevenka S. Gould)

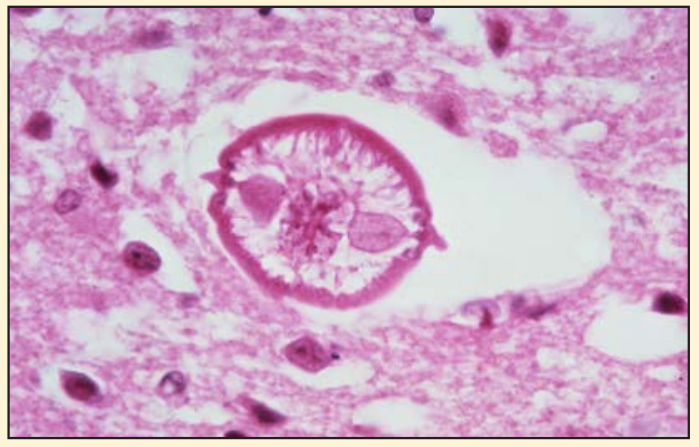

L. Histology of cross section of Baylisascaris larva in the brain of child with neural larva migrans in Illinois. (Photo by Nevenka S. Gould)

J. Histology of Baylisascaris larva in the brain of child with neural larva migrans in Pennsylvania. (Photo by Kevin Kazacos; specimen courtesy of Dale S. Huff) 


\section{A History of Baylisascaris Ocular Larva Migrans}

As a cause of human ocular larva migrans (OLM), Baylisascaris was quick to arrive on the scene but slower to be accepted. Toxocara spp. of dogs and cats were well-known causes of human OLM, having first been documented in human eyes in 1950 by pathologist Helenor Wilder (Wilder, 1950) and later identified as Toxocara (Nichols, 1956). Toxocara larvae do not grow as they migrate, remaining small (approximately 400 micrometers $[\mu \mathrm{m}]$ long by $16-18 \mu \mathrm{m}$ in diameter), whereas Baylisascaris larvae grow quickly, reaching a size of 1,500-2,000 $\mu \mathrm{m}$ long by $60-80 \mu \mathrm{m}$ in diameter in about 2 weeks (Goldberg and others, 1993). In studies of B. procyonis in nonhuman primates, mainly examining NLM, ophthalmoscopic examinations also were done $(A)$, and it was found that larvae entered the eyes of every animal, producing lesions of OLM (Kazacos, Wirtz, and others, 1981; Kazacos, Vestre, Kazacos, and Raymond, 1984; Kazacos, Vestre, and Kazacos, 1984) $(B, C)$. Previously, nematodes in the exact size range of Baylisascaris (1,500-2,000 $\mu \mathrm{m})$ were found in the eyes of a 13-year-old girl in Kentucky $(D)$ and a 23-year-old man in Michigan (Raymond and others, 1978). The girl had obtained a pet raccoon 6 weeks prior to developing visual symptoms, suggesting these were previously unrecognized cases of Baylisascaris OLM.

In 1983, evidence was presented that a previously described ocular syndrome, called diffuse unilateral subacute neuroretinitis (DUSN) (Gass and others, 1978), was caused by at least two unidentified nematodes of different sizes (Gass and Braunstein, 1983). In 12 patients primarily from the southeastern United States, the parasite measured $400-1,000 \mu \mathrm{m}$, and in 6 patients from the Upper Midwest, including the 2 patients mentioned above (Raymond and others, 1978), the parasite measured 1,500-2,000 $\mu \mathrm{m}$. B. procyonis was suggested as the probable cause of the large nematode variant of DUSN, based on the compatible size of the larvae, similar disease development by B. procyonis in animals, including nonhuman primates, the geographic location of cases, and the fact that one of the patients had acquired a pet raccoon 6 weeks prior to developing ocular disease (Kazacos, Vestre, Kazacos, and Raymond, 1984; Kazacos, Vestre, and Kazacos, 1984; Kazacos, Raymond, and others, 1985).

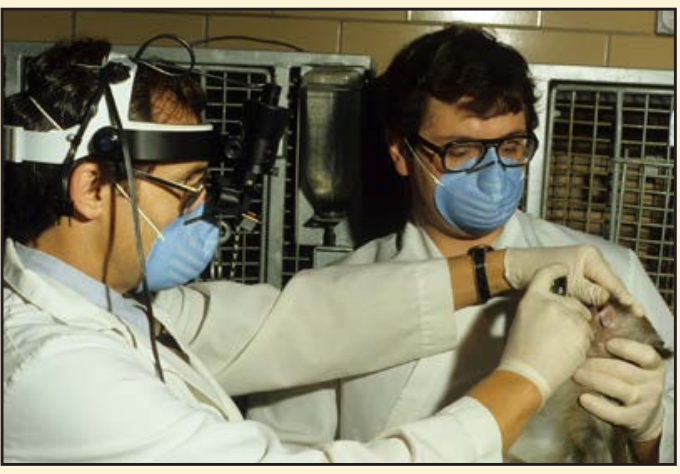

A. Kevin Kazacos (right) and Dr. W.A. Vestre performing an ophthalmoscopic exam on a macaque with NLM and OLM-DUSN. (Photo by Sam Royer)

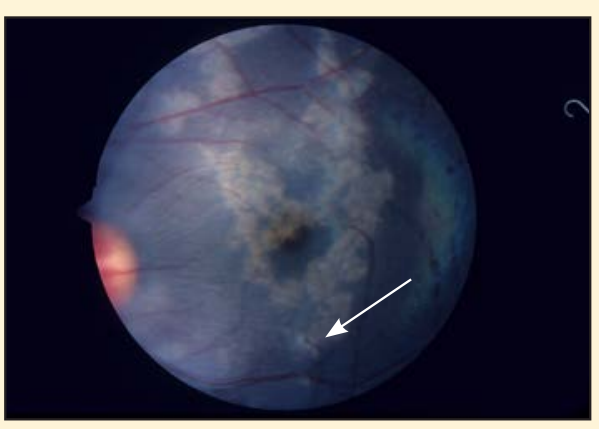

$B$. The interior of a macaque's eye showing larva (arrow) and migration tracks (white areas). (Photo by William A. Vestre)

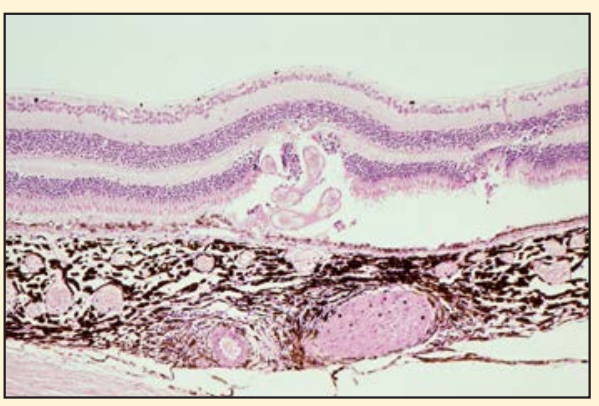

C. Histology of larva migrating in retina of macaque with OLM. (Photo by Kevin Kazacos)

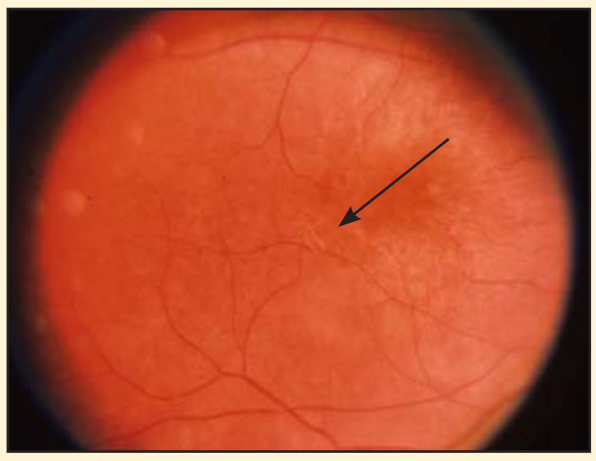

D. Baylisascaris larva (arrow) in the eye of a Kentucky girl. A. Raymond) (Photo by Lawrence 


\section{A History of Baylisascaris Ocular Larva Migrans}

During the 1980s, however, this conclusion was controversial to some members of the ophthalmology community. Opponents argued that "several patients with DUSN lived in highly urban centers in the Northeast and Midwest, making exposure to raccoons highly unlikely" (Lewis, 1985). In addition, "no reported patient with DUSN has had neurologic complaints or has presented with meningoencephalitis, as occurs in both natural and experimental infestations with B. procyonis in all nonhost species," and "a number of patients with DUSN have had a creeping skin eruption during their illness compatible with Ankylostoma [sic]...... cutaneous larva migrans is not a feature of $B$. procyonis infestation” (Lewis, 1985). None of these arguments made practical or scientific sense for discounting the involvement of Baylisascaris in DUSN, because:

1. raccoons are surprisingly common in major urban centers where they have been linked to both human NLM and OLM-DUSN (Perlman and others, 2010; Saffra and others, 2010; Liu and others, 2015; and table 5);

2. B. procyonis can cause a full range of clinical problems, from asymptomatic or covert infection at lower dosages to central nervous system (CNS) disease at higher dosages (Kazacos, 2000; Gavin and others, 2005; Kazacos and others, 2013);

3. Baylisascaris OLM would be similar to Toxocara OLM: primarily, a stand-alone disease resulting from low-level infection, with no "requirement" for concomitant NLM or CNS disease (Kazacos, Vestre, and Kazacos, 1984; Saffra and others, 2010); and

4. larva migrans affecting the skin was described for the small nematode variant of DUSN, not the large (Lewis, 1985; Gass, 1997).

Other ophthalmologists strongly supported B. procyonis as a cause of DUSN and shared additional OLM and DUSN cases they had seen that were probably due to Baylisascaris based on exposure history and the larvae that were seen. One involved a 42-year-old man in central Wisconsin who was an avid outdoorsman and had contact with a likely contaminated area (Williams and others, 1988), and another involved a 27-year-old man in Pennsylvania from an area where raccoons were common (Sivalingam and others, 1991). There was excellent morphometric, serologic, and

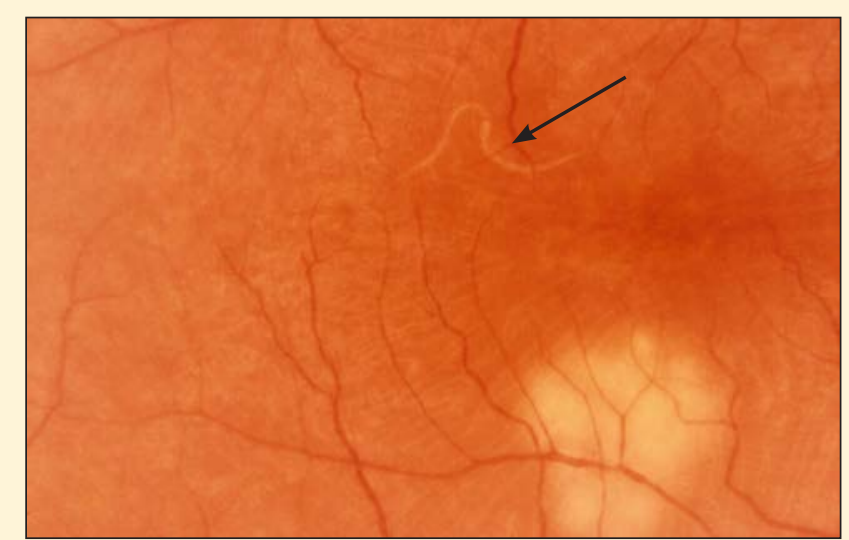

E. Baylisascaris larva (arrow) in the eye of California man, also showing first attempt at laser treatment to kill larva. (Photo by Barrett Katz)

epidemiologic support for Baylisascaris as the cause of OLM-DUSN in a 29-year-old man in northern California (Goldberg and others, 1993) (E). A 48-year-old German woman who obtained a pet raccoon also developed OLMDUSN (Kuchle and others, 1993).

These patients all had large intraocular larvae whose size and other characteristics matched Baylisascaris. Among the expanding group of patients, several cases of Baylisascaris NLM and OLM were reported from urban centers, including seropositive cases of Baylisascaris NLM and OLM in an infant in Brooklyn and a teenager in New York City, one of the largest urban centers (Perlman and others, 2010; Saffra and others, 2010), Baylisascaris OLM-DUSN in a boy in Chicago and a man in Los Angeles (Mets and others, 2003; D.M. Hirota and others, unpub. data, 2009), NLM cases from Chicago, Los Angeles and Toronto (Gavin and others, 2002; Kazacos and others, 2002; Hajek and others, 2009) and another DUSN case in the Bronx in New York City in which the patient was positive for Baylisascaris antibodies in her ocular fluid (Liu and others, 2015). To date, there are 28 reported cases of OLM-DUSN in which the size of the larva, serologic testing, and (or) history implicate Baylisascaris as the likely cause (table 9), and many others may exist since not all cases are referred or reported. Additional experimental studies have supported the role of this parasite in OLM-DUSN (Akao and others, 2003). Baylisascaris is now well accepted as a cause of human OLM and the primary cause of the large nematode variant of DUSN. 


\section{Causative Agent}

Baylisascaris procyonis and its relatives are large roundworms (nematodes, ascarids) (table 3) that live in the small intestine of their respective definitive hosts (Kazacos, 2001) (fig. 1). Species of Baylisascaris occur primarily in carnivores; one species (B. laevis) occurs in rodents (Sprent, 1968; Wu and others, 1987; Tokiwa and others, 2014) (table 4). Similar to other ascarids of terrestrial carnivores, most Baylisascaris species are transmitted to definitive hosts when they ingest larvae present in small mammal paratenic hosts. Direct infection by ingestion of infective eggs is also important for some species, particularly in young definitive hosts (Tiner, 1952a, 1953a; Sprent, 1953b; Sprent and others, 1973; Kazacos, 1983b, 2001; Kazacos and Boyce, 1989).

The different species of Baylisascaris vary in how they affect the central nervous system of paratenic hosts, and this is related to differences in how they migrate through the host's tissues and invade the brain, the growth and aggressiveness of larvae in the CNS, and the ability of the host to wall off or encapsulate the larvae. Baylisascaris procyonis and B. melis are the most pathogenic, with aggressive somatic migration and brain invasion, followed by B. columnaris and the others (Boyce and others, 1988b; Kazacos and Boyce, 1989; Kazacos, 2001).

Experimentally, B. procyonis is biologically different and more pathogenic than $B$. columnaris, requiring host ingestion of fewer infective eggs and fewer larvae in the brain to cause similar or worse clinical disease. One B. procyonis larva in the brain of a mouse is usually fatal, whereas five to six or more B. columnaris larvae in the brain are not necessarily fatal,

Table 3. Taxonomy of Baylisascaris spp.

\begin{tabular}{ll}
\hline Classification & Designation \\
\hline Kingdom & Animalia \\
Phylum & Nematoda \\
Class & Secernentea \\
Order & Ascaridida \\
Family & Ascarididae \\
Genus & Baylisascaris \\
Species & procyonis \\
& potosis \\
& columnaris \\
& melis \\
& devosi \\
& tranfuga \\
& schroederi \\
& ailuri \\
& tasmaniensis \\
& laevis \\
\hline
\end{tabular}

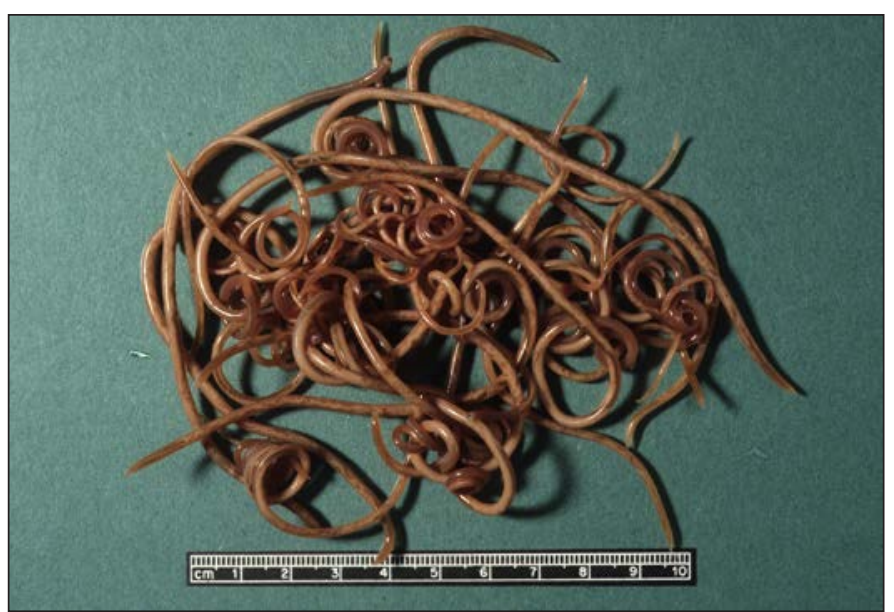

Figure 1. Adult Baylisascaris procyonis roundworms from an Indiana raccoon. (Photo by Kevin Kazacos and Sam Royer)

even when CNS signs are present (Sprent, 1952a, 1955; Tiner, 1953a,b; Clark and others, 1969; Sheppard, 1995, 1996; Sheppard and Kazacos, 1997). Clinical signs appear much earlier and progress much more quickly in mice infected with $B$. procyonis than with $B$. columnaris. In addition, $B$. columnaris larvae in the brain have a greater tendency to settle down and become encapsulated than do larvae of B. procyonis and may not produce clinical signs (Tiner, 1953a,b; Sprent, 1955; Clark and others, 1969). However, it is also known that, at sufficient dosages, B. columnaris has the ability to produce clinically significant NLM in susceptible species, including rodents, rabbits, ratites, and nonhuman primates. People should therefore exercise the same precautions with $B$. columnaris as those for B. procyonis and B. melis.

Table 4. Baylisascaris species and their primary hosts.

[Compiled from Kazacos (2001); Sprent $(1968,1970)$; Tokiwa and others (2014); Wu and others (1987)]

\begin{tabular}{ll}
\hline \multicolumn{1}{c}{ Species } & Primary definitive host(s) \\
\hline B. procyonis & Raccoons. \\
B. potosis & Kinkajous. \\
B. columnaris & Skunks. \\
B. melis & Badgers. \\
B. devosi & Martens, fishers. \\
B. transfuga & Bears. \\
B. schroederi & Giant pandas. \\
B. ailuri & Red pandas. \\
B. tasmaniensis & Tasmanian devils, quolls. \\
B. laevis & Marmots, ground squirrels. \\
\hline
\end{tabular}




\section{Life Cycle of Baylisascaris procyonis}

1. B. procyonis adults are large, tan-colored worms. Mature females are up to 20-22 centimeters $(\mathrm{cm})$ long, males up to 9-11 cm long (Sprent, 1968; Gey, 1998; Kazacos, 2001). Both live in the small intestine of raccoons. Adult female worms are very prolific and produce an estimated 115,000-179,000 eggs per worm per day; thus, infected raccoons shed millions of eggs per day in their feces (Kazacos, 1982, 1983a, 2001; Snyder and Fitzgerald, 1987; Reed and others, 2012).
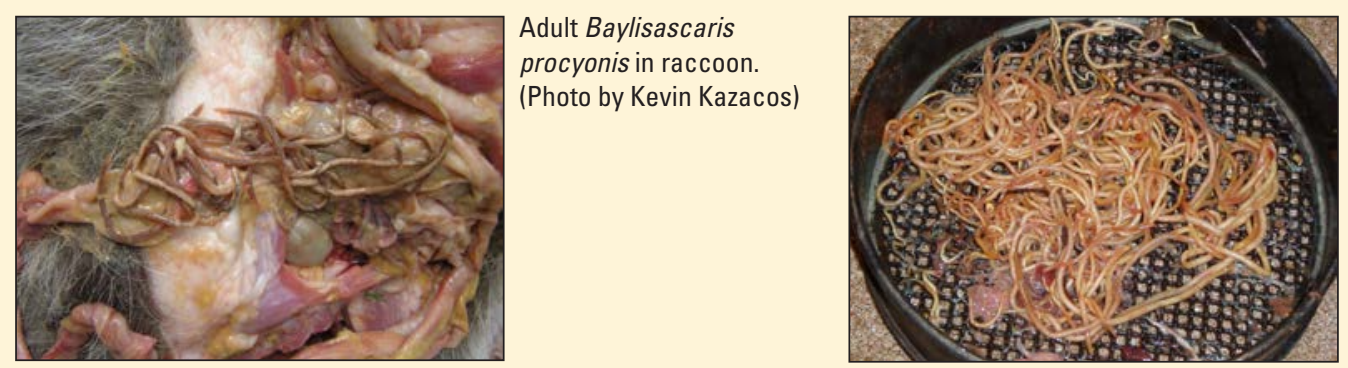

Baylisascaris adults recovered from raccoons at necropsy. (Photo by Kevin Kazacos)

2. The eggs of B. procyonis are roughly oval, brown, contain a large single-celled embryo, and have a thick shell with a finely granular or particulate surface. They range in size from $63-88$ by $50-70$ micrometers $(\mu \mathrm{m})$, and most average 68-76 by 55-61 $\mu \mathrm{m}$ (Kazacos and Turek, 1983; Kazacos and Boyce, 1989; Sakla and others, 1989; Miyashita, 1993; Averbeck and others, 1995; Van Andel and others, 1995; Conboy, 1996; Gey, 1998).
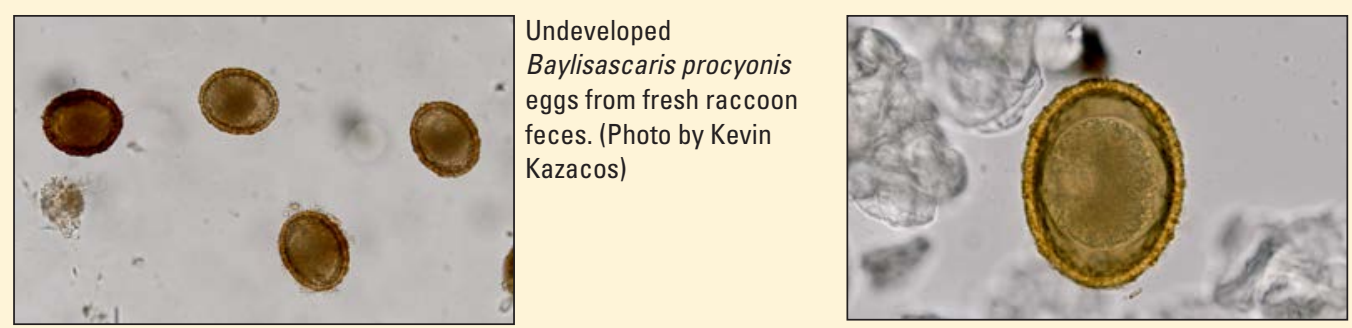

Higher magnification of undeveloped B. procyonis egg from fresh raccoon feces. (Photo by Kevin Kazacos)

3. Given adequate temperature and moisture, B. procyonis eggs can reach infectivity (third-stage larva) in 11-14 days (Sakla and others, 1989), although under natural conditions of fluctuating temperatures, this usually takes several weeks. Once infective, they can remain viable in the environment for years (Kazacos and Boyce, 1989).

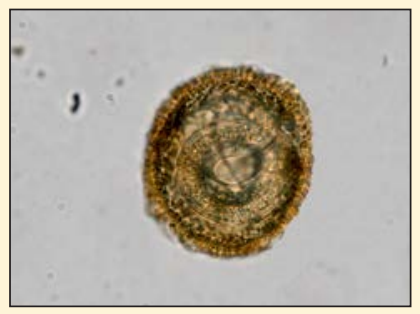

Infective B. procyonis egg from older raccoon feces. Note larva coiled inside. (Photo by Kevin Kazacos)

4. Following ingestion by paratenic hosts, infective eggs hatch in the small intestine, and larvae quickly penetrate the intestinal wall and migrate through the liver to the lungs. B. procyonis larvae cause hemorrhages in the lungs of laboratory mice and other animals as early as 1 day postinfection (PI), peaking on days 2-3 PI, followed shortly by lung inflammation (Wyand-Ouellette and others, 1983; Kazacos, 1986, 2001).

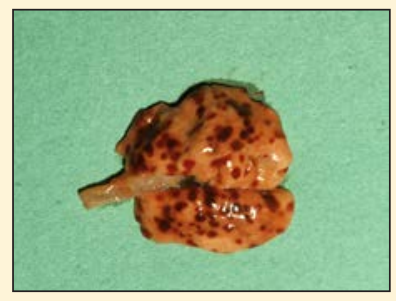

Early migratory hemorrhages in the lungs of a rat and ferret. (Photos by Kevin Kazacos and Sam Royer)

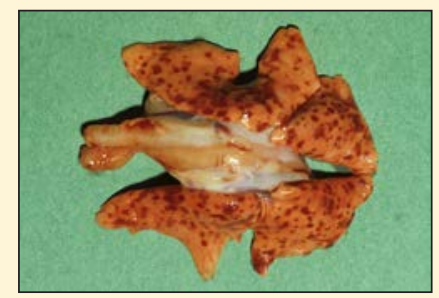




\section{Life Cycle of Baylisascaris procyonis}

5. In the lungs, the larvae gain access to the systemic arterial circulation, which distributes them throughout the body but especially to the forequarters and head, where some end up in the brain (Sprent 1952a, 1955; Tiner 1953b; Sheppard and Kazacos 1997). Some larvae also migrate from the intestine or lungs directly into surrounding tissues.
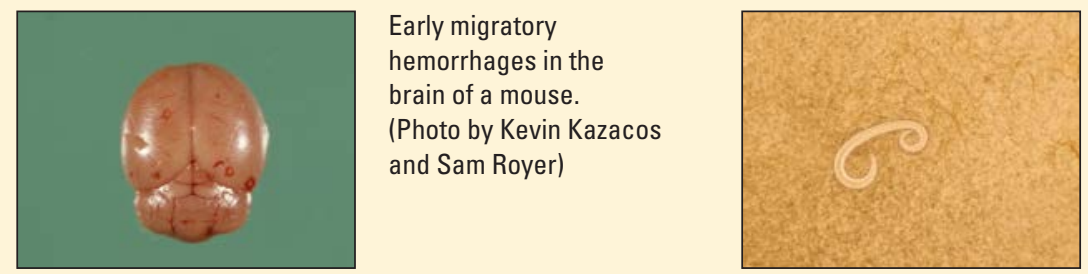

B. procyonis larva in brain squash of a parrot. (Photo by Kevin Kazacos and Sam Royer)

6. B. procyonis larvae grow quickly, from about $300 \mu \mathrm{m}$ long when they hatch from the eggs to 1.3-1.9 millimeters $(\mathrm{mm})$ long at 15 days PI (Tiner 1953a; Bowman 1987; Donnelly and others, 1989; Goldberg and others, 1993). Most B. procyonis larvae recovered from clinical cases of neural larva migrans (NLM) are 1.5-1.9 mm long and 60-80 $\mu \mathrm{m}$ in greatest diameter (Kazacos, 1997, 2001).

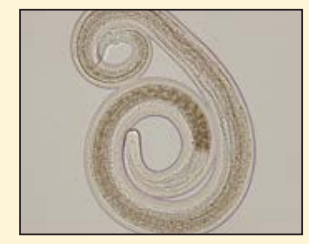

Baylisascaris procyonis larva recovered by digestion from the brain of a chinchilla. (Photo by Kevin Kazacos)

7. Larvae in visceral and somatic tissues become encapsulated in granulomas (inflammatory nodules composed of connective tissue, white blood cells, and other cells) where they become quiescent and survive for months to years, essentially waiting to be ingested by a raccoon (Kazacos, 1983a, 1997).
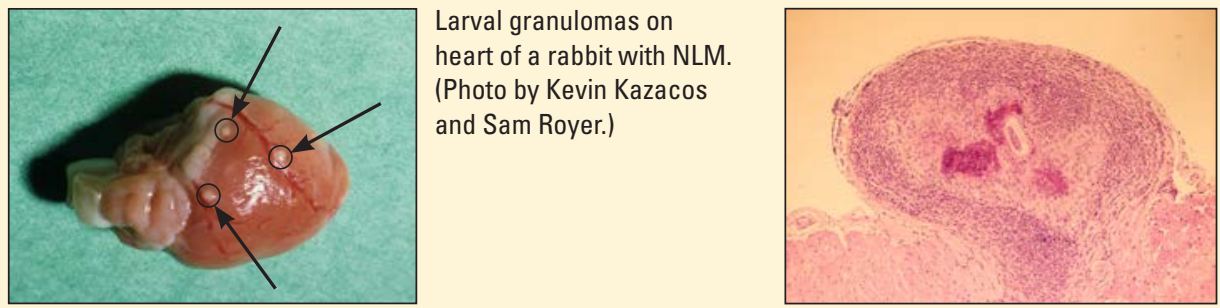

Histology of Baylisascaris larva in granuloma in heart of a rabbit with NLM. (Photo by Kevin Kazacos and Sam Royer.)

8. Young raccoons become infected at an early age by ingesting infective eggs from their mother's contaminated teats or fur, the contaminated den, or while visiting or investigating raccoon latrines or other contaminated areas near their den (Kazacos, 1983a,b, 2001).

9. Older raccoons become infected mainly by ingesting third-stage larvae in paratenic hosts, usually rodents (Tiner, 1953a,b; Kazacos, 1983a,b, 2001; Kazacos and Boyce, 1989; Reed and others, 2012), although some egg-induced infections may also occur.

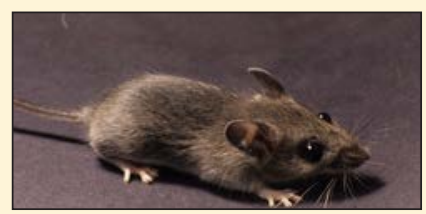

White-footed mouse, a common paratenic host of $B$. procyonis. (Photo by Claudia Sheppard and Sam Royer)

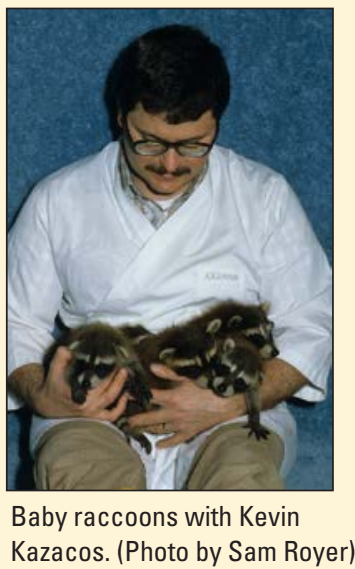

10. In young raccoons, larvae hatching from eggs enter the mucous membranes (mucosa) of the small intestine and develop there for several weeks before reentering the intestinal lumen to mature; these worms reach patency (egg shedding) in 50-76 (mean, 63) days. In older raccoons, larvae from paratenic hosts develop to adult worms in the lumen (interior cavity) of the intestine, reaching patency in 32-38 (mean, 35) days (Kazacos, 1983b; Kazacos and Boyce, 1989). 
Baylisascaris transfuga, B. devosi, and B. tasmaniensis are also potential causes of larva migrans in humans; however, due to differences in migration, larval growth, and encapsulation of their larvae, they are much less pathogenic than the other species. Their larvae mainly enter visceral organs and muscle and have much less CNS invasion (Sprent, 1953b; Matoff and Komandarev, 1965; Sprent and others, 1973; Kazacos and Boyce, 1989; Kazacos, 2001; Papini and others, 1994; Papini, Demi, and others, 1996), although at high dosages in mice, both NLM and OLM were produced following infection with B. transfuga (Papini and Casarosa, 1994; Papini, Renzoni, and others, 1996; Sato and others, 2004). Recently, $B$. potosis was found to be much less pathogenic than $B$. procyonis in experimentally infected squirrel monkeys. At exceptionally high dosages, some larvae became encapsulated at the brain surface, but there was no deep CNS invasion or migration and no clinical disease was produced (Tokiwa and others, 2015). Larvae mainly migrated in the viscera and became encapsulated in the wall of the lower intestine. Less is known about the other species; $B$. schroederi is unusual in that it appears to cause clinical LM in its definitive host, the giant panda (Zhang and others, 2007; Wang and others, 2008).

The vast majority (greater than or equal to 96 percent) of recognized clinical cases of NLM and OLM due to Baylisascaris have been linked to $B$. procyonis from raccoons (Kazacos, 2001), indicating the much greater importance of this species in the causation and epidemiology of these diseases. However, all of the above Baylisascaris species, and perhaps some others, should be considered potentially dangerous for producing larva migrans disease, particularly at higher infection levels.

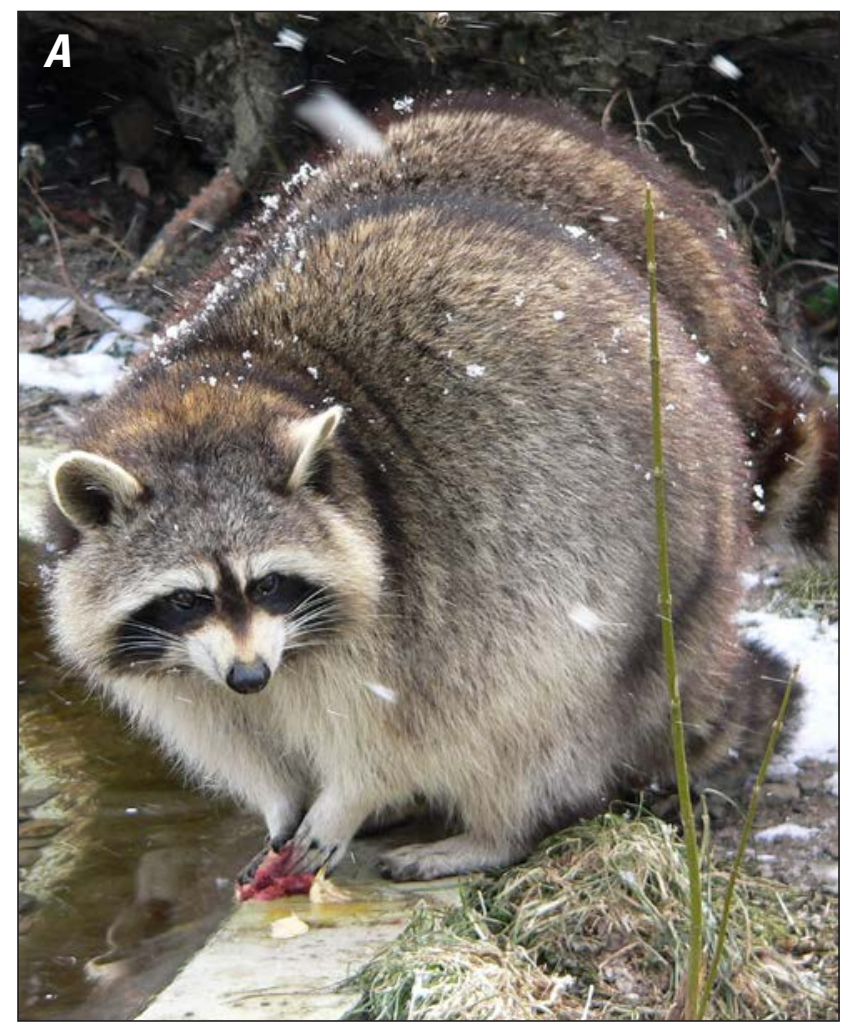

\section{Geographic Distribution}

The geographic distribution of B. procyonis is linked to that of the most common host of the adult worm, namely the raccoon. Common or North American raccoons (fig. 2) are native to North and Central America (Lotze and Anderson, 1979), and their range and population densities have been increasing since the 1940s (Gehrt, 2003) (fig. 3). They have also been introduced elsewhere, such that wild populations now exist in parts of Europe (fig. 4) and Asia. They are common as exotic pets or in zoological parks elsewhere, including in Europe, Japan, and recently described in China (Xie and others, 2014). This expansion of raccoons has been accompanied by the spread of $B$. procyonis to other areas of the world, so that $B$. procyonis is now enzootic in raccoons in North America, Europe, and parts of Asia, leading directly to cases and outbreaks of neural and ocular larva migrans in animals and humans in these areas.

In North America, B. procyonis is more common in the Midwestern and Northeastern United States and contiguous Canada and on the West Coast, where infection prevalence among raccoons reaches 68-100 percent (Kazacos and Boyce, 1989; Kazacos, 2001) (table 5). The prevalence of B. procyonis appears to be stable in enzootic areas, although some differences and fluctuations are possible based on changes in the number of animals and their populations (Page, Gehrt, and others, 2009), as well as ecoregion and soil characteristics (Kresta and others, 2010). In Wisconsin, 75 percent of $B$. procyonis infections are in the southern half of the state and 18 percent are in the northern quarter, related to the higher abundance of raccoons in the southern part of the state versus the northern part (Amundson and Marcquenski, 1986). Similar associations of $B$. procyonis with raccoon abundance were seen in Texas (Kresta and others, 2010). In general, the prevalence of $B$. procyonis decreases from the northern to southern United States, so that the parasite is less common in raccoons in more southern states (Kazacos, 2001) (table 5; fig. 5), although pockets of higher prevalence exist there (Kerr and others, 1997).

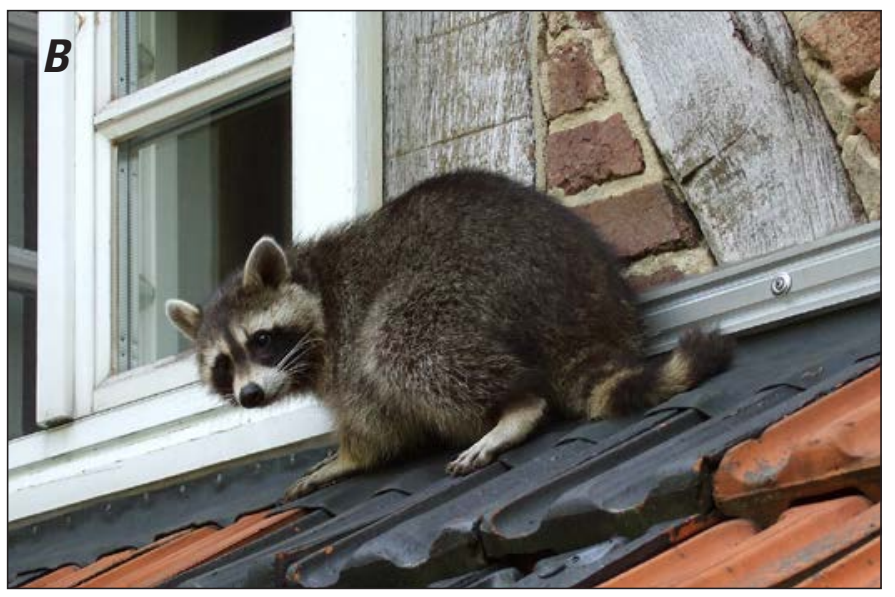

Figure 2. Common raccoons ( $A$, photo by B.S. Thurner Hof; $B$, photo by Carsten Volkwein). 


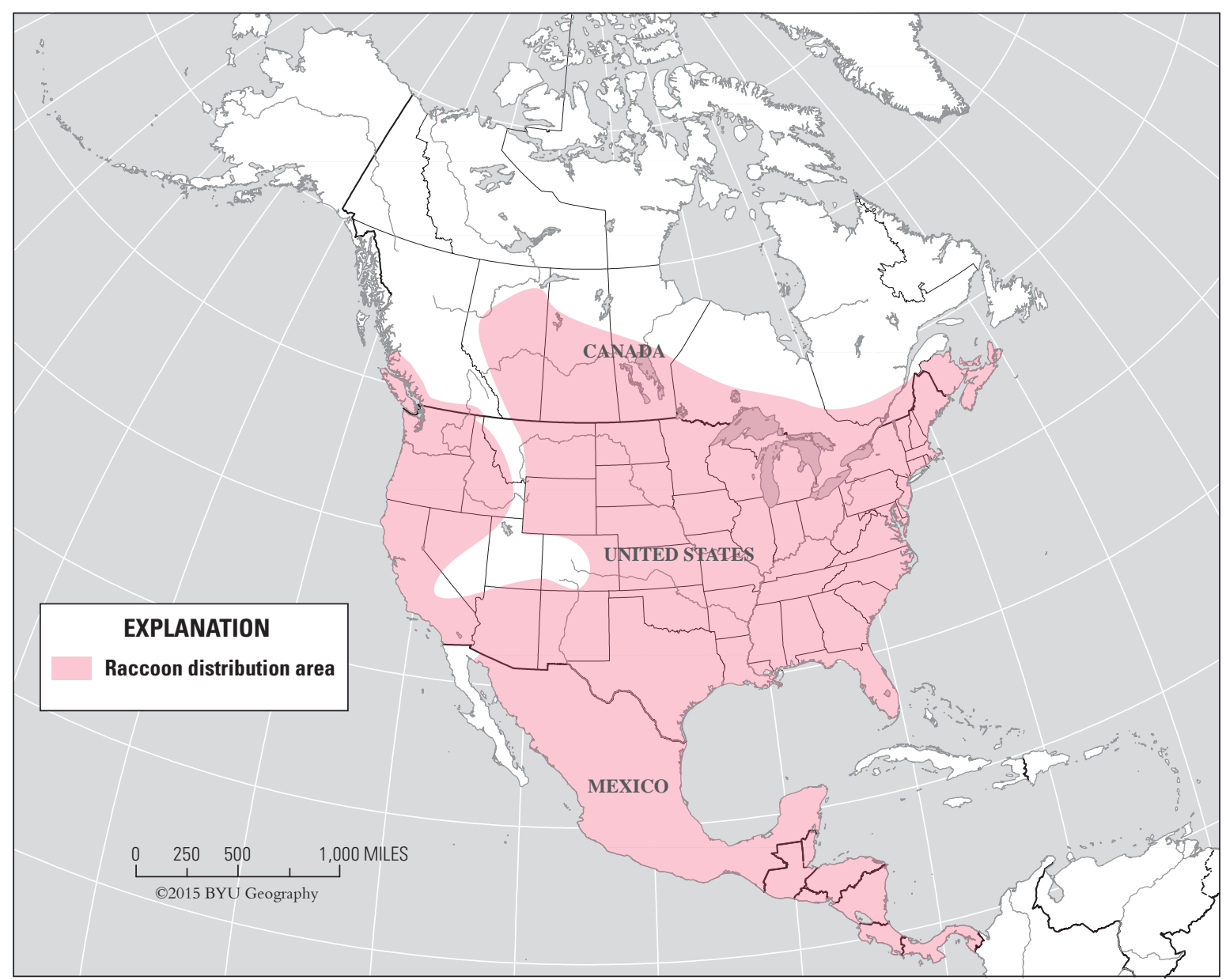

Figure 3. Distribution of the common raccoon in North and Central America. (Modified from Goldman, 1950, and Boggess, 1994, and including Pipas and others, 2014.)

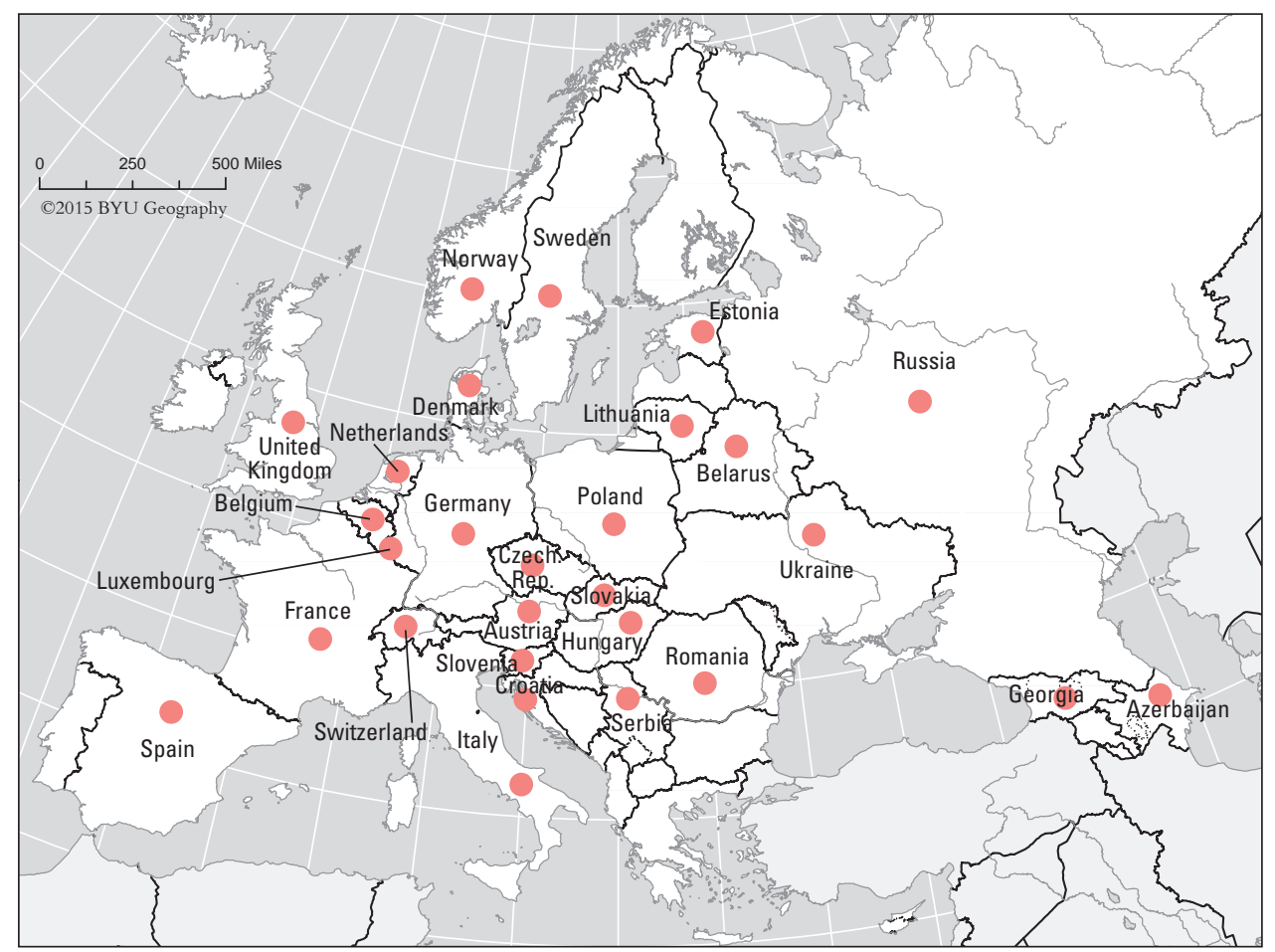

EXPLANATION

Country with raccoons, including sporadic detections

Figure 4. Distribution of the common raccoon in Europe. (Modified from Beltrán-Beck and others, 2012) 
Table 5. Location, prevalence, and numbers of intestinal Baylisascaris procyonis in raccoons.

[Each line in the table represents a separate study or examination; <, less than; , approximately; NR, not reported; Positive, percent unknown]

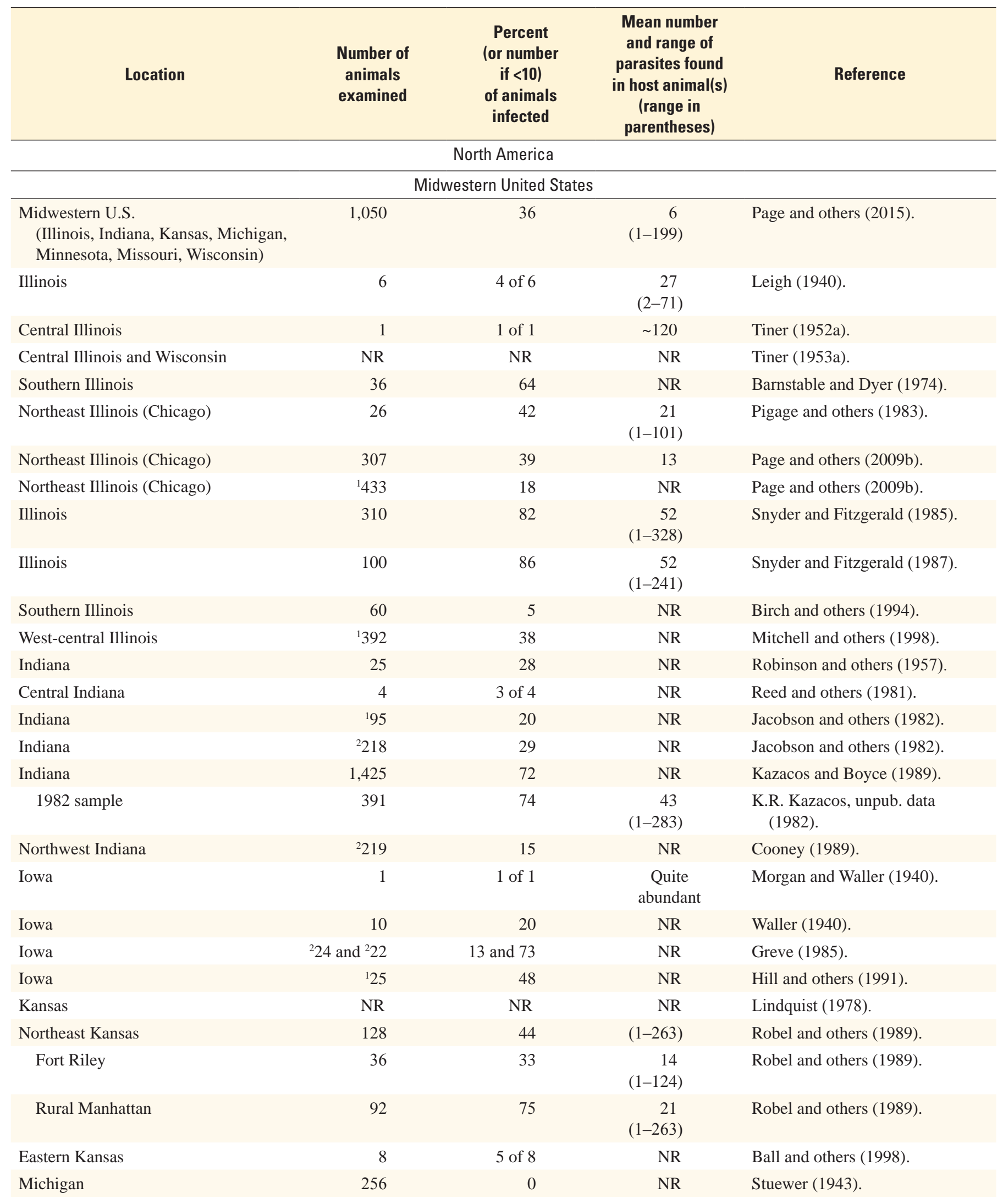


Table 5. Location, prevalence, and numbers of intestinal Baylisascaris procyonis in raccoons.-Continued

[Each line in the table represents a separate study or examination; <, less than; , approximately; NR, not reported; Positive, percent unknown]

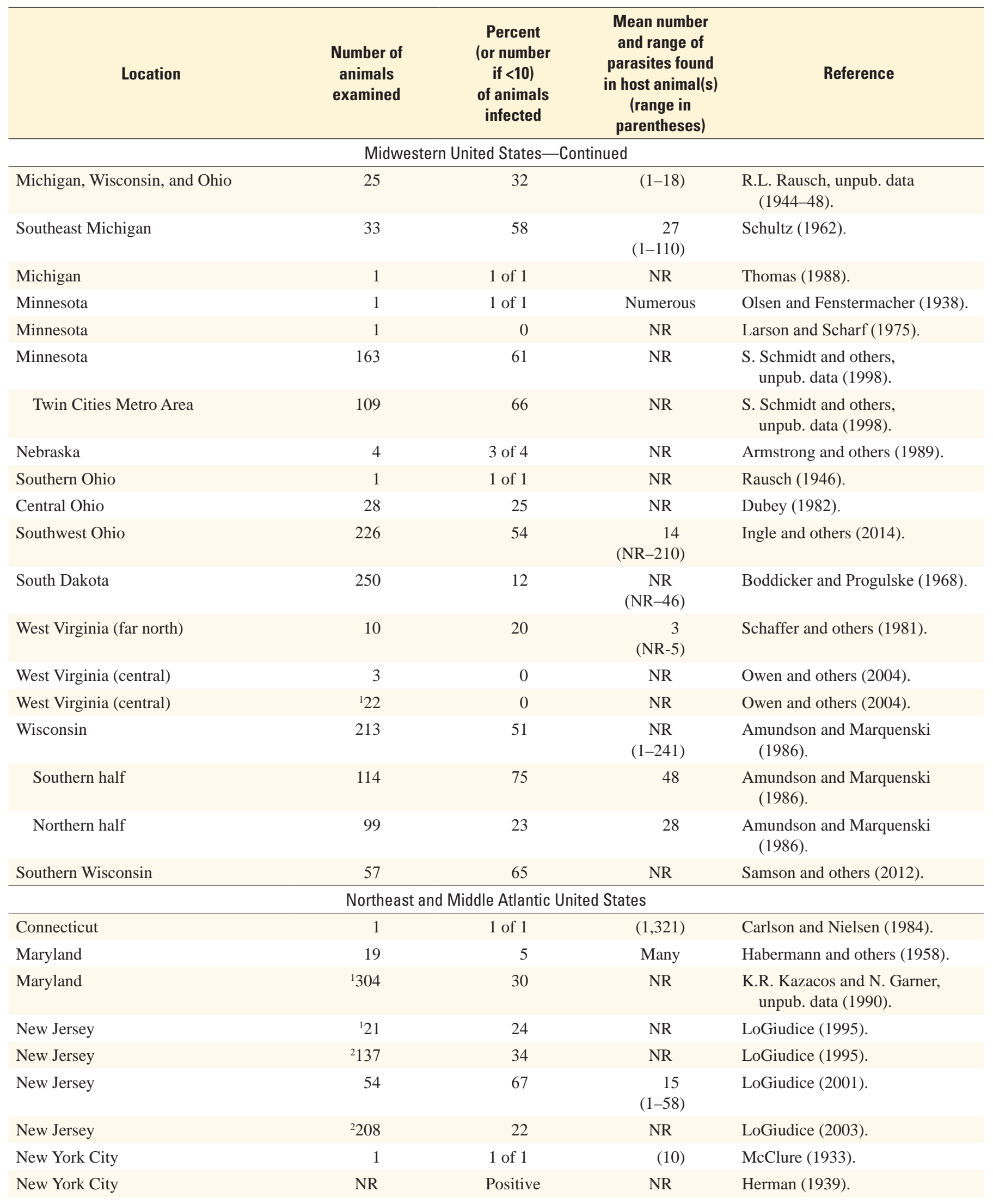


Table 5. Location, prevalence, and numbers of intestinal Baylisascaris procyonis in raccoons.-Continued

[Each line in the table represents a separate study or examination; <, less than; , approximately; NR, not reported; Positive, percent unknown]

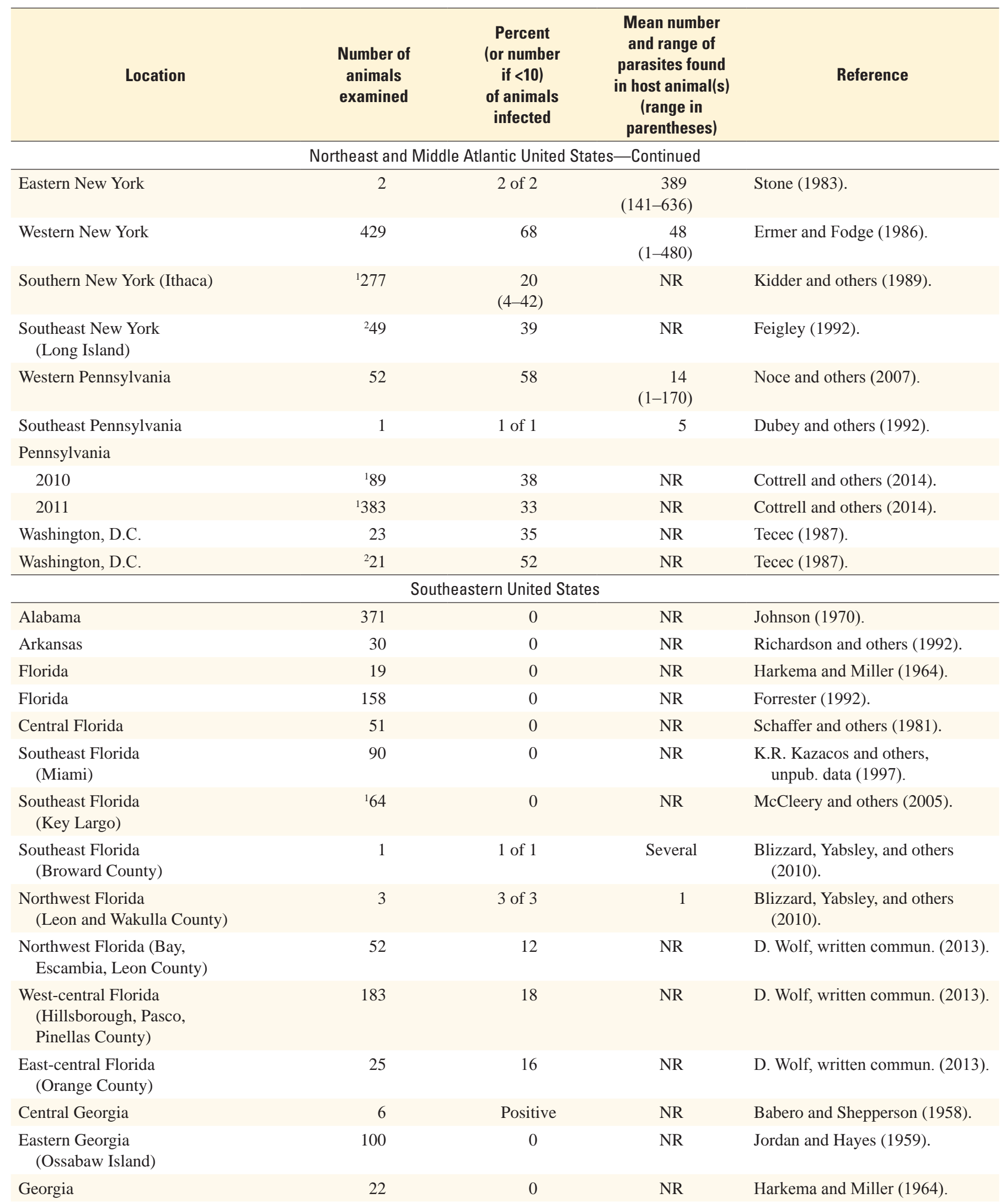


Table 5. Location, prevalence, and numbers of intestinal Baylisascaris procyonis in raccoons.-Continued

[Each line in the table represents a separate study or examination; <, less than; , approximately; NR, not reported; Positive, percent unknown]

\begin{tabular}{|c|c|c|c|c|}
\hline Location & $\begin{array}{c}\text { Number of } \\
\text { animals } \\
\text { examined }\end{array}$ & $\begin{array}{c}\text { Percent } \\
\text { (or number } \\
\text { if }<10 \text { ) } \\
\text { of animals } \\
\text { infected }\end{array}$ & $\begin{array}{l}\text { Mean number } \\
\text { and range of } \\
\text { parasites found } \\
\text { in host animal(s) } \\
\text { (range in } \\
\text { parentheses) }\end{array}$ & Reference \\
\hline \multicolumn{5}{|c|}{ Southeastern United States-Continued } \\
\hline $\begin{array}{l}\text { Northern Georgia } \\
\text { (Clarke County) }\end{array}$ & 116 & 10 & $\begin{array}{c}7 \\
(1-22)\end{array}$ & $\begin{array}{l}\text { Blizzard, Davis, and others } \\
\text { (2010). }\end{array}$ \\
\hline Northern Georgia & 110 & 1 & NR & $\begin{array}{l}\text { V.R. Nettles, unpub. data } \\
\quad(1976-77) \text {. }\end{array}$ \\
\hline $\begin{array}{l}\text { Northeast Georgia } \\
\text { (Atlanta) }\end{array}$ & 50 & 22 & $\begin{array}{c}6 \\
(1-24)\end{array}$ & Eberhard and others (2003). \\
\hline Southeast Georgia & 10 & 0 & NR & Schaffer and others (1981). \\
\hline $\begin{array}{l}\text { Eastern Georgia } \\
\text { (St. Catherine Island) }\end{array}$ & 32 & 0 & NR & Price and Harman (1983). \\
\hline Western Kentucky & 70 & 30 & $\begin{array}{c}\mathrm{NR} \\
(\mathrm{NR}-61)\end{array}$ & Cole and Shoop (1987). \\
\hline \multicolumn{5}{|l|}{ North Carolina } \\
\hline Coastal & 61 & 0 & NR & Harkema and Miller (1964). \\
\hline Inland & 148 & 0 & NR & Harkema and Miller (1964). \\
\hline Southeast North Carolina & 10 & 0 & NR & Schaffer and others (1981). \\
\hline Inland & 31 & 0 & NR & Harkema and Miller (1964). \\
\hline Tennessee & 253 & 8 & $(1-221)$ & Bafundo and others (1980). \\
\hline Northeast Tennessee/Virginia & 20 & 0 & NR & Schaffer and others (1981). \\
\hline Eastern Tennessee & 118 & 13 & $\begin{array}{c}7 \\
(1-15)\end{array}$ & Souza and others (2009). \\
\hline $\begin{array}{l}\text { Northwest Tennessee and } \\
\text { southwest Kentucky }\end{array}$ & 145 & 3 & $\begin{array}{c}\mathrm{NR} \\
(\mathrm{NR}-83)\end{array}$ & Smith and others (1985). \\
\hline Virginia & 6 & 0 & NR & Harkema and Miller (1964). \\
\hline Western Virginia & 7 & 5 of 7 & $(17-93)$ & Jacobson and others (1976). \\
\hline Eastern Virginia (coastal) & 10 & 0 & NR & Schaffer and others (1981). \\
\hline Eastern Virginia & 38 & 0 & NR & Jones and McGinnes, (1983). \\
\hline Western Virginia (mountains) & 34 & 56 & $\begin{array}{r}16 \\
(\mathrm{NR}-129)\end{array}$ & Jones and McGinnes (1983). \\
\hline Northern Virginia & 44 & 2 & NR & Hancock and others (2002). \\
\hline
\end{tabular}


Table 5. Location, prevalence, and numbers of intestinal Baylisascaris procyonis in raccoons.-Continued

[Each line in the table represents a separate study or examination; <, less than; , approximately; NR, not reported; Positive, percent unknown]

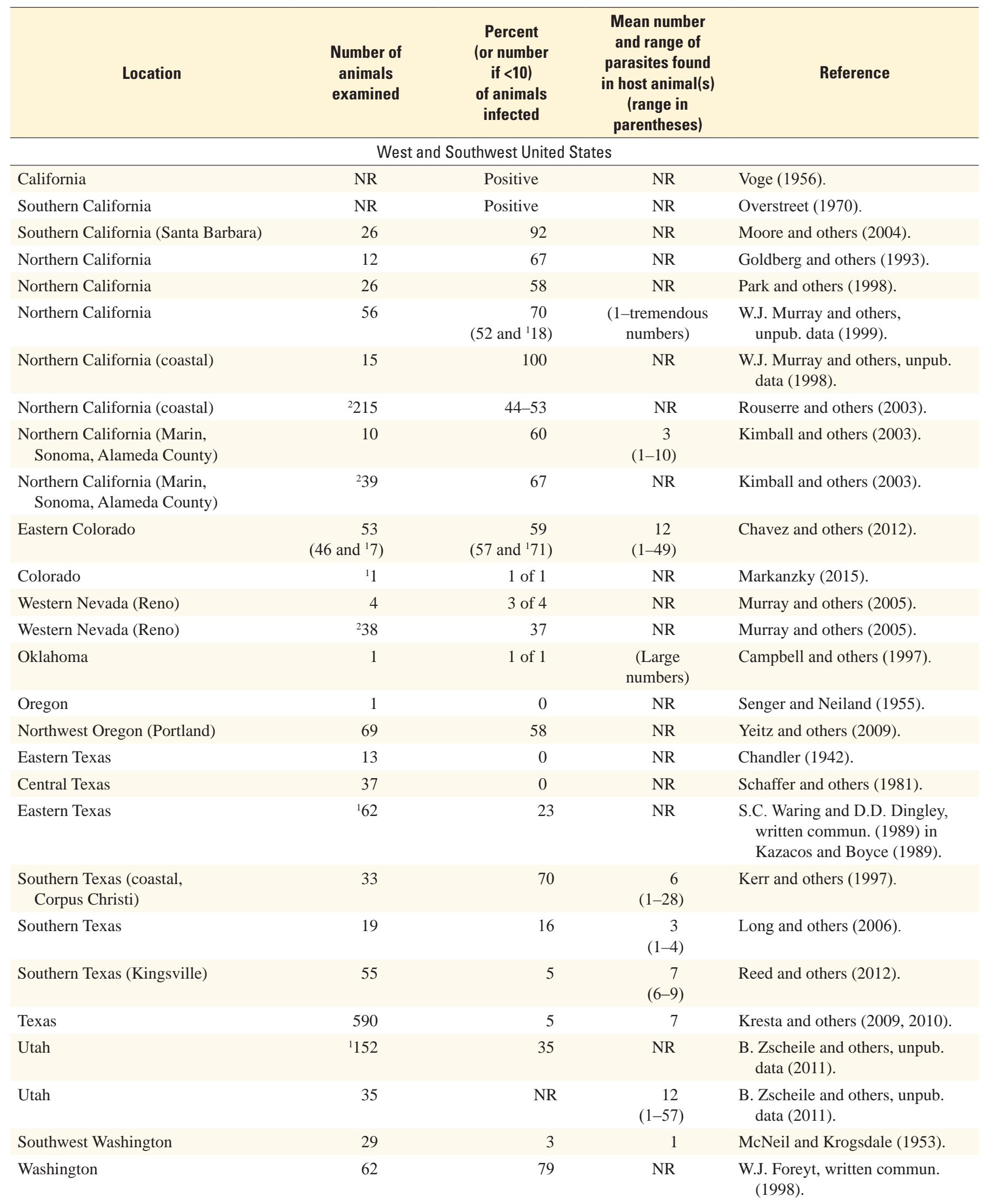


Table 5. Location, prevalence, and numbers of intestinal Baylisascaris procyonis in raccoons._-Continued

[Each line in the table represents a separate study or examination; <, less than; , approximately; NR, not reported; Positive, percent unknown]

\begin{tabular}{|c|c|c|c|c|}
\hline Location & $\begin{array}{c}\text { Number of } \\
\text { animals } \\
\text { examined }\end{array}$ & $\begin{array}{c}\text { Percent } \\
\text { (or number } \\
\text { if }<10 \text { ) } \\
\text { of animals } \\
\text { infected }\end{array}$ & $\begin{array}{l}\text { Mean number } \\
\text { and range of } \\
\text { parasites found } \\
\text { in host animal(s) } \\
\text { (range in } \\
\text { parentheses) }\end{array}$ & Reference \\
\hline \multicolumn{5}{|c|}{ West and Southwest United States-Continued } \\
\hline \multicolumn{5}{|c|}{ Canada } \\
\hline Southwest British Columbia & 82 & 61 & $\begin{array}{c}27 \\
(1-226)\end{array}$ & Ching and others (2000). \\
\hline Nova Scotia & 219 & 8 & NR & Anderson and Mills (1991). \\
\hline Nova Scotia & 236 & 7 & $(1-46)$ & Smith (1992). \\
\hline Nova Scotia & 491 & 7 & NR & J. Mills, unpub. data (1993). \\
\hline Ontario & NR & Positive & NR & Sprent (1968). \\
\hline Ontario (Toronto) & 23 & 43 & Numerous & Cranfield and others (1984). \\
\hline Southern Ontario (Guelph) & 41 & 51 & $(1-40)$ & Berry (1985). \\
\hline Ontario & 128 & 38 & $\begin{array}{r}3 \\
(1-116)\end{array}$ & Jardine and others (2014). \\
\hline Prince Edward Island & 50 & 2 & NR & G.A. Conboy, unpub. data (1998). \\
\hline Czech and Slovak Republics & 1 & 1 of 1 & 28 & Tenora and Stanek (1990). \\
\hline Denmark & ${ }^{1} 19$ & $11-21$ & NR & Brinch (2006). \\
\hline \multicolumn{5}{|l|}{ Germany } \\
\hline Brandenburg & 41 & 0 & NR & Lux and Priemer (1995). \\
\hline Hessen & 185 & 71 & $(1-232)$ & Gey (1998). \\
\hline Bad Karlshafen & ${ }^{1} 15$ & 80 & NR & Hoffmann and others (2002). \\
\hline Saxony & 56 & 39 & NR & Winter and others (2005). \\
\hline Netherlands & NR & NR & Present & $\begin{array}{l}\text { H. van Bolhuis, written commun. } \\
\text { (2009). }\end{array}$ \\
\hline Norway & 4 & 4 of 4 & $\begin{array}{c}53 \\
(11-115)\end{array}$ & Davidson and others (2013). \\
\hline Poland & 1 & 1 of 1 & 50 & Stefański and Žarnowski (1951). \\
\hline Poland & ${ }^{2} 27$ & 4 & NR & Bartoszewicz and others (2008). \\
\hline Warta Mouth National Park & 191 & 3 & NR & Popiotek and others (2011). \\
\hline Spain & 3 & 0 & NR & $\begin{array}{l}\text { Jimenez Martinez and others } \\
\text { (2015). }\end{array}$ \\
\hline
\end{tabular}


Table 5. Location, prevalence, and numbers of intestinal Baylisascaris procyonis in raccoons.-Continued

[Each line in the table represents a separate study or examination; <, less than; , approximately; NR, not reported; Positive, percent unknown]

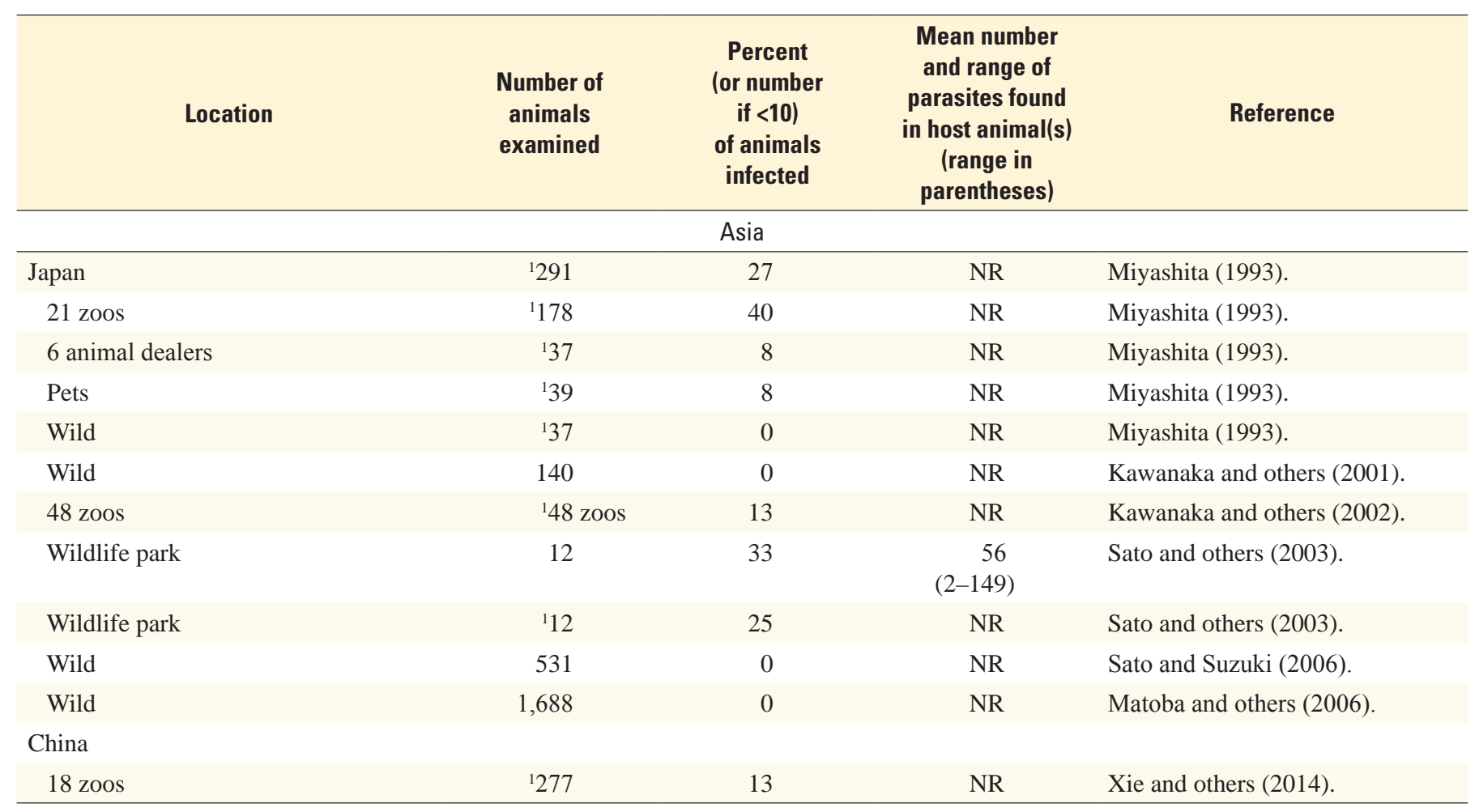

${ }^{1}$ Examination of raccoon feces for eggs.

${ }^{2}$ Examination of raccoon feces from latrines for eggs. 


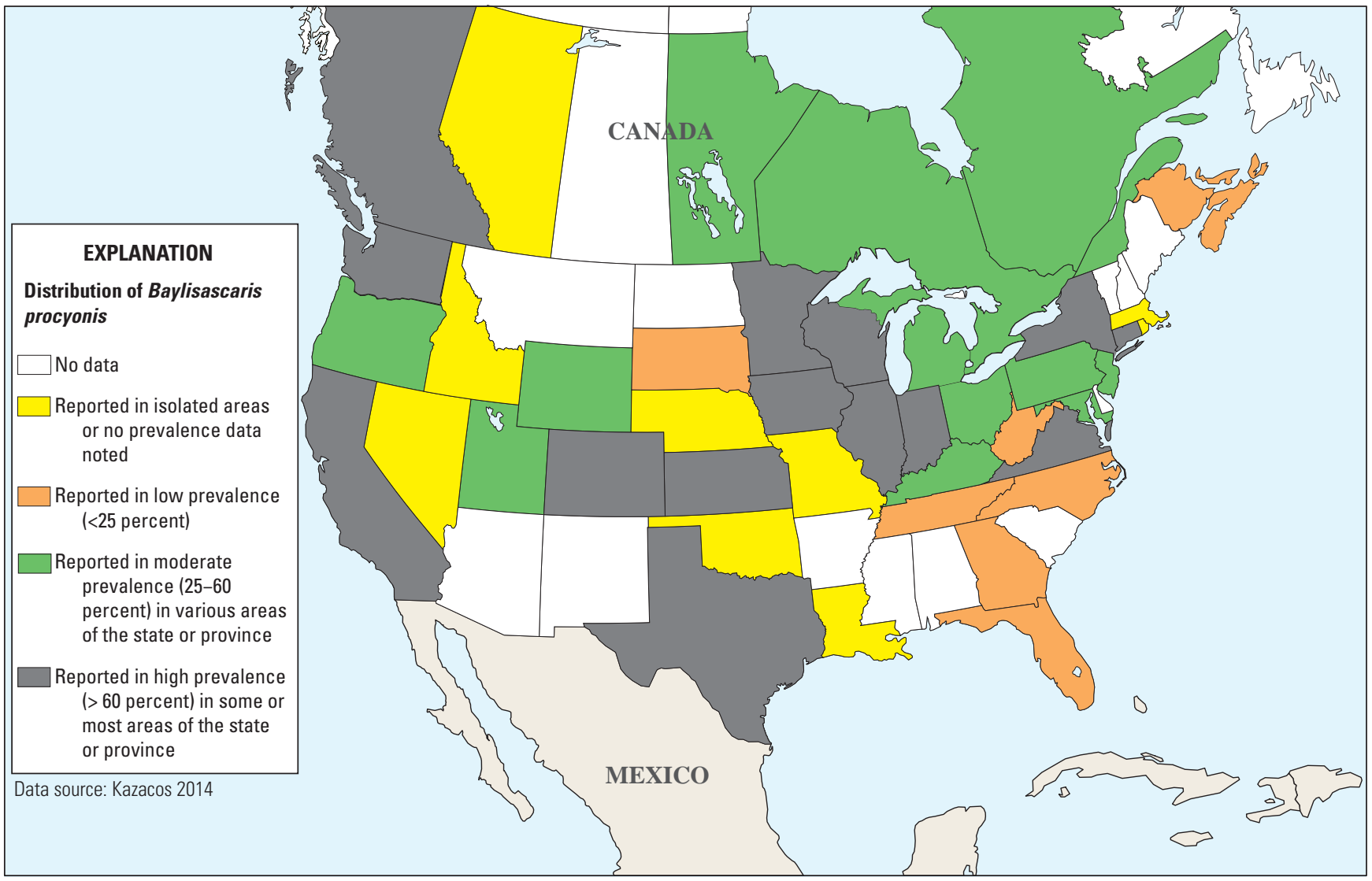

Figure 5. Distribution and general prevalence of Baylisascaris procyonis in raccoons in the United States and Canada. (Modified from Hernandez and others, 2013)

Until recently, the farthest known southeastern distribution of B. procyonis was in central Georgia (Babero and Shepperson, 1958), but the parasite was recently found in raccoons in Florida (Yabsley, 2010; Blizzard, Yabsley, and others, 2010; D. Wolf, written commun., 2013). In the Southeast and Mid-Atlantic states, B. procyonis has been found primarily in mountainous areas, not in coastal regions or on coastal islands, except in south coastal Texas (Kerr and others, 1997) and Florida (Yabsley, 2010; Blizzard, Yabsley, and others, 2010; D. Wolf, written commun., 2013). It is doubtful that the lack of $B$. procyonis in the deep southeastern United States is related to environmental limitations, because Toxocara spp., roundworms of dogs, cats, and foxes, and other ascarids do very well there (Kazacos, 2001). It likely has more to do with expansion of the parasite into new areas, especially past the Appalachian mountains, and its establishment and maintenance in the southeast is likely related to host densities and other factors. In areas with diverse ecoregions, such as Texas, a combination of average rainfall, temperature, soil type, and host abundance appear to influence the relative prevalence of B. procyonis. Prevalence was higher in central Texas ecoregions and in areas with clayey soil, which retains water better and likely helps ameliorate the effects of high temperatures on egg survival compared to other soil textures (Kazacos, 1991; Kresta and others, 2010). With the introduction, translocation, movement, and population increases of raccoons and other definitive hosts, $B$. procyonis has now become established in new areas of the South and Southeast. Local prevalences of $B$. procyonis may vary widely and change over time, so it is important not to discount its occurrence in a particular area until an adequate number of raccoons and other potential definitive hosts have been examined.

B. procyonis has been found recently in areas formerly unaffected, indicating its introduction and (or) spread. Although B. procyonis was not previously found in east or central Texas (Chandler, 1942; Schaffer and others, 1981), it was identified recently in raccoons in these areas as well as in south Texas (Kerr and others, 1997; Kresta and others, 2009, 2010; Reed and others, 2012) (table 5; fig. 5). Variation in the prevalence of $B$. procyonis over time and its presence in isolated "pockets" is well demonstrated in south Texas, where a high prevalence in the Corpus Christi area (70 percent) on the Gulf Coast differed considerably from that seen in Kingsville (5 percent), about 35 miles further south and inland, and Duval County (16 percent), even further inland (Kerr and others, 1997; Long and others, 2006; Reed and others, 2012). B. procyonis was also found at a very low prevalence (0.9 percent) in north Georgia in 1976-77 (Kazacos and Boyce, 1989), but recently, 22 percent of raccoons in suburban Atlanta (Eberhard and others, 2003) as well as 10 percent of raccoons in nearby 
Clarke County (Blizzard, Davis, and others, 2010) were found to be infected. B. procyonis had been previously unknown in Florida (Forrester, 1992; Kazacos, 2001; McCleery and others, 2005; K.R. Kazacos and others, unpub. data, 1997), but it was recently found in raccoons in four counties in the Panhandle region as well as in southeast, west-central and east-central Florida (Yabsley, 2010; Blizzard, Yabsley, and others, 2010; D.Wolf, written commun., 2013) (table 5). Whether it was introduced into these areas by the translocation of infected raccoons or dogs or spread naturally is unknown. Limited data are available on the prevalence of B. procyonis in the Rocky Mountain or Southwestern states, although it was recently found in raccoons in Nevada (Murray and others, 2005), Colorado (Chavez and others, 2012), Utah (B. Zscheile and others, unpub. data, 2011), and Wyoming (Pipas and others, 2014).

Introduction to new areas has clearly been shown with $B$. procyonis in raccoons in Europe and Asia, and with B. potosis in kinkajous. Both animal species have been translocated and introduced either for their fur (in the case of raccoons) or as part of zoo collections and the exotic pet trade. For example, kinkajous were imported from the Cooperative Republic of Guyana in South America by a breeding facility in MiamiDade County, Florida (Kazacos and others, 2011). Infected kinkajous originating from that breeding facility were first identified in a pet store in Tennessee. Infected pet kinkajous from Guyana were also identified recently in Japan (Taira and others, 2013). It remains unknown if this parasite has entered the local paratenic host population near the breeding facility in Florida or if it can also infect and be spread by raccoons or other hosts.

The distribution of clinical cases of Baylisascaris larva migrans (NLM and OLM-DUSN) follows the distribution and prevalence of B. procyonis in infected raccoons in North America and elsewhere. This is likely related to the pathogenicity of $B$. procyonis, that is, its ability to produce disease in other species, as well as to the widespread distribution of raccoons and their ability to live in close association with humans and domestic animals. In North America, both animal and human cases of Baylisascaris LM are more numerous in the Midwestern and Northeastern regions of the United States and contiguous Canada and along the West Coast than in other areas, although some cases have occurred elsewhere (figs. 6 and 7). Fewer cases have been reported from outside North America, and these were primarily in areas where infected raccoons had been introduced previously and (or) are now well established. This trend may be expected to increase as both raccoons and the parasite proliferate in new areas and awareness of $B$. procyonis as a disease agent also rises. One must also consider other Baylisascaris species as possible causes of larva migrans following exposure to other definitive hosts, but at this time all cases but a few (greater than or equal to 96 percent) have been linked to B. procyonis from raccoons (Kazacos, 2001).

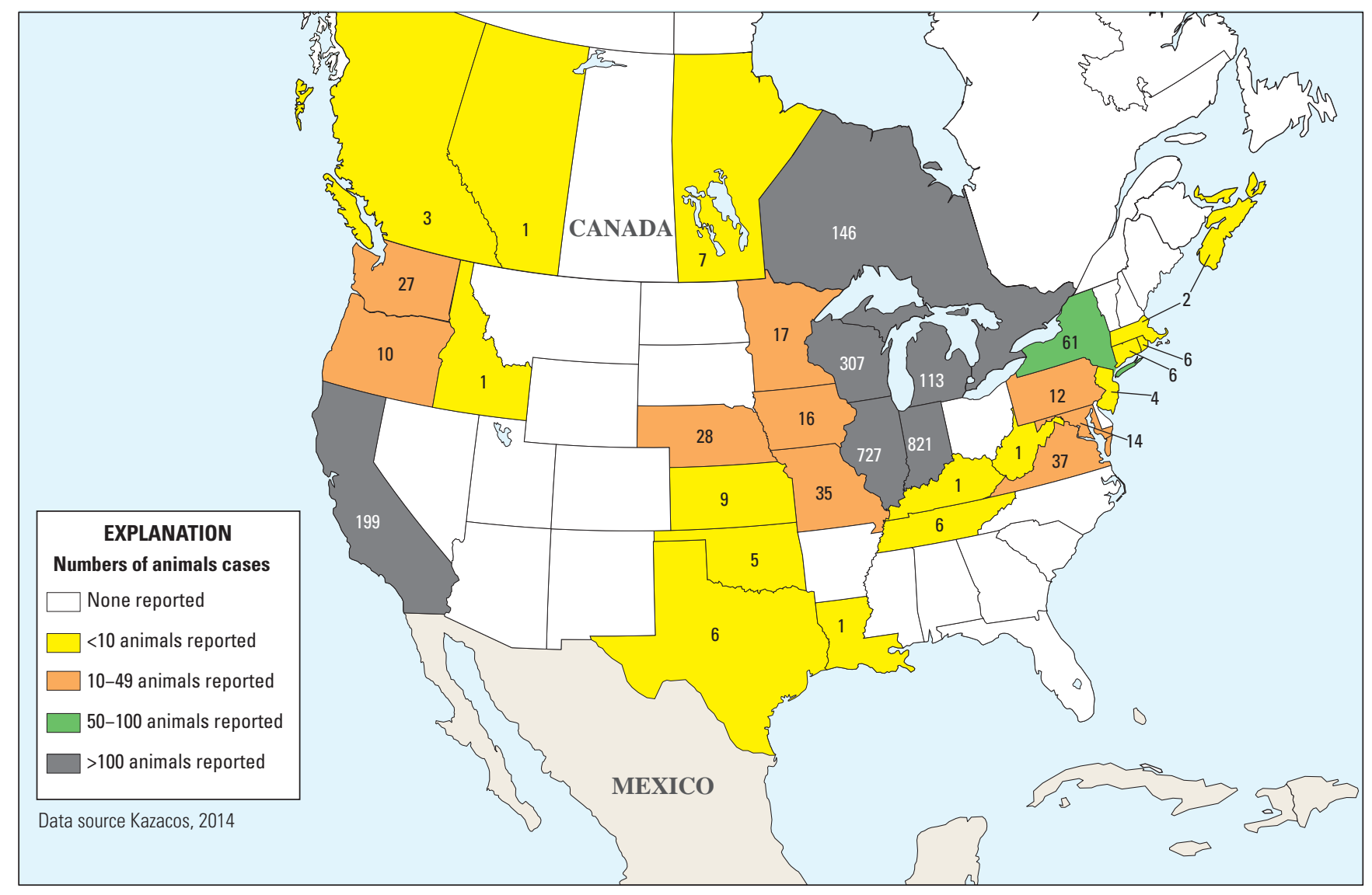

Figure 6. Numbers and locations of animal cases and outbreaks of Baylisascaris larva migrans in the United States and Canada. 


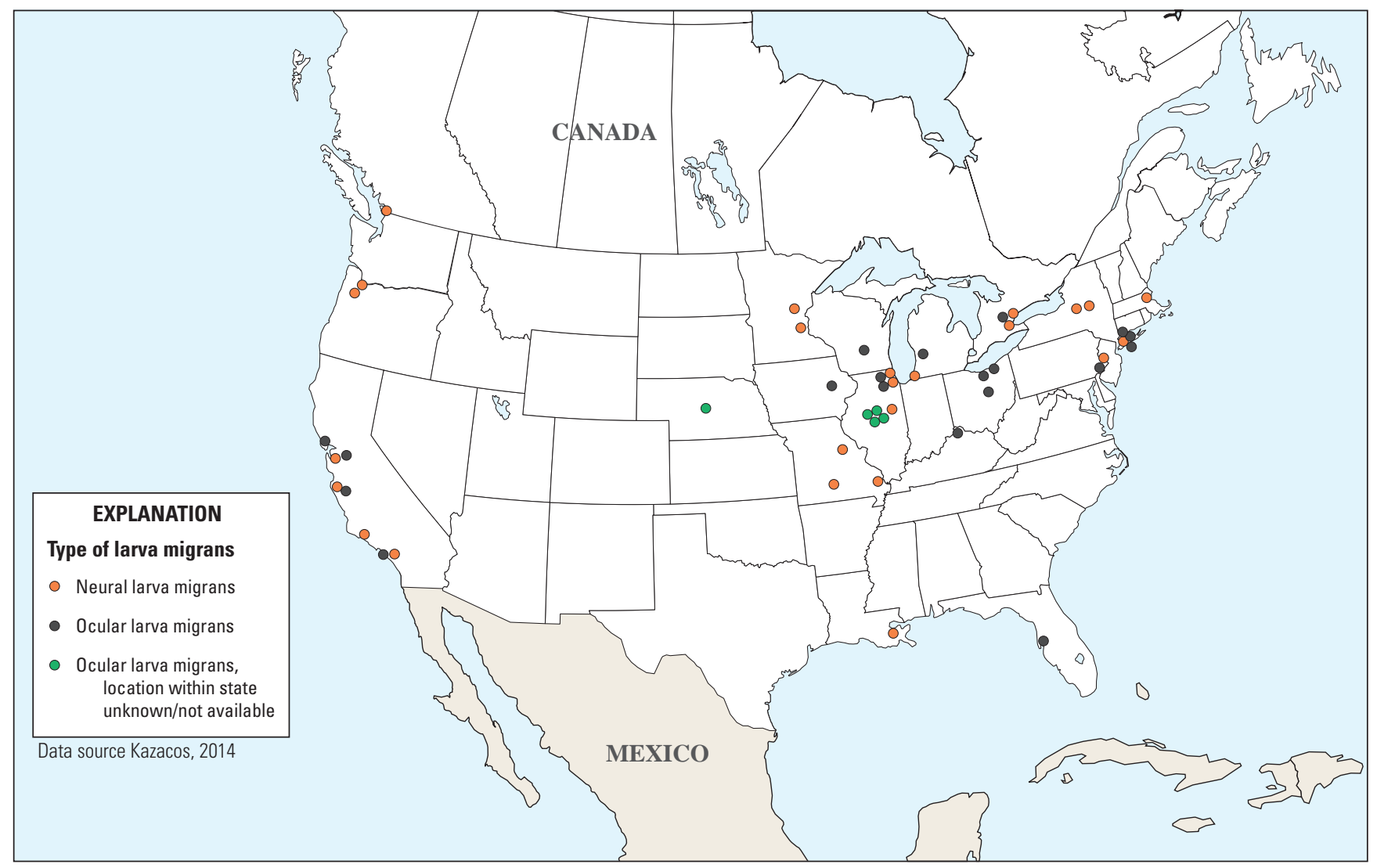

Figure 7. Locations of human cases of Baylisascaris larva migrans in the United States and Canada.

Raccoons have become well established in major areas of Europe (fig. 4) and Asia, following their intentional release to the wild or escape from fur farms or zoos. Raccoons were introduced for hunting and fur into Germany in 1927 and 1934 (Müller-Using, 1959; Lutz, 1984, 1996; Stubbe, 1990) and into the former Soviet Union beginning in 1936; the Soviets released 1,243 raccoons into widely scattered areas from 1936 to 1958 (Aliev and Sanderson, 1966). These programs were very successful; in 1964, the raccoon population in the former Soviet Union was estimated at 40,000-45,000, and an additional 4,000-5,000 were in Germany. In the 1960s, populations of raccoons were present for a limited time in nine territories of the former Soviet Union, including western regions, areas in central Asia, and far eastern territories northwest of Japan (Aliev and Sanderson, 1966), although presently they exist only in the Caucasus region. Raccoons have proliferated in Germany, Poland, and several other areas and spread elsewhere, especially since the mid-1970s, and have now been recorded in the wild throughout most of Europe. Established or limited populations have now been documented in Spain, France, Belgium and the Netherlands eastward to Belarus, Ukraine, and Russia (Winter, 2006; Bartoszewicz, 2011; Beltrán-Beck and others, 2012; Garcia and others, 2012). Sporadic detections have also occurred in a number of other countries, including England, Norway, Sweden, Denmark, and Italy (Beltrán-Beck and others, 2012). Raccoons are also present in southern Russia, Georgia, and Azerbaijan, much of Japan
(Ochiai and others, 2002; Ikeda and others, 2004; Matoba and others, 2006) and in zoological parks in China (Xie and others, 2014). No data exist showing their establishment in the wild in China, although this would be expected at some point.

Following the introduction of wild raccoons and their subsequent proliferation, it was estimated that by the 1990 s more than 100,000 wild raccoons were living in Germany (C. Bauer, pers. commun., 1991), with a prevalence of B. procyonis infection of 71 percent (Gey, 1998). Other surveys have also found the parasite at high prevalence in Germany, ranging from 39 percent (Winter and others, 2005) to 80 percent (Hoffmann and others, 2002). B. procyonis has also been identified in raccoons in Poland (Stefański and Žarnowski, 1951; Bartoszewicz and others, 2008; Popiotek and others, 2011), the Czech Republic (Tenora and Stanek, 1990), and recently in Denmark (Brinch, 2006), the Netherlands (H. van Bolhuis, written commun., 2009), and Norway (Davidson and others, 2013); it will likely be found elsewhere as more raccoons are examined. Typical of what happens, four raccoons confiscated from a farm in southern Norway had been illegally imported (along with raccoon dogs and coatis, also alien species) from an undisclosed location, and all of the raccoons were moderately infected with B. procyonis. Two additional raccoons escaped, with one later captured and killed and the other still at large (Davidson and others, 2013). The increase and spread of raccoons in Europe has been accompanied by B. procyonis-induced larva migrans in 
various species, including humans (Schrott, 1961; Kelly and Innes, 1966; Koch and Rapp, 1981; Küchle and others, 1993; Jimenez Martinez and others, 2015). The occurrences of such cases may increase, and the parasite deserves closer scrutiny and investigation as a cause of animal and human disease in Europe and Asia.

Japan encountered major problems with B. procyonis, stemming from the importation of over 20,000 raccoons from North America as exotic pets for 15 years starting in 1977, following a new popular television cartoon series, "Rascal Raccoon” (Miyashita, 1993; Beltrán-Beck and others, 2012); many of these animals escaped and now inhabit wild areas of the country (Ochiai and others, 2002; Ikeda and others, 2004). In Japan, B. procyonis was found in raccoons kept by wild animal dealers, wildlife parks, zoos, and pet owners (Miyashita, 1993; Sato and others, 2003) (table 5). A survey of raccoons in 48 zoos in Japan found that 6 zoos housed raccoons infected with B. procyonis (Kawanaka and others, 2002). Related to this, several outbreaks of NLM have been documented in animals in Japan, including in a rabbitry and a primate facility (Sato and others, 2003, 2005), but to date no human cases have been reported. The Japanese acted quickly in the early 2000s to try to eliminate the parasite by testing and euthanasia or treatment of infected raccoons, and the hope is that B. procyonis has not become established in the wild in Japan. In studies, 140 wild raccoons were examined from Kanagawa and Aichi Prefectures (Kawanaka and others, 2001), 531 raccoons from 12 municipalities in Wakayama Prefecture (Sato and Suzuki, 2006), and 1,688 free-ranging raccoons from the three main islands (Matoba and others, 2006); none were found to be infected with $B$. procyonis.

China is facing similar problems with B. procyonis. Over 320 captive raccoons were present in 18 zoological gardens throughout China, and, based on fecal examinations, 35 of 277 (13 percent) were positive for B. procyonis. A questionnaire survey found that most people interacting with these raccoons, including animal keepers and veterinarians, were not aware of $B$. procyonis or larva migrans. To date, no animal or human cases of larva migrans due to $B$. procyonis have been reported from China nor have raccoons been found in the wild (Xie and others, 2014; Y. Xie, written commun., 2014), although both will likely occur. Similar to what was seen in China, a questionnaire survey in the United States found that many people keeping or interacting with raccoons or nonraccoon procyonids had no prior knowledge of raccoon roundworm, did not know it could be transmitted to other species including humans, and did not know that captive animals could serve as hosts (Parkanzky, 2015).

The finding of Baylisascaris (originally identified as B. procyonis) in a kinkajou from Colombia (Overstreet, 1970) extended the geographical range of what is now known as B. potosis (Tokiwa and others, 2014) into South America, where kinkajous are widely distributed. Baylisascaris was also found in pet kinkajous in Indiana and Tennessee, in a breeding facility in southeast Florida, and in Japan, where the animals had originated from Guyana, South America (Kazacos,
Kilbane, and others, 2011; Taira and others, 2013). In a survey in the United States, both kinkajous and coatis were found to be shedding Baylisascaris eggs (Parkanzky, 2015), and there is anecdotal evidence of a patent infection in a coati in the Netherlands (H. van Bolhuis, pers. comm. to K. Kazacos, 2012). The species of Baylisascaris occurring in coatis is not known, and it is also unknown if $B$. procyonis will infect other nonraccoon procyonids such as coatis and kinkajous when they are in areas enzootic for that parasite. It is possible but also unknown if $B$. procyonis or another species occurs in raccoons in Central and South America or the Caribbean, or in other nonraccoon procyonids in the Americas. Surveys of helminths in crab-eating raccoons and coatis in Brazil and in Cozumel raccoons did not find any animals infected with Baylisascaris spp. (McFadden and others, 2005; Vieira and others, 2008). Two cases of human OLM-DUSN with large larvae were recently reported from Brazil (Cialdini and others, 1999; Amaro, 2000), and transmission from infected raccoons, kinkajous, coatis, or other indigenous animals is a likely possibility in these cases. The finding of Baylisascaris spp. in kinkajous and coatis in the United States and Japan has raised the question of possible zoonotic exposure of humans through contact with these animals in the wild or via the exotic pet trade (Kazacos and others, 2011; Taira and others, 2013). However, based on the lack of aggressive somatic migration including into the brain and failure to produce clinical disease in heavily infected monkeys (Tokiwa and others, 2015), B. potosis should be considered of lesser zoonotic importance, especially for NLM and (or) OLM-DUSN, than B. procyonis and some other species. Additional surveys using molecular methods (Tokiwa and others, 2014) are needed to better understand the identities and distribution of Baylisascaris species occurring in various procyonids in the Americas and elsewhere.

\section{Patterns and Trends}

Baylisascariasis has progressed from a parasitic curiosity to a well-known animal and human disease in a relatively short span of 40-50 years. Awareness of the parasite, especially as a zoonosis, has increased dramatically in the past 25 years, as more animal and human cases have been described and publicized. Both recognition and treatment of the first few human cases met with difficulty for three important reasons:

1. medical schools in North America had or have eliminated much of the parasitology training from their curricula, based on the premise that parasites were (and for many, still are) primarily "foreign" disease problems that have been eliminated from North America (Nelson, 1983);

2. the average physician received or receives little if any training in zoonotic diseases (Kahn, 2006; Kahn and others, 2007); and 
3. the parasite simply was not known to the medical community, even to medical pathologists, so it was not considered a possible cause of human disease (Huff and others, 1984; Kazacos, Vestre and Kazacos, 1984; Sanders, 2015).

In the first few human cases, it took considerable time to rule out a long list of other possible infectious and parasitic causes and to eventually consider Baylisascaris, if at all, as being involved. Thus, there were unfortunate delays in diagnosis and treatment, even though potentially useful drugs were available and being used for toxocaral larva migrans. In one case, Baylisascaris was not even considered as a possible cause of progressive neurologic disease in an infant until several years later, when characteristic ocular lesions of DUSN were noted during a routine eye exam and prompted the diagnosis of Baylisascaris by the use of serologic tests, which analyze the blood serum for antibodies (Gavin and others, 2002; Mets and others, 2003). Unfortunately, due to the amount of damage to the child's brain, treatment at that time was without benefit and the patient remained profoundly impaired until his death from complications years later. Several early patients were subjected to open brain biopsies in an attempt to reach a diagnosis, and larval sections were fortuitously identified in brain tissue (Cunningham and others, 1994; Rowley and others, 2000; Kazacos, Gavin, and others, 2002). With the present availability of serologic tests for Baylisascaris, it is no longer necessary for these invasive procedures to be used.

The overall situation for Baylisascaris LM diagnosis has improved dramatically in the past several decades, based primarily on relentless efforts to educate physicians, veterinarians, and public health personnel about the parasite. Baylisascaris is now included in various medical textbooks and other infectious disease resources, including Web sites from the Centers for Disease Control and Prevention (CDC, www.cdc.gov), the Center for Food Security and Public Health (www.cfsph.iastate.edu), and the Companion Animal Parasite Council (www.capcvet.org). The CDC launched updated Web coverage of Baylisascaris in spring 2011 and, along with the National Reference Centre for Parasitology in Montreal, Canada, took over serologic testing for the parasite, based on a recently developed recombinant antigen (Dangoudoubiyam and others, 2010; Rascoe and others, 2013). The current situation is still one of inadequate awareness of Baylisascaris by front-line physicians such as pediatricians and general practitioners, but good awareness on the part of infectious disease specialists, who are often called in to consult on difficult cases; ophthalmologists, who are well aware of OLM and DUSN; and veterinarians, who deal with animal cases and have considerable training in zoonotic diseases. Today, if a child in North America is diagnosed with eosinophilic meningoencephalitis and an infectious disease expert is consulted, Baylisascaris will be very high on the differential list, and not only will serum and (or) CSF samples be sent for testing within days, but often the patient will be started on immediate aggressive anthelmintic and steroid treatment (K.R. Kazacos, pers. observation, 2008-15; Hajek and others, 2009; Haider and others, 2012; Peters and others, 2012; Sanders, 2015). Diagnosis and treatment of human cases will continue to improve as additional cases are documented and the medical profession gains greater awareness of the infection.

The risk of human and animal infection with Baylisascaris will continue to increase as populations of raccoons expand in close proximity to humans and become established in new areas through dispersal and translocation. Because they are extremely adaptable, raccoons do well in peridomestic urban and suburban environments, which record some of the highest population densities of these animals (Hoffman and Gottschang, 1977; Kidder, 1990; Rosatte and others, 1991; Feigley, 1992; Gehrt, 2003; Prange and others, 2003; Roussere and others, 2003; Page, 2013). In these environments, raccoons have few natural enemies and benefit from excellent food availability, shelter, and den sites, allowing them to flourish in close association with humans. They have truly become an urban and suburban wildlife species, and most cities and towns in the animal's range support large numbers of raccoons. Urban raccoon populations carrying B. procyonis have been documented recently in Chicago, Atlanta, the Twin Cities metroplex in Minnesota; Portland, Oregon; Orange County, California; and Toronto (Kazacos, 2001; Evans, 2001; Eberhard and others, 2003; Page, Gehrt, and others, 2009; Yeitz and others, 2009). Unfortunately, along with these animals come their feces, to which both humans and animals are routinely exposed in urban and suburban environments. This, combined with the high prevalence of B. procyonis in raccoon populations, makes the likelihood of human exposure and infection with this parasite high (Kazacos, 2001; Page, Anchor, and others, 2009).

Many cases of Baylisascaris encephalitis in humans and animals are seen in suburban and even urban areas of major cities, where it is not unusual to find raccoon latrines around peoples' homes, in their yards, in children's play areas, parks, and other sites with significant human contact (Kazacos, 2001; Roussere and others, 2003; Page, Anchor, and others, 2009; Page, 2013). Indeed, three cases of B. procyonis larva migrans, one involving an infant with severe NLM and two being teenagers with OLM-DUSN, were documented recently from Brooklyn and the Bronx, in the urban heart of New York City, where raccoons are commonly seen (Perlman and others, 2010; Saffra and others, 2010; Liu and others, 2015). The recent finding that $B$. procyonis will also mature in some other animal species, including domestic dogs, further increases possible human exposure from lesser known animal sources (Greve and Obrien, 1989; Kazacos, 2006; Kazacos, Kilbane, and others, 2011) (table 6). Because of the seriousness of this infection and the limitations of diagnosis and treatment, prevention of infection with Baylisascaris is of obvious importance. In addition, greater efforts may be useful to prevent the spread of the parasite to new areas, both within and outside North America. 
Table 6. Location, type of infection, number of animals infected, and numbers of intestinal Baylisascaris procyonis, B. potosis, or Baylisascaris spp. in nonraccoon definitive hosts.

[NR, not reported]

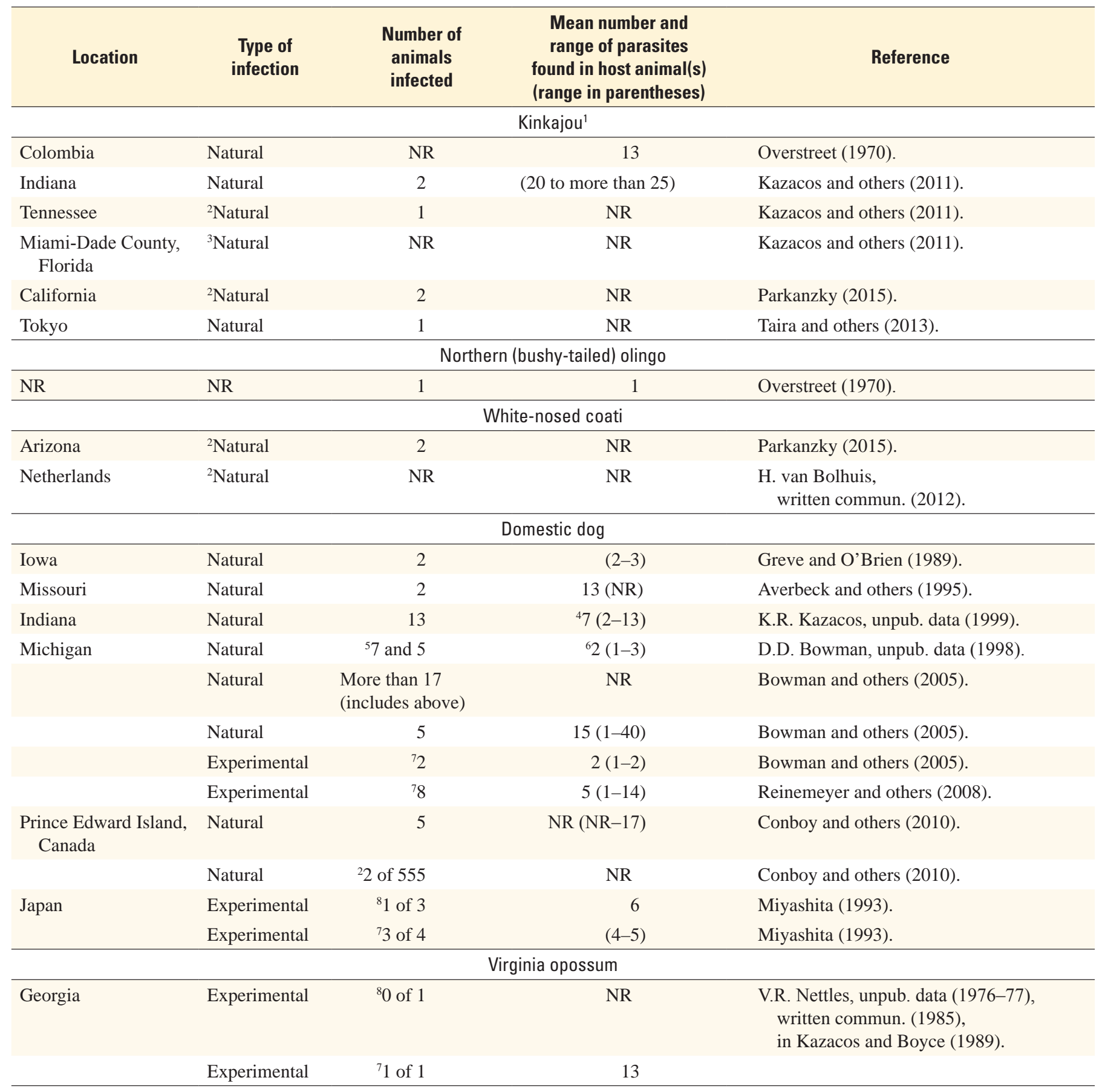

${ }^{1}$ Parasite redescribed as new species, B. potosis (Tokiwa and others, 2014).

${ }^{2}$ Based on identification of eggs in fecal samples.

${ }^{3}$ Based on identification of eggs in soil samples under cages.

${ }^{4}$ Based on 10 dogs.

${ }^{5}$ Probable infections; based on single fecal exam.

${ }^{6}$ Based on four dogs.

${ }^{7}$ Fed third-stage larvae.

${ }^{8}$ Fed infective eggs. 


\section{Other Hosts of Adult Baylisascaris procyonis}

\section{Other Procyonids}

As a group, members of the taxonomic family Procyonidae (procyonids) are relatively small, omnivorous mammals, including raccoons, coatis, ringtails, cacomistles, kinkajous, and olingos $(A)$. Like the raccoon, most other procyonids have distinct masklike facial markings and banded tails. The primary definitive host of B. procyonis is the common raccoon. It is possible that other raccoon species, such as the crab-eating raccoon and Cozumel raccoon, or related procyonids could become infected with $B$. procyonis, although this is not well known. The extent of cross infectivity of $B$. procyonis for other procyonids and the exact species involved in some cases of infection remain to be determined by molecular and other methods.

Patent intestinal infections with Baylisascaris sp. have been documented multiple times in kinkajous, one captured in Colombia, South America (Overstreet, 1970) and others kept as pets or in breeding facilities, zoos, or animal rescue/wildlife sanctuary facilities in the United States (Yabsley, 2010; Kazacos, Kilbane, and others, 2011; Parkanzky, 2015) and Japan (Taira and others, 2013).

These infections were thought to involve $B$. procyonis, but the parasite in kinkajous was recently described as a new species, B. potosis (Tokiwa and others, 2014). Kinkajous are routinely imported from South America and (or) bred for sale as exotic pets in the United States and elsewhere. $B$. procyonis infection was also documented in a Northern olingo, but researchers were unsure if it resulted from natural or experimental infection (Overstreet, 1970) and the actual identity of the parasite is open to question. Eggs of B. procyonis or a related species were also found in the feces of coatis in the United States (Parkanzky, 2015) and the Netherlands (H. van Bolhuis, written commun., 2012). Coatis, ringtails and the other procyonids live in the wild in the Americas and may be imported, raised, and sold as exotic pets, similar to kinkajous. More attention could beneficially focus on all of these animals as additional potential sources of Baylisascaris infection for animals and humans in North and South America or wherever else they may be imported, raised, or sold. If the animals are kept as pets, owners and family members will have considerable direct contact with them as well as their potentially contaminated cages or enclosures, similar to keeping pet raccoons. The animal sources in cases of human OLM-DUSN caused by a large nematode and recently reported from South America (Cialdini and others, 1999; Amaro, 2000) are presently

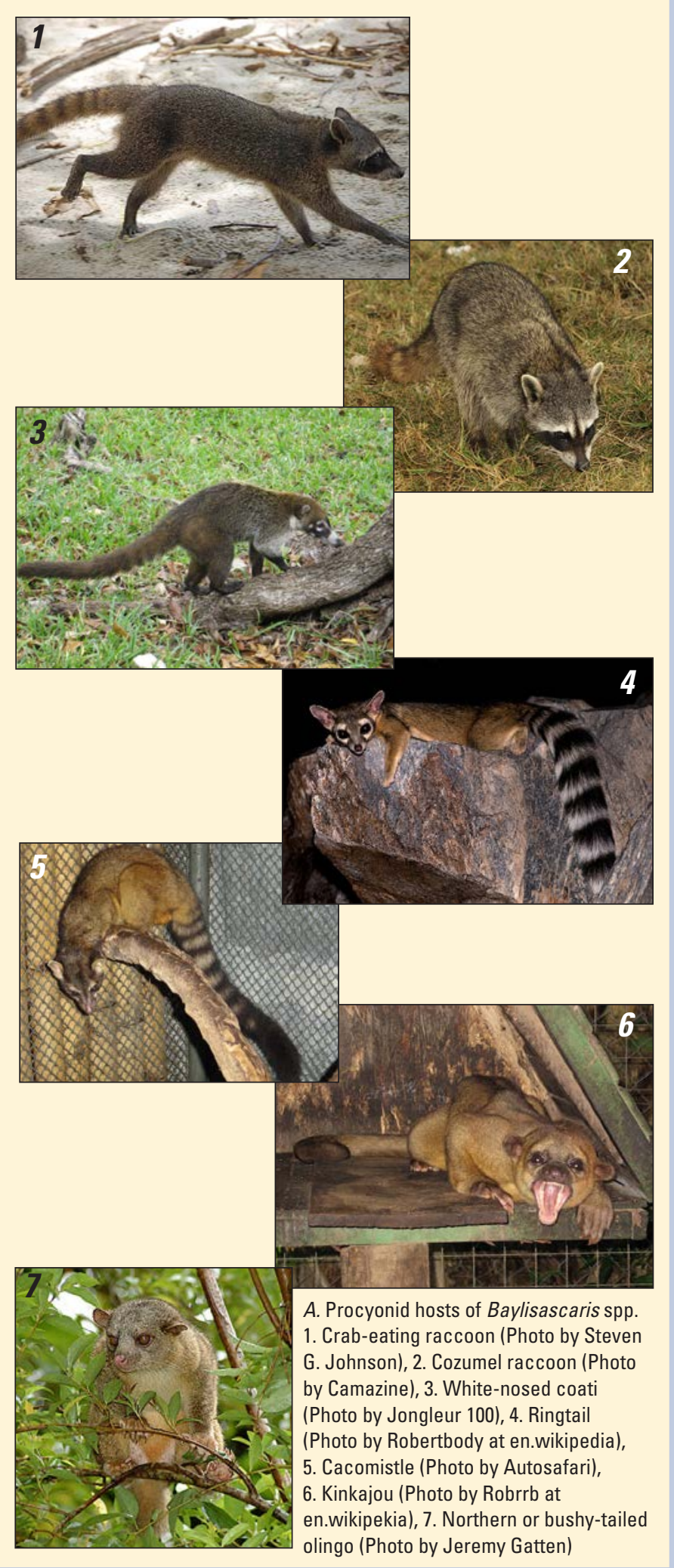




\section{Other Hosts of Adult Baylisascaris procyonis}

unknown and may involve contact with one or more of these animal species infected with $B$. procyonis or related Baylisascaris species.

\section{Domestic Dog}

Adult B. procyonis parasites have also been found in the domestic dog, which is a troubling association given the dog's importance as a working, service, and companion animal. Patent infections with $B$. procyonis were first seen in dogs in Iowa in 1988 (Greve and O’Brien, 1989), and since then dozens of cases have been identified in domestic dogs from the Midwest and other parts of the United States and Canada where raccoons are common (Kazacos, 2001, 2006). In several of these cases, B. procyonis occurred as a mixed infection with Toxocara canis and other helminths $(B, C)$.

It is not known how these particular dogs became infected with B. procyonis; however, in experimental studies, one of three dogs fed infective eggs and three of four dogs fed third-stage larvae from mice developed intestinal B. procyonis infections (Miyashita, 1993). Patent infections were also produced in dogs fed eggs or larvae as part of trials of deworming drugs in the United States (Bowman and others, 2005; Reinemeyer and others, 2008). It appears from experimental studies that tissue larvae are more efficient than eggs for inducing patent intestinal infection in dogs. In addition, based on the very young age of several infected dogs, there is circumstantial evidence of prenatal (transplacental) infection in dogs, similar to the situation with Toxocara canis (Kazacos, 2006). There is already a precedent for prenatal infection with $B$. procyonis larvaelarva migrans was documented in newborn lambs in Idaho (Anderson, 1999), thus indicating the role of hormonal activation of larval migration with Baylisascaris that is well known with Toxocara in dogs.

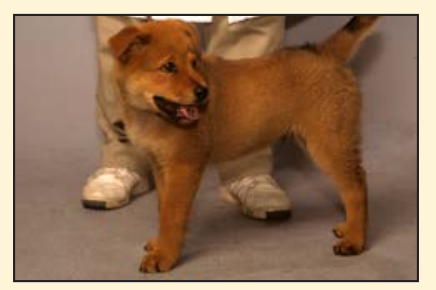

$B$. A young dog found to be infected with both $B$. procyonis and Toxocara canis. Animals with intestinal infection usually do not show clinical signs. (Photo by Sam Royer)
The biological relationship of $B$. procyonis and dogs is particularly interesting when one considers that, in addition to supporting patent intestinal infections, several dogs have died from severe neural larva migrans (NLM) due to this parasite (Snyder, 1983; Thomas, 1988; Rudmann and others, 1996; H.R. Galano and others, unpub. data, 2005). Whether dogs with patent infections also have larvae in their somatic tissues, or vice versa, is not known, because NLM and patent infections have not been documented in the same dog. Differences in how the parasite behaves in dogs may be related to how dogs become infected, as well as their age, immune status, and prior infection history at the time of infection, including prior infection with $T$. canis, the dog roundworm.

Dogs infected with B. procyonis pose a definite zoonotic threat because they can contaminate the domestic environment with eggs and would not be suspected as a source of B. procyonis. Because dogs are indiscriminate defecators, contamination from them would be more widespread than from raccoons, which favor focal latrine sites (Kazacos, 2001, 2006). Because pet dogs often travel with their owners, infected dogs could also spread the parasite to new geographical areas. If pet dogs can support $B$. procyonis, then another open question is whether the parasite can become patent in other canine species, including coyotes and wolves. These canids would be at an increased risk of contracting the parasite, based on their predatory habits and regular ingestion of infected paratenic hosts. At present, data addressing this question are limited. Among numerous $(\mathrm{n}=311)$ coyotes examined from the Midwest, none were found to be infected with B. procyonis (K.R. Kazacos, unpub. data, 2005); the primary ascarid found in them was Toxascaris leonina, and it is unknown if prior infection with that parasite would somehow prevent infection with B. procyonis.

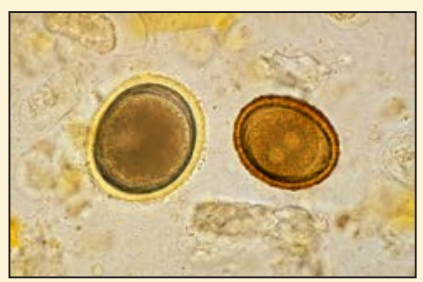

C. Eggs of Toxocara canis (left) and $B$. procyonis (right) from the dog with a dual infection. (Photo by Kevin Kazacos) 


\section{Other Hosts of Adult Baylisascaris procyonis}

\section{Opossum}

Another animal that needs greater examination is the Virginia opossum (D). An attempt was made to infect two opossums using either infective eggs or tissue larvae of B. procyonis (V.R. Nettles, unpub. data, 1976-77, written commun., 1985, cited in Boyce and Kazacos, 1989). Although the egg inoculation failed, an intestinal infection was established in the opossum fed tissue larvae. There have been anecdotal reports of Baylisascaris eggs present in the feces of opossums at wildlife rehabilitation centers; however, these cases were not followed up with deworming to isolate and identify any parasites present. Consequently, it is unknown if these reports represent eggs merely passing through the intestinal tract resulting from opossums feeding on feces at raccoon latrines (Page and others, 1999, 2001a; Smyser, Page, and others, 2013) or true intestinal infection with $B$. procyonis. It has become apparent that development of $B$. procyonis in nonraccoon hosts is a definite possibility and must be examined in greater detail.

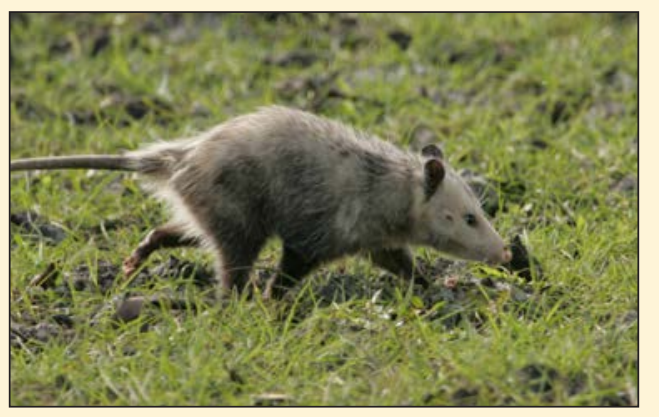

D. Virginia opossum. (Photo by U.S. Fish and Wildlife Service)
The export and translocation of raccoons has already spread B. procyonis to Europe and Asia, where it has become an established problem, and prevalence rates in some areas are at or approaching those in parts of North America (C. Bauer, pers. commun., 1991; Miyashita, 1993; Gey, 1998) (table 5). Similarly, importation of infected kinkajous with $B$. potosis from South America, as well as the spread of infected raccoons, has introduced both parasites into Florida, which had previously been free of Baylisascaris (Kazacos, 2001; Blizzard, Yabsley, and others, 2010; Yabsley, 2010; Kazacos, Kilbane, and others, 2011; D. Wolf, written commun., 2013). Humans and animals in those areas may suffer consequences from this exposure, especially from $B$. procyonis, with cases of NLM and OLM similar to those seen in other parts of North America; this has already occurred in parts of Europe and in Japan (Schrott, 1961; Koch and Rapp, 1981; Kuchle and others, 1993; Sato and others, 2003, 2005; Jimenez Martinez and others, 2015).

These are all excellent examples of how better education, regulations, and oversight may be useful concerning the movement and prophylactic treatment of wildlife and exotic animals to prevent the spread of parasites and infectious diseases to new regions of the globe. Frequently, the emphasis is on domestic animals and communicable diseases, and not on wildlife, exotic animals, or parasites (Kahn, 2006; Centers for Disease Control and Prevention, 2015; U.S. Department of Agriculture-Animal and Plant Health Inspection Service, 2015).

\section{Species Susceptibility}

Few other parasites are as indiscriminate, or noteworthy, as $B$. procyonis in causing neurologic disease in wild, zoo, and domestic animals as well as humans (Kazacos, 2001). The parasite has been implicated in causing NLM in over 150 species of birds and mammals, including humans, in North America and elsewhere (tables 1 and 2). B. procyonis is also a well-known cause of ocular disease (OLM, DUSN) in humans and experimental animals. Clinical larva migrans may also occur with some other Baylisascaris species, particularly $B$. columnaris of skunks and B.melis of badgers (table 4).

\section{Human Infections}

Baylisascaris infection in humans causes a spectrum of disease depending on the dose of infective eggs and the location and extent of tissue damage and inflammation caused by migrating larvae. Baylisascaris infection has been found by use of serologic tests many times in apparently healthy humans (Cunningham and others, 1994; Conraths and others, 1996; Brinkman and others, 2003; C.A. Hall and others, unpub. data, oral commun., 2014) and in nonhuman primates in zoos (Zimmerman and others, 2010) (table 7), indicating that low-level, subclinical, or covert infection is common. This would be expected from a ubiquitous organism with a resistant 
transmission stage and with varying exposure levels affecting great numbers of people. Subclinical and covert infections would be characterized by low levels of serum antibodies, with or without mild eosinophilia, and without signs of VLM, OLM, or NLM; such cases could be missed by clinicians (Kazacos, 1991, 1997, 2000, 2001; Cunningham and others, 1994; Conraths and others, 1996). These cases would, however, account for the fact that a background level of Baylisascaris seropositivity would occur in any exposed population, similar to the situation for human infections with dog and cat roundworms (Won and others, 2008; Lee and others, 2010; Fan and others, 2015).

Baylisascaris infection is most commonly associated with encephalitis due to neural larva migrans (Kazacos, 1997, 2000, 2001). Twenty-five cases of Baylisascaris encephalitis in humans have been published or reported (table 8), and many additional cases also are known (K.R. Kazacos, unpub. data, 1995-2010). Baylisascaris encephalitis is seen most often in children less than 2 years old (table 8 ), who are at the greatest risk of infection because of poorer hygiene and greater oral sampling of their environment; however, this does not preclude the disease in older children or adults if they contract a heavy infection. Young children may ingest very large numbers of eggs from raccoon feces or soil at raccoon latrines and have sufficient numbers of larvae entering the brain to produce severe damage and clinical signs. Because raccoon feces may contain tens to hundreds of thousands of eggs per gram, a child can ingest surprisingly little material and acquire a heavy infection and severe clinical disease from encephalitis. In an early fatal case in Illinois, 3 larvae per gram of brain were found in an 18-month-old boy during autopsy, resulting in an estimated brain burden of 3,207 larvae and an infecting dose of 46,000-64,000 eggs (Fox and others, 1985). Such a dose of eggs could certainly occur in 1 gram of raccoon feces, and a child could easily ingest this amount or more of feces from a contaminated area. This child was believed to have become infected by sucking or chewing on pieces of contaminated firewood bark that contained infective eggs from raccoon feces that were present on the original fallen log that was cut up as firewood and brought into the home. Most affected children have been male, although several recent cases have involved infant girls. Other risk factors for infection include developmental delay, mental retardation, dementia, and drug abuse, all of which result in altered awareness and behavior and have led to heavy infections in adults (Cunningham and others, 1994; Kazacos, Gavin, and others, 2002; Chun and others, 2009; Ciarlini and others, 2011; Hung and others, 2012). Such individuals often exhibit the same behaviors seen in young children at risk of infection, including increased oral sampling of their environment and an urge to eat nonfood substances (pica) and dirt (geophagia).

Table 7. Primates seropositive for Baylisascaris larva migrans. ${ }^{1}$

[>, greater than]

\begin{tabular}{|c|c|c|c|}
\hline Host & Location & $\begin{array}{c}\text { Number of animals } \\
\text { affected }\end{array}$ & Reference $^{2}$ \\
\hline Black-and-white ruffed lemur & Missouri & 1 & Zimmerman and others (2010). \\
\hline $\begin{array}{l}\text { Mantled guereza } \\
\text { (Abyssinian black-and-white } \\
\text { Colobus monkey) }\end{array}$ & Tennessee & 9 & Zimmerman and others (2010). \\
\hline Diana monkey & Oklahoma & 6 & Zimmerman and others (2010). \\
\hline Francois' langur & Tennessee & 1 & Zimmerman and others (2010). \\
\hline Rhesus macaque & Wisconsin & 8 & K.R. Kazacos, unpub. data (2006). \\
\hline Lion-tailed macaque & Tennessee & 9 & Zimmerman and others (2010). \\
\hline Northern white-cheeked gibbon & Tennessee & 4 & Zimmerman and others (2010). \\
\hline \multirow[t]{2}{*}{ Siamang } & Oklahoma & 2 & Zimmerman and others (2010). \\
\hline & Tennessee & 2 & Zimmerman and others (2010). \\
\hline Western lowland gorilla & Tennessee & 3 & Zimmerman and others (2010). \\
\hline Sumatran orangutan & Tennessee & 2 & Zimmerman and others (2010). \\
\hline Bornean orangutan & Tennessee & ${ }^{3} 1$ & D. Zimmerman, unpub. data (2005). \\
\hline Bornean orangutan hybrid & Wisconsin & ${ }^{3} 1$ & Hanley and others (2006). \\
\hline
\end{tabular}


Table 7. Primates seropositive for Baylisascaris larva migrans. ${ }^{1}$ - Continued

[>, greater than]

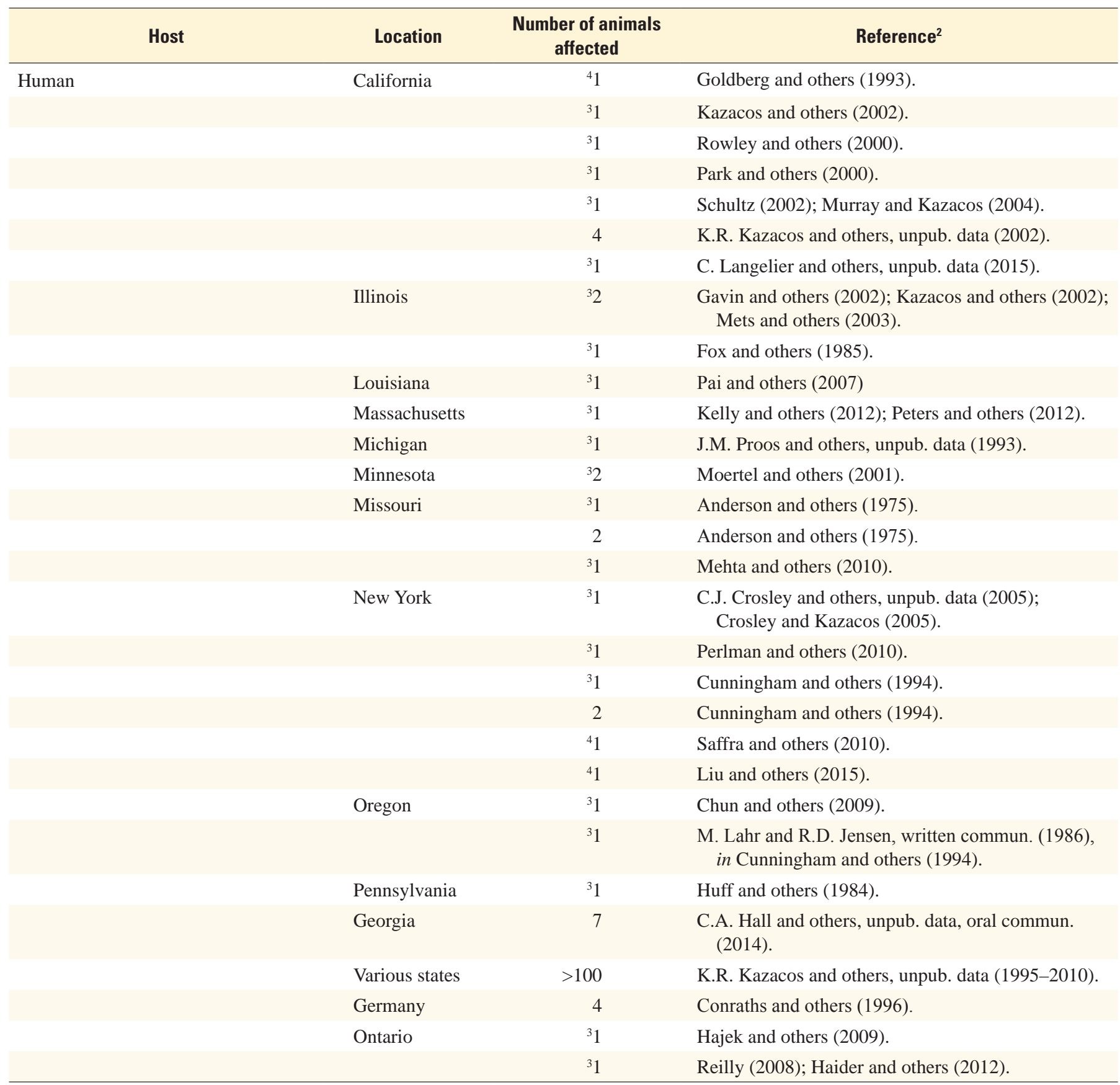

\footnotetext{
${ }^{1}$ Serology was done at Purdue University by enzyme-linked immunosorbent assay (ELISA) using B. procyonis larval excretory-secretory antigens
} (Dangoudoubiyam and others, 2011), except for Anderson and others (1975 [indirect hemagglutination and bentonite flocculation for Ascaris]),

Huff and others (1984 [indirect immunofluorescence]), Fox and others (1985 [indirect immunofluorescence and ELISA using embryonated egg antigens]), Goldberg and others (1993 [Western blotting]), Conraths and others (1996 [Western blotting]), and C. Langelier and others, unpub. data (2015 [Western blotting]).

${ }^{2}$ Cases have been confirmed by the author and information and data are on file with the author.

${ }^{3}$ Clinically affected with Baylisascaris NLM.

${ }^{4}$ Clinically affected with Baylisascaris OLM. 
Table 8. Cases of Baylisascaris neural larva migrans in humans.

[Partial list; there may be other cases of which the author is not aware. NR, not reported]

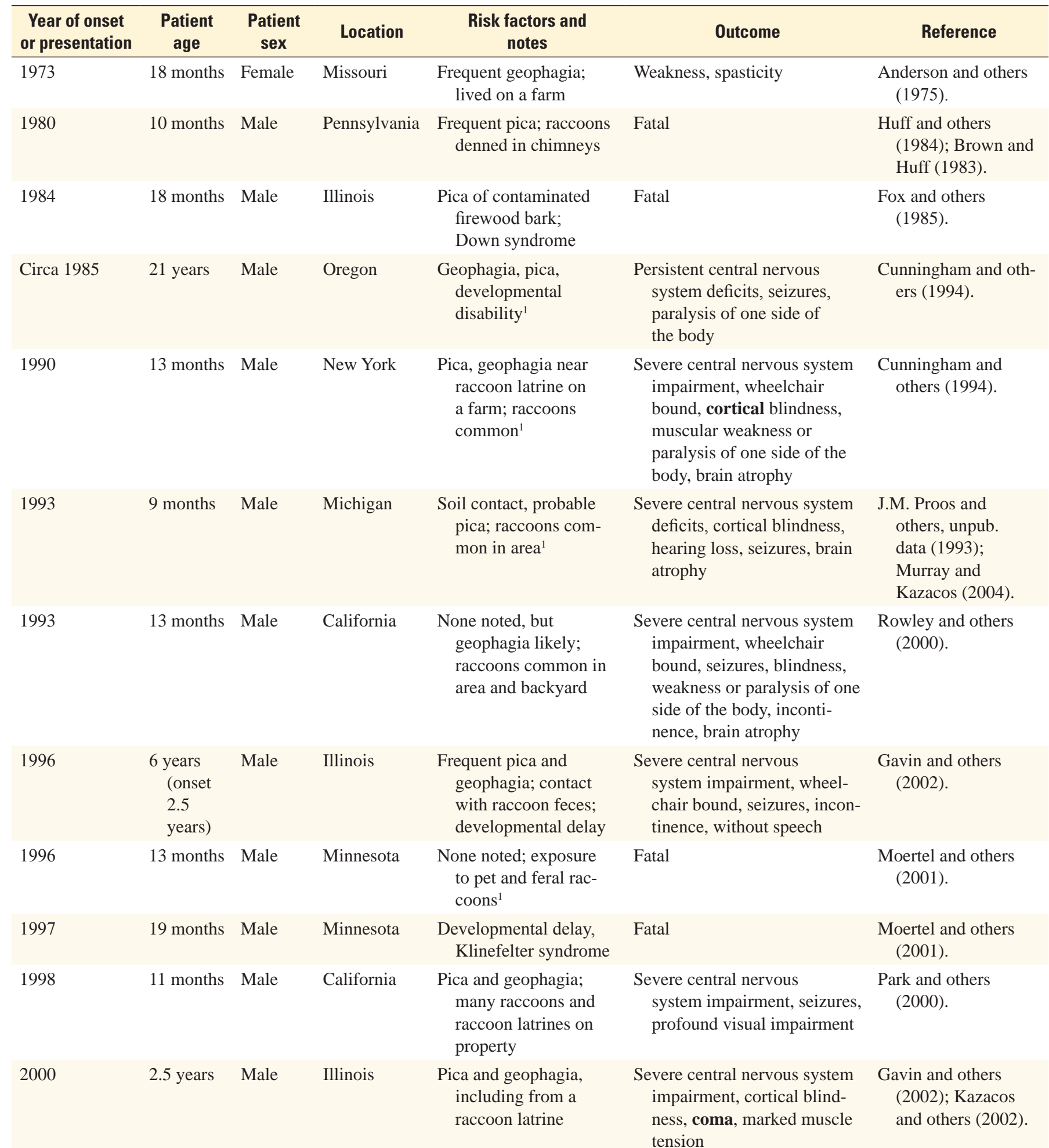


Table 8. Cases of Baylisascaris neural larva migrans in humans-Continued.

[Partial list; there may be other cases of which the author is not aware. NR, not reported]

\begin{tabular}{|c|c|c|c|c|c|c|}
\hline $\begin{array}{l}\text { Year of onset } \\
\text { or presentation }\end{array}$ & $\begin{array}{l}\text { Patient } \\
\text { age }\end{array}$ & $\begin{array}{l}\text { Patient } \\
\text { sex }\end{array}$ & Location & $\begin{array}{c}\text { Risk factors and } \\
\text { notes }\end{array}$ & Outcome & Reference \\
\hline 2000 & 17 years & Male & California & $\begin{array}{l}\text { Marked geophagia, } \\
\text { including. from a con- } \\
\text { taminated sandbox; } \\
\text { severe developmental } \\
\text { disability }\end{array}$ & Fatal & $\begin{array}{l}\text { Kazacos and others } \\
\text { (2002). }\end{array}$ \\
\hline 2004 & 4 years & Male & Louisiana & $\begin{array}{l}\text { None noted; raccoons } \\
\text { present in neighbor- } \\
\text { hood }^{1}\end{array}$ & $\begin{array}{l}\text { Mild central nervous system } \\
\text { deficits, incoordination, } \\
\text { then full recovery }\end{array}$ & Pai and others (2007). \\
\hline 2005 & 7 years & Male & Ontario & $\begin{array}{l}\text { Contact with positive } \\
\text { raccoon latrines and } \\
\text { an open sandbox in a } \\
\text { yard; geophagia; puts } \\
\text { hands in his mouth; } \\
\text { autism; attention } \\
\text { deficit-hyperactivity } \\
\text { disorder }\end{array}$ & $\begin{array}{l}\text { Improvement with treatment; } \\
\text { seizures, cortical visual im- } \\
\text { pairment, no speech, brain } \\
\text { atrophy }\end{array}$ & $\begin{array}{l}\text { Cheney (2005); Chris } \\
\text { (2005); Hajek and } \\
\text { others (2009). }\end{array}$ \\
\hline 2007 & 17 years & Male & Oregon & $\begin{array}{l}\text { Multiple substance } \\
\text { abuse; neuropsychiat- } \\
\text { ric problems }\end{array}$ & $\begin{array}{l}\text { Gradual improvement with } \\
\text { significant cognitive deficits } \\
\text { in memory, processing, } \\
\text { communication, attention, } \\
\text { insight }\end{array}$ & $\begin{array}{l}\text { Chun and others } \\
\text { (2009). }\end{array}$ \\
\hline 2008 & 12 months & Male & New York & $\begin{array}{l}\text { None noted; } \\
\text { raccoons known in } \\
\text { neighborhood }\end{array}$ & $\begin{array}{l}\text { Severe central nervous system } \\
\text { impairment, cortical blind- } \\
\text { ness, lack of cognitive } \\
\text { function, spastic paralysis } \\
\text { of corresponding parts on } \\
\text { both sides of the body, brain } \\
\text { atrophy }\end{array}$ & $\begin{array}{l}\text { Perlman and others } \\
\text { (2010). }\end{array}$ \\
\hline 2008 & 14 months & Male & $\begin{array}{l}\text { Massa- } \\
\text { chusetts }\end{array}$ & $\begin{array}{l}\text { Frequent pica and geo- } \\
\text { phagia; oral contact } \\
\text { with family members' } \\
\text { shoes; raccoons com- } \\
\text { mon in area }\end{array}$ & $\begin{array}{l}\text { Improvement following } \\
\text { treatment; residual partial } \\
\text { paralysis of the lower limbs, } \\
\text { language delay, } \\
\text { brain atrophy }\end{array}$ & $\begin{array}{l}\text { Kelly and others } \\
\text { (2009, 2012); } \\
\text { Peters and others } \\
\text { (2012). }\end{array}$ \\
\hline
\end{tabular}


Baylisascaris Larva Migrans

Table 8. Cases of Baylisascaris neural larva migrans in humans.-Continued

[Partial list; there may be other cases of which the author is not aware. NR, not reported]

\begin{tabular}{|c|c|c|c|c|c|c|}
\hline $\begin{array}{l}\text { Year of onset } \\
\text { or presentation }\end{array}$ & $\begin{array}{l}\text { Patient } \\
\text { age }\end{array}$ & $\begin{array}{l}\text { Patient } \\
\text { sex }\end{array}$ & Location & $\begin{array}{c}\text { Risk factors and } \\
\text { notes }\end{array}$ & Outcome & Reference \\
\hline 2008 & 14 months & Male & Ontario & $\begin{array}{l}\text { Puts hands in his mouth; } \\
\text { raccoons in the } \\
\text { immediate vicinity }\end{array}$ & $\begin{array}{l}\text { Severe central nervous system } \\
\text { deficits, cortical } \\
\text { blindness, unable to stand }\end{array}$ & $\begin{array}{l}\text { Reilly (2008); } \\
\text { Haider and } \\
\text { others (2012). }\end{array}$ \\
\hline 2009 & 54 years & Male & Missouri & $\begin{array}{l}\text { Mental retardation; eat- } \\
\text { ing food scraps from } \\
\text { public garbage cans }{ }^{1}\end{array}$ & Fatal & $\begin{array}{l}\text { Moore (2009); } \\
\text { Ciarlini and } \\
\text { others (2011). }\end{array}$ \\
\hline 2015 & 63 years & Male & California & $\begin{array}{l}\text { Worked under a house } \\
\text { where raccoons and } \\
\text { their feces were } \\
\text { frequently observed. } \\
\text { Ate lunch without } \\
\text { washing hands. }\end{array}$ & $\begin{array}{l}\text { Severe progressive central } \\
\text { nervous system impairment; } \\
\text { confusion, cognitive deficits, } \\
\text { incoordination; gradual } \\
\text { improvement following } \\
\text { treatment }\end{array}$ & $\begin{array}{l}\text { C. Langelier and } \\
\text { others, written } \\
\text { commun. (2015). }\end{array}$ \\
\hline
\end{tabular}

${ }^{1}$ K.R. Kazacos, unpub. data (1985-2009); data on file with the author. 


\section{Clinical Disease in Humans}

Human infection with Baylisascaris includes asymptomatic infection, covert infection, visceral infection or disease (visceral larva migrans, VLM), central nervous system (CNS) infection or disease (neural larva migrans, NLM), and (or) ocular infection or disease (ocular larva migrans, OLM) (Kazacos, 1991, 1997, 2000, 2001; Sorvillo and others, 2002; Murray and Kazacos, 2004; Gavin and others, 2005; Wise and others, 2005; Shafir and others, 2006; Kazacos and others, 2013; Singaravelu and others, 2016). The different types vary primarily in the dose of infecting eggs and the location and extent of tissue damage and inflammation caused by migrating larvae. The two most important clinical problems related to Baylisascaris infection are CNS disease resulting from brain invasion and encephalitis (NLM) and ocular disease caused by invasion of the eye (OLM and diffuse unilateral subacute neuroretinitis, DUSN). The more eggs ingested by a person, the greater the chances of developing one or both of these conditions, due to the increased likelihood of larvae entering the brain or eye. If enough eggs are ingested to result in CNS disease, the patient may also show evidence of visceral disease (VLM) caused by early larval migration through the liver and lungs, and (or) eye disease (OLM) caused by concomitant larval invasion of the eye.

\section{Asymptomatic Infection}

Most cases of Baylisascaris infection are the result of incidental or low-level infection with eggs and are asymptomatic, that is, they will not result in recognizable clinical signs. This is because, in addition to the low levels involved, the vast majority (an estimated 93-95 percent) of migrating larvae enter the muscles, connective tissue, or visceral organs, where they are walled off in granulomas (Kazacos, 1986, 1991, 1997, 2001). Once this happens, they settle down, become quiescent, and will not usually migrate further or cause additional harm. A few larvae may also enter the CNS and become encapsulated there, ceasing their migration; this is known in animals (Tiner 1953a; Kazacos, 1997, 2001; Sheppard and Kazacos, 1997) and was recently demonstrated in humans (Hung and others, 2012). Humans may have incidental CNS invasion without recognizable clinical signs more often than is presently known. Such individuals may or may not (but often do) develop detectable levels of antibodies that indicate that they are infected, but they do not have any or enough larvae in sensitive or critical locations such as the brain or eyes to result in serious clinical problems. In essence, these people represent a background level of low infection in the population that, along with covert infection, may only be identified through antibody testing (Cunningham and others, 1994; Brinkman and others, 2003; Zimmerman and others, 2010; Rascoe and others, 2013).

\section{Covert Infection}

Larger numbers of ingested eggs and larvae migrating in various tissues may result in nonspecific clinical signs, so-called covert or hidden infection. Best described for Toxocara infection (Taylor and others, 1987), covert infection is also known to occur with Baylisascaris. With covert infection, more tissue is damaged and inflamed, causing some clinical problems that are generally too nonspecific to allow a physician to make a correct diagnosis. With Toxocara, and probably Baylisascaris, patients’ complaints include abdominal pain, cough, headache, sleep disturbances, and the like, all of which can occur with or are mimicked by other infections or conditions. Depending on the level of infection, patients may or may not have an eosinophilia, but their blood tests usually will show they are seropositive for antibodies (Taylor and others, 1987). Even though they are known to occur based on epidemiologic studies, the vast majority of these cases will be missed and (or) misdiagnosed by clinicians.

\section{Baylisascaris Visceral Larva Migrans}

Once someone ingests Baylisascaris eggs, larvae hatch in the intestine and begin their migration through the intestinal wall and into internal organs. Damage to the liver and lungs can cause migration-induced pathological changes and clinical signs including an enlarged liver, fever, cough, and difficulty breathing (Kazacos, 1997, 2000; Kazacos and others, 1981, 2013; Wyand-Oullette and others, 1983; Singaravelu and others, 2016). Patients will often develop high numbers of eosinophils in their blood in response to larval antigens (Fox and others, 1985; Kazacos, 1997). In one case, B. procyonis VLM apparently caused the sudden death of a 10-year-old boy in Massachusetts from a nodular eosinophilic mass inside the heart (Boschetti and Kasznica, 1995). Within the mass were the remains of a large (60-70 micrometer diameter) degenerating ascarid larva. 


\section{Clinical Disease in Humans}

\section{Baylisascaris Neural Larva Migrans and Encephalitis}

Clinical neurologic disease due to NLM represents the high end of the spectrum of Baylisascaris infection, in which a person has ingested many eggs and sufficient larvae are entering the brain and spinal cord to result in clinically significant and potentially life-threatening disease. The severity and progression of CNS disease in Baylisascaris encephalitis depends on the number of eggs ingested, the number of larvae entering the brain, the location and extent of migration damage and inflammation in the brain, and, to some extent, the size of the brain (Kazacos, 1996b, 1997, 2000, 2001; Kazacos and others, 2013; Singaravelu and others, 2016). Thus, clinical disease varies from mild or insidious, slowly progressive CNS disease with subtle clinical signs, to severe, rapidly progressive disease with marked clinical signs (Kazacos, 2001; Murray and Kazacos, 2004). Even though a single larva in the brain of a mouse or small bird can be fatal, the brain of a human is quite large by comparison and can absorb a certain level of larvae and damage before clinical signs become apparent (Hung and others, 2012). Clinical signs of Baylisascaris encephalitis can develop as early as 2-4 weeks postinfection and progress rapidly in children, who are both smaller in size and likely to have ingested a larger number of infective eggs than adults (Kazacos, 2000).

Clinical signs in affected humans resemble those seen in nonhuman primates suffering from Baylisascaris NLM (Kazacos, Wirtz, and others, 1981). There are subtle initial changes in behavior or habits, and with increasing neural damage and inflammation, clinical signs may worsen quickly (Kazacos, 2000, 2001; Murray and Kazacos, 2004; Kazacos and others, 2013). As seen in animals, including nonhuman primates, milder disease from lower level infection can manifest as any combination of subtle neurologic problems and deficits. Clinical signs in heavily infected children are more severe, reflecting extensive damage to the nervous system by migrating larvae. Such patients may undergo rapidly progressive brain damage that may result in coma and death (Kazacos, 2000).
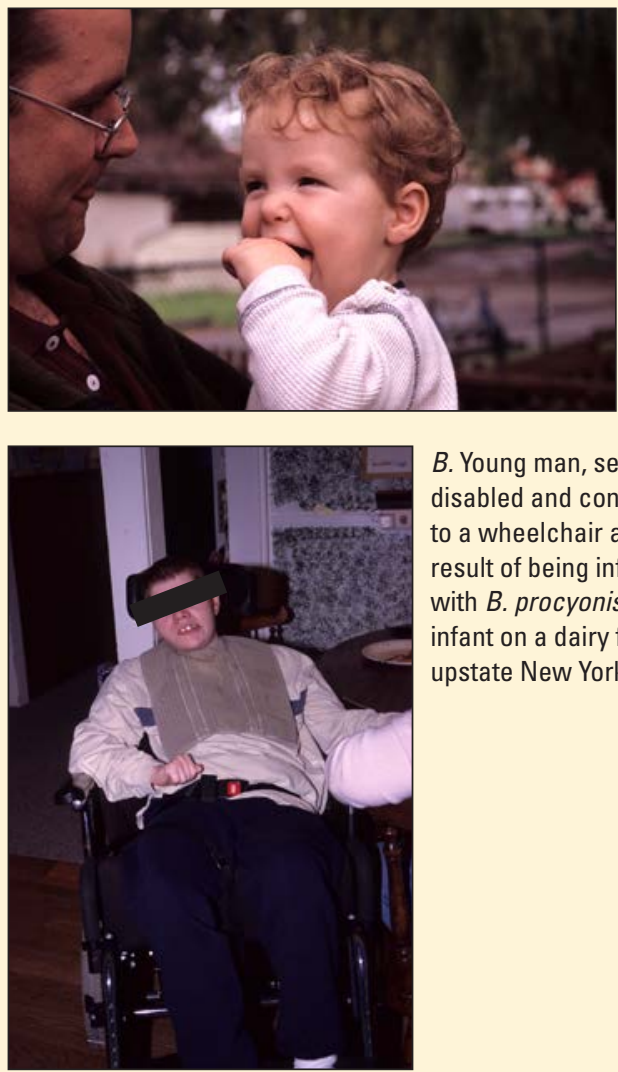

A. Young child with central nervous system disease and blindness, infected with $B$. procyonis at a university daycare facility in southern California.
B. Young man, severely disabled and confined to a wheelchair as a result of being infected with $B$. procyonis as an infant on a dairy farm in upstate New York.

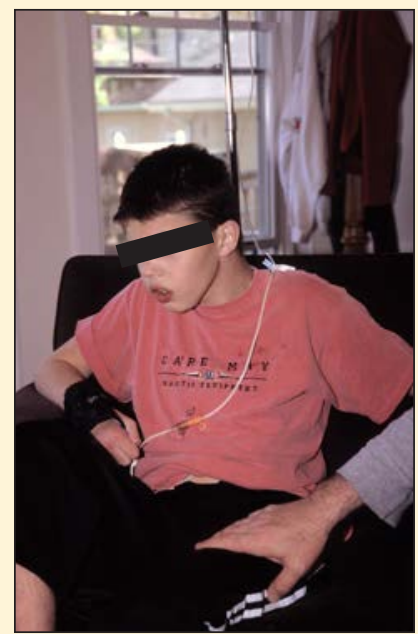

C. Young man, severely disabled with both NLM and OLM-DUSN after being infected with $B$. procyonis as a child in his yard in the Chicago suburbs. 


\section{Clinical Disease in Humans}

Children who survive may have profound neurologic impairment, with muscular weakness or paralysis, blindness, seizures, incontinence, and severe developmental delays. They may be incapacitated, wheelchair-bound, or in a chronic vegetative state (Kazacos, 2000). Even if they can be stabilized initially with aggressive treatment, patients may progressively worsen over time as the brain undergoes postinflammatory wasting with shrinkage and selective loss of white matter (Cunningham and others, 1994; Rowley and others, 2000). Signs of VLM may also be present in patients with clinical NLM, but VLM signs are greatly overshadowed by the signs affecting the nervous system. Patients with clinical NLM may also develop lesions of OLM due to concomitant larval invasion of the eye.

\section{Baylisascaris 0cular Larva Migrans and Diffuse Unilateral Subacute Neuroretinitis}

Some patients with Baylisascaris encephalitis also develop eye disease, because of increased larval numbers, dissemination, and eye invasion (Rowley and others, 2000; Park and others, 2000; Gavin and others, 2002; Mets and others, 2003; Hajek and others, 2009). However, most cases of Baylisascaris-induced eye disease are stand-alone cases and do not have any other recognizable clinical signs (Goldberg and others, 1993; Saffra and others, 2010; Liu and others, 2015). This is because a single larva entering the eye can cause serious clinical problems, and this occurs by chance, based on accidental ingestion of infective eggs. On a population level, the more people who are exposed to even low-level infection, which is common, the greater the chance of ocular invasion and clinical eye disease developing in some individuals. This explains why more cases of OLM and DUSN than cases of clinical NLM are seen in humans.

Patients with ocular invasion typically experience sudden blurred or loss of vision in one eye, and ophthalmologic examination reveals lesions of DUSN, including inflammatory and degenerative changes affecting the retina, retinal vessels, and optic nerve head (Gass and Braunstein, 1983; Goldberg and others, 1993; Saffra and others, 2010). These changes may be accompanied by migration tracks and infiltrates in the retina and (or) choroid, and sometimes granuloma formation (Goldberg and others, 1993; Liu and others, 2015). If larvae are seen in the eye and are away from sensitive structures, they are usually killed using laser photocoagulation (Goldberg and others, 1993; Casella and others, 1998; Saffra and others, 2010). Larvae seen in the eye can be photographed and measured, and their length and other morphologic characteristics can be used to identify them as probable Baylisascaris, separating them from other possible parasites (Goldberg and others, 1993).

Anthelmintic treatment of DUSN has also been advocated (Gass and others, 1992), but has had mixed results; in several cases anthelmintic treatment was apparently successful (Cortez and others, 2005; Tarantola and others, 2011), while in others it was not effective (Casella and others, 1998).

\section{Clinical signs of neural larva migrans in children.}

[From Kazacos (2000)]

\begin{tabular}{ll}
\hline \multicolumn{1}{c}{ Lower level infection } & \multicolumn{1}{c}{ Heavy infection } \\
\hline Dullness and somnolence & Sudden onset of lethargy. \\
Tremors or unsteadiness & Dullness and irritability. \\
Confusion & Neck rigidity and (or) twisting. \\
Learning disability & Loss of fine motor skills. \\
Developmental regression & Decreased head control. \\
& Inability to sit, stand, or walk \\
& without assistance. \\
& Impaired vision or blindness. \\
& Eye deviation and (or) rapid \\
& involuntary eye movements. \\
& Speech deterioration. \\
& Problems with eating. \\
Increase or loss of muscle & tone. \\
Extension of the extremities. & Arching of the body. \\
Stupor. & Coma. \\
Death. &
\end{tabular}


Baylisascaris is also well known as a cause of clinical OLM, and at least 28 cases have been recognized in North America and Europe, including 24 published reports (table 9). OLM and DUSN due to $B$. procyonis are usually seen in older children and adults and are clinically similar to toxocaral OLM and DUSN, except that the larvae are much larger and ocular damage from larval migration may be more severe. Human cases have been linked to keeping pet raccoons (Raymond and others, 1978; Kuchle and others, 1993) or having contact with wild raccoons and contaminated environments.

Table 9. Cases of Baylisascaris ocular larva migrans-diffuse unilateral subacute neuroretinitis in humans.

[Partial list, there are likely other cases of which the author is not aware; NR, not reported; CLM, cutaneous larva migrans; NLM, neural larva migrans; DUSN, diffuse unilateral subacute neuroretinitis]

\begin{tabular}{|c|c|c|c|c|c|c|c|}
\hline $\begin{array}{c}\text { Year of } \\
\text { onset or } \\
\text { presentation }\end{array}$ & $\begin{array}{l}\text { Patient } \\
\text { age }\end{array}$ & $\begin{array}{l}\text { Patient } \\
\text { sex }\end{array}$ & Location & $\begin{array}{l}\text { Worm } \\
\text { seen? }\end{array}$ & $\begin{array}{l}\text { Length of } \\
\text { worm in } \\
\text { micrometers }\end{array}$ & Notes & Reference \\
\hline 1949 & 25 years & Male & Florida & Yes & 1,500 & - & Parsons (1952). \\
\hline 1960 & 22 years & Female & Austria & Yes & 1,700 & $\begin{array}{l}\text { Infected raccoons } \\
\text { present in area }^{1}\end{array}$ & Schrott (1961). \\
\hline 1974 & 23 years & Male & Michigan & Yes & 1,600 & $\begin{array}{l}\text { Infected raccoons } \\
\text { common in area }\end{array}$ & Raymond and others (1978). \\
\hline 1976 & 13 years & Female & Kentucky & Yes & 2,000 & Pet raccoon & Raymond and others (1978). \\
\hline NR & 13 years & Male & Nebraska & Yes & $1,500-2,000$ & $\begin{array}{l}\text { Infected raccoons } \\
\text { common in area }^{1}\end{array}$ & Gass and Braunstein (1983). \\
\hline NR & 65 years & Female & Illinois & Yes & $1,500-2,000$ & $\begin{array}{l}\text { Infected raccoons } \\
\text { common in area }^{1}\end{array}$ & Gass and Braunstein (1983). \\
\hline NR & 25 years & Male & Illinois & Yes & $1,500-2,000$ & $\begin{array}{l}\text { Infected raccoons } \\
\text { common in area }^{1}\end{array}$ & Gass and Braunstein (1983). \\
\hline NR & NR & Female & Illinois & Yes & $1,500-2,000$ & $\begin{array}{l}\text { Infected raccoons } \\
\text { common in area }^{1}\end{array}$ & Gass and Braunstein (1983). \\
\hline 1985 & 42 years & Male & Wisconsin & Yes & 1,260 & $\begin{array}{l}\text { Outdoorsman; contact } \\
\text { with raccoon den }\end{array}$ & Williams and others (1988). \\
\hline NR & 27 years & Male & Pennsylvania & Yes & 1,600 & $\begin{array}{l}\text { Infected raccoons } \\
\text { common in area }\end{array}$ & $\begin{array}{l}\text { Sivalingam and others } \\
\text { (1991). }\end{array}$ \\
\hline 1991 & 48 years & Female & Germany & Yes & 1,500 & Pet raccoon & Kuchle and others (1993). \\
\hline Circa 1992 & 29 years & Male & California & Yes & 1,727 & $\begin{array}{l}\text { Infected raccoons } \\
\text { common in area }^{1}\end{array}$ & Goldberg and others (1993). \\
\hline 1995 & 15 years & Male & Brazil & Yes & $1,500-2,000$ & $\begin{array}{l}\text { Nonraccoon } \\
\text { procyonids and } \\
\text { skunks in area }\end{array}$ & Cialdini and others (1999). \\
\hline 1996 & 6 years & Male & Illinois & No & NR & $\begin{array}{l}\text { NLM with ocular } \\
\text { lesions of DUSN, } \\
\text { positive serology }\end{array}$ & $\begin{array}{l}\text { Gavin and others (2002); } \\
\text { Mets and others (2003). }\end{array}$ \\
\hline 1997 & 16 years & Female & Brazil & Yes & $1,600-2,000$ & Dog contact; CLM & Amaro (2000). \\
\hline NR & 13 months & Male & California & NR & NR & $\begin{array}{l}\text { NLM with ocular } \\
\text { lesions suggestive } \\
\text { of DUSN; positive } \\
\text { brain biopsy and } \\
\text { serology }\end{array}$ & Rowley and others (2000). \\
\hline 1998 & 11 months & Male & California & No & NR & $\begin{array}{l}\text { NLM with ocular } \\
\text { lesions of DUSN; } \\
\text { positive serology }\end{array}$ & Park and others (2000). \\
\hline
\end{tabular}


Table 9. Cases of Baylisascaris ocular larva migrans-diffuse unilateral subacute neuroretinitis in humans.-Continued

[Partial list, there are likely other cases of which the author is not aware; NR, not reported; CLM, cutaneous larva migrans; NLM, neural larva migrans; DUSN, diffuse unilateral subacute neuroretinitis]

\begin{tabular}{|c|c|c|c|c|c|c|c|}
\hline $\begin{array}{c}\text { Year of } \\
\text { onset or } \\
\text { presentation }\end{array}$ & $\begin{array}{l}\text { Patient } \\
\text { age }\end{array}$ & $\begin{array}{l}\text { Patient } \\
\text { sex }\end{array}$ & Location & $\begin{array}{l}\text { Worm } \\
\text { seen? }\end{array}$ & $\begin{array}{l}\text { Length of } \\
\text { worm in } \\
\text { micrometers }\end{array}$ & Notes & Reference \\
\hline 1999 & 16 years & Male & Ohio & Yes & 1,500 & $\begin{array}{l}\text { Infected raccoons } \\
\text { common in area; } \\
\text { larva recovered }^{1}\end{array}$ & $\begin{array}{l}\text { L.J. Chorich III and others, } \\
\text { unpub. data (2000). }\end{array}$ \\
\hline 2000 & 2.5 years & Male & Illinois & No & NR & $\begin{array}{l}\text { NLM with ocular } \\
\text { lesions; positive } \\
\text { serology }\end{array}$ & $\begin{array}{l}\text { Gavin and others (2002); } \\
\text { Mets and others (2003). }\end{array}$ \\
\hline NR & 7 years & Male & Ontario & No & NR & $\begin{array}{l}\text { NLM with ocular } \\
\text { lesions of DUSN; } \\
\text { positive serology }\end{array}$ & Hajek and others (2009). \\
\hline 2001 & 40 years & Male & Ohio & Yes & 1,500 & $\begin{array}{l}\text { Infected raccoons } \\
\text { common in area; } \\
\text { positive serology }\end{array}$ & $\begin{array}{l}\text { S.M. Gordon and others, } \\
\text { unpub. data (2001). }\end{array}$ \\
\hline Circa 2006 & 37 years & Male & Ohio & Yes & NR & $\begin{array}{l}\text { Positive serology; } \\
\text { infected raccoons } \\
\text { common in area }\end{array}$ & Brasil and others (2006). \\
\hline NR & 15 years & Female & New York & Yes & 1,850 & $\begin{array}{l}\text { Infected raccoons } \\
\text { in area; raccoons } \\
\text { seen in immediate } \\
\text { vicinity }\end{array}$ & Saffra and others (2010). \\
\hline 2009 & 45 years & Male & Iowa & Yes & 1,270 & $\begin{array}{l}\text { Turkey hunter; contact } \\
\text { with soil positive } \\
\text { for infective } B \text {. } \\
\text { procyonis eggs }{ }^{1}\end{array}$ & Tarantola and others (2011). \\
\hline
\end{tabular}

${ }^{1}$ K.R. Kazacos, unpub. data (1985-2010); data on file with the author. 


\section{Animal Infections}

\section{Raccoons}

The common raccoon is a member of the Family Procyonidae, which also includes the crab-eating raccoon of Central and South America, the critically endangered Cozumel or pygmy raccoon on Cozumel Island in Mexico, coatis, the ringtail and cacomistle, the kinkajou, and olingos, all occurring in different parts of the Americas. With regard to raccoons, Baylisascaris procyonis has thus far only been found in the common raccoon, and unless otherwise specified, "raccoon" will refer to that species. Prevalence of B. procyonis in raccoons varies as a function of the examination technique used (necropsy, fecal examination of individuals or latrines), season, predominant land use where the animals live, animals' ages, and other factors (Kazacos, 2001; Page and others, 2005). Raccoons infected with $B$. procyonis usually appear normal and do not show any clinical signs, although very heavy infections in young raccoons have occasionally caused intestinal blockage and death (Stone, 1983; Carlson and Nielsen, 1984). Migration of $B$. procyonis beyond the intestines, including somatic migration, does not appear to occur in raccoons.

Due to age-related differences in susceptibility and transmission, $B$. procyonis typically has a higher prevalence in juvenile raccoons (91-94 percent) than in adults (37-55 percent), although this does not hold true in all surveys. In areas of high prevalence, the average number of parasites in an animal (the intensity) typically ranges from 43 to 52 worms, with juvenile raccoons usually having a higher mean intensity (48-62, range 1-480) than adult raccoons (12-22, range 1-257); males usually have a higher prevalence of infection than females, although this may also vary by study (Snyder and Fitzgerald, 1985; Ermer and Fodge, 1986; Kazacos, 2001; Cottrell and others, 2014; Jardine and others, 2014). In some areas, such as the southern United States, prevalences and mean intensities of infection may be considerably lower (Blizzard, Davis, and others, 2010; Blizzard, Yabsley, and others, 2010; Kresta and others, 2010; Reed and others, 2012) (table 5). The age distribution of $B$. procyonis in raccoons correlates with what is known about the parasite's life cycle (fig. 8): namely, that young raccoons in their first season are very susceptible to egg infection and appear to recruit the parasite into the raccoon population and have higher worm burdens, egg shedding, and prevalence of infection.

In some areas, primarily northern temperate regions, the prevalence of $B$. procyonis varies with season (Page and others, 2005), and the parasite population undergoes a yearly cycle with an apparent self-cure in raccoons during the winter months (Kazacos, 2001). Studies involving 1,050 raccoons from the Midwestern United States corroborated this, with strong evidence of a decrease in the worm population from January through June and an increase from June to December (Page and others, 2016). Seasonal recruitment of the parasite and its increase in prevalence in juvenile raccoons likely contributes to the overall increase in prevalence in raccoons seen in an area over the summer and fall months (Kazacos, 2001; Jardine and others, 2014), although this may also be affected by other factors (Page, 2013). As raccoons become older, age resistance and (or) intestinal immunity combined with spontaneous elimination of the parasites may contribute to the lower prevalence of $B$. procyonis in adults. However, adults continue to become infected when they ingest paratenic hosts carrying larvae through predation or scavenging (Kazacos, 1983b; Kazacos and Boyce, 1989; Kazacos, 2001; Reed and others, 2012), and in some cases by ingesting infective eggs (the age dichotomy in transmission method is likely not 100 percent).

\section{Paratenic Hosts}

When it comes to larval infection, Baylisascaris procyonis is a remarkably nonspecific parasite. Larvae can infect a surprisingly wide variety of paratenic (transport) hosts. In fact, this parasite has one of the widest host infection and diseaseproducing capabilities of any worm parasite known, affecting numerous free-ranging and captive wildlife, zoo animals, domestic animals, and humans with NLM (Kazacos, 2001; Kazacos and others, 2013; Singaravelu and others, 2016).

Both wild and domestic animals act as paratenic hosts of B. procyonis and develop NLM (tables 1, 2, 10-21); however, susceptibility to Baylisascaris larva migrans varies among animal groups and species (Wirtz, 1982; Sheppard, 1995, 1996; Sheppard and Kazacos, 1997; Kazacos, 2001). Animal groups particularly susceptible to Baylisascaris NLM include rodents, rabbits, primates, and birds, based on the number of cases and species affected. Some animal groups and species appear to be less or only marginally susceptible, and parasite migration is limited to the intestinal wall or viscera; other groups and species appear to be resistant (Kazacos and Boyce, 1989; Kazacos, 2001). Despite this, one should be cautious concerning species susceptibility, because a determination of low susceptibility may simply reflect a lack of recognition of cases, and new species records are regularly added to the list of animals affected with NLM. However, no cases of B. procyonis NLM have been documented in opossums, which are commonly exposed when they forage at raccoon latrines (Page, 1998; Page and others, 1999), nor in cats, which groom considerably and eat rodents possibly contaminated with eggs and (or) containing third-stage larvae. No infections were seen in cats fed infective eggs or tissue larvae (Miyashita, 1993; K.R. Kazacos, unpub. data, 1981). Until recently, no cases had been seen in raptors, which are exposed when they prey on other animals or consume carcasses, or in adult hoofstock, which are exposed when they consume contaminated hay. Because limited or no migration was seen in sheep, goats, and swine experimentally infected with B. procyonis (Dubey, 1982; Snyder, 1983; Kazacos and Kazacos, 1984), it was believed that ungulates were only marginally susceptible to infection and would not develop NLM. However, lambs in Idaho were born 
In humans, larvae migrate and become encapsulated

in tissues and cause VLM, NLM, and OLM

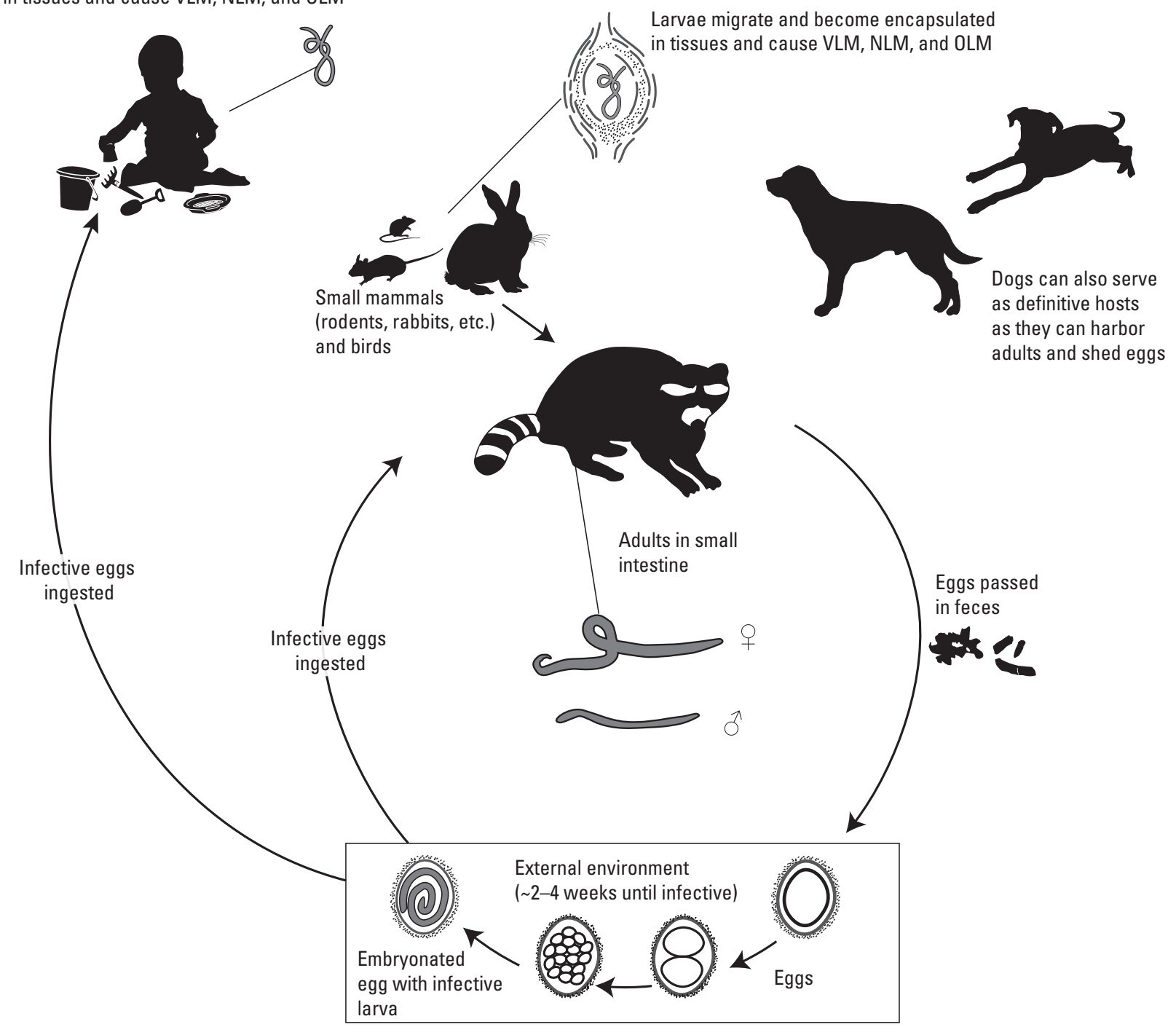

Figure 8. The life cycle of Baylisascaris procyonis.

with Baylisascaris encephalitis (Anderson, 1999), indicating not only that larvae can migrate through the body tissues of sheep, but that they can move through the placenta (transplacental transfer) of pregnant ewes to infect unborn lambs, similar to Toxocara canis in dogs. How often this occurs in different mammals is unknown, but transplacental infection followed by subsequent parasite maturation in puppies is believed to occur in dogs (Kazacos, 2001, 2006). Recently, a feedlot steer was diagnosed with Baylisascaris encephalitis in Alberta, Canada (E. Janzen, pers. commun., 2009), further showing that ruminants can be infected in some instances and should now be considered paratenic hosts. Interestingly, shrews were found to be resistant to experimental infection with $B$. procyonis eggs and larvae, at dosages much higher than those lethal to mice (Sheppard, 1996); the reasons for this resistance are unknown, but may include unique or potent gastrointestinal enzymes and (or) failure of eggs to hatch or larvae to survive (Kazacos, 2001). Unless complete necropsies are done, including a thorough examination of the brain in all cases of CNS disease, then apparent species limitations to Baylisascaris larva migrans should be regarded with caution. 
Table 10. Rodents with naturally occurring Baylisascaris neural larva migrans. ${ }^{1}$

[NR, not reported; >, greater than]

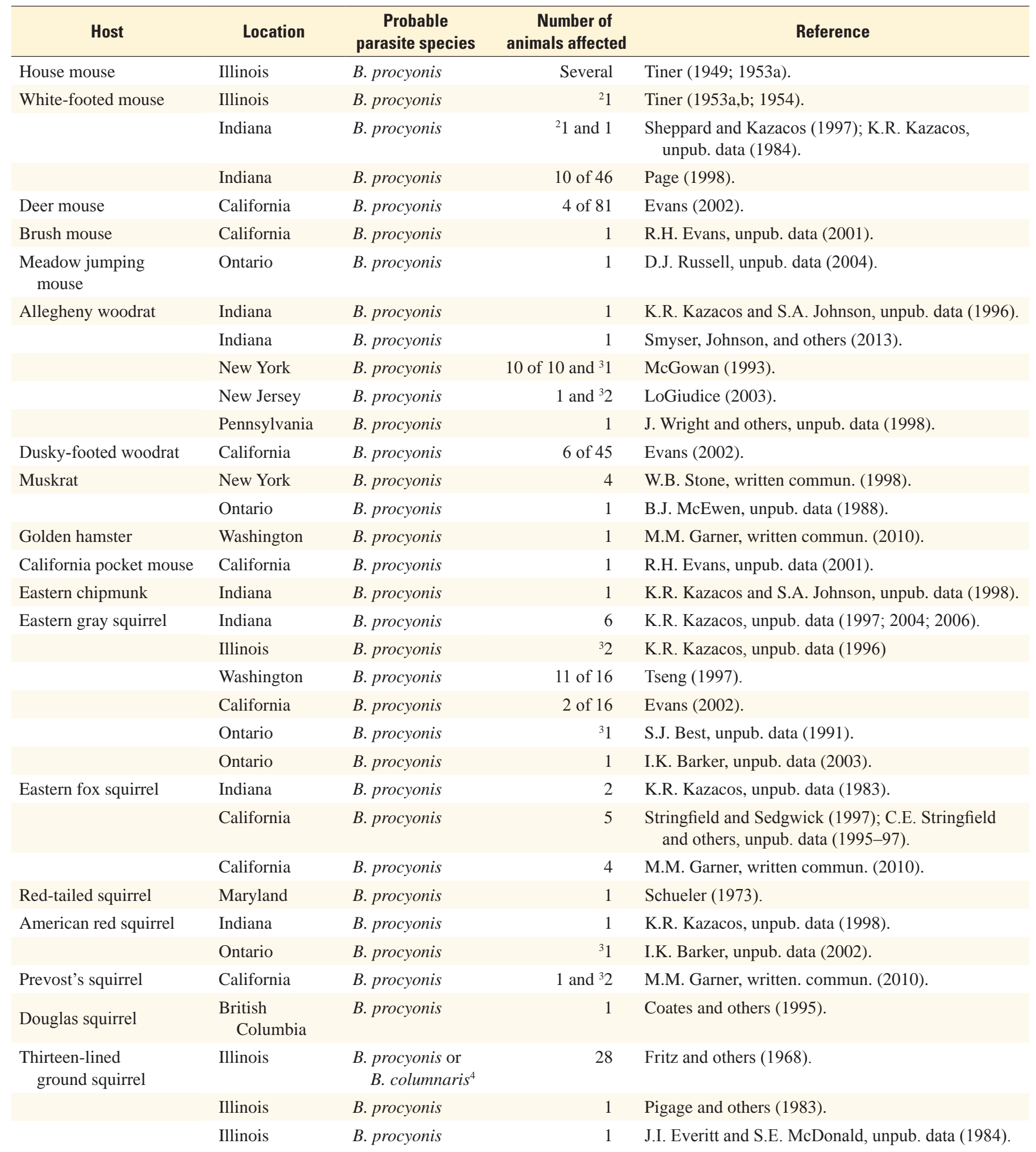


Table 10. Rodents with naturally occurring Baylisascaris neural larva migrans. ${ }^{1}$-Continued

[NR, not reported; >, greater than]

\begin{tabular}{|c|c|c|c|c|}
\hline Host & Location & $\begin{array}{l}\text { Probable } \\
\text { parasite species }\end{array}$ & $\begin{array}{c}\text { Number of } \\
\text { animals affected }\end{array}$ & Reference \\
\hline \multirow{2}{*}{$\begin{array}{l}\text { California ground } \\
\text { squirrel }\end{array}$} & California & B. procyonis & 20 of 119 & Evans (2002). \\
\hline & California & B. procyonis & 1 & C.E. Stringfield and others, unpub. data (1995). \\
\hline \multirow[t]{5}{*}{ Black-tailed prairie dog } & Iowa & B. procyonis & NR & Greve (1985). \\
\hline & $\begin{array}{l}\text { New York and } \\
\text { Wisconsin }\end{array}$ & B. procyonis & 3 of 52 & Dixon and others (1988). \\
\hline & Ohio & B. procyonis & Several & M.T. Barrie, written commun. (2008). \\
\hline & Illinois & B. procyonis & 1 & K.R. Kazacos and P.L. Wolff, unpub. data (1988). \\
\hline & Ontario & B. procyonis & ${ }^{3} 1$ & D.A. Smith, unpub. data (2012). \\
\hline \multirow[t]{6}{*}{ Woodchuck } & Pennsylvania & $\begin{array}{l}\text { B. procyonis or } \\
\text { B. columnaris }{ }^{4}\end{array}$ & 4 of 4 & Richter and Kradel (1964). \\
\hline & New York & $\begin{array}{l}\text { B. procyonis or } \\
\text { B. columnaris }\end{array}$ & 6 & Fleming and Caslick (1978). \\
\hline & New York & $\begin{array}{l}\text { B. procyonis or } \\
\text { B. columnaris }\end{array}$ & 5 of 5 & Fleming and others (1979). \\
\hline & Indiana & B. procyonis & 1 and 3 & $\begin{array}{l}\text { Kazacos and others (1981); K.R. Kazacos, } \\
\text { unpub. data (1985-1986). }\end{array}$ \\
\hline & New York & $\begin{array}{l}\text { B. procyonis or } \\
\text { B. columnaris }\end{array}$ & 12 of 12 & Roth and others (1982). \\
\hline & Iowa & $\begin{array}{l}\text { B. procyonis or } \\
\text { B. columnaris }\end{array}$ & NR & Greve (1985). \\
\hline Western pocket gopher & California & B. procyonis & 1 & K.R. Kazacos and F.H. Dunker, unpub. data (1996). \\
\hline \multirow[t]{2}{*}{ Botta’s pocket gopher } & California & B. procyonis & 2 of 2 & Evans (2002). \\
\hline & California & B. procyonis & 2 & K.R. Kazacos and F.H. Dunker, unpub. data (1997). \\
\hline \multirow[t]{2}{*}{ Domestic guinea pig } & Missouri & B. procyonis & 30 of 50 & Van Andel and others (1995). \\
\hline & Nova Scotia & B. procyonis & 2 & Craig and others (1995). \\
\hline Patagonian mara & Illinois & B. procyonis & 4 & K.R. Kazacos and others, unpub. data (1989). \\
\hline Capybara & Illinois & B. procyonis & 1 & K.R. Kazacos and others, unpub. data (1987). \\
\hline \multirow[t]{3}{*}{ Long-tailed chinchilla } & Pennsylvania & $\begin{array}{l}\text { B. procyonis or } \\
\text { B. columnaris }\end{array}$ & 6 & Richter and Kradel (1964). \\
\hline & Ontario & B. procyonis & 100 & Sanford (1989). \\
\hline & Minnesota & B. procyonis & 17 of 1,400 & $\begin{array}{l}\text { A.Wuenschmann and K.R. Kazacos, } \\
\text { unpub. data (2007). }\end{array}$ \\
\hline
\end{tabular}


Table 10. Rodents with naturally occurring Baylisascaris neural larva migrans. ${ }^{1}$ - Continued

[NR, not reported; >, greater than]

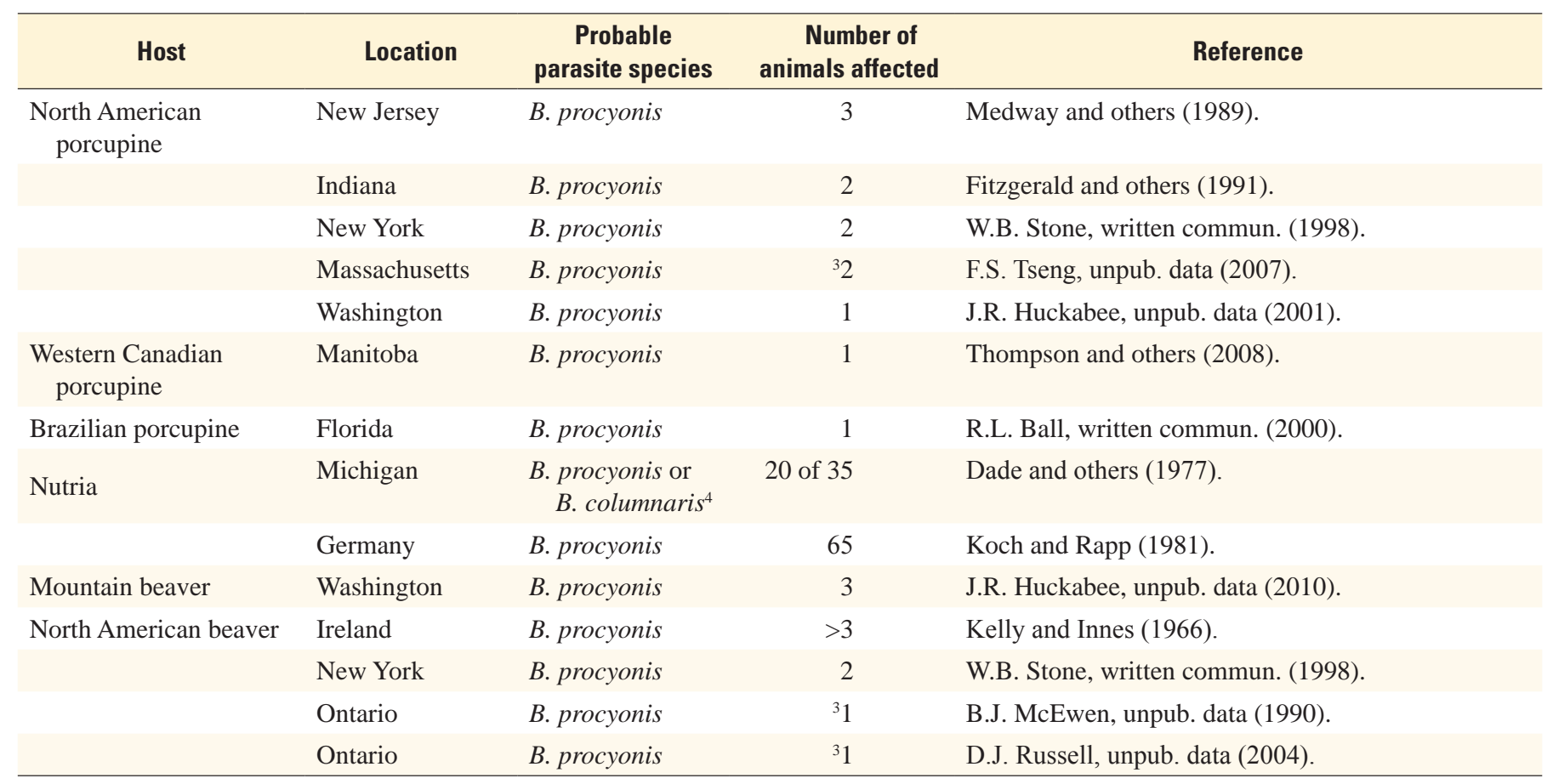

${ }^{1}$ Cases have been confirmed by the author or cooperating board-certified pathologists, and information and data are on file with the author.

${ }^{2}$ Positive for Baylisascaris neural larva migrans, but without clinical central nervous system disease.

${ }^{3}$ Probable case based on characteristic lesions, clinical signs, and (or) history of exposure; larvae not found or animals survived.

${ }^{4}$ In some cases, involvement of B. columnaris could not be ruled out. However, most of these cases are most likely B. procyonis. 
Table 11. Rabbits with naturally occurring Baylisascaris neural larva migrans. ${ }^{1}$

[NR, not reported]

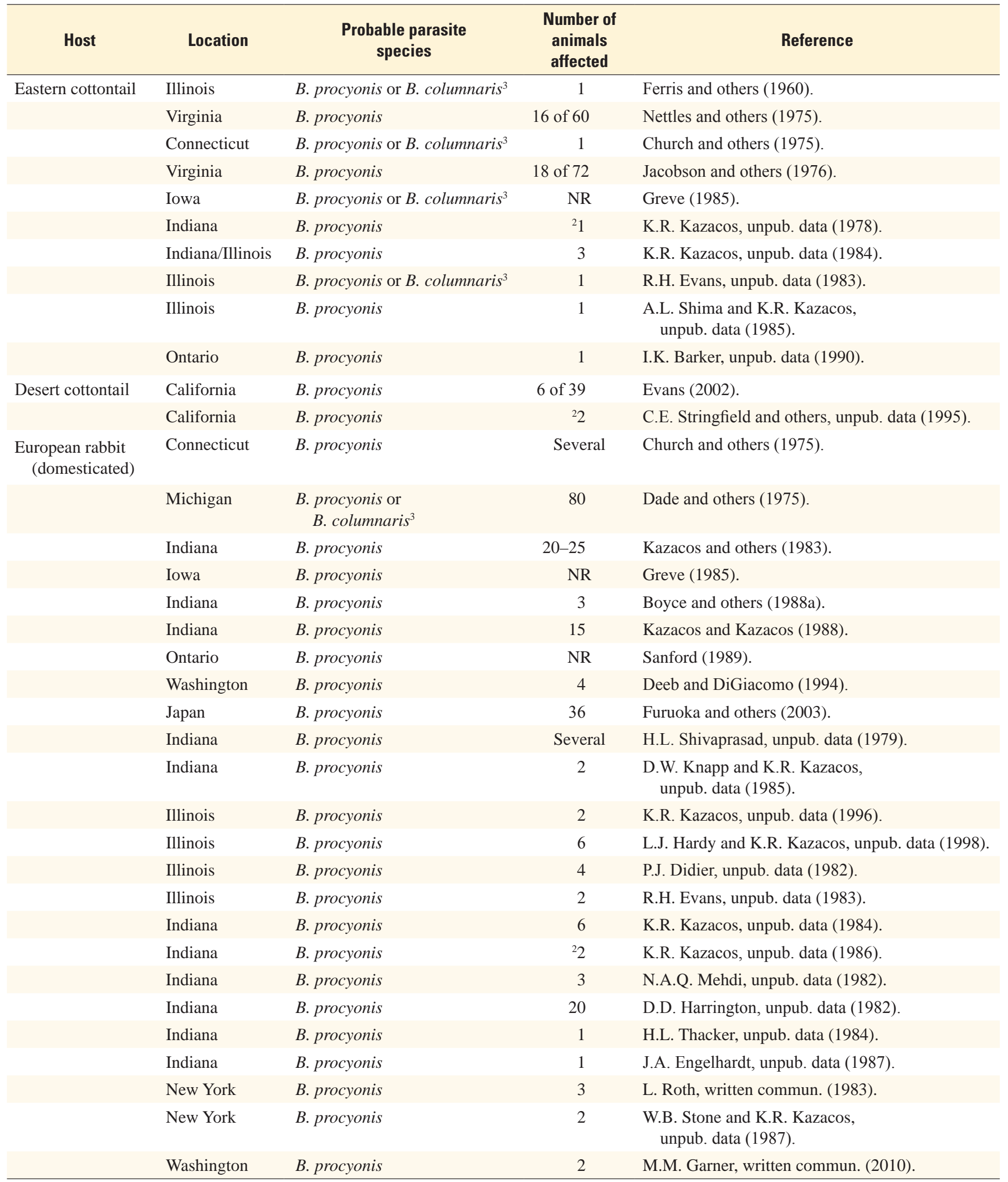

\footnotetext{
${ }^{1}$ Cases have been confirmed by the author or cooperating board-certified pathologists, and information and data are on file with the author.
}

${ }^{2}$ Probable case based on characteristic lesions, clinical signs, and (or) history of exposure; larvae not found or animals survived.

${ }^{3}$ In some cases, involvement of B. columnaris could not be ruled out; however, most of these cases are most likely B. procyonis. 
Table 12. Carnivores with naturally occurring Baylisascaris neural larva migrans. ${ }^{1}$

[Probable parasite species B. procyonis]

\begin{tabular}{llcl}
\hline \multicolumn{1}{c}{ Host } & \multicolumn{1}{c}{ Location } & $\begin{array}{c}\text { Number of } \\
\text { animals affected }\end{array}$ & \multicolumn{1}{c}{ Reference } \\
\hline Red (silver) fox & Iowa & 4 of 4 & Larson and Greve (1983); Greve (1985). \\
Domestic dog & Michigan & 1 & Thomas (1988). \\
& Indiana & 1 & Rudmann and others (1996). \\
& California & 1 & Windsor and others (2009). \\
& California & 1 & H.R. Galano and others, unpub. data (2005). \\
American badger & California & 1 & Evans (2002). \\
Southern sea otter & California & 1 & N.J. Thomas and others, unpub. data (1998). \\
Long-tailed weasel & California & 1 of 7 & Evans (2002). \\
\hline
\end{tabular}

${ }^{1}$ Cases have been confirmed by the author or cooperating board-certified pathologists, and information and data are on file with the author. 
Table 13. Primates with naturally occurring Baylisascaris neural larva migrans. ${ }^{1}$

\begin{tabular}{|c|c|c|c|c|}
\hline Host & Location & $\begin{array}{l}\text { Probable } \\
\text { parasite } \\
\text { species }\end{array}$ & $\begin{array}{l}\text { Number of } \\
\text { animals } \\
\text { affected }\end{array}$ & Reference \\
\hline \multirow[t]{4}{*}{ Black-and-white ruffed lemur } & Oklahoma & B. procyonis & 2 & Campbell and others (1997). \\
\hline & Rhode Island & B. procyonis & 6 & J.C. Martin,unpub. data (1998-99). \\
\hline & Tennessee & B. procyonis & 3 & S.J. Barrett, unpub. data (1996). \\
\hline & California & B. procyonis & 1 & M.M. Garner, written commun. (2010). \\
\hline Red ruffed lemur & Rhode Island & B. procyonis & 3 & J.C. Martin, unpub. data (1998-99). \\
\hline Ring-tailed lemur & Ontario & B. procyonis & ${ }^{3} 1$ & T. Van Dreumel, unpub. data (2014). \\
\hline White-headed lemur & Spain & B. procyonis & 2 & Jimenez Martinez and others (2015). \\
\hline $\begin{array}{l}\text { Coquerel's giant } \\
\text { mouse lemur }\end{array}$ & California & B. procyonis & 1 & K.R. Kazacos and F.H. Dunker, unpub. data (1995). \\
\hline White-headed marmoset & Illinois and Texas & B. columnaris & 1 & K.R. Kazacos and P.L. Wolff, unpub. data (1986). \\
\hline Black-mantled tamarin & Texas & B. columnaris & 1 & $\begin{array}{l}\text { Huntress and Spraker (1985); T.R. Spraker, } \\
\text { written commun. (1986). }\end{array}$ \\
\hline \multirow[t]{2}{*}{ Red-handed (Midas) tamarin } & Texas & B. columnaris & 1 & $\begin{array}{l}\text { Huntress and Spraker (1985); T.R. Spraker, } \\
\text { written commun. (1986). }\end{array}$ \\
\hline & Indiana & B. procyonis & 1 & M.C. Spriggs, unpub. data (2009). \\
\hline Cottontop tamarin & Louisiana & B. procyonis & ${ }^{2} 1$ & M.M. Garner, written commun. (2010). \\
\hline Emperor tamarin & California & B. procyonis & 1 & M.M. Garner, written commun. (2010). \\
\hline White-handed gibbon & Kansas & B. procyonis & 1 & Ball and others (1998). \\
\hline Spider monkey & Maryland & B. procyonis & 1 & Garlick and others (1996). \\
\hline De Brazza's monkey & Indiana & B. procyonis & 2 & C.L. Eng and K.R. Kazacos, unpub. data (1997). \\
\hline Japanese macaque & Japan & B. procyonis & 9 & Sato and others (2005). \\
\hline Rhesus macaque & Maryland & B. procyonis & 7 of 13 & Gozalo and others (2008). \\
\hline Crab-eating macaque & Connecticut & B. procyonis & 1 & Shoieb and Radi (2014). \\
\hline Bornean orangutan & Tennessee & B. procyonis & 1 & D. Zimmerman and others, unpub. data (2005). \\
\hline Bornean orangutan hybrid & Wisconsin & B. procyonis & 1 & Hanley and others (2006). \\
\hline \multirow[t]{6}{*}{ Human $^{3}$} & Pennsylvania & B. procyonis & 1 & Huff and others (1984). \\
\hline & Illinois & B. procyonis & 1 & Fox and others (1985). \\
\hline & California & B. procyonis & 1 & Rowley and others (2000). \\
\hline & & B. procyonis & 1 & Kazacos and others (2002). \\
\hline & Missouri & B. procyonis & 1 & Moore (2009); Ciarlini and others (2011). \\
\hline & British Columbia & B. procyonis & 1 & Hung and others (2012). \\
\hline
\end{tabular}

\footnotetext{
${ }^{1}$ Cases have been confirmed by the author or cooperating board-certified pathologists, with information and data on file with the author.

${ }^{2}$ Probable case based on characteristic lesions, clinical signs, and (or) history of exposure; larvae not found or animals survived.

${ }^{3}$ Does not include serologically diagnosed cases.
} 
Table 14. Miscellaneous mammals with naturally occurring Baylisascaris neural larva migrans. ${ }^{1}$

[Probable parasite species B. procyonis]

\begin{tabular}{llcl}
\hline \multicolumn{1}{c}{ Host } & Location & $\begin{array}{c}\text { Number of } \\
\text { animals affected }\end{array}$ & \multicolumn{1}{c}{ Reference } \\
\hline Red kangaroo & Marsupials & \\
Yellow-footed rock wallaby & Michigan & 11 of 20 & Agnew and others (1994). \\
Woylie & California & ${ }^{2} 2$ & Stringfield and Sedgwick (1997). \\
Long-nosed potoroo & California & ${ }^{2} 1$ & J.E. Wynne, written commun. (1998). \\
Bennett's wallaby & New York & ${ }^{2} 1$ & K.A. Volle, unpub. data (2010). \\
& Indiana & 1 & J.A. Beck and others, unpub. data (2014). \\
\hline Indian flying fox & & Bats & \\
& California & ${ }^{2} 1$ & Stringfield and Sedgwick (1997). \\
Rodrigues flying fox & Ontario & 2 & S.J. Best, unpub. data (1990). \\
\hline & Washington & & K.E. Helmick, unpub. data (2007). \\
\hline Domestic sheep & Idaho & Ungulates & \\
Domestic cow & Alberta & 1 of 3 & Anderson (1999). \\
\hline
\end{tabular}

${ }^{1}$ Cases have been confirmed by the author or cooperating board-certified pathologists, and information and data are on file with the author.

${ }^{2}$ Probable case based on characteristic lesions, clinical signs, and (or) history of exposure; larvae were not found or animals survived.

Table 15. Gamebirds with naturally occurring Baylisascaris neural larva migrans. ${ }^{1}$

[NR, not reported]

\begin{tabular}{|c|c|c|c|c|}
\hline Host & Location & $\begin{array}{c}\text { Probable parasite } \\
\text { species }\end{array}$ & $\begin{array}{c}\text { Number of } \\
\text { animals affected }\end{array}$ & Reference \\
\hline Domestic chicken & Indiana & B. procyonis & 622 & Richardson and others (1980). \\
\hline \multirow[t]{2}{*}{ Chukar } & Maryland & B. procyonis & 1 of 30 & Sass and Gorgacz (1978). \\
\hline & Illinois & B. procyonis & ${ }^{2} 1$ & P.J. Didier, unpub. data (1984). \\
\hline Ruffed grouse & New York & B. procyonis & 3 & W.B. Stone, written commun. (1998). \\
\hline Common pheasant & Wisconsin & B. procyonis & $200-400$ & Kazacos and others (1986). \\
\hline Wild turkey & New York & B. procyonis & 2 & W.B. Stone, written commun. (1998). \\
\hline Indian peafowl & Nebraska & B. procyonis & ${ }^{2} 1$ & Armstrong and others (1989). \\
\hline \multirow{3}{*}{ Northern bobwhite } & Iowa & B. procyonis & NR & Greve (1985). \\
\hline & Kansas & $\begin{array}{l}\text { B. procyonis or } \\
\text { B. columnaris }\end{array}$ & 1 & Williams and others (1997). \\
\hline & Illinois & B. procyonis & 640 of 712 & K.R. Kazacos and others, unpub. data (2002). \\
\hline California quail & California & B. procyonis & 7 of 29 & Evans (2002). \\
\hline Australian brushturkey & Indiana and Missouri & B. procyonis & 1 & Kazacos and others (1982). \\
\hline
\end{tabular}

${ }^{1}$ Cases have been confirmed by the author or cooperating board-certified pathologists, and information and data are on file with the author.

${ }^{2}$ Probable case based on characteristic lesions, clinical signs, and (or) history of exposure; larvae were not found or animals survived.

${ }^{3}$ In some cases, involvement of B. columnaris could not be ruled out; however, most of these cases are most likely B. procyonis. 
Table 16. Perching birds with naturally occurring Baylisascaris neural larva migrans. ${ }^{1}$

[Probable parasite species B. procyonis]

\begin{tabular}{|c|c|c|c|}
\hline Host & Location & $\begin{array}{c}\text { Number of } \\
\text { animals affected }\end{array}$ & Reference \\
\hline House sparrow & California & 3 of 111 & Evans (2002). \\
\hline \multirow[t]{2}{*}{ Canary } & California & 3 & B.C. Barr, written commun. (1998). \\
\hline & California & 12 of 22 & Loretti and others (2008). \\
\hline Spotted towhee & California & 1 & Evans (2002). \\
\hline Loggerhead shrike & California & 1 of 13 & Evans (2002). \\
\hline California thrasher & California & 3 of 8 & Evans (2002). \\
\hline Northern mockingbird & California & 8 of 74 & Evans (2002). \\
\hline Western scrub jay & California & 7 of 8 & Evans (2002). \\
\hline \multirow[t]{2}{*}{ American crow } & New York & 1 & B.P. Tangredi and K.R. Kazacos, unpub. data (1998). \\
\hline & California & 1 of 122 & Evans (2002). \\
\hline
\end{tabular}

${ }^{1}$ Cases have been confirmed by the author or cooperating board-certified pathologists, and information and data are on file with the author.

Table 17. Wading birds, shorebirds, diving birds, and waterfowl with naturally occurring Baylisascaris neural larva migrans. ${ }^{1}$

[Probable parasite species B. procyonis]

\begin{tabular}{llcl}
\hline \multicolumn{1}{c}{ Host } & Location & $\begin{array}{c}\text { Number of } \\
\text { animals affected }\end{array}$ & \multicolumn{1}{c}{ Reference } \\
\hline Black-crowned night heron & California & 2 of 38 & Evans (2002). \\
Sanderling & California & 1 of 4 & Evans (2002). \\
Inca tern & California & 21 & M.M. Garner, written commun. (2010). \\
Mallard X & California & 2 of 3 & Evans (2002). \\
Crested screamer & Manitoba & 2 & Thompson and others, (2008). \\
& Tennessee & 2 & D. Zimmerman and others, unpub. data (2003). \\
\hline
\end{tabular}

\footnotetext{
${ }^{1}$ Cases have been confirmed by the author or cooperating board-certified pathologists, and information and data are on file with the author.
}

${ }^{2}$ Probable case based on characteristic lesions, clinical signs, and (or) history of exposure; larvae were not found or animals survived. 
Table 18. Parrots with naturally occurring Baylisascaris neural larva migrans. ${ }^{1}$

[Probable parasite species B. procyonis]

\begin{tabular}{|c|c|c|c|}
\hline Host & Location & $\begin{array}{c}\text { Number of } \\
\text { animals affected }\end{array}$ & Reference \\
\hline Budgerigar & California & 11 & B.C. Barr, written commun. (1998). \\
\hline Eastern rosella & Ontario & ${ }^{2} 1$ & D.A. Smith, written commun. (2015). \\
\hline Rosella, unknown species & Ontario & ${ }^{2} 4$ & D.A. Smith, written commun. (2015). \\
\hline Scarlet macaw & Iowa & 2 & M.A. Nieves and others, unpub. data (1989). \\
\hline Red-and-green macaw & California & 1 & M.M. Garner, written commun. (2010). \\
\hline $\begin{array}{l}\text { Hybrid blue-and-yellow } \\
\text { macaw X scarlet macaw }\end{array}$ & Nebraska & 2 of 2 & Armstrong and others $(1987 ; 1989)$ \\
\hline Blue-fronted Amazon & California & 1 & B.C. Barr, written commun. (1998). \\
\hline \multirow[t]{2}{*}{ Yellow-headed Amazon } & Indiana & 2 & A.M. Lennox and others, unpub. data (1996); Lennox and others (2015). \\
\hline & Ontario & 3 and ${ }^{2} 1$ & Russell (2006); D.A. Smith, written commun. (2015). \\
\hline Yellow-naped Amazon & Ontario & 1 & Russell (2006); D.A. Smith, written commun. (2015). \\
\hline Cuban Amazon & Ontario & 1 & Russell (2006); D.A. Smith, written commun. (2015). \\
\hline Red-crowned Amazon & California & 1 & Done and Tamura (2014). \\
\hline Blue-crowned parakeet & Indiana & 5 & A.M. Lennox and others, unpub. data (1996); Lennox and others (2015). \\
\hline Orange-fronted parakeet & Indiana & 1 & A.M. Lennox and others, unpub. data (1996); Lennox and others (2015). \\
\hline Sun parakeet & Indiana & 2 & A.M. Lennox and others, unpub. data (1996); Lennox and others (2015). \\
\hline \multirow[t]{2}{*}{ Swainson’s lorikeet } & Iowa & ${ }^{2} 2$ & M.M. Garner, written commun. (2010). \\
\hline & Ontario & 4 & Russell and others (2005); Russell (2006). \\
\hline Marigold (Edward's) lorikeet & Ontario & ${ }^{2} 1$ & Russell (2006). \\
\hline Yellow-backed lorikeet & Ontario & ${ }^{2} 1$ & I.K. Barker, unpub. data (2005). \\
\hline Ornate lorikeet & Ontario & ${ }^{2} 1$ & D.A. Smith, written commun. (2015). \\
\hline Lorikeet, unidentified species & Missouri & 236 & A. Alexander and others, unpub. data (2013). \\
\hline \multirow[t]{4}{*}{ Cockatiel } & Iowa & 3 of 3 & Myers and others (1983); Greve (1985). \\
\hline & California & ${ }^{2} 2$ & B.C. Barr, written commun. (1998). \\
\hline & California & 34 of 35 & Diab and others (2012). \\
\hline & Ontario & ${ }^{2} 1$ & D.A. Smith, written commun. (2015). \\
\hline Galah & California & 3 & Stringfield and Sedgwick (1997). \\
\hline Red-tailed black cockatoo & California & ${ }^{2} 1$ & Stringfield and Sedgwick (1997) \\
\hline Salmon-crested cockatoo & Kansas & 1 & Wolf and others (2007). \\
\hline White (umbrella) cockatoo & Ontario & ${ }^{2} 1$ & D.A. Smith, written commun. (2015). \\
\hline
\end{tabular}

\footnotetext{
${ }^{1}$ Cases have been confirmed by the author or cooperating board-certified pathologists, and information and data are on file with the author.

${ }^{2}$ Probable case based on characteristic lesions, clinical signs, and (or) history of exposure; larvae were not found or animals survived.
} 
Table 19. Flightless birds with naturally occurring Baylisascaris neural larva migrans. ${ }^{1}$

[>, greater than]

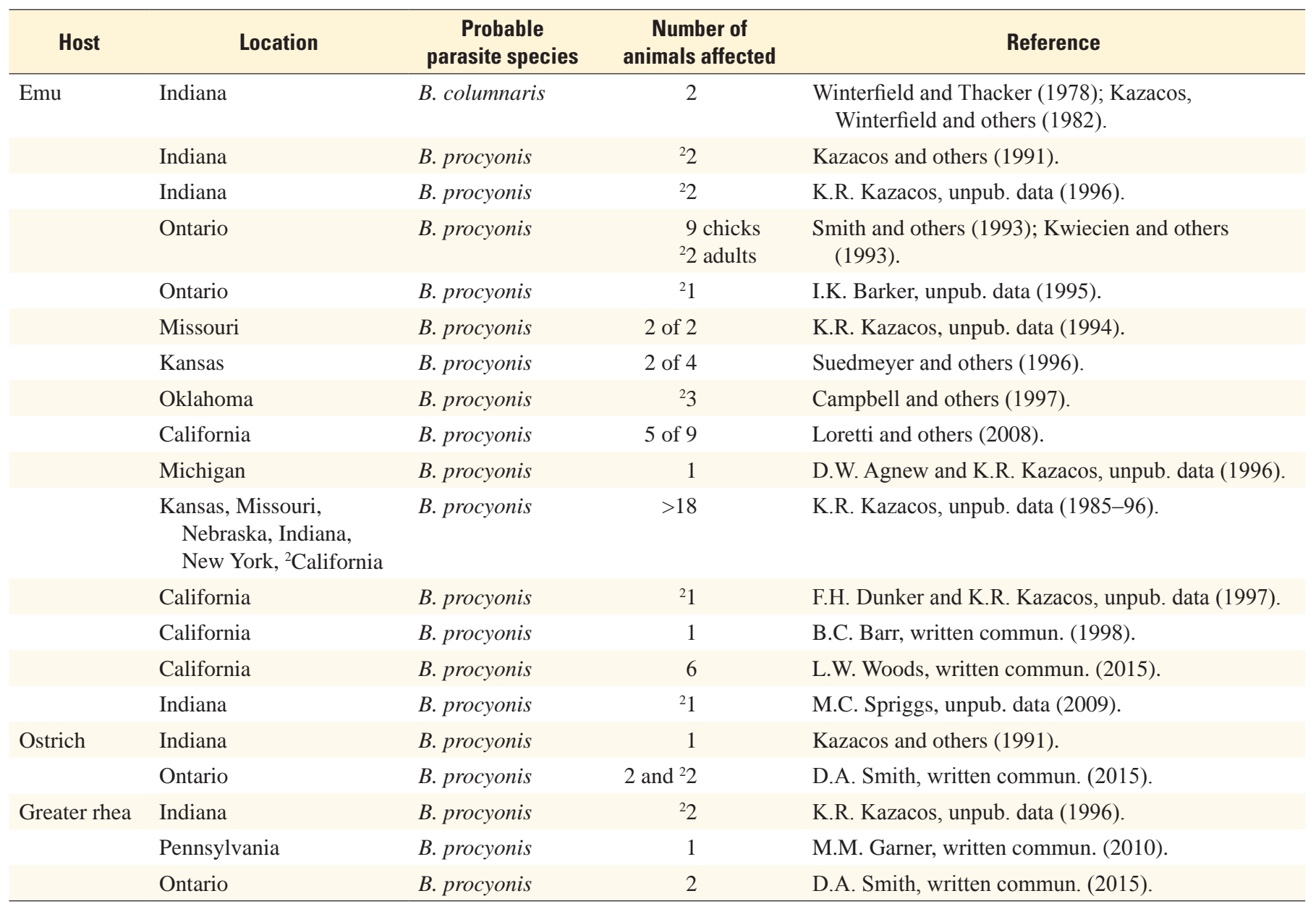

${ }^{1}$ Cases have been confirmed by the author or cooperating board-certified pathologists, and information and data are on file with the author.

${ }^{2}$ Probable case based on characteristic lesions, clinical signs, and (or) history of exposure; larvae were not found or animals survived. 
Table 20. Miscellaneous birds with naturally occurring Baylisascaris neural larva migrans. ${ }^{1}$

[Probable parasite species B. procyonis; >, greater than]

\begin{tabular}{|c|c|c|c|}
\hline Host & Location & $\begin{array}{c}\text { Number of } \\
\text { animals affected }\end{array}$ & Reference \\
\hline \multirow[t]{4}{*}{ Rock pigeon } & Oregon & 10 of 60 & Helfer and Dickinson (1976). \\
\hline & Illinois & 1 & Evans and Tangredi (1985). \\
\hline & British Columbia & 2 & Coates and others (1995). \\
\hline & Nebraska & $>15$ of 200 & E.N. Pendleton and V.W. Rinne, unpub. data (1992). \\
\hline \multirow[t]{4}{*}{ Mourning dove } & New York & 2 & Evans and Tangredi (1985). \\
\hline & Illinois & $>25$ & C.U. Meteyer and others, unpub. data (1992). \\
\hline & Missouri & 1 & R.H. Evans, written commun. (1983). \\
\hline & California & 30 of 81 & Evans (2002). \\
\hline Northern red-billed hornbill & Ontario & ${ }^{2} 1$ & D.A. Smith, written commun. (2015). \\
\hline Speckled mousebird & Ontario & 5 & $\begin{array}{l}\text { D.A. Smith, unpub. data (2006); I.K. Barker, } \\
\text { unpub. data (2006). }\end{array}$ \\
\hline Blue-naped mousebird & Ontario & ${ }^{2} 1$ & I.K. Barker, unpub. data (2006). \\
\hline Barn owl & California & 1 & Evans (2002). \\
\hline
\end{tabular}

${ }^{1}$ Cases have been confirmed by the author or cooperating board-certified pathologists, and information and data are on file with the author.

${ }^{2}$ Probable case based on characteristic lesions, clinical signs, and (or) history of exposure; larvae were not found or animals survived. 
Table 21. Animals experimentally susceptible to Baylisascaris neural larva migrans. ${ }^{1}$

[NR, not reported]

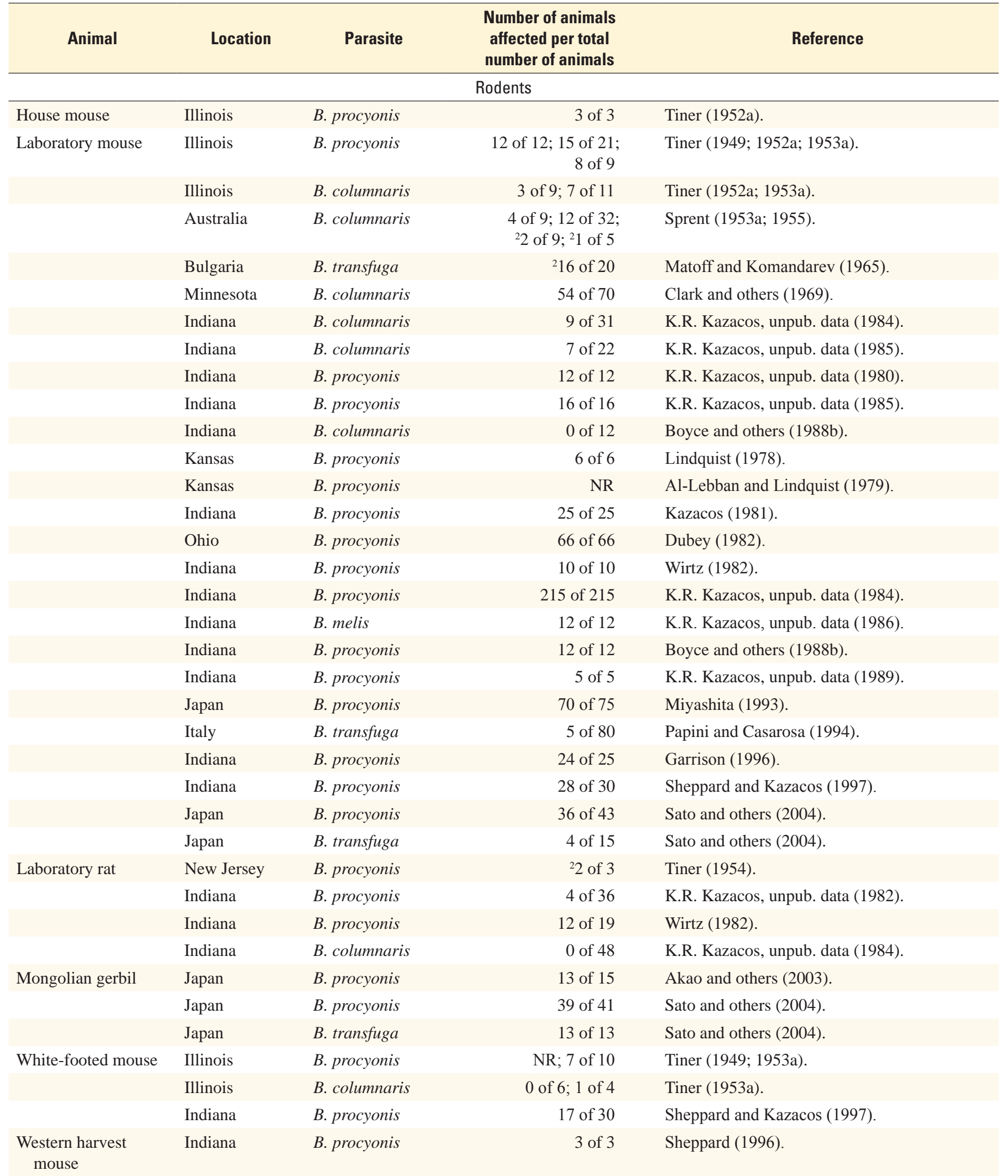


Table 21. Animals experimentally susceptible to Baylisascaris neural larva migrans. ${ }^{1}$ - Continued

[NR, not reported]

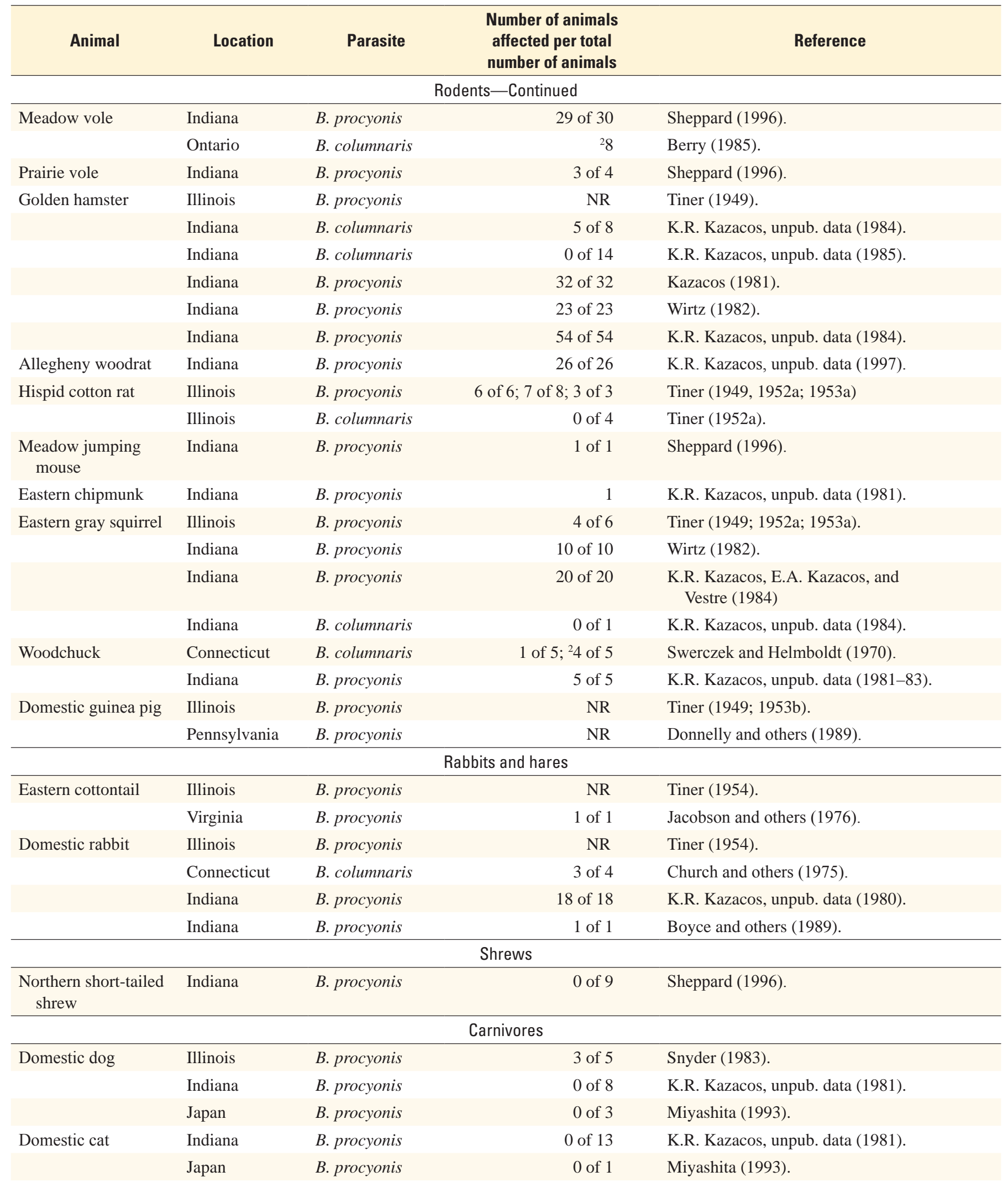


Table 21. Animals experimentally susceptible to Baylisascaris neural larva migrans. ${ }^{1}$ - Continued

[NR, not reported]

\begin{tabular}{|c|c|c|c|c|}
\hline Animal & Location & Parasite & $\begin{array}{l}\text { Number of animals } \\
\text { affected per total } \\
\text { number of animals }\end{array}$ & Reference \\
\hline \multicolumn{5}{|c|}{ Carnivores-Continued } \\
\hline Domestic ferret & Indiana & B. procyonis & 4 of 4 & $\begin{array}{l}\text { Kazacos (1981); E.A. Kazacos and } \\
\text { K.R. Kazacos (1988). }\end{array}$ \\
\hline Least weasel & Indiana & B. procyonis & 1 & K.R. Kazacos, unpub. data (1982). \\
\hline \multirow[t]{2}{*}{ Squirrel monkey } & Indiana & B. procyonis & 4 of 4 & Kazacos, Wirtz and others (1981) \\
\hline & Japan & B. potosis & 0 of 2 & Tokiwa and others (2015). \\
\hline Crab-eating macaque & Indiana & B. procyonis & 4 of 4 & Kazacos, Vestre and Kazacos (1984). \\
\hline Olive baboon & Georgia & B. procyonis & 1 & M.L. Eberhard and others, unpub. data (2002). \\
\hline \multirow[t]{2}{*}{ Domestic chicken } & Indiana & B. procyonis & 17 of 50 & Kazacos and Wirtz (1983). \\
\hline & Italy & B. transfuga & ${ }^{2} 32$ of 35 & Papini and others (1993). \\
\hline Cockatiel & Ontario & B. procyonis & 24 of 27 & Russell (2006). \\
\hline Domestic duck & Indiana & B. procyonis & 8 of 21 & Wirtz (1982). \\
\hline
\end{tabular}

\section{Infecting Dose and Onset of Disease}

B. procyonis is not a parasite that must migrate within or through the nervous system of host animals (that is, it is not neurotropic), and it is estimated that only 5-7 percent of ingested larvae enter the brains of paratenic hosts. Similar to humans, animals with low-level infection will remain asymptomatic if no larvae enter the brain (Kazacos, 2001); however, a single $B$. procyonis larva in the brain of a small mammal or bird is usually fatal (Tiner, 1953a,b; Sheppard and Kazacos, 1997; K.R. Kazacos, unpub. data, 1980-85). In natural cases of clinical NLM, one to five or more larvae are often recovered from the brain during postmortem examination of an animal, and in some cases hundreds to several thousand larvae were present in the brain, due to heavy infection with eggs (Tiner, 1953a; Fox and others, 1985; Armstrong and others, 1989; Van Andel and others, 1995; Lennox and others, 2015). Those larvae migrating in the brain produce traumatic damage and inflammation, resulting in progressive neurologic disease, the onset and severity of which are related to the number of larvae. Animals that are infected with high numbers of larvae may become dull and lethargic and stop eating. Labored breathing and increased respiratory rates develop $2-5$ days following infection (postinfection), due to hemorrhage and inflammation in the lungs caused by larval migration through the lungs (Church and others, 1975; Kazacos, Wirtz, and others, 1981; Wyand-Ouellette and others, 1983; Donnelly and others, 1989; Kazacos, 1997). Although larvae enter the somatic tissues, eyes, and brain of laboratory rodents as early as 3 days postinfection (Tiner, 1953b; Kazacos and others, 1985; Kazacos, 1986), clinical CNS disease is not usually apparent before 9-10 days postinfection, due to the lag time in development of CNS damage and inflammation (Kazacos, 1997; Sheppard and Kazacos, 1997). Infection among animal species also varies, based on apparent differences in larval migration patterns and host responses; for example, the onset of clinical signs was 20-21 days postinfection, on average, in white-footed mice compared with 9-14 days postinfection in white laboratory mice, and fewer larvae were recovered from the anterior carcass, head, and brain and more from the abdominal and thoracic viscera of white-footed mice (Sheppard, 1995; Sheppard and Kazacos, 1997). Nonetheless, single larvae entering the brains of white-footed mice produced fatal NLM. In larger animals, signs may not become apparent until at least 2-4 weeks postinfection, which is related to the animals' larger brain sizes and the greater infective dose needed to cause clinical disease. If the larvae leave the brain proper and (or) become encapsulated, clinical signs may abate or stabilize and the animal can survive and function, albeit with variable CNS deficits depending on the location and severity of migration damage. 


\section{Clinical Signs}

Clinical signs in rodents and other small mammals are directly related to systemic migration and CNS damage (table 22; fig. 9; fig. 10; fig. 11). A 12-week-old beagle puppy was lethargic, had progressive rear-limb weakness, and was unable to swallow, circled, fell onto its side, and was apparently blind. Its condition worsened rapidly; it developed a severe head tilt, lay on its side, became stuporous, and paddled its legs aimlessly (Rudmann and others, 1996). Similar signs were seen in experimentally infected squirrel monkeys (Kazacos, 2001; Kazacos, Wirtz, and others, 1981), and matched those seen in naturally infected nonhuman primates and children with Baylisascaris (Huff and others, 1984; Fox and others, 1985; Huntress and Spraker, 1985; Kazacos, 1996b, 2000, 2001; Campbell and others, 1997; Ball and others, 1998). Mildly affected nonhuman primates showed only subtle forelimb tremors or stumbling (C.L. Eng and K.R. Kazacos, unpub. data, 1997) or had slight head tilts and incoordination (ataxia) (Pessier and others, 1997), indicating low-level and (or) more covert infection, a possibility that should be considered more often in the diagnosis of humans with this infection.

Table 22. Clinical signs of Baylisascaris neural larva migrans in small mammals.

[Compiled from Church and others (1975); Kazacos (2001); Kazacos and Boyce (1989); Sheppard and Kazacos (1997); Wirtz (1982); and various case reports]

Initial clinical signs

Decreased activity.

Depression or nervousness.

Rough hair coat.

Tremors in the front paws.

Slight head and (or) body tilts.

Circling or jumping when disturbed.

\begin{tabular}{l} 
Worsening clinical signs; various combinations of: \\
\hline Severe head and (or) body tilts. \\
Slow arching of the head and neck with “stargazing.” \\
Extension and rigidity of the forelimbs. \\
Motor weakness. \\
Incoordination (ataxia). \\
Continuous circling. \\
Leaning and (or) falling over. \\
Arching of the body. \\
Lying on the side (lateral recumbency). \\
Paddling movements while lying down. \\
Rolling. \\
Blindness. \\
Rapid eye movements. \\
Coma. \\
Death.
\end{tabular}

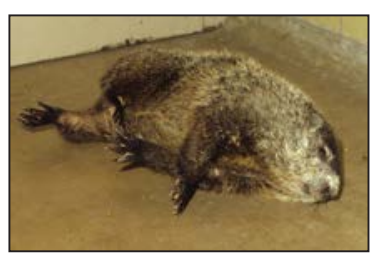

Woodchuck lying on its side and paddling its forelimbs. (Photo by Kevin Kazacos and Sam Royer)

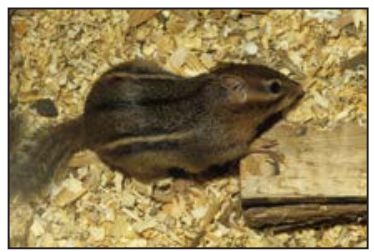

Chipmunk with head tilt. (Photo by Kevin Kazacos and Sam Royer)

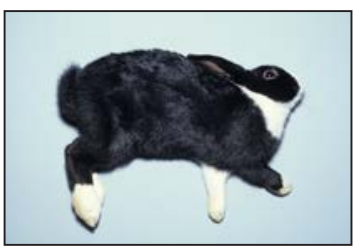

Domestic rabbit with arching of the head and neck. (Photo by Kevin Kazacos and Sam Royer)

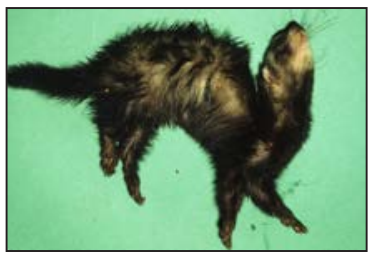

Ferret with arching of the body and head and extension of its forelimbs. (Photo by Kevin Kazacos and Sam Royer)

Figure 9. Mammals affected with Baylisascaris procyonis neural larva migrans.

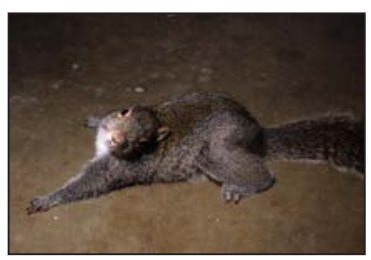

Gray squirrel with severe head tilt and extension of its forelimbs. (Photo by Kevin Kazacos and Sam Royer)

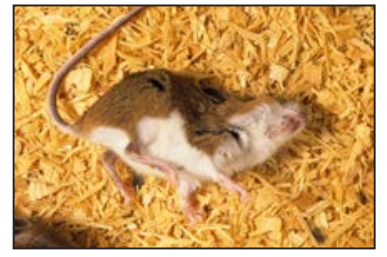

White-footed mouse recumbent on its side with head tilt and rigidity of its forelimbs. (Photo by Claudia Sheppard)

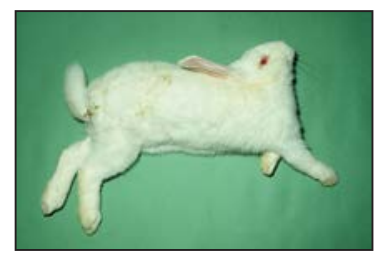

Domestic rabbit with arching of the head and neck and extension of its forelimb. (Photo by Kevin Kazacos and Sam Royer)

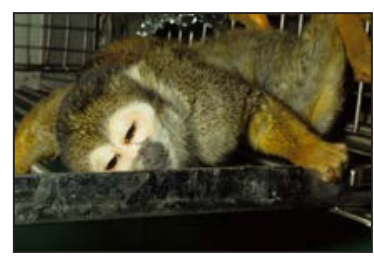

Squirrel monkey lying prostrate and semicomatose. (Photo by Kevin Kazacos and Sam Royer) 

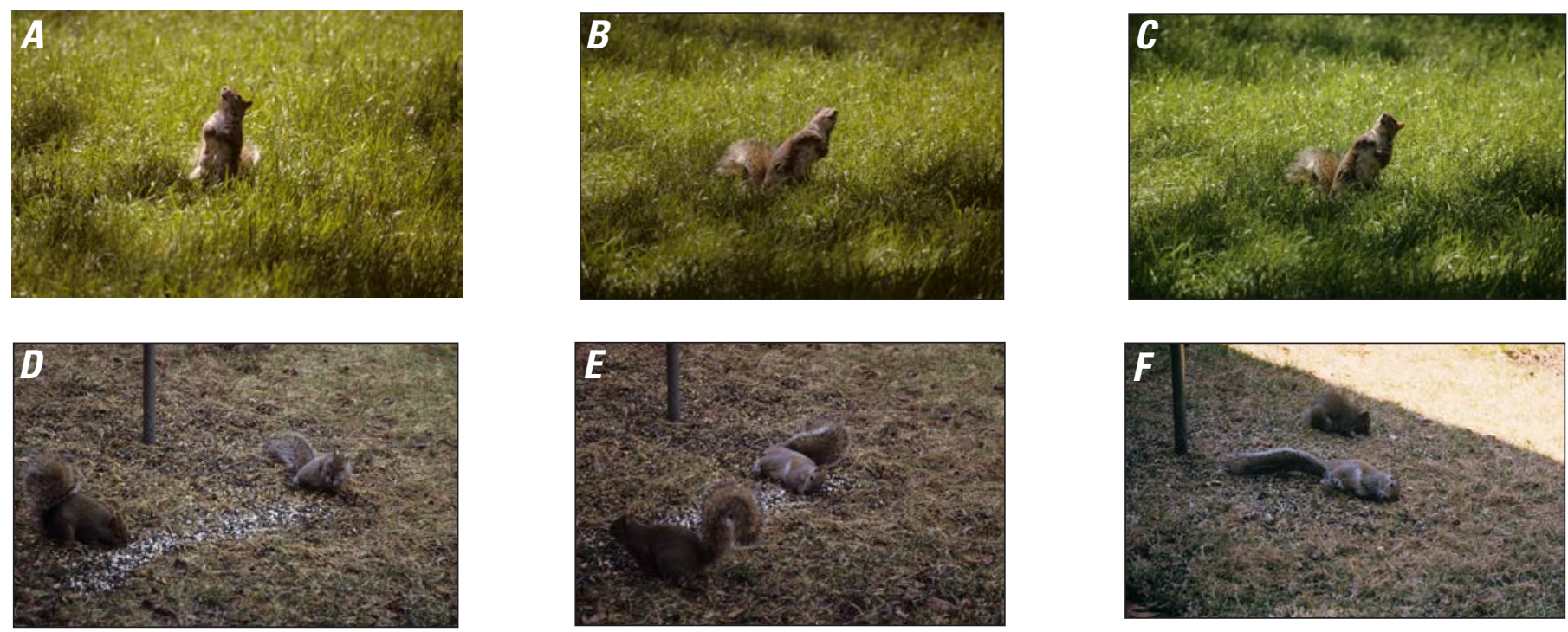

Figure 10. The sequence of clinical neural larva migrans in a wild gray squirrel. $A, B, C$, The slow arching of the head and neck with "stargazing"' progressing to leaning of the body. $D$, The squirrel with a wide stance, trying to steady itself while eating a sunflower seed. $E, F$, The squirrel has fallen over, lying on its side while continuing to eat the seed. (Photos by Kevin Kazacos)

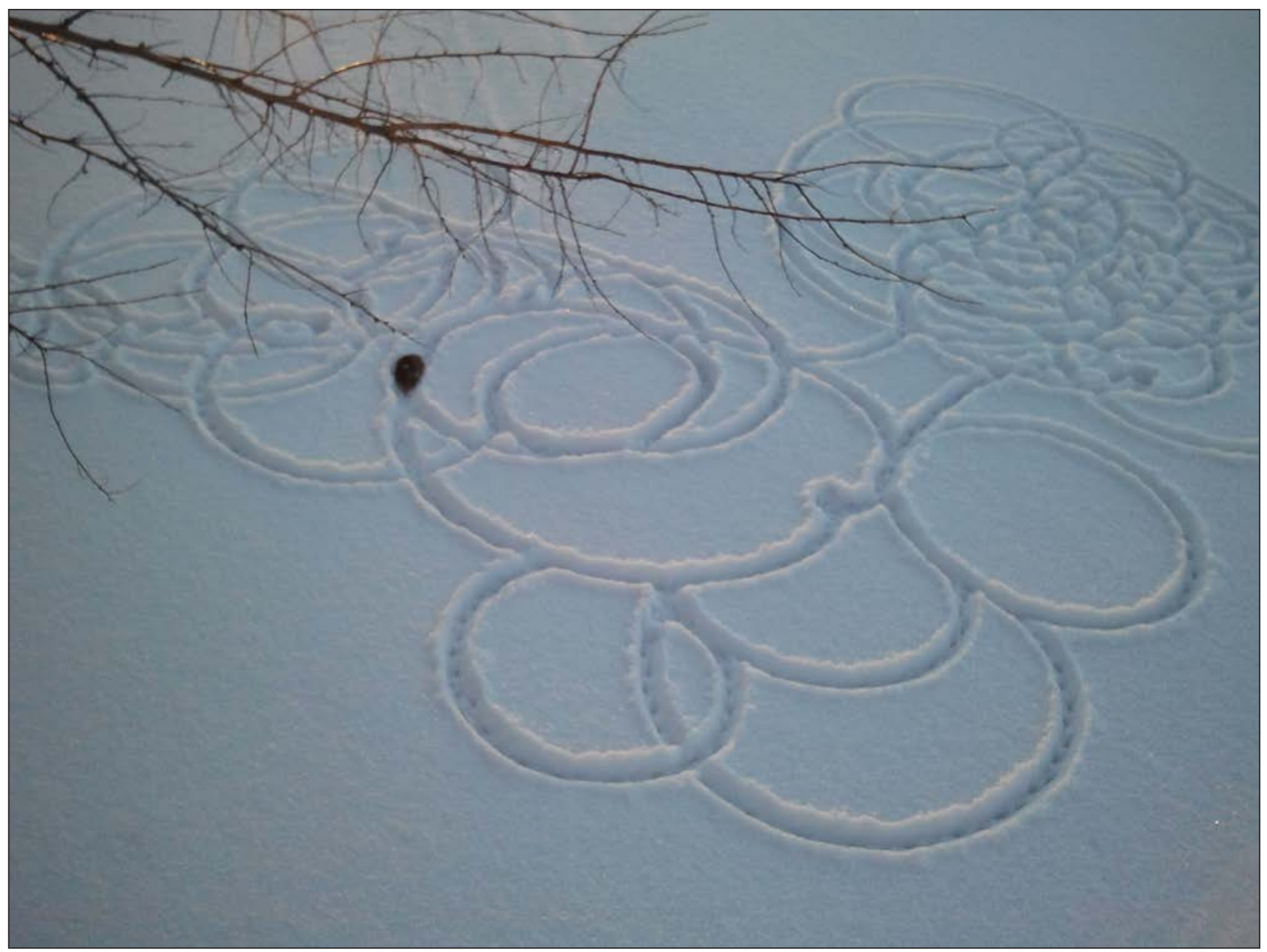

Figure 11. Abnormal circling behavior of a mouse or vole (dead in photo) in the snow along the Bighorn River near Worland, Wyoming, likely caused by Baylisascaris neural larva migrans. (Photo by David G. Frahm) 
Clinical signs in birds are similar to those seen in mammals (table 23; fig. 12). Clinically affected ostriches and emus show varying degrees of incoordination, with loss of equilibrium and balance, muscle weakness, wobbling, and progressive ataxia. An infected ostrich typically staggers, walks in circles, assumes a wide, splay-legged stance with its head extended downward for balance, and walks rapidly backward, stumbling and falling; eventually it is unable to stand or walk and becomes increasingly emaciated (Kazacos, Fitzgerald, and Reed, 1991; Kwiecien and others, 1993; Suedmeyer and others, 1996). It is quite impressive that this degree of clinical disease in a large bird such as an ostrich can be caused by one or two Baylisascaris larvae in the brain; however, despite its large body size, an ostrich's brain is relatively small and suffers considerable damage.

Table 23. Clinical signs of Baylisascaris neural larva migrans in birds.

[Compiled from Coates and others (1995); Kazacos ( 2001); Kazacos and Wirtz (1983); Kazacos and others (1991); Kwiecien and others (1993); A. M. Lennox and others, unpub. data (1996); Richardson and others (1980); Reed and others (1981); Russell (2006); Russell and others (2005); Wirtz (1982)]

\begin{tabular}{l}
\hline$\quad$ Various combinations of: \\
\hline Ruffled feathers. \\
Disorientation. \\
Head tremors or bobbing. \\
Twisted neck. \\
Inability to stand. \\
Muscle weakness and (or) tremors. \\
Rigidity of the legs. \\
Blindness. \\
Vocalizations. \\
Poor grip reflexes. \\
Incoordination. \\
Loss of balance. \\
Walking in circles. \\
Falling. \\
Rolling. \\
Inability to fly or loss of flight control. \\
Paralysis of one or both wings or legs. \\
Lying on the side with eyes closed. \\
Death.
\end{tabular}

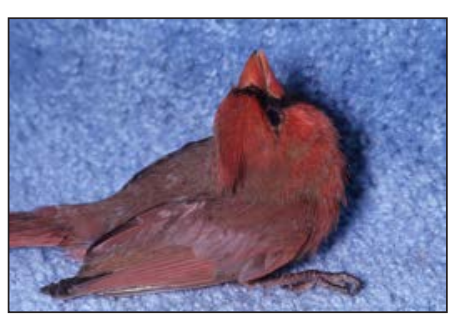

Cardinal with twisted neck. (Photo by Kevin Kazacos and Sam Royer)

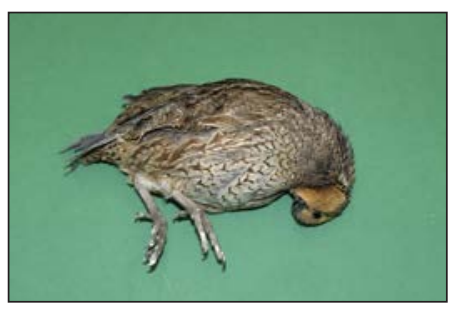

Bobwhite with twisted neck, ruffled feathers, and rigidity of the feet. (Photo by Kevin Kazacos and Andy Dziubinskyj)

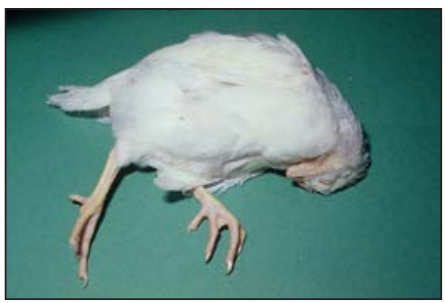

Domestic chicken with twisted neck and rigidity of the legs. (Photo by Kevin Kazacos and Sam Royer)

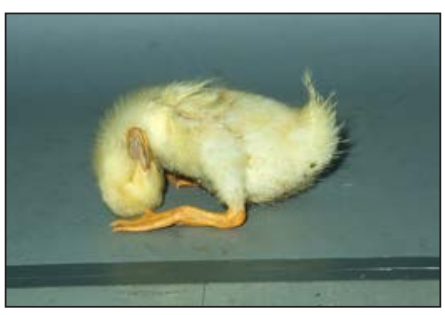

Domestic duck with twisted neck and inability to stand. (Photo by Kevin Kazacos and Sam Royer)

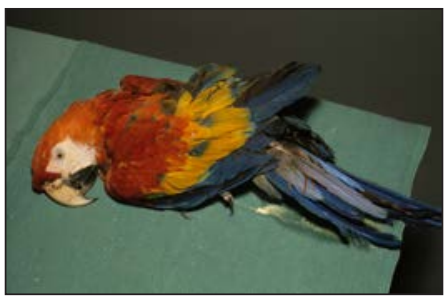

Blue and gold macaw unable to stand or hold its head up. (Photo by Kevin Kazacos and Sam Royer)

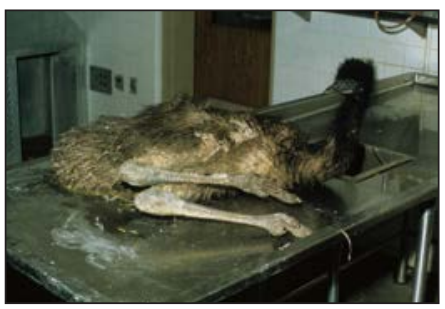

Emu (with $B$. columnaris) unable to stand or use its legs. (Photo by Sam Royer)

Figure 12. Birds affected with Baylisascaris procyonis neural larva migrans. 


\section{Granuloma Formation}

Following migration in mammals, larvae become encapsulated in various tissues in well-circumscribed granulomas (fig. 13). Larval granulomas are white, easily visible (1-3 millimeters in diameter) and are found in many organs and tissues, including the skeletal muscles, liver, lungs, heart, diaphragm, pancreas, spleen, kidneys, abdominal lymph nodes, intestinal wall and connective tissue, brain, and eyes (Sprent, 1952a; Kazacos, Wirtz, and others, 1981; Kazacos, 1986, 1997, 2001; Sato and others, 2004). The development and (or) distribution of $B$. procyonis larval granulomas varies somewhat with animal species, but they are generally found in these locations in all types of infected mammals during necropsy examinations for this infection (Sheppard and Kazacos, 1997; Kazacos, 2001; Sato and others, 2004) (table 24).

On the other hand, gross lesions typically are not found during necropsies of birds, and tissue alterations are usually confined to the brain, especially within the cerebellum (Kazacos and Boyce, 1989; Kazacos, 2001). No larval granulomas were found grossly in experimentally infected chickens and ducks, and only a single granuloma was seen in an outer muscle of the eye during microscopic examination of tissue (Wirtz, 1982). Solitary larval granulomas were also found in the lungs of a naturally infected brushturkey and bobwhite (Kazacos, Kazacos, and others, 1982; Williams and others,
1997). The comparative lack of gross lesions and scarcity of larval granulomas in birds with Baylisascaris NLM has been reported in numerous natural cases and outbreaks (Richardson and others, 1980; Reed and others, 1981; Myers and others, 1983; Evans and Tangredi, 1985; Armstrong and others, 1989; Kazacos and others, 1991; Kwiecien and others, 1993; Russell and others, 2005; Russell, 2006; Lennox and others, 2015). In most clinical cases of NLM in birds, including large flightless birds, few or no larvae are found in somatic or visceral tissues, even though one to three larvae are found in the brain. Thus, most cases in birds appear to involve low-level infections and a higher probability of larval migration to the brain. However, much higher infection levels have occasionally been documented in the somatic tissues and viscera of birds. In an outbreak involving a mixed collection of parrots and conures, 17-150 (mean, 87) B. procyonis larvae were recovered from the brains and 47-285 (mean, 173) larvae from the viscera and carcasses of 6 birds dying from rapid onset, severe CNS disease (Lennox and others, 2015); no gross lesions or larval granulomas were seen during necropsy. This difference in the reaction of birds, compared to mammals, may be related to differences in immune system recognition of larvae or their products and (or) mobilization of different types of inflammatory cells, including those involved in granuloma formation; it is well known that inflammation involving multiple types of cells in the brains of birds can be quite intense.

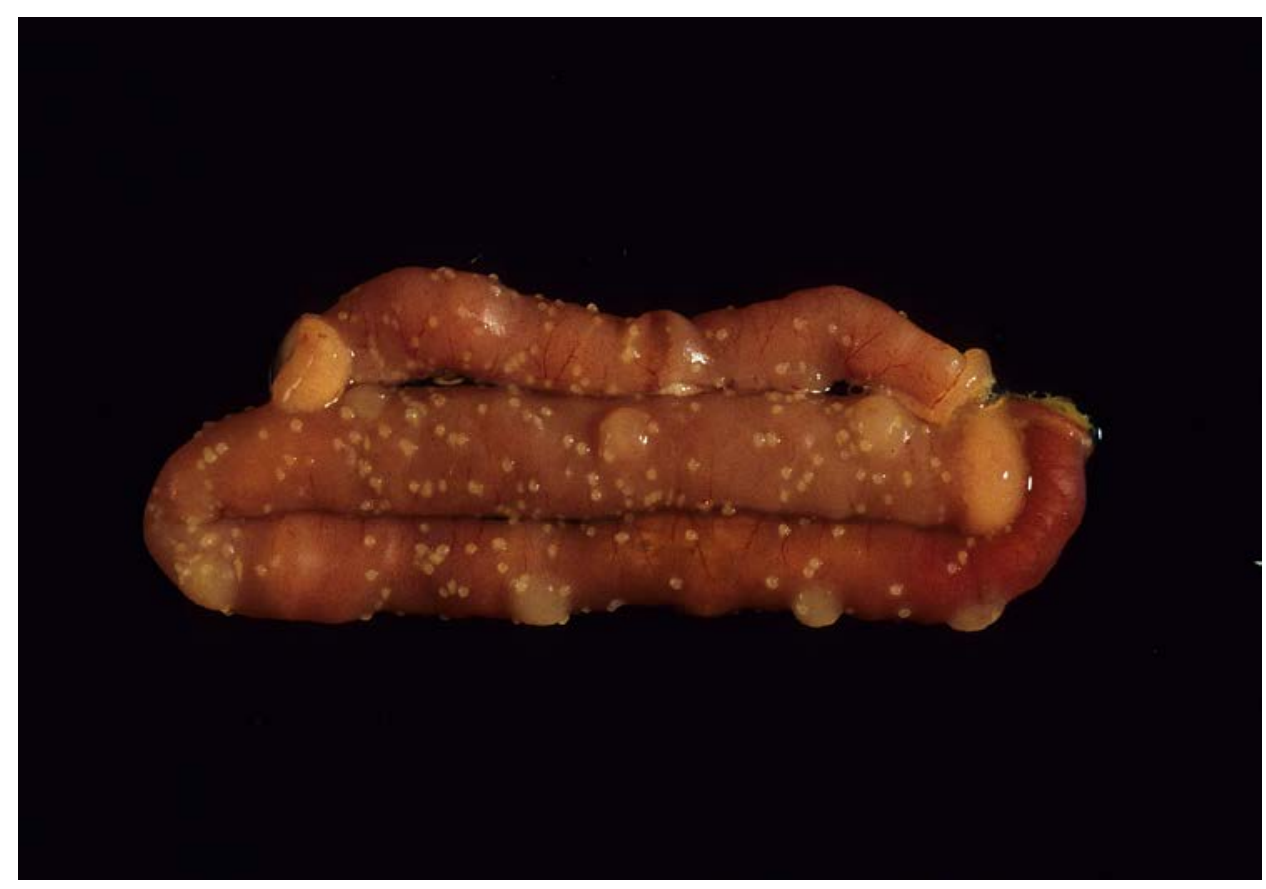

Figure 13. Larval granulomas on the intestinal tract of a hamster with $B$. columnaris neural larva migrans. (Photo by Kevin Kazacos and Sam Royer) 
Table 24. Examples of locations of Baylisascaris larval granulomas in mammals.

\begin{tabular}{|c|c|c|}
\hline Animal & Body sites & References \\
\hline $\begin{array}{l}\text { Mice and other } \\
\text { small rodents }\end{array}$ & $\begin{array}{l}\text { Heart surfaces and muscle, lungs, diaphragm, and } \\
\text { skeletal muscles especially front end of the car- } \\
\text { cass, along the intestinal tract, other locations }\end{array}$ & $\begin{array}{l}\text { Tiner (1953a,b); Kazacos (2001); Sheppard and } \\
\text { Kazacos (1997); Wirtz (1982). }\end{array}$ \\
\hline Gray squirrel & $\begin{array}{l}\text { Wall of the veins that return blood to the heart, the } \\
\text { heart, lungs, diaphragm, intercostal muscles and } \\
\text { other skeletal muscles, along the intestinal tract, } \\
\text { other locations }\end{array}$ & $\begin{array}{l}\text { Tiner (1953a); Kazacos (2001) and unpub. } \\
\text { data (1984); Wirtz (1982). }\end{array}$ \\
\hline Rabbit & $\begin{array}{l}\text { Heart, lungs, diaphragm, liver, mesentery (the } \\
\text { membrane that envelops the intestines), along the } \\
\text { intestinal tract, skeletal muscles, other locations }\end{array}$ & $\begin{array}{l}\text { Church and others (1975); Kazacos (2001); } \\
\text { Kazacos and others (1983); Nettles and others } \\
\text { (1975); K.R. Kazacos, unpub. data (1985). }\end{array}$ \\
\hline Monkey, lemur, marmoset & $\begin{array}{l}\text { Heart and great vessels, lungs, diaphragm, liver, } \\
\text { stomach wall, mesentery, along intestinal tract, } \\
\text { intercostal muscles, other skeletal muscles, } \\
\text { other locations }\end{array}$ & $\begin{array}{l}\text { Kazacos (2001); Kazacos, Wirtz and others (1981); } \\
\text { K.R. Kazacos, unpub. data (1998); K.R. Kazacos } \\
\text { and P.L. Wolff, unpub. data (1986). }\end{array}$ \\
\hline
\end{tabular}

\section{Obtaining a Diagnosis}

Diagnosis of Baylisascaris larva migrans in animals or humans is based on a combination of clinical, laboratory, and pathologic findings. Of these, only identification of larvae in or from the tissues is a confirmed diagnosis, although positive serology would indicate infection (Kazacos, 2001).

Unlike the situation in animals, relatively few clinical cases of Baylisascaris NLM in humans have been documented in North America and elsewhere, making physicians less likely to consider this dangerous pathogen in the diagnoses of their patients. Most documented human cases involved heavy infections and severe clinical signs, and it is likely that cases of lower level infection with more subtle or nonspecific signs are routinely missed. The disease consequences of $B$. procyonis infection are so important that it simply must be considered in cases of neurologic disease in children as well as cases of eye disease in all age groups, especially those involving eosinophilic meningoencephalitis and DUSN, respectively.
Diagnosis of adult Baylisascaris infection in raccoons, skunks, dogs, kinkajous, or other species is based on identification of their eggs in the feces by using fecal flotation methods, identification of worms passed by the animal, or necropsy and examination of the small intestinal contents for the worms (Kazacos, 2001, 2006; Page and others, 2005). Young animals and occasionally others may be infected but not pass eggs in their feces, based on the presence of developing worms that are still immature and not yet shedding eggs; this is a so-called prepatent infection (Kazacos and Boyce, 1989). These animals still pose a threat to others, because as the worms mature, they will proceed to egg shedding in a few days to weeks, leading to contamination of the environment. Raccoons and probably other definitive hosts may also have intermittent and uneven egg shedding, related to the intensity of infection and (or) the age of worms present (Reed and others, 2012). 


\section{Diagnosis of Baylisascaris Neural Larva Migrans}

Diagnosis of Baylisascaris neural larva migrans (NLM) in animals or humans is based on a combination of clinical signs, a history of exposure to the parasite, and results of serology, imaging, and other diagnostic tests, as well as postmortem gross and histopathologic lesions. However, only identification of larvae in or from the tissues provides a confirmed diagnosis (Huff and others, 1984; Kazacos, Vestre, Kazacos, and Raymond, 1984; Kazacos, Vestre, and Kazacos, 1984; Kazacos, Raymond, and others, 1985; Fox and others, 1985; Kazacos, 1991, 1997, 2000, 2001; Goldberg and others, 1993; Murray and Kazacos, 2004; Gavin and others, 2005).

\section{Cerebrospinal Fluid Analysis}

Diagnosis of Baylisascaris NLM in ill humans or animals depends on an assessment of clinical signs, compatible exposure history, serology, and evidence of white blood cells called eosinophils in the cerebrospinal fluid (CSF), so-called eosinophilic pleocytosis, which often will accompany increased numbers of eosinophils in the blood (Kazacos, 2000, 2001; Murray and Kazacos, 2004; Gavin and others, 2005; Windsor and others, 2009; Kazacos and others, 2013). Eosinophil numbers appear to be higher in the CSF during acute disease, and their levels are related to the amount of damage and eosinophilic inflammation caused by the migrating larvae. In humans with severe NLM, so many eosinophils are in the central nervous system (CNS) that toxic eosinophil-derived proteins are released into brain tissue (Hamann and others, 1989). These proteins have been isolated directly from the CSF of affected children (Moertel and others, 2001), and they appear to be important contributors to the neurologic pathology and clinical signs associated with the infection. Similar proteins are likely released into the CNS of animals with NLM (Kazacos, 2001) and into the eye in cases of ocular larva migrans (OLM-DUSN) (Kazacos, 1996a).

\section{Imaging Methods}

Medical imaging techniques, including computed tomography (CT) and magnetic resonance imaging (MRI), are useful for assessing the amount of brain damage and postinfection atrophy associated with Baylisascaris and for locating lesions in particular areas of the brain or spinal cord in humans (Huff and others, 1984; Fox and others, 1985; Cunningham and others, 1994; Rowley and others, 2000; Kelly and others, 2009, 2012; Peters and others, 2012) and animals (Ball and others, 1998; Hanley and others, 2006). Baylisascaris NLM in children is usually associated with localized or widespread brain lesions deep in the white matter that are shown by MRI (A). MRI showed a large lesion in the frontal cortex of a gibbon (Ball and others, 1998) and involvement of deep central white matter in an orangutan with NLM (Hanley and others, 2006).

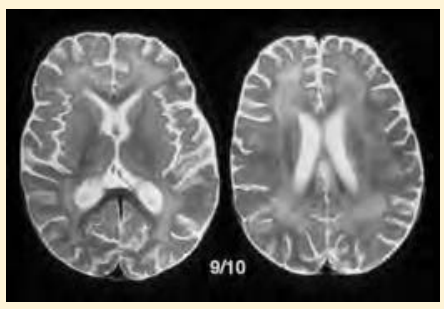

A. Magnetic resonance images of the brain of a child affected by Baylisascaris NLM, showing widespread deep white matter abnormalities. (Image by Howard A. Rowley)

\section{Serology}

Serologic methods including indirect immunofluorescence, Western blotting, and enzyme-linked immunosorbent assay (ELISA), using culture-derived or recombinant DNA-generated larval excretory-secretory (ES) antigens, are very useful for diagnosing Baylisascaris NLM in humans (Boyce and others, 1988a,b; 1989; Conraths and others, 1996; Moertel and others, 2001; Kazacos, 2001; Dangoudoubiyam and Kazacos, 2009; Dangoudoubiyam and others, 2010, 2011; Rascoe and others, 2013). The ES antigen ELISA has been used as a screening test, and even though it is known to cross-react with Toxocara spp. and some other parasites, the geographical distribution and epidemiology of most other causes of eosinophilic meningitis (except for Toxocara spp.) do not overlap with Baylisascaris NLM (Rowley and others, 2000). Further identification and (or) confirmation is done using the recombinant ES antigen ELISA and (or) Western blotting, which can separate Baylisascaris from Toxocara infection based on greater specificity and the recognition of specific ES proteins, respectively (Dangoudoubiyam and Kazacos, 2009; Dangoudoubiyam and others, 2010, 2011). The screening ELISA showed that 8 percent of 389 nonclinical 1-to-4-year-old Chicago children were seropositive for Baylisascaris infection (Brinkman and others, 2003), as were 29 percent of 259 nonhuman primates at 6 major zoos (Zimmerman and others, 2010).

The current "gold standard" for serologic diagnosis in humans involves Western blotting using the recombinant ES antigen (Dangoudoubiyam and others, 2010; Rascoe and others, 2013), which is highly sensitive and specific. Testing is available at the Centers for Disease Control and 


\section{Diagnosis of Baylisascaris Neural Larva Migrans}

Prevention in Atlanta, Georgia, and the National Reference Centre for Parasitology in Montreal, Canada. By use of this assay, 7 of 43 nonclinical raccoon trappers from Georgia were seropositive for B. procyonis infection (C.A. Hall and others, unpub. data, oral commun., 2014). Better data on human seroprevalence will be obtained when the recombinant ES antigen Western blot is used to test blood samples from a wide segment of the population. Such methods could also be developed and applied to diagnosing NLM in various animal species.

\section{Necropsy and Tissue Collection}

Noncarnivorous animals suffering from neurologic disease should be captured if possible and submitted alive to a veterinary diagnostic laboratory with a request to examine them for Baylisascaris in addition to other causes. Dead animals should be submitted promptly, unless a field necropsy is done.

For Baylisascaris NLM, because most larvae are encapsulated in granulomas in various parts of the body other than the brain, tissues should be searched for these and representative samples collected and preserved. Baylisascaris larvae can be dissected from these granulomas and identified microscopically, thereby aiding in the diagnosis of $\operatorname{NLM}(B, C)$.

\section{Histopathology}

Many diagnostic laboratories rely heavily on histopathology for disease diagnosis, but this has important limitations in the diagnosis of Baylisascaris larva migrans. Even in clinically affected animals, only a few (one to five) larvae may be present in the brain (Armstrong and others, 1989). In such cases, finding a larva in histopathologic

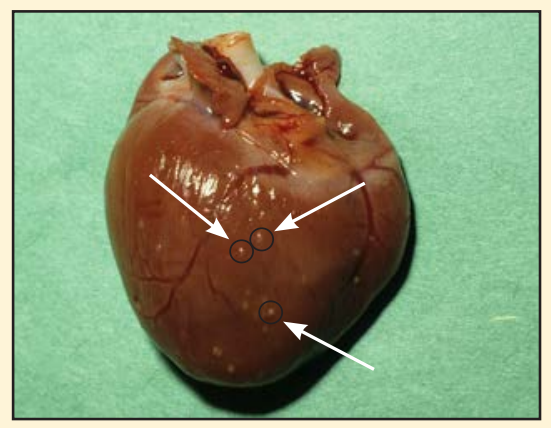

B. Baylisascaris larval granulomas (arrows) on the heart of a woodchuck with NLM. (Photo by Kevin Kazacos and Sam Royer) sections is a matter of chance, which will increase when either more larvae are present or more slides are examined (Kazacos, 1997, 2001). Often, however, histopathologic lesions compatible with Baylisascaris migration are seen, and a tentative or probable diagnosis is made in the absence of identified larvae.

\section{Larval Isolation}

Brain tissue can be processed in various ways to find larvae, including by squash techniques, Baermann funnel preparations, or digestion (Kazacos, 2001). Other tissues (heart, lung, etc.) can also be processed for larvae by digestion. These methods are particularly useful if multiple affected animals are available for examination. In the brain squash method, small pieces (approximately 1 gram) of tissue are placed between two glass plates and pressed out until they are very thin (Kazacos, 2001) ( $D$, $E$ ). The preparation is then examined under a dissecting microscope and searched for the presence of whole living larvae in the tissue $(F, G)$, which are then recovered $(H)$. Although it is time consuming for a large brain, this method works extremely well for small brains and will find single larvae if present. Brain tissue can also be finely minced and placed on cheesecloth in a Baermann funnel in warm saline or water, and larvae can be collected after a few hours or overnight (Richardson and others, 1980; Reed and others, 1981; Fox and others, 1984; Kazacos, 2001). A drawback of this technique is that not all larvae may make it out of the tissue and down through the funnel, so in light infections they may be missed, but the method is particularly useful if multiple affected animals are examined. Finally, artificial digestion of blended or finely minced tissues by using a pepsin:hydrochloric acid mixture, followed by filtering and settling, is a very efficient method of larval recovery, especially for muscle tissue or viscera (Kazacos, 2001).

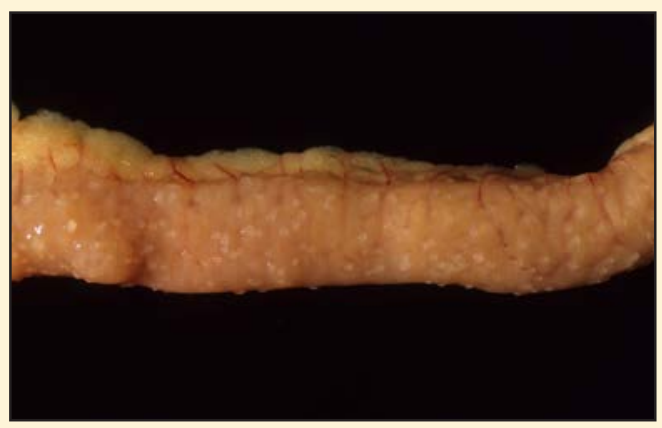

C. Larval granulomas on the intestinal tract of a marmoset with B. columnaris NLM. (Photo by Kevin Kazacos) 


\section{Diagnosis of Baylisascaris Neural Larva Migrans}

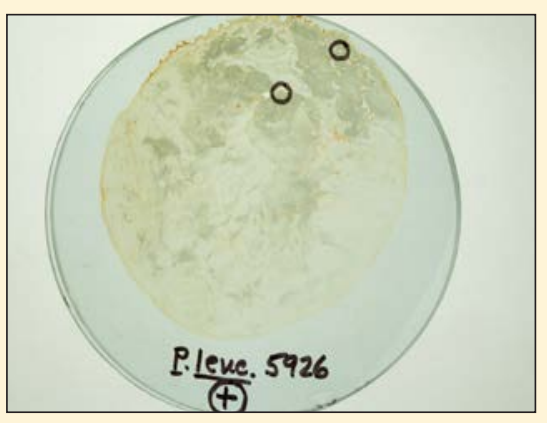

D. Brain squash of a white-footed mouse with two Baylisascaris larvae in the brain (circles). (Photo by Kevin Kazacos and Sam Royer)

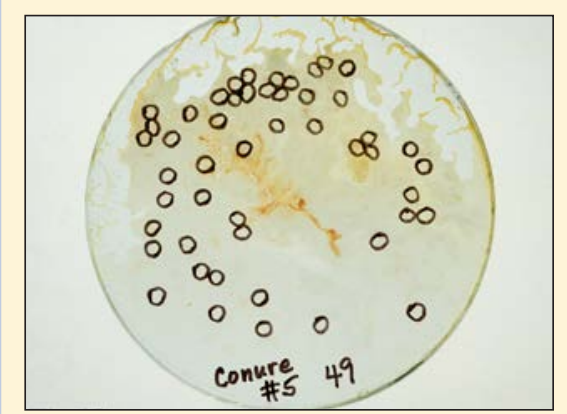

E. Brain squash of a conure with severe NLM, showing 49 larvae (circles) in about one-third of its brain. (Photo by Kevin Kazacos and Sam Royer)

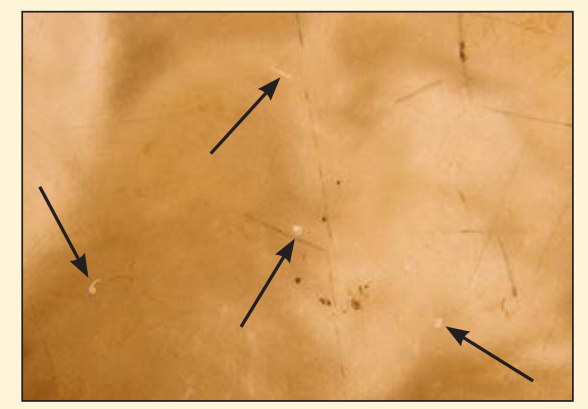

F. Positive brain squash from a conure showing multiple larvae (arrows). (Photo by Kevin Kazacos and Sam Royer)

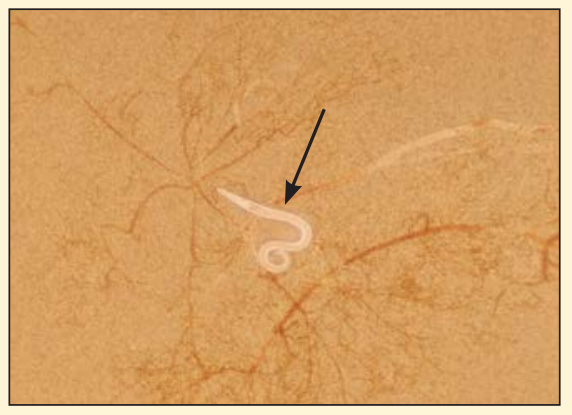

$G$. Higher magnification of conure brain squash showing $B$. procyonis larva (arrow). (Photo by Kevin Kazacos and Sam Royer)

\section{Molecular Analysis}

Recently, the complete sequence of DNA contained in the mitochondria, energy producing structures within cells, of $B$. procyonis was determined using polymerase chain reaction (PCR) methodologies (Xie and others, 2011). Diagnostic PCR tests were also developed for Baylisascaris, and they can identify the parasite's eggs in environmental samples or animal feces, as well as larvae recovered from paratenic host tissues or even in a single histopathologic section (Dangoudoubiyam and others, 2009; Gatcombe and others, 2010; Jimenez Martinez and others, 2015). Standard PCR methods can distinguish $B$. procyonis from other parasites, including $B$. transfuga, but the tests do not distinguish $B$. procyonis from $B$. columnaris, which indicates how closely related these two species are (Kazacos, 2001; Dangoudoubiyam and others, 2009; Gatcombe and others, 2010). These two species can, however, be separated by DNA sequencing (Nadler and others, 2010; Franssen and others, 2013), but these methods are not used routinely in assessing cases or outbreaks. Therefore, epidemiologic evidence of exposure to raccoons, skunks, or other animals and their feces remains very important for determining which Baylisascaris species is involved in a case or outbreak (Kazacos, 2001). Molecular methods are also being used in phylogenetic studies of the parasite (Nadler and Hudspeth, 2000; Nadler and others, 2010) and for genetic characterization and species identification of specimens recovered from raccoons (Blizzard, Davis and others, 2010; Blizzard, Yabsley and others, 2010) and other hosts (Tokiwa and others, 2014). As molecular methods become more widely available, they will increasingly be used to identify particular Baylisascaris species involved in clinical cases and outbreaks (Sato and others, 2004; Dangoudoubiyam and others, 2009).

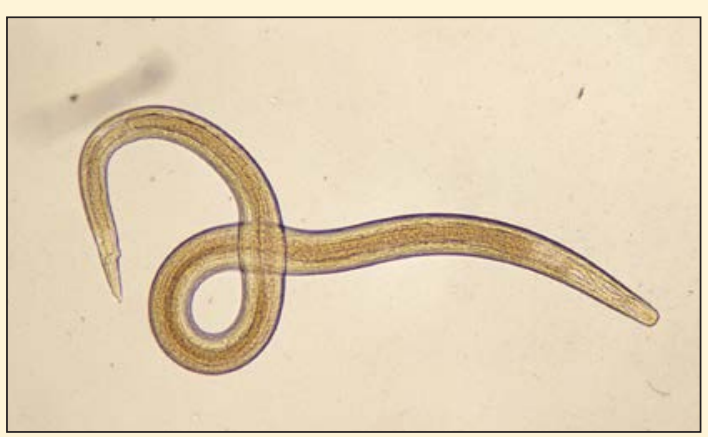

H. B. procyonis larva recovered from brain squash of conure with NLM. (Photo by Kevin Kazacos and Sam Royer) 


\section{Disease Ecology}

The disease ecology of Baylisascaris larva migrans is straightforward, in that humans and animals become infected through accidentally ingesting infective eggs from the environment (Kazacos, 2001) (figs. 8 and 14). Thus, the ecology of the disease is directly related to the interaction of humans and animals with raccoons or other definitive hosts contaminating the environment, and in particular with their feces containing infective eggs. The longevity and resistance of infective eggs in the environment is the key feature in the transmission of baylisascariasis, because it ensures eventual contact and accidental ingestion of the eggs by animals or humans and the production of larva migrans.

In nature, the ability of $B$. procyonis to produce CNS disease in paratenic hosts has great survival value for the parasite, because altered behavior, debilitation, or death of paratenic hosts results in increased transmission of $B$. procyonis back to raccoons when they prey on infected smaller animals or scavenge infected carcasses (Tiner, 1953a,b; Kazacos and Boyce, 1989; Sheppard and Kazacos, 1997; Kazacos, 2001). Raccoons are opportunistic carnivores, and it is likely that the increased pathogenicity of B. procyonis in paratenic hosts has been beneficial for the survival of $B$. procyonis over time, because of its importance in facilitating transmission and completion of the life cycle (Kazacos, 2001).

Because most $B$. procyonis eggs are found associated with raccoon latrines, contact and interaction of humans and animals with these sites is of considerable importance for transmission of the parasite (Page, 1998, 2013; Page and others, 1998, 1999, 2001a,b,c; Page, Anchor, and others, 2009; Kazacos, 2001; Smyser and others, 2010). In fact, raccoon latrines are central to the epidemiology and disease ecology of $B$. procyonis larva migrans, because they are the most dangerous areas for transmission of the parasite to humans and animals (Kazacos, 2001). Contact with other areas or articles contaminated with raccoon feces also poses a risk (fig. 14), as does contact with fecal material from dogs, skunks infected with B. columnaris, or other animals infected with Baylisascaris spp.. It is known that multiple raccoons will use a particular latrine and that individual raccoons will visit multiple latrines in their area (Hirsch and others, 2014). This ensures contamination of latrines with $B$. procyonis eggs and increases the risk of infection of paratenic hosts from latrine sites.

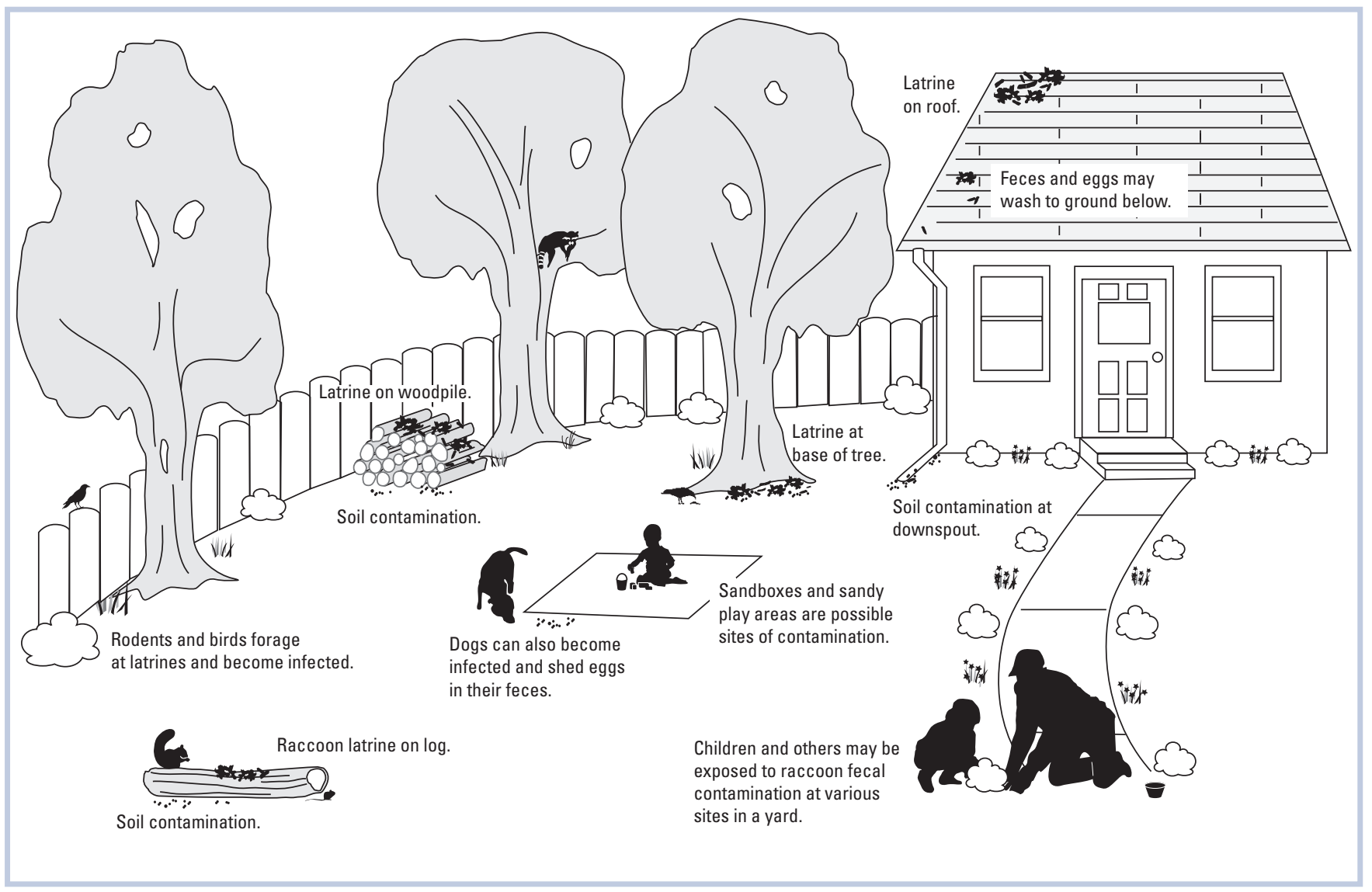

Figure 14. Areas near homes where humans and animals are at risk of contacting raccoon feces containing $B$. procyonis eggs. 


\section{Latrines and Eggs-This is the Dangerous Part}

Both animals and humans become infected with B. procyonis larvae by accidentally ingesting infective eggs from areas or articles contaminated with raccoon feces. These areas are often raccoon latrines, the preferred sites of raccoon defecation where large amounts of their feces and large numbers of $B$. procyonis eggs accumulate (Cooney, 1989; Page, 1998, 2013; Page and others, 1999; Page, Anchor, and others, 2009; Kazacos, 2001). Raccoon latrines can be identified by the accumulation of characteristic feces, which are dark and tubular, have a pungent odor, and often contain abundant seed material (Page and others, 1998). They also contain abundant $B$. procyonis eggs, which present a real danger to animals and humans who may come into contact with them. Latrines in an area are used by multiple raccoons at different times, and individual raccoons will use multiple latrines (Hirsch and others, 2014). Sampling latrines in an area for $B$. procyonis eggs provides important information concerning the potential risk of human and animal exposure to infection with this parasite (Kazacos, 2001; Page and others, 2005; Page, Anchor, and others, 2009).

In woodlots where raccoons are common, it is not unusual to find raccoon latrines and scattered feces on large logs and rocks, on stumps, on debris piles, at the base of trees, in the raised crotches and on large limbs of trees, and other horizontal structures (Yeager and Rennels, 1943; Stains, 1956; Cooney, 1989; Kazacos and Boyce, 1989; Page, 1998; Page and others, 1998) (A). Latrines can be found in various locations throughout the forest, particularly along streambeds and the banks of creeks and rivers (B). In one study of raccoons in a suburban park intercut by ravines, most latrines were found in the upper reaches of the park just inside the forest edge, near homes. These locations were presumably related to greater food resources and den sites nearby, compared to the densely wooded and steeper sloped areas of the park (Cooney, 1989). Other latrines were found along the streambed running through the park and near shelters and picnic areas.

Food sources related to humans are very important for supporting urban and suburban raccoon populations (Prange and others, 2003, 2004), and if raccoons are encouraged through feeding to frequent peoples' yards and homes or have access to stored grain or animal feed, they often will establish latrines nearby (C) (Kazacos, 2001; Roussere and others, 2003; Page, Anchor, and others, 2009). Latrines may be found in barn lofts, outbuildings, attics, garages, on woodpiles, decks, roofs, and other locations in the domestic environment $(D)$ (Kazacos, 2001;

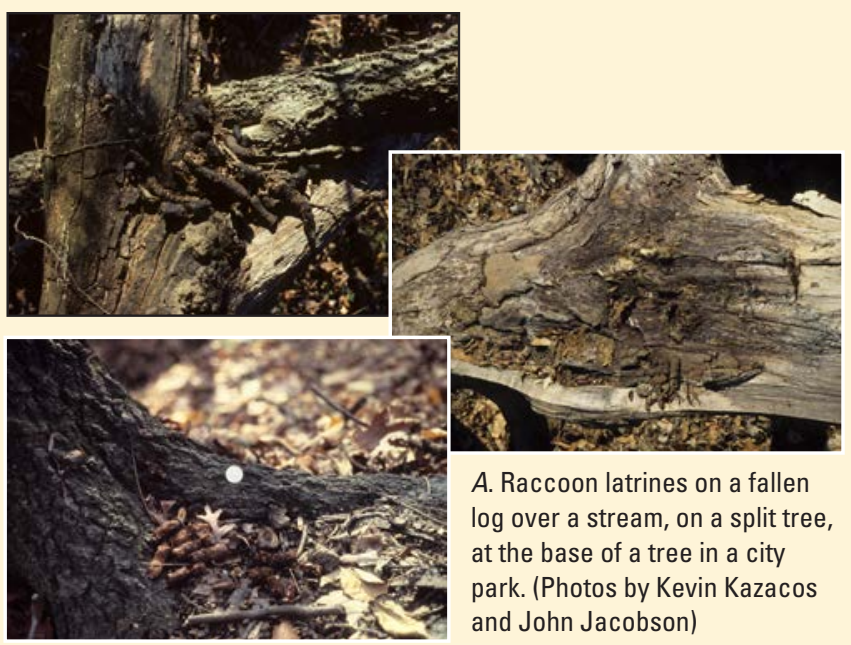

Kazacos and others, 1983; Kazacos and Boyce, 1989; Rouserre and others, 2003; Page, Anchor, and others, 2009). Raccoon latrines vary in size from small to quite large and extensive. Some of the largest latrines are in barn lofts, attics, and other choice locations of raccoon denning and defecation, where they may measure several yards across and 8-10 inches or more deep with feces (Cunningham and others, 1994; Kazacos, 2001). Interestingly, one study found a lower number of urban raccoons infected with $B$. procyonis as well as lower worm burdens in urban raccoons than rural raccoons, presumably due to urban raccoons' greater dependence on human-related food rather than predation of paratenic hosts (Page and others, 2008). However, latrines containing abundant eggs were still common in urban and suburban landscapes, including peoples' backyards (Roussere and others, 2003; Page, Anchor, and others, 2009).

Latrines can be surprisingly common in suburban communities where raccoons are common. In three communities in northern California, 244 raccoon latrines were found on 164 residential properties with a latrine density of 3.5-8.8 per acre; nearly half (44-53 percent) of the latrines examined contained $B$. procyonis eggs, many of which were infective (Rouserre and others, 2003). In the Chicago suburbs, 61 of 119 backyards examined (51 percent) had 1-6 latrines, and 23 percent of the latrines contained B. procyonis eggs (Page, Anchor, and others, 2009). Both studies indicate the potential risk of contact with raccoon latrines and $B$. procyonis eggs in domestic environments where raccoons are common.

In areas of high prevalence, infected raccoons shed on average 20,000-26,000 B. procyonis eggs per gram of 


\section{Latrines and Eggs-This is the Dangerous Part}

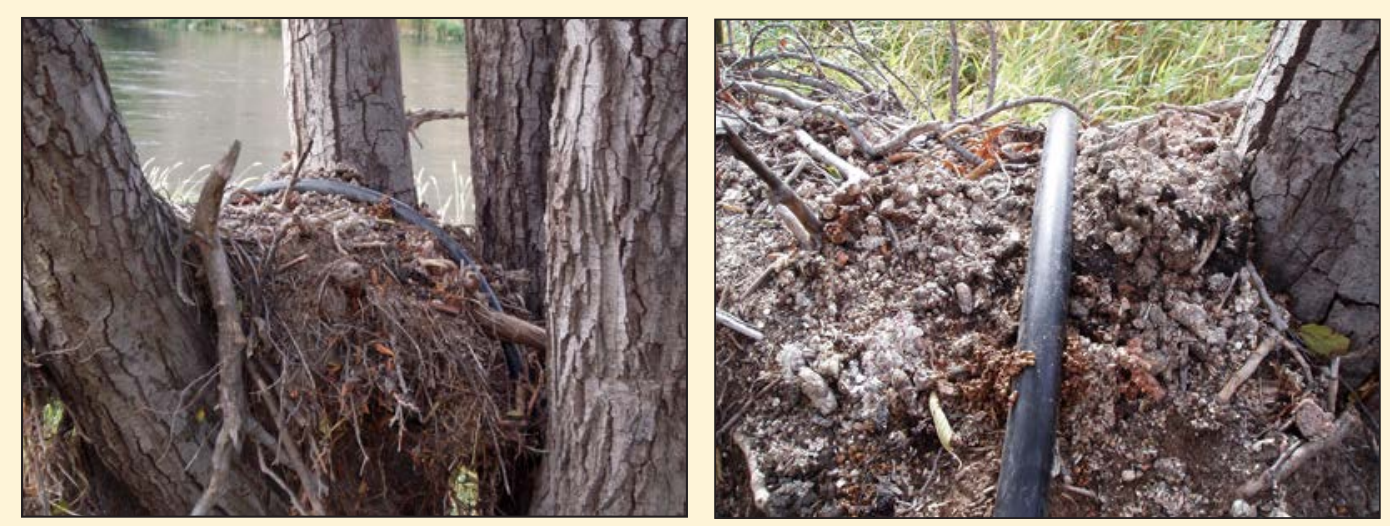

$B$. Large latrine in flood-debris laden tree, Deschutes River, Oregon. Closeup of same latrine showing extent of contamination with raccoon feces. (Photos by Kevin Kazacos)

feces, and juvenile raccoons shed more eggs than adults (Kazacos, 1982, 1983a; Snyder and Fitzgerald, 1987). In an area of much lower prevalence, infected raccoons were shedding on average 17,527 eggs per gram of feces (Reed and others, 2012), which is still quite substantial. Many animals shed more than 100,000 eggs per gram of feces, and the highest reported egg shedding by a raccoon is 256,700 eggs per gram of feces (Kazacos, 1983a). Thus, raccoon latrines and other contaminated areas can contain extraordinary numbers of infective eggs $(E)$. At these concentrations, an animal or person would not have to ingest much material to take in a dangerous number of eggs that could cause severe clinical disease. Very young children who put soil and other materials into their mouths would be at the greatest risk of infection (Kazacos, 2000). Once the eggs reach infectivity, which takes a minimum of 11-14 days (Sakla and others, 1989) but usually 2 or more weeks under natural conditions, they will remain viable for years, given adequate moisture from rainfall or other sources. On the other hand, eggs present in latrines in attics, barn lofts, and other hot, dry locations die from desiccation, but even under these conditions they will remain viable for 7 months (Shafir and others, 2011). The eggs can also survive freezing, and they were viable after 8 weeks at -20 degrees Celsius $\left({ }^{\circ} \mathrm{C}\right)$ (Garrison and Kazacos, 1994) and 6 months at $-15^{\circ} \mathrm{C}$ (Shafir and others, 2011).

Because large numbers of $B$. procyonis eggs are present at raccoon latrines, these areas become important long-term sources of infection. As first alluded to by Tiner (1952a), there is good evidence that paratenic hosts, particularly grain-eating rodents, become infected with $B$. procyonis by foraging for undigested seeds and other materials present in raccoon feces at latrines (Wirtz, 1982; Kazacos and Boyce, 1989; Sheppard and Kazacos, 1997;
Page, 1998; Page and others, 1999). Visitation to raccoon latrines by 17 species of mammals and 19 species of birds has been documented, and white-footed mice, eastern chipmunks, eastern fox squirrels, Virginia opossums, white-breasted

Mammals and birds that visited raccoon latrines.

[Bold type indicates an active forager of seeds in raccoon feces. From Page (1998); Page and others (1999; 2001a)]

\begin{tabular}{ll}
\hline \multicolumn{1}{c}{ Mammals } & \multicolumn{1}{c}{ Birds } \\
\hline White-footed mouse & Mourning dove. \\
Meadow jumping mouse & White-breasted nuthatch. \\
Eastern chipmunk & Brown thrasher. \\
Eastern fox squirrel & Blue jay. \\
Eastern gray squirrel & Hermit thrush. \\
American red squirrel & Swainson's thrush. \\
Southern flying squirrel & Wood thrush. \\
Woodchuck & Ovenbird. \\
Eastern cottontail & Northern junco. \\
Virginia opossum & Yellow-rumped warbler. \\
Raccoon & Northern flicker. \\
Striped skunk & American robin. \\
Long-tailed weasel & Tufted titmouse. \\
Red fox & Downy woodpecker. \\
Domestic cat & House wren. \\
Domestic dog & Black-capped chickadee. \\
White-tailed deer & Cardinal. \\
& Carolina wren. \\
& Eastern screech owl. \\
\hline
\end{tabular}




\section{Latrines and Eggs-This is the Dangerous Part}

nuthatches, and hermit thrushes were documented actively foraging for undigested seeds (Page, 1998; Page and others, 1999, 2001a). Visitation by white-footed mice was significantly greater when corn, their most highly preferred seed type, was present in raccoon feces. Caching of raccoon feces by white-footed mice (Page, 1998) and Allegheny woodrats (McGowan, 1993; LoGiudice, 2001; Page and others, 2012; K.R. Kazacos and others, unpub. data, 1995) has also been documented, and such behavior has been linked to extirpation of Allegheny woodrats from parts of their northeastern range where raccoon populations have increased (McGowan, 1993; LoGiudice, 2003) (See "Plight of the Allegheny Woodrat"). Animals could also become infected while investigating a latrine site, or indirectly through grooming, after having become contaminated at a latrine (Sheppard and Kazacos, 1997; Page and others, 1999).

Humans, primarily young children, have become infected and developed fatal or severe CNS disease after ingesting material from or near raccoon latrines. This has taken place in the domestic environment in and around homes, on farms, in county parks or other areas along rivers, in childcare facilities, and group homes for developmentally disabled individuals (Huff and others, 1984; Fox and others, 1985; Cunningham and others, 1994; Park and others, 2000;

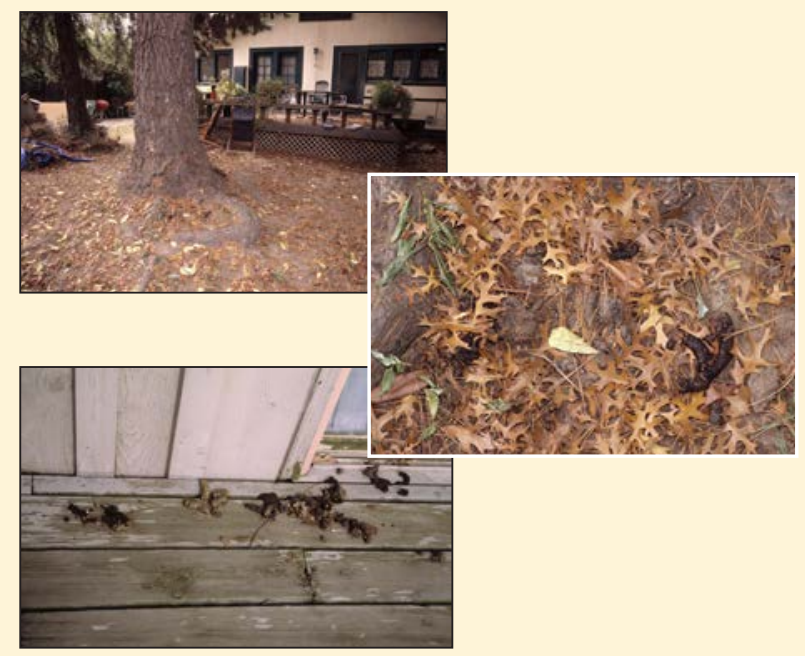

C. Raccoon latrines around homes: at the base of a pine tree in a backyard in northern California; closeup of same latrine showing multiple ages of raccoon feces in latrine and feces with seeds; raccoon feces on a deck just outside the backdoor of a home in Indiana. (Photos by Kevin Kazacos)
Rowley and others, 2000; Moertel and others, 2001; Kazacos, Gavin, and others, 2002; Gavin and others, 2002; Chun and others, 2009; Hajek and others, 2009). Several cases in children have involved contact with raccoon latrines in sandboxes or sandy play areas at their homes, at the base of trees in yards, or other locations with easy access by young children. Pica and geophagia by young children increase the likelihood of infection from such areas and have been incriminated in a number of these cases. It is important to realize that not only do curious young children find the material associated with raccoon latrines to be fascinating, but children younger than a certain age do not have an aversion to ingesting that material, resulting in potentially life-threatening infection with B. procyonis (Kazacos, 2001, 2002; Gavin and others, 2002; Murray and Kazacos, 2004; Sanders, 2015).
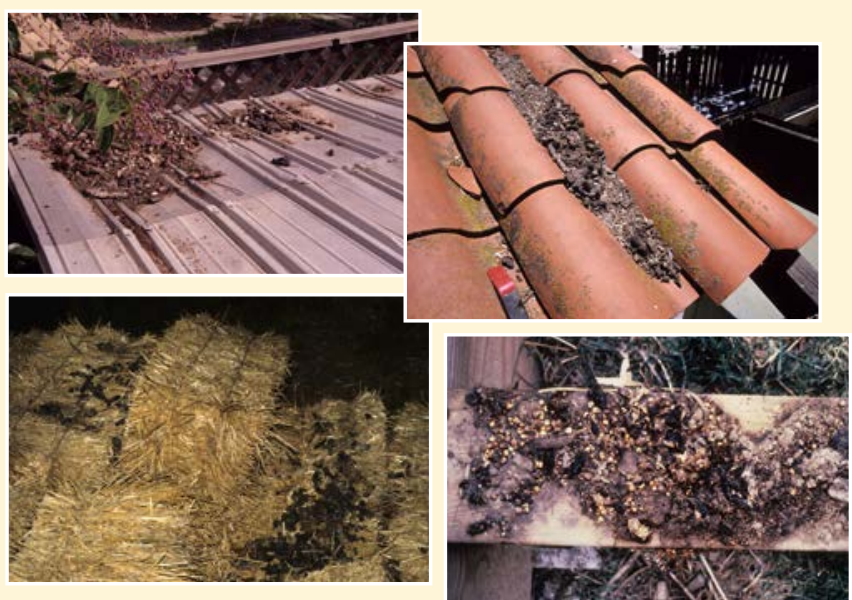

$D$. Raccoon latrines on roofs and in or near barns: on a shed roof near a garage; on a tile roof of married student housing at a university in southern California; on straw bales in a barn in Indiana; on a 2- by-10-inch board under a corn crib associated with NLM in a child in upstate New York. (Photos by Kevin Kazacos and William J. Murray)

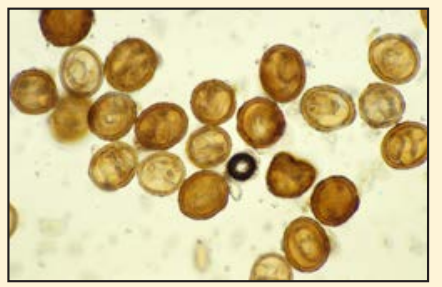

E. Infective B. procyonis eggs recovered from a raccoon latrine in Indiana. (Photo by Kevin Kazacos and Sam Royer) 
In addition to ingestion of infective eggs, humans or animals may also become infected with Baylisascaris larvae through ingestion of larvae in paratenic hosts. Paratenic transfer of larvae by ingestion of host tissues is well known for Toxocara and some other carnivore ascarids (Akao and Ohta, 2007; Hoffmeister and others, 2007; Yoshikawa and others, 2008), but it has not been examined for Baylisascaris. Nonetheless, it is a possible means of infection with larvae of these parasites, albeit it would be less important overall than ingestion of infective eggs. Therefore, any paratenic hosts destined for human consumption, especially wild mammals and birds, should be cooked thoroughly to kill any Baylisascaris larvae and other infectious agents that might be present. Another way animals, and probably humans, may become infected with Baylisascaris LM is through transplacental transfer of larvae undergoing somatic migration in pregnant females, as occurred in newborn lambs in Idaho (Anderson, 1999). Similar to the situation for Toxocara infection in dogs (Kazacos, 1991), Baylisascaris larvae apparently are stimulated and (or) activated by the hormones of pregnancy.

People and animals are at risk of infection with B. procyonis in essentially all geographic areas where raccoons are found (Kazacos, 2001). Except for a few localized or regional areas where raccoons may not be infected with the parasite, $B$. procyonis is generally found to some extent in raccoons wherever they occur (table 5). In many urban and suburban areas, raccoon populations are large because of abundant food sources intentionally or unintentionally provided by humans, numerous den sites, and a lack of natural predators (Hoffman and Gottschang, 1977; Kidder, 1990; Rosatte and others, 1991; Riley and others, 1998; Smith and Engeman, 2002; Gehrt, 2003; Prange and others, 2003, 2004; Page, 2013). Raccoons in such areas have higher reproductive rates and, with abundant available food, maintain strong, viable populations; unfortunately, this leads directly to increased environmental contamination with raccoon feces and $B$. procyonis eggs in these areas. In urban and suburban areas, raccoons are commonly considered a nuisance (de Almeida, 1987; Bluett and others, 2003) and frequently cause property damage and forage on refuse in garbage cans and dumpsters in neighborhoods and parks (Prange and others, 2004). Raccoons also scavenge food left out for dogs and cats (Roussere and others, 2003). It is not uncommon to see raccoon latrines established throughout such environments, posing a risk of Baylisascaris LM to people and animals living there (Roussere and others, 2003; Page and others, 2009a; Page, 2013).

Wild raccoons are also a well-recognized nuisance in and around zoos and other animal facilities, where they are responsible for considerable property damage and widespread fecal contamination. Raccoons are excellent climbers and will readily establish latrines in elevated locations, posing unique problems for zoos using large wire "roundhouse" enclosures and for people who may not notice rooftop contamination. Raccoon latrines in open exhibits or on the tops of roundhouse or other enclosures, as well as contaminated logs and tree limbs placed into exhibits, have resulted in numerous infections with
B. procyonis (Armstrong and others, 1987, 1989; Kazacos and Boyce, 1989; Stringfield and Sedgwick, 1997; Kazacos, 2001; C.L. Eng and K.R. Kazacos, unpub. data, 1997) (tables 10-20). Latrines on rooftops are common (Roussere and others, 2003), can be quite extensive, and pose a threat because rain runoff will carry fecal material and eggs through rain gutters or directly to ground areas below, where they may be contacted by people or animals. This scenario led to the exposure of over 80 children in a childcare facility in southern California, where an infant boy contracted severe NLM due to $B$. procyonis; several other children were seropositive, indicating infection (Schultz, 2002; Murray and Kazacos, 2004; K.R. Kazacos and others, unpub. data, 2002). Similarly, DeBrazza's monkeys contracted NLM in Indiana from raccoon feces and eggs raining down into their living area from a latrine on the top of their wire roundhouse enclosure (C.L. Eng and K.R. Kazacos, unpub. data, 1997).

Ample opportunities exist for contact and infection of domestic animals with $B$. procyonis. Fatal CNS disease due to $B$. procyonis has been seen in a wide variety of domestic animals, including pet dogs, rabbits, North American porcupines, canaries, parrots, and farm-raised rabbits, chinchillas, foxes, poultry, quail, pheasants, and large flightless birds (Kazacos, 2001) (tables 10-20). Infection with B. procyonis has been linked many times to the use of straw, hay, and feed contaminated by wild raccoons denning and (or) defecating in such materials (Richardson and others, 1980; Kazacos, Kazacos, and others, 1982; Kazacos, Reed, and others, 1983; Kazacos, Reed, and Thacker, 1986; Armstrong and others, 1987, 1989; Sanford, 1991; Van Andel and others, 1995; Campbell and others, 1997; Pessier and others, 1997; Lennox and others, 2015). In agricultural areas, it is common to find raccoon latrines in barns and other outbuildings or on old farm machinery, especially if stored grain or other animal feed is present nearby. Other cases have been linked to direct contamination of animal facilities and enclosures by raccoons and to the use of contaminated cages and enclosures that previously kept or housed raccoons (Schueler, 1973; Church and others, 1975; Koch and Rapp, 1981; Reed and others, 1981; Larson and Greve, 1983; Myers and others, 1983; Dixon and others, 1988; Medway and others, 1989; Fitzgerald and others, 1991; Coates and others, 1995; Garlick and others, 1996; M.A. Nieves and others, unpub. data, 1989). Other infections have occurred in wildlife rehabilitation and animal dealer facilities following the use of contaminated cages or enclosures, hay, or feed (Pigage and others, 1983; Dixon and others, 1988; K.R. Kazacos, unpub. data, 1983, 1984). A large outbreak occurred in guinea pigs in a "closed" American Association of Laboratory Animal Care-accredited research animal facility, due to the unwitting introduction of contaminated bedding that had been stored in an outbuilding accessed by raccoons (Van Andel and others, 1995). In the United States, Rhesus macaques at a research animal breeding facility became infected, presumably due to direct contamination of large enclosures by wild raccoons (Gozalo and others, 2008), and in Japan, cases in Japanese macaques were linked to contamination from raccoons 
also kept in a safari-style zoo (Sato and others, 2005). Zoo contamination and infection is common, as evidenced by 29 percent of nonhuman primates at six major zoos in the United States testing positive for antibodies against Baylisascaris during blood serum tests (Zimmerman and others, 2010). An extensive outbreak involving $B$. columnaris infection in three species of marmosets and tamarins at a zoo was linked to two infected skunks kept in the same exhibit, presumably to make it more "natural" (Huntress and Spraker, 1985; K.R. Kazacos and P.L. Wolff, unpub. data, 1986). Marmosets and tamarins spend much of their time on the ground foraging, which apparently led to infection with Baylisascaris (Pessier and others, 1997).

Animals may die rapidly or over longer periods of time due to Baylisascaris NLM. In the largest outbreak of NLM ever recorded, 640 bobwhite quail died following exposure to pens and straw contaminated by wild raccoons (K.R. Kazacos and others, unpub. data, 2002). This rivaled an earlier outbreak in which 622 chickens in a poultry facility died over a 7-week period, following the use of straw litter contaminated by raccoon feces (Richardson and others, 1980). In another incident, 85 bobwhite quail were placed in a 12-by-24 foot dirt pen that had housed 3 young pet raccoons and was heavily contaminated with Baylisascaris eggs; all of the quail died (Reed and others, 1981; Kazacos, 1982). In a fourth dramatic outbreak, all 10 pet birds in a mixed collection of parrots and conures succumbed quickly to massive $B$. procyonis infection acquired from contaminated feed. Feral raccoons had contaminated a seed mixture stored in a large container in the owner's garage, and this material was unwittingly fed to the birds, resulting in severe disease (Lennox and others, 2015). Other outbreaks have been insidious, with sporadic or constant low-level losses of animals from NLM. This type of outbreak took place on a pheasant ranch in Wisconsin, where 1-2 percent of young birds were affected over a 2-year period (Kazacos, Reed, and Thacker, 1986). The young birds were raised in groups in a barn, whereas older pheasants kept in outside wire pens were not affected. Problems began when the bedding for the young birds was changed to straw, which was obtained from a neighbor's barn and subsequently found to be contaminated with raccoon feces and B. procyonis eggs. Subtle disease and losses have been seen in numerous other instances in animals with isolated or low-level exposures and indicate the commonality of low-level, covert infection in both animals and humans.

To date, 25 cases of Baylisascaris NLM have been reported in humans (table 8) (Kazacos, 2001; Kazacos, Gavin, and others, 2002; Schultz, 2002; Murray and Kazacos, 2004; Cheney, 2005; Chris, 2005; Gavin and others, 2005; Pai and others, 2007; Reilly, 2008; Chun and others, 2009; Hajek and others, 2009; Moore, 2009; Kelly and others, 2009, 2012; Mehta and others, 2010; Perlman and others, 2010; Ciarlini and others, 2011; Hung and others, 2012; Haider and others, 2012), and at least a dozen additional cases are known (C.J. Crosley and others, unpub. data, 2005; Crosley and Kazacos, 2005; K.R. Kazacos, unpub. data, 1995-2010). Six of these cases resulted in death from overwhelming infection. Most cases have involved infants.

The first two recognized cases of B. procyonis NLM in humans were fatalities in infants who became infected within their homes, not in the outside environment. The first case was a 10-month-old boy in southeastern Pennsylvania who rapidly deteriorated into a comatose state, dying 14 months later. He was believed to have ingested raccoon feces from open fireplaces within the home, contaminated by raccoons denning in the chimneys (Huff and others, 1984). The other case was an 18-month-old boy with Down syndrome in northeastern Illinois who developed severe disease that progressed quickly to death; infection resulted from chewing on pieces of bark from contaminated firewood brought into the home. The bark came from logs originating as downed timber in a local woodlot that had many established raccoon latrines (Fox and others, 1985; Sanders, 2015). Another early case was a 13-month-old boy in upstate New York who became infected on a dairy farm while playing in the soil near a large raccoon latrine under a corn crib (Cunningham and others, 1994). In a case in northern California, many infective B. procyonis eggs were recovered from the sand in a child's swing set play area and from 21 raccoon latrines found on the property and an adjacent vacant lot (Park and others, 2000). In the Chicago suburbs, two infant boys became infected in their own or neighbor's yards (Gavin and others, 2002). Both children regularly put fingers and objects, including backyard dirt, into their mouths. One boy became infected while playing "fort" in a cluster of small trees that contained an active raccoon latrine, from which he ate material. An 11-month-old child in southern California became infected in a university childcare facility, where feces and eggs from large raccoon latrines on the roof of the building washed off into the infant play area below; this child also mouthed objects and ate dirt (K.R. Kazacos, unpub. data, 2002; Schultz, 2002; Murray and Kazacos, 2004; Sanders, 2015). A more recent case in an infant girl in Missouri (Mehta and others, 2010) involved probable ingestion of contaminated soil and (or) raccoon feces in a picnic area in a small rural county park along a river, where there was abundant raccoon activity and contamination (K.R. Kazacos, unpub. data, 2007). Due to their tendency for oral sampling of their environment, including pica and geophagia, infants are at markedly increased risk of severe infection (Kazacos, 2000, 2001; Murray and Kazacos, 2004; Gavin and others, 2005; Kazacos and others, 2013; Singaravelu and others, 2016).

Severe CNS disease developed in a 63-year-old man in northern California after he worked under his house in a raccoon feces-contaminated area and ate lunch there without handwashing (C. Langelier and others, written commun., 2015). At least six cases have occurred in developmentally disabled, autistic, mentally retarded, or demented adolescents or adults, and a seventh in a teenage drug abuser, all of whom exhibited altered behavior (pica, geophagia) that put them at a greater risk of infection (Fox and others, 1985; Cunningham and others, 1994; Moertel and others, 2001; Kazacos, Gavin, 
and others, 2002; Chris, 2005; Chun and others, 2009; Hajek and others, 2009; Ciarlini and others, 2011; Hung and others, 2012). In one such case in southern California, a 17-year-old in a group home for developmentally disabled adolescents became comatose and died following ingestion of large amounts of sand from a contaminated sandbox at the facility; a brain biopsy was positive for larvae (Kazacos, Gavin, and others, 2002). In Oregon, a teenager somehow became infected during or following drug abuse while camping along a river in a remote area (Chun and others, 2009).

Although most cases of NLM and OLM-DUSN are related to contact with contaminated areas in the outside environment, infected animals kept as pets or in zoos and other collections may also be a source of infection. Cases of clinical OLM-DUSN were seen in a teenager in Kentucky and an adult in Germany several weeks after they acquired pet raccoons (Raymond and others, 1978; Kuchle and others, 1993). Contact with areas or articles contaminated by infected pet skunks, other procyonids, bears, or pet dogs could also result in infection (Kazacos, 2001, 2006; Kazacos, Kilbane, and others, 2011). Skunks are raised for the exotic pet trade on large breeding farms in Iowa and elsewhere, and young descented skunks are sold in late spring in pet stores in states where it is legal. Small breeders also contribute to the pet trade in these animals, which may be sold infected with $B$. columnaris (K.R. Kazacos, unpub. data, 1997-99). Kinkajous and coatis are imported from South America and (or) raised in breeding facilities in Florida and elsewhere and then sold throughout the United States and in other countries in pet stores or by private owners or small breeders; these animals may be infected with B. potosis or other species (Kazacos, Kilbane, and others, 2011; Taira and others, 2013; Tokiwa and others, 2014; Parkanzsky, 2015). Raccoons are also bred and raised by animal dealers who sell the young as exotic pets and export them to other countries for pets or placement in zoos; thousands of raccoons have been introduced into Japan in this way (Miyashita, 1993) and hundreds into China (Xie and others, 2014). Other hosts of Baylisascaris species, including other procyonids such as ringtails and olingos, or bears, bred and sold as pets or for collections are also of concern. All of these animals pose a potential threat for introducing Baylisascaris into households, animal facilities, and local environments and exposing people and animals to possible infection.

\section{Points to Ponder}

Baylisascariasis is an excellent example of a disease where human and domestic animal infection results from close association with a common wildlife species, the raccoon, which many people consider to be both engaging and relatively harmless. It is a disease to be reckoned with in humans and animals alike, as individuals, groups, as well as populations. Cases may involve only one or a few affected individuals or, in heavier exposures, entire groups may be affected with mortality at or near 100 percent (Richardson and others,
1980; Reed and others, 1981; Kazacos, Reed, and others, 1983; A.M. Lennox and others, unpub. data, 1996; Lennox and others, 2015). The remarkable pathogenicity of B. procyonis and its ability to infect a wide variety of hosts are such that once it becomes established in an area, the consequences of its presence become known through clinical cases of neurologic and ocular disease affecting a wide range of animals as well as people (Kazacos, 2001; Page, 2013). Depending on the prevalence of infection in raccoons and the animal species affected, $B$. procyonis could have devastating effects on particular species or populations, even at relatively low environmental levels. Thus, it is very important for wildlife biologists and public health and medical personnel to be aware of the parasite and what it can do clinically and to urge caution and restraint pertaining to the translocation of raccoons to new areas for whatever purpose. Because current high raccoon densities in different areas maintain B. procyonis at high levels, indiscriminate translocation of raccoons by hunting clubs, pet owners, and others could introduce the parasite into new areas, where it could become established and pose a threat to indigenous birds and mammals, including humans (Kazacos and Boyce, 1989; Kazacos, 2001; Page, 2013).

Animals other than raccoons, including other procyonids and domestic dogs that are being bred and sold in North America and elsewhere as pets, could also be involved in introducing and (or) spreading B. procyonis and related parasites to new areas. In addition to kinkajous and coatis infected with Baylisascaris spp., several dozen dogs have also been found to have patent infections with $B$. procyonis in areas where it occurs in raccoons and, due to the commonality of pet travel, infected dogs could spread B. procyonis to new areas (Kazacos, 2001, 2006). These situations point to the need for increased veterinary vigilance, routine deworming of animals, and better regulations for animal health certifications and prophylactic deworming of potential definitive hosts before importation, exportation, or interstate transport. Infected paratenic hosts carrying larvae could also introduce and spread $B$. procyonis if they are translocated from enzootic areas and released, provided that competent definitive hosts are present in the new location.

Early field studies estimated that B. procyonis was responsible for as much as 5 percent of rodent mortality in Illinois woodlots where raccoons were common (Tiner, 1954). More recently, larva migrans due to Baylisascaris was found to be surprisingly common in white-footed mice collected in woodlots in agricultural north-central Indiana, where 28-29 percent of mice were infected (Page and others, 2001c; Beasley and others, 2013). Similarly, 33 percent of mice in urban forest preserves in Chicago, Illinois were infected with B. procyonis (Kellner and others, 2012). Based on the pathogenicity of B. procyonis larvae in mice, levels of clinical disease similar to or greater than those seen by Tiner (1954) could easily be expected. Landscape type as well as land-use are important attributes affecting prevalence of $B$. procyonis, as they affect host density, the behaviors and interactions of raccoons and paratenic hosts, the availability of food resources, contact 
rates and interactions of paratenic hosts with latrine sites, and other factors (Page, 2013). In Indiana, raccoons in agriculturedominated landscapes had a higher prevalence of $B$. procyonis infection than those in forest-dominated landscapes (Page and others, 2001c). Similar results were seen in Wisconsin, where infected raccoons had more agricultural and fewer forested areas in their home ranges than did uninfected raccoons (Samson and others, 2012). This type of habitat correlates with a greater abundance of food resources, including paratenic hosts such as white-footed mice (Nupp and Swihart, 2000; Page and others, 2010c), and favors transmission to paratenic hosts in these areas. Despite their sometimes lower prevalence of $B$. procyonis infection, urban raccoons remain important contributors to environmental contamination and thus transmission of the parasite because of their high numbers (Page and others, 2008; Kellner and others, 2012; Page, 2013).

It is estimated that hundreds, if not thousands, of clinical cases presently occur each year in animals in North America, especially cases affecting granivorous rodents and birds. The vast majority of clinically affected wild animals would escape human notice because of their small size, isolated location, and the fact that they would be more readily taken by predators and scavengers. Numerous wildlife species ranging from songbirds to large mammals forage at raccoon latrines and are thus in a direct line to become infected with this parasite (Page and others, 1999, 2001a,b). NLM due to B. procyonis was a common finding in wild animals in southern California (Evans, 2002), where the prevalence of the parasite in raccoons was also high (Evans, 2001).

The potential impact of Baylisascaris infection on natural populations of wildlife, including threatened and endangered species, is well demonstrated by the plight of the Allegheny woodrat in the northeastern United States. The demise of the woodrat in this region serves as an excellent example of the potential effects of $B$. procyonis on animal populations, following the introduction and (or) increase in raccoons in an area (Kazacos, 2001; Page, 2013). It is also a glaring example of the consequences for humans and domestic animals of living in close association with infected raccoons. People in such areas need to be made aware of parasites such as $B$. procyonis, so that they can take appropriate precautions concerning wildlife, the outside environment, and especially raccoon latrines, and follow basic preventive measures to protect themselves, their families, and their animals from infection.

\section{Disease Prevention and Control}

Prevention of $B$. procyonis infection in humans and animals depends on preventing ingestion of infective eggs from environmental sources contaminated by raccoons. This, in turn, requires preventing or limiting raccoon fecal contamination and dealing with it effectively once it has occurred. Because of the seriousness of Baylisascaris infection in humans and animals, and the present lack of effective treatment for NLM (see "Treatment," below), prevention of infection with Baylisascaris is of utmost importance (Kazacos, 2001). Three key elements for preventing and controlling Baylisascaris infections in humans and animals include (1) reducing environmental contamination with infective eggs; (2) preventing contact with contaminated areas or articles; and (3) educating people about Baylisascaris as a cause of human and animal disease so that they can take appropriate precautions (Kazacos, 1991, 2000, 2001; Kazacos and Boyce, 1989). These approaches should be carried out together as part of an overall prevention and control program and should apply not only to raccoons, but as well to other procyonids, dogs, skunks, and other definitive hosts of Baylisascaris spp.

\section{Reducing Environmental Contamination}

Environmental contamination with Baylisascaris eggs in an area is reduced by treating, removing, and (or) relocating infected raccoons and skunks (LoGiudice, 1995; Kazacos, 2001; Page and others, 2011). Keeping raccoons and skunks as pets should be strongly discouraged, particularly in households with young children (Kazacos, 2000, 2001). Precautions are also important when keeping kinkajous, coatis, ringtails, other procyonids, or bears as exotic pets. Dogs infected with B. procyonis can also contaminate peridomestic areas. Anthelmintic treatment of raccoons, other procyonids, skunks, bears, and dogs kept as pets or for other reasons is easily accomplished, but it must be done adequately in order to prevent contamination with eggs (Kazacos, 2001).

\section{Depopulation and Removal}

Wild raccoons are involved in most Baylisascaris infections (Kazacos, 2001). The most straightforward method of dealing with infected raccoons in an area is through depopulation and removal (Kazacos, 2001). This immediately reduces new environmental contamination in an area and is best combined with latrine cleanup and decontamination. Depending on a particular state's regulations as to how these animals are dealt with, trapped animals may be relocated to distant sites or euthanized. It is not uncommon for suburban zoos to have ongoing wildlife control programs in an effort to reduce and control nuisance wildlife and the diseases they carry. Trapping and removal may be applied on a localized basis, directed against particular nuisance animals, or on a broader scale.

Typically, these efforts must be sustained or periodically applied, because removal of animals creates niche and population voids, which will be filled by new raccoons moving into the area. Consider the situation in the late 1990s, on the Monterey Peninsula in northern California, where the adjacent cities of Pacific Grove and Carmel had ongoing nuisance raccoon problems, with frequent complaints from citizens (Roussere and others, 2003). A case of severe NLM in a child in Pacific Grove in August 1998 (Park and others, 2000) prompted a program of trapping and euthanasia of nuisance raccoons, as 


\section{Plight of the Allegheny Woodrat}

The Allegheny woodrat $(A)$ is threatened or endangered through much of its Northeastern and Midwestern range. It has become extirpated from New York, Connecticut, and much of New Jersey and continues to decline in other areas (Balcom and Yahner, 1996; LoGiudice, 2006). Although a number of factors may be involved, declines in woodrats in the Hudson Highlands region of New York were convincingly linked to neural larva migrans (NLM) caused by $B$. procyonis, related to increases in the raccoon population in the area over time (Kazacos, 2001; LoGiudice, 2003). Similar associations were also made with raccoon fecal contamination in woodrat habitat in southern Indiana (Page and others, 2012).

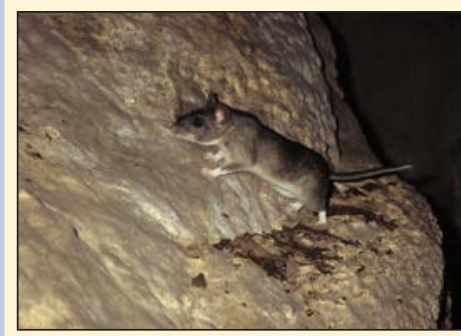

A. Allegheny woodrat in a cave in southern Indiana along the Ohio River. (Photo by Kevin Kazacos)

Based on long-term naturalist's records at the Mohonk Preserve in New Paltz, N.Y., raccoons were considered a rarity there in 1923-32, but they were abundant by the end of 1949 and subsequently (Smiley, 1977a). Declines in the woodrat population had also been noted, and it was thought that this might have been related somehow to the increase in raccoon numbers (Smiley, 1977b). In 1986, abnormal behavior was documented in various animals in the preserve, including gray squirrels and deer mice found circling or unable to climb trees (Smiley and Huth, 1986). B. procyonis NLM was suggested as the probable cause of this abnormal behavior, in addition to its possible role in the extirpation of woodrats from the preserve between 1959 and 1977 (W.B. Stone, written commun., 1998; Kazacos, 2001). Woodrats became extirpated from the state in 1987, and subsequent woodrat release studies undertaken by the New York Department of Environmental Conservation at Mohonk in 1991 indicated that $B$. procyonis was the likely cause of the loss of woodrats from the region, in combination with other factors (McGowan, 1993).

The problem stemmed from both habitat type and the inherent behavior of woodrats. Allegheny woodrats prefer steep rock and boulder talus slopes, escarpments, cliff ledges and caves, with deep secluded areas for nesting $(B, C)$. In eastern New York State, these areas are also very attractive to raccoons, which used them as den and latrine sites $(D)$ (Kazacos, 2001). As the raccoon population increased, so

did raccoon latrines, with increased chances of woodrats contacting those latrines and B. procyonis eggs. Uninfected woodrats from West Virginia released into these areas, as well as their offspring, died of Baylisascaris NLM, evidence of which was documented in all 11 woodrats recovered and examined; 4 of these animals had exhibited abnormal behavior when they were live-trapped (McGowan, 1993). Baylisascaris NLM was also identified in Allegheny woodrats in southern Indiana (E) (K.R. Kazacos and S.A. Johnson, unpub. data, 1996) and south-central Pennsylvania (J. Wright and others, unpub. data, 1998), and in woodrats released in New Jersey (LoGiudice, 2003) and southern Indiana (Smyser, Johnson, and others, 2013). Studies of raccoon latrine associations in woodrat habitat in southern Indiana found a correlation between positive latrines containing infective eggs and lower woodrat numbers (Page and others, 2012).

Woodrats, a type of packrat, are well known for their caching behavior, and in New York, New Jersey, and Indiana, the extensive caching of raccoon feces by woodrats was documented, indicating a direct behavioral link to raccoon latrines and B. procyonis infection. Caching behavior was examined further and revealed that whereas a white-footed mouse tends to pick apart feces and take out seeds immediately upon finding fresh raccoon feces, a woodrat prefers older dried feces (mean, 21 days old) and would carry the

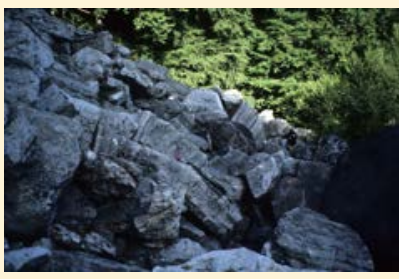

$B$. Talus boulder slope habitat of Allegheny woodrat in eastern New York State. (Photo by Kevin Kazacos)

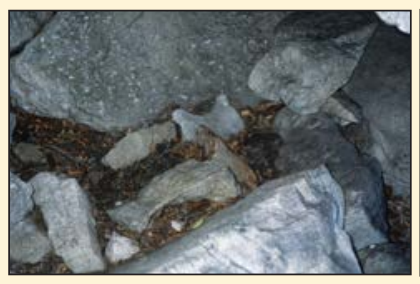

$D$. Raccoon latrine in talus boulder habitat in eastern New York State. (Photo by Kevin Kazacos)

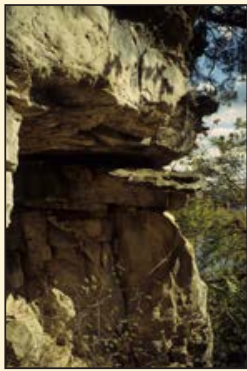

C. Cliff ledge habitat of Allegheny woodrat in southern Indiana. (Photo by Kevin Kazacos)

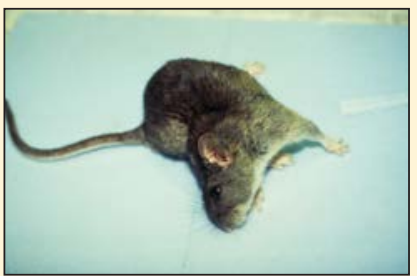

E. Allegheny woodrat from southern Indiana with Baylisascaris NLM, showing severe head and body tilt, extension of the forelimbs, and falling over. (Photo by Scott A. Johnson) 


\section{Plight of the Allegheny Woodrat}

entire piece of feces back to its den and cache it in its midden $(F)$ (LoGiudice, 2001). Carrying raccoon feces in their mouths, as well as later consumption of seeds present in older fecal material, puts woodrats at great risk of infection with $B$. procyonis eggs, which would have reached infectivity by then.

Experimental studies on the susceptibility of woodrats to $B$. procyonis found them to be highly susceptible to NLM (G) (K.R. Kazacos, unpub. data, 1997). Because one larva in the brain of a susceptible small rodent is usually fatal (Tiner, 1953a,b; Sheppard and Kazacos, 1997), and a rodent may die following infection with a surprisingly low number of eggs (Dubey, 1982), woodrats are at particular risk when they are repeatedly exposed to even low numbers of eggs. Thus, they would be at risk of NLM even in areas of low B. procyonis prevalence in local raccoons and latrine sites (Page and others, 2012). Studies of woodrats released in New Jersey showed that those in less contaminated sites were at risk of NLM, but that the hazard of death increased 2.67 times for those in highly contaminated sites (LoGiudice, 2003). Every additional raccoon latrine found per 1 hour of search time increased the death hazard to woodrats by 10 percent (LoGiudice, 2003).

The unique plight of the Allegheny woodrat demonstrates that Baylisascaris can have a significant impact on certain indigenous wildlife, especially species that are already compromised due to low population numbers and (or) habitat loss. At particular risk are grain-eating species that may forage at raccoon latrines (Page and others, 1999, 2001a), especially those like the woodrat that normally cache materials.

Therefore, it becomes very important to consider the consequences of raccoon translocation into new areas, as well as their natural dispersal and population increases, because all could affect $B$. procyonis prevalence and its effect on other species (Page, 2013). If other species are threatened or endangered like the Allegheny woodrat, the consequences may be dire (Kazacos, 2001; LoGiudice, 2003; Page, 2013). Prevention or limitation of raccoon translocations as well as thorough deworming of translocated raccoons would be important in reducing the spread of $B$. procyonis to new areas and its consequences for other species. Other interventions being studied to prevent the impact of B. procyonis on woodrat populations (as well

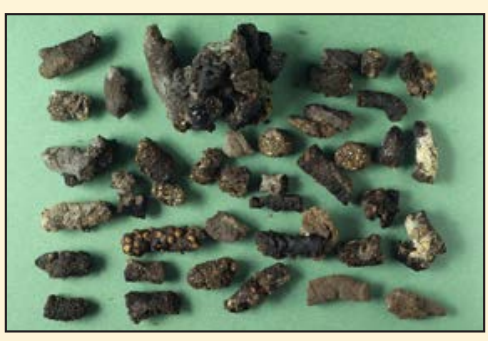

F. Portion of raccoon feces cached by a woodrat in its midden in southern Indiana. (Photo by Kevin Kazacos and Sam Royer)

as other species, including humans) include the use of anthelmintic-laced baits to deworm local raccoon populations (Kazacos, 2001; Page, 2013). Limited experiments in New Jersey indicated that this might work, because following the use of deworming medications in baits, $B$. procyonis worms and tracking dye were found in raccoon feces at latrines (LoGiudice, 1995). A study in Indiana showed that bait deworming decreased the prevalence of B. procyonis eggs in raccoon latrines as well as larval infections in white-footed mice in areas where the raccoons were treated (Page and others, 2011). Another study found that the use of anthelmintic-containing baits increased the success of Allegheny woodrat translocations into previously occupied sites (Smyser, Johnson, and others, 2013). One problem not usually considered with this approach, however, is that the eggs in worms passed by treated raccoons will still develop to infectivity and be present in latrines, available for reinfection of raccoons as well as infection of other animals, including woodrats. However, bait deworming is a step in the right direction, and regular treatment combined with regular latrine cleanup and decontamination in an area may have a measurable impact on decreasing the extent of this problem, particularly in smaller targeted areas including in and around known woodrat habitats.
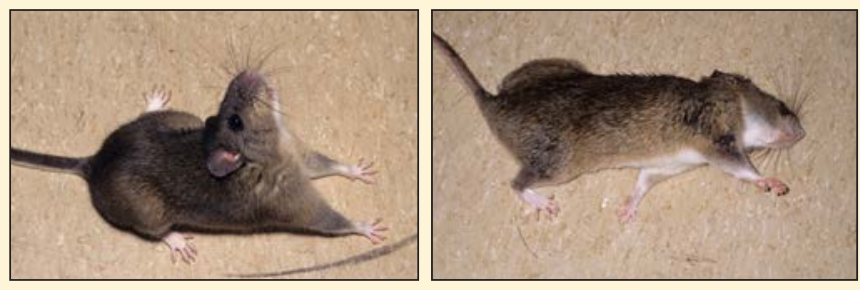

G. Allegheny woodrat with NLM following experimental infection with $B$. procyonis. Photos show arching of the head and neck, extension and rigidity of the forelimbs, and paddling movements while lying down. (Photos by Kevin Kazacos and Sam Royer) 
well as educational efforts aimed at discouraging people from feeding or providing shelter for these animals. These efforts, which were instituted in Pacific Grove but not in Carmel, prompted lawsuits from animal rights groups, cease-and-desist orders, and finally legal resumption of trapping when, for public health reasons, opposition was denied in local courts (W.J. Murray, pers. commun., 2001). Subsequent studies found a marked difference in latrine densities in the two cities, with 8.7 latrines per hectare in Pacific Grove versus 21.7 per hectare in Carmel, apparently related to their different respective efforts to control local raccoons (Roussere and others, 2003).

\section{Anthelmintic Baiting}

Other than trapping and removal, B. procyonis prevalence in an area may be reduced by using baits containing anthelmintics to deworm wild raccoons, similar to the bait treatment of Echinococcus in foxes in Europe or the use of baits for rabies vaccination of wildlife (Kazacos, 2001). Although the frequency, timing, and logistics of such treatments related to their overall effectiveness are not well known, encouraging results were seen in studies done in woodrat habitat in central New Jersey (LoGiudice, 1995), in agricultural areas of northcentral Indiana (Page and others, 2011), and in woodrat habitat in southern Indiana (Smyser, Johnson, and others, 2013; Smyser, Page, and others, 2013). In New Jersey, raccoons were baited with piperazine at two sites. The number of scats containing eggs was significantly reduced overall at the treatment sites compared to the control sites, but it was impossible to identify the contributions of individual animals to feces at latrines. However, successful treatment was indicated by finding adult Baylisascaris in two of three scats that also contained a fluorescent marker indicating bait consumption. Nothing could be concluded as to the effects of anthelmintic baiting on overall prevalence of the parasite, because too few raccoons were trapped and examined for eggs.

These results of anthelmintic treatment of raccoons in woodrat habitats were strongly supported by the studies in Indiana (Page and others, 2011; Smyser, Johnson, and others, 2013; Smyser, Page, and others, 2013). In the first study, raccoons were baited monthly with pyrantel pamoate, a deworming agent used to treat roundworm infections, after first removing and torch-sterilizing latrines in eight forest treatment patches. The prevalence of $B$. procyonis eggs in latrines in treatment patches declined by over threefold in all sampling periods after baiting, and during one year, there was a significant decline in the prevalence of $B$. procyonis larvae in white-footed mice in treatment areas compared with control patches. This was the first study to show a direct effect on larva migrans in paratenic hosts in an area following the bait deworming of raccoons, and served as a baseline for later studies assessing the efficacy of baiting for sustained control of Baylisascaris in wild raccoons.

In the other studies, monthly baiting with pyrantel pamoate was conducted in nine sites in woodrat habitat (limestone and sandstone cliffs) in southern Indiana that included all five known extant woodrat populations in the state. Anthelmintic baiting for 24 months led to reductions in prevalence of $B$. procyonis eggs in latrines from prevalences of 9-11 percent before treatment to near 0 percent after treatment (Smyser, Page, and others, 2013). Six sites were used to assess experimental translocation or reintroduction of woodrats from other states. It was found that anthelmintic baiting facilitated woodrat reintroduction and recovery in treated sites as compared to untreated sites (Smyser, Johnson, and others, 2013). Recently, an automated dispenser was developed for the delivery of anthelmintics or vaccines to raccoons in the wild (Smyser and others, 2015) and an anthelmintic fishmeal polymer bait was evaluated for the control of $B$. procyonis in wild raccoons (Smyser, Johnson, and others, 2015).

As promising as these results have been, because wild raccoons have high population densities in suburban areas and are likely to become reinfected after treatment, controlling Baylisascaris in raccoons in such areas by bait deworming may be challenging or ineffective, as well as expensive, if it is attempted on too large a scale. However, it may be advantageous to continually deworm a stable, localized resident population of raccoons on a regular basis as part of overall control efforts, combined with latrine cleanup and decontamination. It would also be very important to discourage people from intentionally feeding wild raccoons and to control other human-generated food sources (garbage, pet food) that serve to maintain large populations of raccoons (Roussere and others, 2003; Prange and others, 2003, 2004). This approach, combined with other population control methods (for example, contraception, neuter and release) could help stabilize and (or) limit local raccoon populations as well as reduce the establishment of new latrine sites. It could also reduce levels of raccoon fecal contamination and $B$. procyonis eggs in targeted areas, such as domestic or zoo environments, as well as habitats of threatened or endangered species, such as Allegheny woodrats.

\section{Preventing Contact with Contaminated Areas or Articles}

Captive raccoons, skunks, and other definitive hosts should be housed away from other species, in clean dedicated cages or enclosures that can be easily decontaminated. Regular feces removal, preferably daily but at least weekly, should be part of routine husbandry practices. These animals should not be housed in egg-contaminated enclosures or fed raw meat from wild animals (for example, rodents, rabbits, birds), as either could result in patent Baylisascaris infection and subsequent egg shedding (Kazacos and Boyce, 1989).

Once in the environment, Baylisascaris eggs can survive for years, so dealing with contaminated areas is problematic (Kazacos, 2001). Contaminated locations can be dealt with by using straightforward methods, but these must match the serious challenge put forth by the eggs. It is important to 
prevent contact with known or suspected contaminated areas or articles until they can be properly assessed and effectively decontaminated, removed, and (or) destroyed (Kazacos, 1983c, 2001). This would include cages or enclosures that had housed raccoons, skunks or other potential definitive hosts, raccoon latrine sites in and around the domestic or zoo environment, and other contaminated materials. It is important to prevent access by raccoons to buildings, animal facilities, and zoo exhibits and to prevent raccoon fecal contamination of hay, straw, and feed used for other animals. Fallen timber, large tree limbs, and rocks obtained from the wild and destined for use in animal enclosures or exhibits should first be carefully inspected, washed, and heat treated before use. It may be prudent to first strip the bark from dead trees that are collected for use in animal exhibits.

\section{Education}

Baylisascaris infection (NLM, OLM) can have devastating effects at many levels, affecting individuals, families, populations, facilities, and whole organizations. Baylisascaris is not well known among the general public or the medical profession, but the situation has improved considerably in the last several decades. Despite this, a body of misinformation and misunderstanding exists concerning $B$. procyonis and its health effects and, justifiably so, the parasite continues to generate considerable fear in those who feel they may have been exposed or infected. Therefore, education of individuals and groups about the dangers associated with raccoons and Baylisascaris continues to be the most important aspect of prevention and control (Kazacos, 1991, 2000, 2001).

Educational programs about these parasites could be beneficial to a wide spectrum of people, including wildlife biologists, natural resources personnel, animal care directors and staff, wildlife rehabilitators, animal damage control officers, pet dealers and suppliers, public health personnel, veterinarians, physicians, and the general public. Questionnaire surveys in China (Xie and others, 2014; Y. Xie, written commun., 2014) and the United States (Parkanzky, 2015) found a lack of awareness about $B$. procyonis, including its health effects, transmission, and relationship to animals, among people keeping raccoons and nonraccoon procyonids, including some zoo personnel. For parents and families, the main focus should be on infant children, because they are at the greatest risk of heavy infection and, therefore, demand close parental supervision to avoid becoming infected. Better availability of information about the real dangers posed to children by raccoons and Baylisascaris would be especially helpful for parents and pediatricians. It is critical that infectious disease specialists, neurologists (especially pediatric), and ophthalmologists are made aware of this common parasite and its potentially devastating consequences, and that this information is disseminated to the general medical community. Public awareness is also very important, so that parents can take appropriate precautions to protect their young children from infection. Parents who witness potential exposure of infant children at raccoon latrines must quickly seek correct information and prophylactic treatment from medical professionals, who should at least understand the seriousness of the situation or be able to obtain information quickly. Those seeking medical assistance because of neurologic disease and (or) problems with vision may need to communicate with their health professionals about this infection and its treatment, in addition to providing information about potential exposure to raccoons, skunks, or other animals and their feces.

Residential properties, including homes and yards, contiguous wooded areas, childcare facilities, farm buildings, etc., should be monitored for raccoon activity as well as latrine sites, and raccoons should be deterred from contaminating peridomestic areas and other facilities where children may have contact. Raccoon latrine sites should be identified and children and animals kept away from these areas until they can be decontaminated. Children should be taught at an early age not to play with animal feces, to identify and avoid raccoon latrines they may encounter in their environment, and to wash their hands after playing outside or with animals. Infection and clinical disease caused by Baylisascaris are both preventable through simple, straightforward means. These preventative measures may be most likely undertaken when people have greater awareness, understanding, and appreciation of the problem.

\section{Treatment}

\section{Intestinal Worms}

Fecal samples from potential hosts kept in captivity, which could include raccoons, skunks, and even dogs, should be examined regularly by fecal flotation, and potentially infected animals should be strategically dewormed for Baylisascaris to prevent or decrease environmental contamination with eggs and possible transmission to humans and other animals (Kazacos and Boyce, 1989; Kazacos, 2001; Kazacos and others, 2013). Newly acquired raccoons and other hosts should be quarantined and dewormed immediately, with at least two additional anthelmintic treatments at 14-day intervals to ensure elimination of all developing worms (Kazacos and Boyce, 1989; Kazacos, 2001). Young raccoons, skunks and other definitive hosts, including dogs, pose a greater threat than adults, because they have a higher prevalence of infection and are often acquired during the prepatent period, when they will be harboring young developing worms but will be false negative for eggs (Kazacos, 1983b; Kazacos and Boyce, 1989). These animals can be fecal negative for as long as 9-10 weeks, then suddenly begin shedding large numbers of eggs when the worms mature, resulting in extensive contamination. Because the eggs are microscopic, shedding will not be noted by the owners, and when the eggs reach infectivity, the situation will become dangerous. Therefore, strategic deworming of young animals should be started early, at about 5-6 weeks of age (and earlier for puppies, at 2 weeks of age, 
due to transplacental transmission) and repeated regularly, for example, every 2 weeks for five or six treatments, then continued monthly (Kazacos and Boyce, 1989; Bauer and Gey, 1995; Kazacos, 1991, 2001). The minimum known prepatent period of Baylisascaris in raccoons and skunks is about 1 month postinfection (32 days for B. procyonis, via larvae), so once infections are eliminated, regular monthly deworming should prevent any future environmental contamination with eggs (Kazacos and Boyce, 1989; Bauer and Gey, 1995; Kazacos, 2001). Drugs effective against intestinal Baylisascaris include pyrantel pamoate, piperazine, fenbendazole, milbemycin oxime, moxidectin, and several others, all of which can be administered mixed in moist cat food, which is highly palatable to raccoons and skunks (Kazacos, 1986, 2001; Bauer and Gey, 1995; Bowman and others, 2005).

\section{Migrating Larvae}

As opposed to the treatment of intestinal worms, which is relatively easy, treatment of migrating Baylisascaris larvae is difficult and, with or without treatment, NLM due to Baylisascaris carries a guarded prognosis. The clinical efficacy of anthelmintic treatment of NLM depends on several factors, including drug pharmacokinetics, activity against larvae in the CNS, the level and duration of CNS infection, and the extent of CNS damage at the time of treatment (Kazacos, 2001). Treatment of low-level or early CNS infection appears possible by using larvicidal drugs, such as albendazole, which effectively cross the blood-brain barrier and steroids to control inflammation (Murray and Kazacos, 2004; Gavin and others, 2005; Kazacos and others, 2013). With early and aggressive therapy, cases of clinical NLM in humans and animals have been stabilized, and in some cases the patients have improved (Kazacos, 2001; Pai and others, 2007; Hajek and others, 2009; Jimenez Martinez and others, 2015; Langelier and others, written commun., 2015); however, in most reported cases treatment did not affect the progression of CNS disease.

It is very important that any treatments for Baylisascaris NLM be started as early as possible, in an effort to kill larvae in the CNS and thus limit further damage and to kill larvae migrating in other tissues before they can reach the CNS. The anthelmintic of choice for treatment of Baylisascaris NLM is albendazole, although diethylcarbamazine also had good efficacy. Ivermectin is not a good choice for clinical cases, because it does not readily cross the blood-brain barrier
(Kazacos, 2001). Mice infected with fatal doses of B. procyonis eggs and treated daily with albendazole (25-50 mg/kg) for 10 days starting 1-3 days postinfection were protected 95-100 percent from developing CNS disease (Miyashita, 1993; Garrison, 1996). In cases of known or probable exposure, such as when a child is seen or suspected of ingesting material from a raccoon latrine, immediate treatment with albendazole daily for 10 days is recommended to prevent the development of NLM and CNS disease.

\section{Preventive Treatment}

In addition to treatment of early infection or clinical NLM, several anthelmintics show great promise as preventives for this infection in animals and possibly humans (Kazacos, 2001). These include the pyrantel salts, pyrantel tartrate and pyrantel pamoate, which prevent initial infection in the intestine following egg ingestion, and thus subsequent larval migration and development of NLM. These drugs must be given daily or continuously to have a preventive effect against larvae hatching in the gut and are ineffective against larvae already in migration. Mice experimentally infected with B. procyonis eggs and given pyrantel tartrate at 0.25 percent or 0.5 percent, or pyrantel pamoate at 0.2 percent concentration in their feed were fully protected against $B$. procyonis infection and NLM, which proved 100 percent fatal to untreated mice (Lindquist, 1978). In cases of known or suspected exposure of animals to Baylisascaris eggs, pyrantel tartrate feed additive for swine (such as Banminth®48) or the pelleted formulation for horses (such as Strongid ${ }^{\circledR C}$ ) can be mixed directly into the feed for large flightless birds, nonhuman primates, or other animals, or used as a top dressing on the animals' usual food (Suedmeyer and others, 1996; Kazacos, 2001). Because of their high efficacy, acceptance, safety, and ease of use, these drugs are recommended for the prevention of Baylisascaris larval infection in mammals and birds (Kazacos, 2001). They are particularly useful on premises with ongoing problems, where the source of infection either has not been identified or effectively decontaminated. They would most likely be highly effective for preventing Baylisascaris infection in children, when given as a daily dose, but this has not been studied. Although pyrantel pamoate is a safe and approved human drug for general deworming, it is not labeled for prevention of Baylisascaris, even though it still could be used for this purpose. 


\section{Decontamination Procedures for Baylisascaris Eggs}

Baylisascaris eggs are exceptionally resistant to physical and chemical factors, but they can be effectively killed by using various forms of heat. In addition, they, along with raccoon feces, can be physically removed, making it possible to decontaminate contaminated areas and articles (Kazacos and Boyce, 1989; Kazacos, 2001). Guidelines for cleaning up raccoon latrines are on the Web sites of several governmental agencies. Baylisascaris eggs are resistant to all common disinfectants, including bleach, although certain solvent mixtures will kill them (Kazacos and Boyce, 1989; Kazacos, 2001). Treatment of an area with a solution of 20 percent bleach (1 percent sodium hypochlorite) removes the outer protein coat of the eggs, making them unable to adhere to surfaces and able to be washed away, but this will not kill them. B. procyonis eggs exposed to undiluted household bleach for 90 minutes were still viable (Shafir and others, 2011). Chemical treatments that will kill the eggs are generally not practical for use in the environment, and indeed may be illegal to use (Kazacos and Boyce, 1989; Kazacos, 1991, 2001).

Similar to other ascarid eggs, the thermal death point of B. procyonis eggs is about 144 degrees Fahrenheit $\left({ }^{\circ} \mathrm{F}\right.$; 62 degrees Celsius $\left[{ }^{\circ} \mathrm{C}\right]$ ) (Shafir and others, 2007, 2011), making them susceptible to killing at temperatures lower than most people realize, and because heat comes in many forms, the eggs can be killed by various means, depending on the situation and location of contamination. Boiling or scalding water $\left(150^{\circ} \mathrm{F}\right.$ to more than $\left.160^{\circ} \mathrm{F}\right)$, a steam cleaner, propane flame gun, autoclave, burning straw, or other means can be used to effectively decontaminate small or large areas of contaminated soil or concrete, metal cages, enclosures, holding pens, and contaminated tools and utensils (Kazacos and Boyce, 1989; Kazacos, 1991, 2001).

Government Web sites with guidelines for cleaning raccoon latrines.

\begin{tabular}{cc}
\hline \multicolumn{1}{c}{ Agency } & Website \\
\hline $\begin{array}{c}\text { Centers for Disease } \\
\text { Control }\end{array}$ & http://www.cdc.gov/parasites/ \\
& baylisascaris/resources/ \\
raccoonlatrines.pdf \\
Santa Barbara County & http://www.dshs.state.tx.us/idcu/ \\
Animal Services & health/zoonosis/outdoor/ \\
& raccoonLatrine.pdf \\
Seattle and King County & http://www.kingcounty.gov/ \\
Public Health & healthservices/health/ehs/ \\
& RaccoonLatrine.aspx \\
\hline
\end{tabular}

Direct flame from a propane gun is very effective for destroying eggs and is easily used to decontaminate live traps, cages, and enclosures that have held Baylisascarisinfected raccoons as well as shovels and other metal tools $(A, B)$. This method is also used to decontaminate concretefloored animal rooms, kennel runs, and raccoon latrine sites in zoos and around homes (Pegg, 1977; Abdelrasoul and Fowler, 1979; Kazacos and Boyce, 1989; Kazacos, 1991, 2001). Surface soil can be flamed, broken up, and turned over several times with a shovel or rake, and reflamed each time to ensure decontamination. Large tractor-mounted units are also available for use on soil areas. Obviously, appropriate precautions should be taken when using this method, particularly in or around buildings and other flammable materials, or another less dangerous heat method such as steam cleaning should be used instead. A wide variety of steam cleaners, both large and hand-held, are available and could be effectively used, depending on the situation.
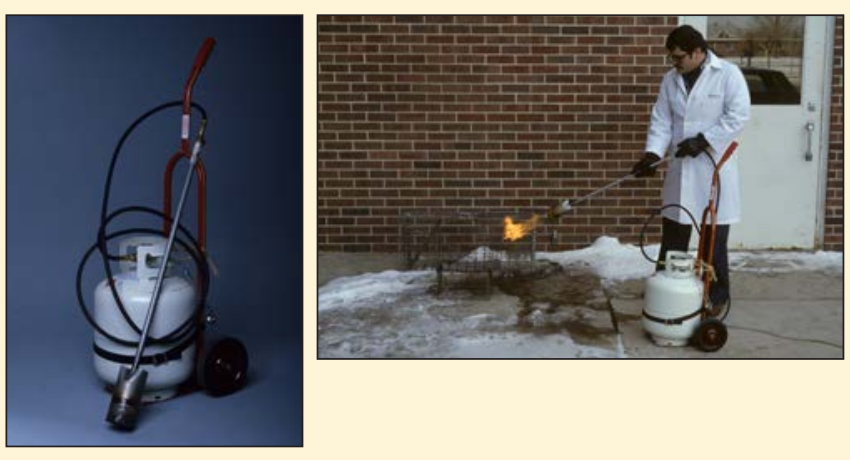

A. Propane flame gun (VT 3-30 Red Dragon Vapor Torch) with 20-pound gas tank. (Photo by Kevin Kazacos and Sam Royer)

$B$. Use of propane flame gun to decontaminate a raccoon trap for B. procyonis eggs. (Photo by Sam Royer)

Raccoons defecating on patios, porches, and decks can be dealt with by trapping and removing them and (or) regularly cleaning up their feces and using heat decontamination. Eggs in fresh feces are not yet dangerous and such material can be picked up weekly, bagged and disposed of in the trash, and the area treated with boiling or scalding water (for example, from a large pan or teapot) to kill any residual eggs that may be present $(C)$. Heavily contaminated areas may also be dealt with by removing and discarding the top several inches of soil or substrate and replacing it; this may be combined with heat treatment of the area $(D, E)$. 


\section{Decontamination Procedures for Baylisascaris Eggs}

Dried raccoon feces and other contaminated material (hay, straw, leaves) in attics, barn lofts, garages, etc., should be carefully removed, double-bagged, and disposed of in a landfill or destroyed by incineration. Lightly wetting the material first with water from a pump sprayer will allow removal without stirring up much dust. Residual material in buildings can then be removed by wiping the area with hot soapy water and (or) by using a powerful canister-type vacuum cleaner containing a fine (less than 15 micrometers) disposable filter bag. The surfaces can be further treated with steam or scalding water. Residential and commercial steam vacuums could also be used. Some commercial remediation companies have powerful truck-mounted vacuum systems that are very effective for removing and trapping fine particles including these eggs. Because Baylisascaris eggs die from desiccation in hot, dry attics and barn lofts, once raccoons have been prevented from regaining access to such areas, feces can be allowed to sit for an extended period,

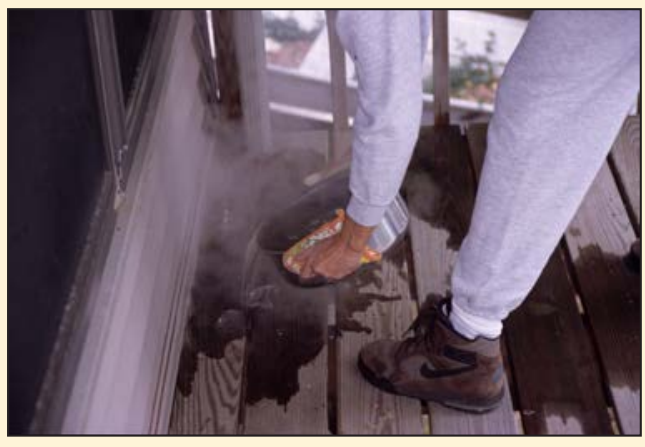

C. Boiling water decontamination of a raccoon latrine area on a deck. (Photo by Kevin Kazacos)

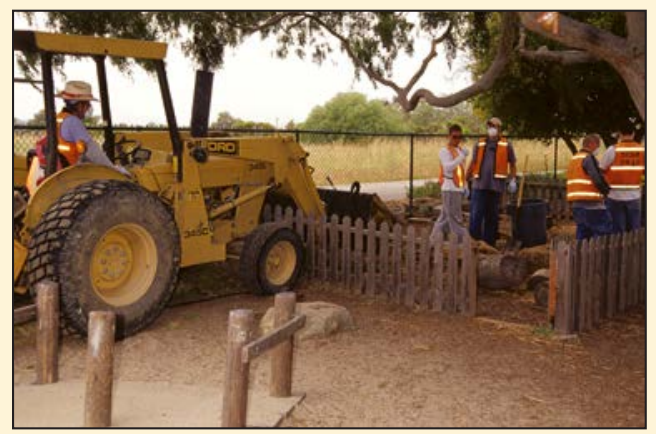

$D$. Substrate removal during remediation of daycare facility in southern California following infection of children with B. procyonis from rooftop latrine. (Photo by William J. Murray) especially during the hot summer, prior to cleanup. Recent studies found that it takes 7 months for B. procyonis eggs to die from desiccation (Shafir and others, 2011). The material can then be safely removed with few precautions because viable eggs will not be present. It is also theoretically possible to kill the eggs on surfaces using cryogenic freezing, similar to methods used for bed bugs and other pests, but this has not been examined.

Homeowners and professionals alike cleaning contaminated areas should wear personal protective equipment including disposable coveralls or old clothes, strong rubber gloves (for example, disposable nitrile), washable rubber boots, and a particulate face mask (for example, N-95) or better respiratory protection to prevent ingesting any eggs or inhaling fecal bacteria and fungi stirred up in dust (Kazacos and Boyce, 1989; Kazacos, 2001). When finished, disposable items should be bagged and discarded, incinerated, or otherwise properly disposed of.

The presence of eggs in soil or environmental debris, as well as the effectiveness of their destruction or removal, can be evaluated using routine centrifugal sedimentation-flotation methods (Kazacos, 1983c). It is very important that this be done by a trained parasitologist or microbiologist with the necessary experience and expertise for proper identification of Baylisascaris eggs. When present in environmental samples, the eggs must be separated from myriad pseudoparasites and other materials (pollen, other plant material, fungal spores, free-living invertebrates, other parasite eggs, etc.) that will also be recovered. For example, certain plant pollen bears a striking resemblance to Baylisascaris eggs and could easily be misidentified as such.

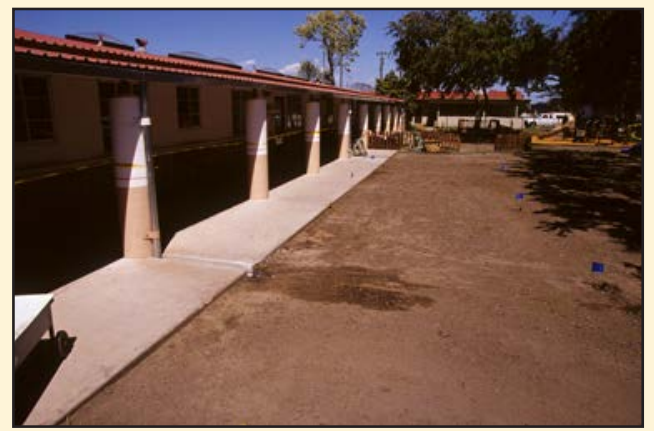

$E$. Daycare facility after remediation that included complete substrate removal. (Photo by William J. Murray) 


\section{Coping with Baylisascaris Neural Larva Migrans-From Individual People, to Wildlife Populations, to Organizations}

The consequences of Baylisascaris infection must be dealt with at many levels, ranging from individual patients and their families to populations, facilities, and organizations.

\section{Individuals and Families}

For the individual patient, severe neural larva migrans (NLM) is life-changing as it can result in considerable brain damage from trauma and inflammation. Because there is a lag time in the development of clinical signs, by the time they are manifest and the diagnosis and treatment are considered, significant brain damage may already have occurred (Kazacos, 2000, 2001; Murray and Kazacos, 2004; Gavin and others, 2005; Kazacos and others, 2013; Singaravelu and others, 2016). This damage is often irreversible. The extent of the damage will vary depending on the infecting dose; however, there may be little hope for much improvement despite aggressive therapy. Thus, prevention of infection is vitally important with this parasite. When clinical signs indicate that a patient may have become infected, diagnosis and treatment must be initiated as early as possible. Once inflammation is brought under control and larvae are either killed or have become walled off, a patient may be stabilized albeit with varying neurologic deficits. In some cases of lower level infection in children, a patient's condition may gradually improve as the brain continues to develop and neural pathways are developed and (or) “rewired” (Sanders, 2015). However, patients may continue to degenerate further as the brain undergoes postinflammatory atrophy and a significant loss of substance. Patients with severe NLM may end up in a vegetative state or with severe neurologic impairments: wheelchair-bound, incontinent, with loss of most normal functions, requiring nursing care for the rest of their lives. Because of severe neurologic disease, they may develop other disabilities, such as muscle atrophy in the extremities, severe tendon contractures that may require surgery, breathing difficulties and (or) aspiration pneumonia.

Families are changed forever as a once ebullient child undergoes a major change and downward spiral, being lost to the devastating effects of larva migrans encephalitis (Sanders, 2015). Parents and siblings must then adapt to an altered lifestyle that includes the demanding needs of the affected child (Huff and others, 1984; Park and others, 2000; Rowley and others, 2000; Moertel and others, 2001; Reilly, 2008; Sanders, 2015). These challenges may be met with love and acceptance or may tear the family apart (Cheney, 2005; Reilly, 2008; Sanders, 2015). A parent may suffer from a level of guilt or blame over a lack of prior knowledge of the parasite or associated risks, as well as possible prevention of the infection in the affected loved one. The real tragedy is that baylisascariasis is a preventable condition based on education, greater awareness, and simple precautions (Kazacos, 2000; Murray and Kazacos, 2004; Gavin and others, 2005).

Baylisascaris encephalitis has also occurred in numerous pets (Appendix 2). It is also important to note that the loss of pet animals, often considered valued members of the family, can have similarly devastating effects on the wellbeing of that family, and many pets have been lost to this disease. Owners are often guilt ridden, thinking they could have avoided the death of the pet somehow. In one particularly touching case, a single man in Indiana lost what was his entire family, namely ten parrots and conures, to severe neurologic disease in a short period of time. The birds had as many as 150 larvae in the brain alone. The owner was absolutely devastated by this and blamed himself for the loss of his birds, although it was purely an accident. Raccoons had accessed a seed mixture he had stored in his garage, and began defecating in the food container. Once the $B$. procyonis eggs became infective, he was essentially feeding highly contaminated feed to the birds, which all died in a short period of time (A.M. Lennox and others, unpub. data, 1996; Lennox and others, 2015).

\section{Wildlife Populations}

Early research by Tiner (1954) estimated that B. procyonis was responsible for 5 percent of natural rodent mortality in Illinois woodlots where raccoons were common. Even higher levels of infection and potential mortality were noted more recently in Indiana (Page, 1998; Page and others, $2001 \mathrm{~b}, \mathrm{c})$. This is a significant population mortality level due to a single parasitic agent, and we now know that this very nonspecific parasite is affecting many more species than were ever considered earlier. Most cases of NLM in wildlife go undetected by humans due to their cryptic occurrence, isolated location, the small size of affected animals, and the fact that affected individuals are removed by predators and scavengers (Kazacos, 2001). For example, thousands of wild rodents and rabbits with neurologic disease are submitted to diagnostic laboratories or public health laboratories every year in the United States and 


\section{Coping with Baylisascaris Neural Larva Migrans-From Individual People, to Wildlife Populations, to Organizations}

Canada with the primary concern being rabies; 99 percent of these animals are rabies negative (Fitzpatrick and others, 2014) and, when examined, Baylisascaris encephalitis turns out to be a common cause of CNS disease in these and other animals (Richter and Kradel, 1964; Fleming and Caslick, 1978; Kazacos, Appel, and Thacker, 1981; Roth and others, 1982; Kazacos, 2001).

The real-time devastating effects of $B$. procyonis on particular animal populations are shown by the plight of the Allegheny woodrat, believed to have been extirpated from a large portion of its northeastern range by $B$. procyonis, and continuing to be adversely affected in other geographic areas (Kazacos, 2001; LoGiudice, 2003; Page and others, 2012) (see “The Plight of the Allegheny Woodrat"). In such cases, the interaction of raccoon populations with the local environment and other animal species becomes very important and is compounded by particular behaviors that place certain animal species at a greater risk of infection than others. Of particular importance is the potential effect of the parasite on threatened or endangered species that are already struggling due to human-generated effects on their environment or other factors. Even at low prevalence in raccoons and latrines, $B$. procyonis could still have important negative consequences, because a very small number of ingested eggs can result in fatal NLM in susceptible species (Page and others, 2012). One could easily extrapolate these findings (Tiner, 1954; Page and others, 2001b,c, 2012), combined with the widespread occurrence of NLM in mammals and birds, to indicate that $B$. procyonis is having a low-grade mortality effect on various animal populations within its range.

\section{Facilities and Organizations}

Baylisascaris NLM has had direct effects on agricultural operations, research animal facilities, zoos and wildlife parks, wildlife rehabilitation facilities, and human childcare facilities, based on significant outbreaks of neurologic disease in animals and humans. Numerous cases exist of either insidious or major devastating losses in animal operations (Appendix 3). In some cases, mortality was 100 percent or involved hundreds of animals.

Many zoos have ongoing problems with $B$. procyonis, because they are commonly overrun with raccoons at night, leading to widespread contamination of the facilities. Fatal or severe NLM has been seen in numerous zoo species. Serologic evidence of infection was found by ELISA in 76 of 259 ( 29 percent) nonhuman primates at 6 major zoos (Zimmerman and others, 2010), indicating just how commonly zoo animals are exposed to this parasite. In addition to raccoons, zoos may have problems with other nuisance wildlife species, including coyotes and skunks. An excellent example of this problem, which exists in many suburban zoos, occurred in the Los Angeles Zoo:

"The Los Angeles Zoo sits in the middle of Griffith Park, which is a large wild area. Previous nonmanagement of pests had allowed the zoo to become overrun with these animals, and problems had reached epidemic proportions in 1995. Coyotes living in the zoo were hunting gerenuk and flamingos, skunks were everywhere, and raccoons had free-roam of the zoo. In the past 3 years at the Los Angeles Zoo, we have seen numerous cases of central nervous system disease secondary to Baylisascaris" (Stringfield and Sedgwick, 1997).

These problems were met by an immediate and aggressive, multifaceted response following a change in zoo management. Response measures entailed trapping and removing the resident raccoon, skunk, and coyote populations from zoo property, repairing gaps in the perimeter fencing to prevent future influx, trimming trees and overhanging foliage, installing wire mesh barriers along the bottoms of exhibits to prevent animal access, repairing garbage bins, cleaning and rehabilitating contaminated exhibits, and instituting ongoing surveillance and control measures, coupled with educating staff. The scope of the task was daunting; however, with thoughtful planning and implementation the program was successful, and nuisance wildlife and Baylisascaris transmission to zoo animals were both brought under control.

Although most human cases have involved individual children, several have involved facilities where additional children or adults were exposed to infection. In one case in southern California, an 11-month-old boy at a well-run university childcare facility developed marked eosinophilic meningoencephalitis with blindness due to $B$. procyonis (Schultz, 2002; Murray and Kazacos, 2004; K.R. Kazacos, unpub. data, 2002-4; Sanders, 2015). He was in a facility where over 80 other children in his class group, as well as others, were potentially exposed. Several other children also were seropositive, indicating infection, but without obvious clinical signs. Infection was linked to the presence of raccoon latrines on the sloped metal roof of the building, with feces and eggs washing down into the infant and toddler play area below $(A-C)$. Following this outbreak, the facility was closed under public health quarantine and 


\section{Coping with Baylisascaris Neural Larva Migrans-From Individual People, to Wildlife Populations, to Organizations}

extensively remediated before being allowed to reopen and accept children again. The victim's family moved to the northeastern United States, was able to secure a major monetary settlement for his care, and the child continues to improve following aggressive therapy at the time of infection and subsequent major physical and learning rehabilitation (K.R. Kazacos, unpub. data, 2004-15; Sanders, 2015) (D).

Cases also have involved adults in group homes or state facilities for developmentally disabled individuals. One case in southern California involved a 17 -year-old boy admitted to a hospital emergency room in a coma, suffering from severe Baylisascaris encephalitis from which he later died (Kazacos, Gavin, and others, 2002). This patient lived in a well-run group home for developmentally disabled adolescents, where he displayed abnormal behavior including eating sand from the sandbox play area. This sandbox was the site of a raccoon latrine and had extensive contamination with $B$. procyonis eggs, and the property had to be decontaminated and remediated to prevent other cases. A similar
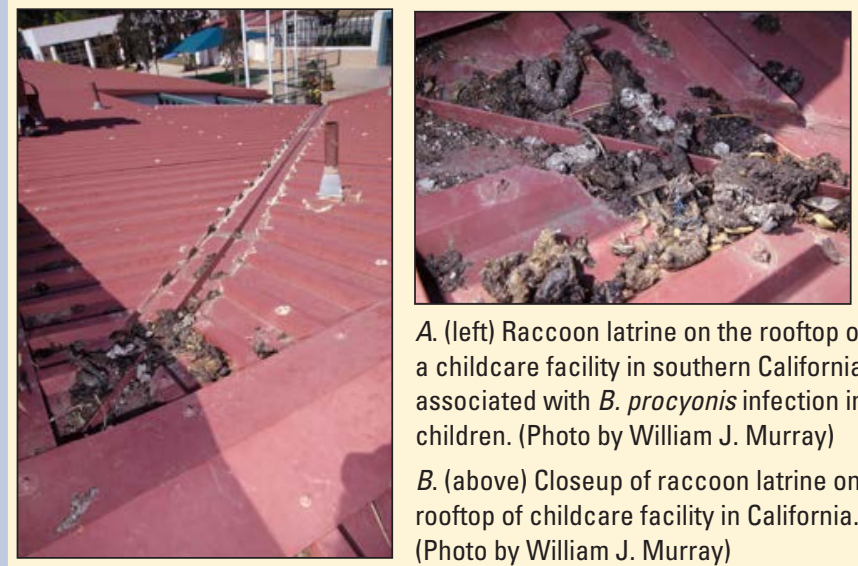

A. (left) Raccoon latrine on the rooftop of a childcare facility in southern California associated with $B$. procyonis infection in children. (Photo by William J. Murray)

$B$. (above) Closeup of raccoon latrine on rooftop of childcare facility in California. (Photo by William J. Murray)

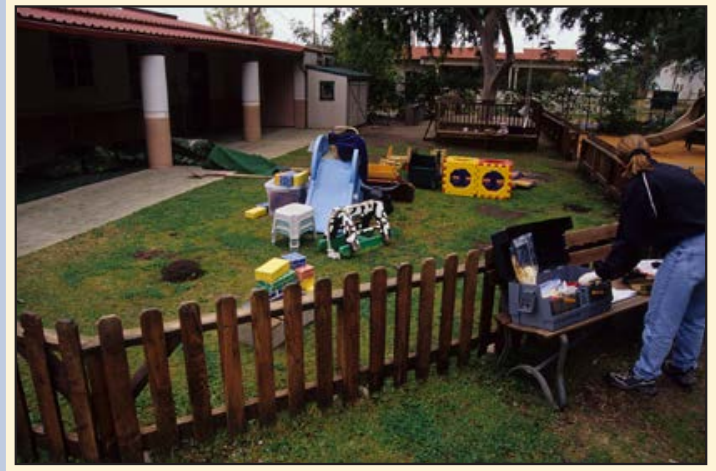

C. Infant and toddler play area in contaminated childcare facility in California. (Photo by William J. Murray) case occurred in Oregon, where a 21-year-old man in a state facility became infected due to geophagia (Cunningham and others, 1994) and subsequently suffered a long course of worsening central nervous system problems and therapies, including partial cranial lobotomy. These cases indicate that individuals in group facilities may be at a particular risk of infection due to their developmentally delayed status and altered behavior, their young age, or both.

Besides the devastating health effects on individuals, these incidents raise important questions concerning previously unconsidered legal liability issues involving $B$. procyonis infection in such facilities and, as previously mentioned, at least one case resulted in a major monetary settlement following legal redress. It is definitely in their own best interest, as well as that of their clients and endusers, that such organizations address potential issues with this parasite at their facilities, through education, heightened awareness and preventive measures, increased animal control and exclusion, fecal cleanup, sanitation, surveillance, and other routine precautions.

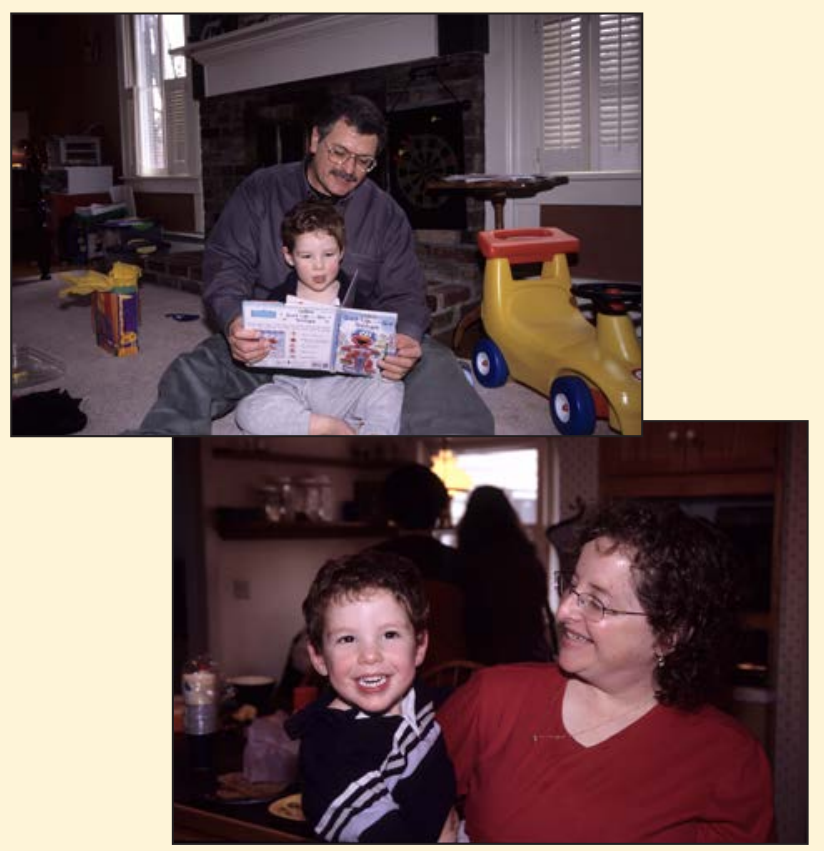

$D$. Child infected with B. procyonis in childcare facility in California, several years later following treatment and extensive physical and learning rehabilitation. (Photos by Anthony R. and Kevin Kazacos) 


\section{References Cited}

Abdelrasoul, K., and Fowler, M., 1979, Epidemiology of ascarid infection in captive carnivores: Proceedings of the American Association of Zoo Veterinarians, p. 105-106a.

Agnew, D.W., Kazacos, K.R., Watson, G.L., Yamini, B., Barbiers, R., and Garrison, R.D., 1994, Neural larva migrans due to Baylisascaris procyonis in red kangaroos: Proceedings of the American Association of Veterinary Parasitologists, v. 39, p. 68.

Akao, N., Hayashi, E., Sato, H., Fujita, K., and Furuoka, H., 2003, Diffuse retinochoroiditis due to Baylisascaris procyonis in Mongolian gerbils: Journal of Parasitology, v. 89 , p. $174-175$.

Akao, N., and Ohta, N., 2007, Toxocariasis in Japan: Parasitology International, v. 56, p. 87-93.

Aliev, F.F., and Sanderson, G.C., 1966, Distribution and status of the raccoon in the Soviet Union: Journal of Wildlife Management, v. 30, p. 497-502.

Al-Lebban, H.M., and Lindquist, W.D., 1979, Comparison between migratory behavior of Toxocara canis and Baylisascaris procyonis larvae in orally and parenterally infected mice: Proceedings of the Conference of Research Workers in Animal Disease, Abstract 130.

Amaro, M.H., 2000, Reports of diffuse unilateral subacute neuroretinitis: Archives of Ophthalmology, v. 118, p. 1593.

American Ornithologists' Union, 2012, Check-list of North American birds: http://checklist.aou.org/taxa/.

Amundson, T., and Marquenski, S., 1986, Baylisascaris procyonis in Wisconsin raccoons: Madison, Wisconsin Department of Natural Resources, p. 1-7.

Anderson, B.C., 1999, Congenital Baylisascaris sp. larval migrans in a newborn lamb: Journal of Parasitology, v. 85, p. 128-129.

Anderson, D.C., Greenwood, R., Fishman, M., and Kagan, I.G., 1975, Acute infantile hemiplegia with cerebrospinal fluid eosinophilic pleocytosis: An unusual case of visceral larva migrans: Journal of Pediatrics, v. 86, p. 247-249.

Anderson, S.B., and Mills, J., 1991, Occurrence of the raccoon roundworm (Baylisascaris procyonis) in raccoons in Nova Scotia: Kentville, Nova Scotia Department of Lands and Forests, Technical Note No. 67, 2 p.

Armstrong, D.L., Montali, R.J., Kazacos, K.R., and Doster, A.R., 1987, Cerebrospinal nematodiasis in blue and gold macaws and scarlet macaws associated with Baylisascaris procyonis: Proceedings of the First International Conference on Zoological and Avian Medicine, p. 489-490.
Armstrong, D.L., Montali, R.J., Doster, A.R., and Kazacos, K.R., 1989, Cerebrospinal nematodiasis in macaws due to Baylisascaris procyonis: Journal of Zoo and Wildlife Medicine, v. 20, p. 354-359.

Averbeck, G.A., Vanek, J.A. Stromberg, B.E. and Laursen, J.R., 1995, Differentiation of Baylisascaris species, Toxocara canis, and Toxascaris leonina infections in dogs: Compendium on Continuing Education for the Practicing Veterinarian, v. 17, p. 475-478, 511.

Babero, B.B., and Shepperson, J.R. 1958, Some helminths of raccoons in Georgia: Journal of Parasitology, v. 44, p. 519.

Bafundo, K.W., Wilhelm, W.E., and Kennedy, M.L., 1980, Geographic variation in helminth parasites from the digestive tract of Tennessee raccoons, Procyon lotor: Journal of Parasitology, v. 66, p. 134-139.

Balcom, B.J., and Yahner, R.H., 1996, Microhabitat and landscape characteristics associated with the threatened Allegheny woodrat: Conservation Biology, v. 10, p. 515-525.

Ball, R.L., Dryden, M., Wilson, S., and Veatch, J., 1998, Cerebrospinal nematodiasis in a white-handed gibbon (Hylobates lar) due to Baylisascaris sp: Journal of Zoo and Wildlife Medicine, v. 29, p. 221-224.

Barnstable, R.W., and Dyer, W.G., 1974, Gastrointestinal helminths of the raccoon, Procyon lotor, in southern Illinois: Transactions of the Illinois State Academy of Science, v. 67, p. 451-460.

Bartoszewicz, M., 2011, NOBANIS—Invasive Alien Species Fact Sheet-Procyon lotor: Online database of the European Network on Invasive Alien Species- NOBANIS, S accessed May 25, 2104, at http://www.nobanis.org/files/ factsheets/Procyon_lotor.pdf.

Bartoszewicz, M., Okarma, H., Zalewski, A., and Szczęsna, J., 2008, Ecology of the raccoon (Procyon lotor) from western Poland: Annales Zoologici Fennici, v. 45, p. 291-298.

Bauer, C., and Gey, A., 1995, Efficacy of six anthelmintics against luminal stages of Baylisascaris procyonis in naturally infected raccoons (Procyon lotor): Veterinary Parasitology, v. 60, p. 155-159.

Beasley, J.C., Eagan, T.S., II, Page, L.K., Hennessy, C.A., and Rhodes, O.E., Jr., 2013, Baylisascaris procyonis infection in white-footed mice: predicting patterns of infection from landscape habitat attributes: Journal of Parasitology, v. 99, p. 743-747.

Beaver, P.C., 1969, The nature of visceral larva migrans: Journal of Parasitology, v. 55, p. 3-12. 
Beck, S.E., Kelly, K., Mankowski, J., Nolte, J., and Graham, D., 2010, Case 8: 1 year, 4 month-old female titi monkey (62078): Proceedings of the 2010 Primate Pathology Workshop, ACVP/ASVCP Pre-Meeting Workshop of American College of Veterinary Pathologists, Baltimore, Maryland, October 30, 2010, p. 26-29.

Beltrán-Beck, B., Garcia, F.J., and Gortazar, C., 2012, Raccoons in Europe: disease hazards due to the establishment of an invasive species: European Journal of Wildlife Research, v. 58, no. 1, p. 5-15.

Berry, J.F., 1985, Phylogenetic relationship between Baylisascaris spp. Sprent, 1968 (Nematoda: Ascarididae) from skunks, raccoons and groundhogs in southern Ontario: Guelph, Ontario, University of Guelph, M.S. Thesis, 99 p.

Birch, G.L., Feldhamer, G.A., and Dyer, W.G., 1994. Helminths of the gastrointestinal tract of raccoons in southern Illinois with management implications of Baylisascaris procyonis occurrence: Transactions of the Illinois State Academy of Science, v. 87, p. 165-170.

Blizzard, E.L., Davis, C.D., Henke, S., Long, D.B., Hall, C.A., and Yabsley, M.J., 2010, Distribution, prevalence, and genetic characterization of Baylisascaris procyonis in selected areas of Georgia: Journal of Parasitology, v. 96, p. 1128-1133.

Blizzard, E.L., Yabsley, M.J., Beck, M.F., and Harsch, S., 2010, Geographic expansion of Baylisascaris procyonis roundworms, Florida, USA: Emerging Infectious Diseases, v. 16, p. $1803-1804$.

Bluett, R.D., Hubert, G.F., Jr., and Miller, C.A., 2003, Regulatory oversight and activities of wildlife control operators in Illinois: Wildlife Society Bulletin, v. 31, p. 104-116.

Boddicker, M.L., and Progulske, D.R., 1968, Helminth parasites of raccoon in South Dakota: Proceedings of the South Dakota Academy of Science, v. 47, p. 161-166.

Boggess, E.K., 1994, Raccoons, in Hygnstrom, S.E., Timm, R.M., and Larson, G.E., Prevention and control of wildlife damage: University of Nebraska-Lincoln, p. C-101-C-107.

Boschetti, A., and Kasznica, J., 1995, Visceral larva migrans induced eosinophilic cardiac pseudotumor: A cause of sudden death in a child: Journal of Forensic Sciences, v. 40, p. 1097-1099.

Bowman, D.D., 1987, Diagnostic morphology of four larval ascaridoid nematodes that may cause visceral larva migrans: Toxascaris leonina, Baylisascaris procyonis, Lagochilascaris sprenti, and Hexametra leidyi: Journal of Parasitology, v. 73, p. 1198-1215.
Bowman, D.D., Ulrich, M.A., Gregory, D.E., Neumann, N.R., Legg, W., and Stansfield, D., 2005, Treatment of Baylisascaris procyonis infections in dogs with milbemycin oxime: Veterinary Parasitology, v. 129, p. 285-290.

Boyce, W.M., Branstetter, B.A., and Kazacos, K.R., 1988a, In vitro culture of Baylisascaris procyonis and initial analysis of larval excretory-secretory antigens: Proceedings of the Helminthological Society of Washington, v. 55, p. 15-18.

Boyce, W.M., Branstetter, B.A., and Kazacos, K.R., 1988b, Comparative analysis of larval excretory-secretory antigens of Baylisascaris procyonis, Toxocara canis and Ascaris suum by western blotting and enzyme immunoassay: International Journal for Parasitology, v. 18, p. 109-113.

Boyce, W.M., Asai, D.J., Wilder, J.K., and Kazacos, K.R., 1989, Physicochemical characterization and monoclonal and polyclonal antibody recognition of Baylisascaris procyonis larval excretory-secretory antigens: Journal of Parasitology 75, p. 540-548.

Brasil, O.F.M., Lewis, H., and Lowder, C.Y., 2006, Migration of Baylisascaris procyonis into the vitreous: British Journal of Ophthalmology, v. 90, p. 1203-1204.

Brinch, K.S., 2006, Baylisascaris procyonis (vaskebjornens spolorm) hos danske vaskebjorne: Dansk Veterinaertidsskrift, v. 89, p. 28-35.

Brinkman, W.B., Kazacos, K.R., Gavin, P.J., Binns, H.J., Robichaud, J.D., O'Gorman, M., and Shulman, S.T., 2003, Seroprevalence of Baylisascaris procyonis (raccoon roundworm) in Chicago area children: Proceedings of the Annual Meeting of the Pediatric Academic Societies, Abstract 1872.

Brown, L.W., and Huff, D., 1983, Human disease due to the raccoon ascarid Baylisascaris procyonis: a new cause of eosinophilic meningitis: Proceedings of the Child Neurology Society, Abstract 110.

Campbell, G.A., Hoover, J.P., Russell, W.C., and Breazile, J.E., 1997, Naturally occurring cerebral nematodiasis due to Baylisascaris larval migration in two black-and-white ruffed lemurs (Varecia variegata variegata) and suspected cases in three emus (Dromaius novaehollandiae): Journal of Zoo and Wildlife Medicine, v. 28, p. 204-207.

Carlson, M.S., and Nielsen, S.W., 1984, Jejunal obstruction due to Baylisascaris procyonis in a raccoon: Journal of the American Veterinary Medical Association, v. 185, p. 1396-1397.

Casella, A.M.B., Farah, M.E., and Belfort, R., Jr., 1998, Anthelmintic drugs in diffuse unilateral subacute neuroretinitis: American Journal of Ophthalmology, v. 125, p. 109-111. 
Centers for Disease Control and Prevention, 2015, Bringing an animal into the United States: accessed September 10, 2015, at http://www.cdc.gov/importation/bringing-an-animal-intothe-United-States/index.html.

Chandler, A.C., 1942, The helminths of raccoons in east Texas: Journal of Parasitology, v. 28, p. 255-268.

Chavez, D.J., LeVan, I.K., Miller, M.W., and Ballweber, L.R., 2012, Baylisascaris procyonis in raccoons (Procyon lotor) from eastern Colorado, an area of undefined prevalence: Veterinary Parasitology, v. 185, p. 330-334.

Cheney, P., 2005, The danger that lurks in the backyard dirt: The Globe and Mail, Globe Toronto, Saturday, October 8, 2005, M1.

Ching, H.L., Leighton, B.J., and Stephen, C., 2000, Intestinal parasites of raccoons (Procyon lotor) from southwest British Columbia: Canadian Journal of Veterinary Research, v. 64 , p. 107-111.

Chris, A., 2005, Baylisascaris-Canada (Ontario): ProMEDmail 2005; 6 September: 20050907.2660 (http://www. promedmail.org).

Chun, C.S., Kazacos, K.R., Glaser, C., Bardo, D., Dangoudoubiyam, S., and Nash, R., 2009, Global neurological deficits with Baylisascaris encephalitis in a previously healthy teenager: Pediatric Infectious Disease Journal, v. 28, p. $925-927$.

Church, E.M., Wyand, D.S., and Lein, D.H., 1975, Experimentally induced cerebrospinal nematodiasis in rabbits (Oryctolagus cuniculus): American Journal of Veterinary Research, v. 36, p. 331-335.

Cialdini, A.P., de Souza, E.C., and Avila, M.P., 1999, The first South American case of diffuse unilateral subacute neuroretinitis caused by a large nematode: Archives of Ophthalmology, v. 117, p. 1431-1432.

Ciarlini, P., Gutierrez, Y., Gambetti, P., and Cohen, M., 2011, Necrotizing eosinophilic meningoencephalitis: Case 2011-06, 52 ${ }^{\text {nd }}$ Annual Diagnostic Slide Session, 87 ${ }^{\text {th }}$ Annual Meeting of the American Association of Neuropathologists, Seattle, Washington, June 23-26, 2011, accessed July 30, 2014, at http://neuro.pathology.pitt.edu/DSSFiles/ DSSCases2011.htm.

Clark, G.M., Philip, C.B., and Fadness, L., 1969, Observations on the effect in mice of concurrent infections with migratory Ascaris columnaris larvae and certain neurotropic arboviruses: Folia Parasitologica, v. 16, p. 67-73.

Coates, J.W., Siegert, J., Bowes, V.A., and Steer, D.G., 1995, Encephalitic nematodiasis in a Douglas squirrel and a rock dove ascribed to Baylisascaris procyonis: Canadian Veterinary Journal, v. 36, p. 566-569.
Cole, R.A., and Shoop, W.L., 1987, Helminths of the raccoon (Procyon lotor) in western Kentucky: Journal of Parasitology, v. 73, p. 762-768.

Conboy, G., 1996, Diagnostic parasitology: Canadian Veterinary Journal, v. 37, p. 181-182.

Conboy, G., Stewart, T.A., and Taylor, A., 2010, Baylisascaris procyonis infection in raccoons and dogs on Prince Edward Island, Canada: Proceedings of the American Association of Veterinary Parasitologists, v. 55, p. 56.

Conraths, F.J., Bauer, C., Cseke, J., and Laube, H., 1996, Arbeitsplatzbedingte Infektionen des Menschen mit dem Waschbärspulwurm Baylisascaris procyonis: Arbeitsmedizin Sozialmedizin Umweltmedizin, v. 31, p. 13-17. [In German with English summary.]

Cooney, T.A., 1989, Environmental contamination with Baylisascaris procyonis in an urban park: West Lafayette, Indiana, Purdue University, M.S. Thesis, 125 p.

Cortez, R., Denny, J.P., Muci-Mendoza, R., Ramirez, G., Fuenmayor, D., and Jaffe, G.J., 2005, Diffuse unilateral subacute neuroretinitis in Venezuela: Ophthalmology, v. 112, p. 2110-2114.

Cottrell, W.O., Heagy, R.L., Johnson, J.B., Marcantuno, R., and Nolan, T.J., 2014, Geographic and temporal prevalence of Baylisascaris procyonis in raccoons (Procyon lotor) in Pennsylvania, USA: Journal of Wildlife Diseases, v. 50, p. 923-927.

Craig, S.J., Conboy, G.A., and Hanna, P.E., 1995, Baylisascaris sp. infection in a guinea pig: Laboratory Animal Science, v. 45, p. 312-314.

Cranfield, M.R., Barker, I.K., Mehren, K.G., and Rapley, W.A., 1984, Canine distemper in wild raccoons (Procyon lotor) at the metropolitan Toronto zoo: Canadian Veterinary Journal, v. 25, p. 63-66.

Crosley, C.J., and Kazacos, K.R., 2005, Baylisascaris meningo-encephalitis in three infants: Abstract P76, Proceedings of the $34^{\text {th }}$ Annual Meeting of the Child Neurology Society, Los Angeles, California, Sept 28-Oct 1, 2005, Annals of Neurology, v. 58 (suppl. 9), p. S114.

Cunningham, C.K., Kazacos, K.R., McMillan, J.A., Lucas, J.A., McAuley, J.B., Wozniak, E.J., and Weiner, L.B., 1994, Diagnosis and management of Baylisascaris procyonis infection in an infant with nonfatal meningoencephalitis: Clinical Infectious Diseases, v. 18, p. 868-872.

Dade, A.W., Williams, J.F., Whitenack, D.L., and Williams, C.S.F., 1975, An epizootic of cerebral nematodiasis in rabbits due to Ascaris columnaris: Laboratory Animal Science, v. 25 , p. 65-69. 
Dade, A.W., Williams, J.F., Trapp, A.L., and Ball, W.H., Jr., 1977, Cerebral nematodiasis in captive nutria: Journal of the American Veterinary Medical Association, v. 171, p. $885-886$.

Dangoudoubiyam, S., and Kazacos, K.R., 2009, Differentiation of larva migrans caused by Baylisascaris procyonis and Toxocara species by Western blotting: Clinical and Vaccine Immunology, v. 16, p. 1563-1568.

Dangoudoubiyam, S., Vemulapalli, R., and Kazacos, K.R., 2009, PCR assays for detection of Baylisascaris procyonis eggs and larvae: Journal of Parasitology, v. 95, p. 571-577.

Dangoudoubiyam, S., Vemulapalli, R., Hancock, K., and Kazacos, K.R., 2010, Molecular cloning of an immunogenic protein of Baylisascaris procyonis and expression in Escherichia coli for use in developing improved serodiagnostic assays: Clinical and Vaccine Immunology, v. 17, p. 1933-1939.

Dangoudoubiyam, S., Vemulapalli, R., Ndao, M., and Kazacos, K.R., 2011, Recombinant antigen-based enzyme-linked immunosorbent assay for diagnosis of Baylisascaris procyonis larva migrans: Clinical and Vaccine Immunology, v. 18, p. $1650-1655$.

Davidson, R.K., Øines, Ø., Hamnes, I.S., and Schulze, J.E., 2013, Illegal wildlife imports more than just animals-Baylisascaris procyonis in raccoons (Procyon lotor) in Norway: Journal of Wildlife Diseases, v. 49, p. 986-990.

de Almeida, M.H., 1987, Nuisance furbearer damage control in urban and suburban areas, in Novak, M., Baker, J.A., Obbard, M.E., and Malloch, B., eds., Wild furbearer management and conservation in North America: North Bay, Canada, Ontario Trappers Association, p. 996-1006.

Deeb, B.J., and DiGiacomo, R.F., 1994, Cerebral larva migrans caused by Baylisascaris sp in pet rabbits: Journal of the American Veterinary Medical Association, v. 205, p. 1744-1747.

Diab, S.S., Uzal, F.A., Giannitti, F., and Shivaprasad, H.L., 2012, Cerebrospinal nematodiasis outbreak in an urban outdoor aviary of cockatiels (Nymphicus hollandicus) in southern California: Journal of Veterinary Diagnostic Investigation, v. 24, p. 994-999.

Dixon, D., Reinhard, G.R., Kazacos, K.R., and Arriaga, C., 1988, Cerebrospinal nematodiasis in prairie dogs from a research facility: Journal of the American Veterinary Medical Association, v. 193, p. 251-253.

Done, L.B., and Tamura, Y., 2014, A presumptive case of Baylisascaris procyonis in a feral green-cheeked Amazon parrot (Amazona viridigenalis): Journal of Zoo and Wildlife Medicine, v. 45, p. 157-160.
Donnelly, J.J., Sakla, A.A., Khatami, M., and Rockey, J.H., 1989, Baylisascaris procyonis (Stefanski and Zarnowski, 1951) Ascarididae: Nematoda. II. Third stage larvae, morphogenesis and migratory behaviour: Assiut Veterinary Medical Journal, v. 21, p. 77-85.

Dubey, J.P., 1982, Baylisascaris procyonis and eimerian infections in raccoons: Journal of the American Veterinary Medical Association, v. 181, p. 1292-1294.

Dubey, J.P., Hamir, A.N., Hanlon, C.A., and Rupprecht, C.E., 1992, Prevalence of Toxoplasma gondii infection in raccoons: Journal of the American Veterinary Medical Association, v. 200, p. 534-536.

Eberhard, M.L., Nace, E.K., Won, K.Y., Punkosdy, G.A., Bishop, H.S., and Johnston, S.P., 2003, Baylisascaris procyonis in the metropolitan Atlanta area: Emerging Infectious Diseases, v. 9, p. 1636-1637.

Ermer, E.M., and Fodge, J.A., 1986, Occurrence of the raccoon roundworm in raccoons in western New York: New York Fish and Game Journal, v. 33, p. 58-61.

Evans, R.H., 2001, Baylisascaris procyonis (Nematoda: Ascaridae) in raccoons (Procyon lotor) in Orange County, California: Vector Borne Zoonotic Diseases, v. 1, p. 239-242.

Evans, R.H., 2002, Baylisascaris procyonis (Nematoda: Ascarididae) larva migrans in free-ranging wildlife in Orange County, California: Journal of Parasitology, v. 88, p. 299-301.

Evans, R.H., and Tangredi, B., 1985, Cerebrospinal nematodiasis in free-ranging birds: Journal of the American Veterinary Medical Association, v. 187, p. 1213-1214.

Fan, C.K., Holland, C.V., Loxton, K., and Barghouth, U., 2015, Cerebral toxocariasis: Silent progression to neurodegenerative disorders?: Clinical Microbiology Reviews, v. 28, p. 663-686.

Feigley, H.P., 1992, The ecology of the raccoon in suburban Long Island, N.Y. and its relation to soil contamination with Baylisascaris procyonis ova: Syracuse, New York, State University of New York College of Environmental Science and Forestry, Ph.D. Thesis, 139 p.

Ferris, D.H., Lord, R.D., Jr., Beamer, P.D., and Fritz, T.E., 1960, A new disease in Illinois cottontails: Journal of Wildlife Management, v. 24, p. 179-184.

Fitzgerald, S.D., White, M.R., and Kazacos, K.R., 1991, Encephalitis in two porcupines due to Baylisascaris larval migration: Journal of Veterinary Diagnostic Investigation, v. 3, p. 359-362. 
Fitzpatrick, J.L., Dyer, J.L., Blanton, J.D., Kuzmin, I.V., and Rupprecht, C.E., 2014, Rabies in rodents and lagomorphs in the United States, 1995-2010: Journal of the American Veterinary Medical Association, v. 245, p. 333-337.

Fleming, W.J., and Caslick, J.W., 1978, Rabies and cerebrospinal nematodiasis in woodchucks (Marmota monax) from New York: Cornell Veterinarian, v. 68, p. 391-395.

Fleming, W.J., Georgi, J.R., and Caslick, J.W., 1979, Parasites of the woodchuck (Marmota monax) in central New York: Proceedings of the Helminthological Society of Washington, v. 46, p. 115-127.

Forrester, D.J., 1992, Parasites and diseases of wild mammals in Florida: Gainesville, University Press of Florida, 480 p.

Fox, A.S., Kazacos, K.R., Gould, N.S., Heydemann, P.T., Thomas, C., and Boyer, K.M., 1985, Fatal eosinophilic meningoencephalitis and visceral larva migrans caused by the raccoon ascarid Baylisascaris procyonis: New England Journal of Medicine, v. 312, p. 1619-1623.

Franssen, F., Xie, K., Sprong, H., and van der Giessen, J., 2013, Molecular analysis of Baylisascaris columnaris revealed mitochondrial and nuclear polymorphisms: Parasites and Vectors, v. 6, p. 124-133.

Fritz, T.E., Smith, D.E., and Flynn, R.J., 1968, A central nervous system disorder in ground squirrels (Citellus tridecemlineatus) associated with visceral larva migrans: Journal of the American Veterinary Medical Association, v. 153, p. 841-844.

Furuoka, H., Sato, H., Kubo, M., Owaki, S., Kobayashi, Y., Matsui, T., and Kamiya, H., 2003, Neuropathological observation of rabbits (Oryctolagus cuniculus) affected with raccoon roundworm (Baylisascaris procyonis) larva migrans in Japan: Journal of Veterinary Medical Science, v. 65 , p. 695-699.

García, J.T., García, F.J., Alda, F., González, J.L., Aramburu, M.J., Cortés, Y., Prieto, B., Pliego, B., Pérez, M., Herrera, J., and García-Román, L., 2012, Recent invasion and status of the raccoon (Procyon lotor) in Spain: Biological Invasions, v. 14, p. 1305-1310.

Garlick, D.S., Marcus, L.C., Pokras, M., and Schelling, S.H., 1996, Baylisascaris larva migrans in a spider monkey (Ateles sp.): Journal of Medical Primatology, v. 25, p. 133-136.

Garrison, R.D., 1996, Evaluation of anthelmintic and corticosteroid treatment in protecting mice (Mus musculus) from neural larva migrans due to Baylisascaris procyonis: West Lafayette, Indiana, Purdue University, M.S. Thesis, 102 p.
Garrison, R.D., and Kazacos, K.R., 1994, Effects of freezing on the development and infectivity of Baylisascaris procyonis eggs: Proceedings of the American Association of Veterinary Parasitologists, v. 39, p. 68.

Gass, J.D.M., 1997, Inflammatory diseases of the retina and choroid, in Stereoscopic atlas of macular diseases: diagnosis and treatment, $4^{\text {th }}$ ed.: St. Louis, Missouri, Mosby-Year Book Inc., p. 622-628.

Gass, J.D.M., and Braunstein, R.A., 1983, Further observations concerning the diffuse unilateral subacute neuroretinitis syndrome: Archives of Ophthalmology, v. 101, p. 1689-1697.

Gass, J.D.M., Gilbert, W.R., Jr., Guerry, R.K., and Scelfo, R., 1978, Diffuse unilateral subacute neuroretinitis: Ophthalmology, v. 85, p. 521-545.

Gass, J.D.M., Callanan, D.G., and Bowman, C.B., 1992, Oral therapy in diffuse unilateral subacute neuroretinitis: Archives of Ophthalmology, v. 110, p. 675-680.

Gatcombe, R.R., Narayanan, J., Dangoudoubiyam, S., Kazacos, K.R., and Hill, V., 2010, Evaluation of a molecular beacon real-time PCR assay for detection of Baylisascaris procyonis in different soil types and water samples: Parasitology Research, v. 106, p. 499-504.

Gavin, P.J., Kazacos, K.R., and Shulman, S.T., 2005, Baylisascariasis: Clinical Microbiology Reviews, v. 18, p. 703-718.

Gavin, P.J., Kazacos, K.R., Tan, T.Q., Brinkman, W.B., Byrd, S.E., Davis, A.T., Mets, M.B., and Shulman, S.T., 2002, Neural larva migrans caused by the raccoon roundworm Baylisascaris procyonis: Pediatric Infectious Disease Journal, v. 21, p. 971-975.

Gehrt, S.D., 2003, Raccoons (Procyon lotor) and allies, in Feldhamer, G.A., Thompson, B.C., and Chapman, J.A., eds., Wild mammals of North America: Biology, management, and conservation, $2^{\text {nd }}$ ed: Baltimore, Maryland, Johns Hopkins University Press, p. 611-634.

Geptner, V.G., and Naumov, N.P., 1967, Mammals of USSR, Vol. 2: Moscow, Visaja skola. [In Russian.]

Gey, A.B., 1998, Synopsis der Parasitenfauna des Waschbären (Procyon lotor) unter Berücksichtigung von Befunden aus Hessen: Giesen, Germany, Justus Liebig Universität, Dissertation, Fachbereich Veterinärmedizin, 203 p. [In German.]

Goldberg, M.A., Kazacos, K.R., Boyce, W.M., Ai, E., and Katz, B., 1993, Diffuse unilateral subacute neuroretinitis. Morphometric, serologic, and epidemiologic support for Baylisascaris as a causative agent: Ophthalmology, v. 100, p. 1695-1701. 
Goldberg, N., and Bhatnagar, P., 2012, Letter to the Editor, Diffuse unilateral subacute neuroretinitis (DUSN): Ocular Immunology \& Inflammation, v. 20, p. 139-142.

Goldman, E.A., 1950, Raccoons of North and Middle America: U.S. Fish and Wildlife Service, North American Fauna, v. $60,158 \mathrm{p}$.

Gozalo, A.S., Cheng, L.I., Maximova, O., St. Claire, M., Montali, R.J., Ward, J.M., Elkins, W.R., and Kazacos, K.R., 2008, Visceral and neural larva migrans in Rhesus macaques: Journal of the American Association for Laboratory Animal Science, v. 47, p. 64-67.

Greve, J.H., 1985, Raccoon ascarids pose public health threat: Iowa State University Veterinarian, v. 47, p. 13-14.

Greve, J.H., and O’Brien, S.E., 1989, Adult Baylisascaris infections in two dogs: Companion Animal Practice, v. 19, p. 41-43.

Habermann, R.T., Herman, C.M., and Williams, F.P., Jr., 1958, Distemper in raccoons and foxes suspected of having rabies: Journal of the American Veterinary Medical Association, v. 132, p. 31-35.

Haider, S., Khairnar, K., Martin, D.S., Yang, J., Ralevski, F., Kazacos, K.R., and Pillai, D.R., 2012, Possible pet-associated baylisascariasis in child, Canada: Emerging Infectious Diseases, v. 18, p. 347-349.

Hajek, J., Yau, Y., Kertes, P., Soman, T., Laughlin, S., Kanani, R., Kazacos, K., Dangoudoubiyam, S., and Opavsky, M.A., 2009, A child with raccoon roundworm meningoencephalitis: A pathogen emerging in your own backyard?: Canadian Journal of Infectious Diseases and Medical Microbiology, v. 20 , p. e177-e180.

Hamann, K.J., Kephart, G.M., Kazacos, K.R., and Gleich, G.J., 1989, Immunofluorescent localization of eosinophil granule major basic protein in fatal human cases of Baylisascaris procyonis infection: American Journal of Tropical Medicine and Hygiene, v. 40, p. 291-297.

Hancock, K., Zajac, A.M., Elvinger, F., and Lindsay, D.S., 2002, Survey of raccoons (Procyon lotor) in northern Virginia for zoonotic parasites: Proceedings of the American Association of Veterinary Parasitologists, v. 47, p. 45.

Hanley, C.S., Simmons, H.A., Wallace, R.S., and Clyde, V.L., 2006, Visceral and presumptive neural baylisascariasis in an orangutan (Pongo pygmaeus): Journal of Zoo and Wildlife Medicine, v. 37, p. 553-557.

Harkema, R., and Miller, G.C., 1962, Helminths of Procyon lotor solutus from Cape Island, South Carolina: Journal of Parasitology, v. 48, p. 333-335.
Harkema, R., and Miller, G.C., 1964, Helminth parasites of the raccoon, Procyon lotor, in the southeastern United States: Journal of Parasitology, v. 50, p. 60-66.

Helfer, D.H., and Dickinson, E.O., 1976, Parasitic encephalitis in pigeons: Avian Diseases, v. 20, p. 209-210.

Herman, C.M., 1939, Parasites obtained from animals in the collection of the New York Zoological Park during 1938: Zoologica (New York), v. 24, p. 481-485.

Hernandez, S.M., Galbreath, B., Riddle, D.F., Moore, A.P., Palamar, M.B., Levy, M.G., DePerno, C.S., Correa, M.T., and Yabsley, M.J., 2013, Baylisascaris procyonis in raccoons (Procyon lotor) from North Carolina and current status of the parasite in the USA: Parasitology Research, v. 112, no. 2, p. 693-698.

Hill, R.E., Jr., Zimmerman, J.J., Greve, J.H., and Beran, G.W., 1991, Use of ivermectin against several nematodes in naturally infected raccoons (Procyon lotor): Journal of Zoo and Wildlife Medicine, v. 22, p. 417-420.

Hirsch, B.T., Prange, S., Hauver, S.A., and Gehrt, S.D., 2014, Patterns of latrine use by raccoons (Procyon lotor) and implications for Baylisascaris procyonis transmission: Journal of Wildlife Diseases, v. 50, p. 243-249.

Hoberg, E.P., and McGee, S.G., 1982, Helminth parasitism in raccoons, Procyon lotor hirtus Nelson and Goldman, in Saskatchewan: Canadian Journal of Zoology, v. 60, p. 53-57.

Hoffman, C.O., and Gottschang, J.L., 1977, Numbers, distribution, and movements of a raccoon population in a suburban residential community: Journal of Mammalogy, v. 58 , p. 623-636.

Hoffmann, U., Voight, S., and Andreas, U., 2002, Raccoons take the offensive. A current assessment, in Kowarik, I., and Starfinger, U., eds., Biologische invasionen. Herausforderung zum Handeln?: Neobiota, v. 1, p. 191-192.

Hoffmeister, B., Glaeser, S., Flick, H., Pornschlegel, S., Suttorp, N., and Bergmann, F., 2007, Cerebral toxocariasis after consumption of raw duck liver: American Journal of Tropical Medicine and Hygiene, v. 76, p. 600-602.

Huff, D.S., Neafie, R.C., Binder, M.J., De León, G.A., Brown, L.W., and Kazacos, K.R., 1984, Case 4. The first fatal Baylisascaris infection in humans: An infant with eosinophilic meningoencephalitis: Pediatric Pathology, v. 2, p. 345-352.

Hung, T., Neafie, R.C., and Mackenzie, I.R.A., 2012, Baylisascaris procyonis infection in elderly person, British Columbia, Canada: Emerging Infectious Diseases, v. 18, p. 341-342.

Huntress, S.L., and Spraker, T., 1985, Baylisascaris infection in the marmoset: Proceedings of the American Association of Zoo Veterinarians, p. 78. 
Ikeda, T., Asano, M., Matoba, Y., and Abe, G., 2004, Present status of invasive alien raccoon and its impact in Japan: Global Environmental Research, v. 8, p. 125-131.

Ingle, M.E., Dunbar, S.G., Gathany, M.A., Vasser, M.M., Bartsch, J.L., Guffey, K.R., Knox, C.J., Nolan, A.N., Rowlands, C.E., and Trigg, E.C., 2014, Predicting Baylisascaris procyonis roundworm prevalence, presence and abundance in raccoons (Procyon lotor) of southwestern Ohio using landscape features: International Journal for Parasitology: Parasites and Wildlife, v. 3, p. 113-117.

Jacobson, H.A., Scanlon, P.F., Nettles, V.F., and Davidson, W.R., 1976, Epizootiology of an outbreak of cerebrospinal nematodiasis in cottontail rabbits and woodchucks: Journal of Wildlife Diseases, v. 12, p. 357-360.

Jacobson, J.E., Kazacos, K.R., and Montague, F.H., Jr., 1982, Prevalence of eggs of Baylisascaris procyonis (Nematoda:Ascaroidea) in raccoon scats from an urban and a rural community: Journal of Wildlife Diseases, v. 18, p. 461-464.

Jardine, C.M., Pearl, D.L., Puskas, K., Campbell, D.G., Shirose, L., and Peregrine, A.S., 2014, The impact of land use, season, age, and sex on the prevalence and intensity of Baylisascaris procyonis infections in raccoons (Procyon lotor) from Ontario, Canada: Journal of Wildlife Diseases, v. 50, p. 784-791.

Jimenez Martinez, M.A., Cano, E.V., and Rois, J.L., 2015, Baylisascaris procyonis larva migrans in two white-headed lemurs (Eulemur albifrons) in Spain and response to treatment derived from a human pediatric protocol: Veterinary Parasitology, v. 210, p. 246-249.

Johnson, S.A., 1970, Biology of the raccoon (Procyon lotor varius), Nelson and Goldman in Alabama: Auburn, Alabama, Auburn University Agricultural Experiment Station Bulletin 402,148 p.

Jones, E.J., and McGinnes, B.S., 1983, Distribution of adult Baylisascaris procyonis in raccoons from Virginia: Journal of Parasitology, v. 69, p. 653.

Jordan, H.E., and Hayes, F.A., 1959, Gastrointestinal helminths of raccoons (Procyon lotor) from Ossabaw Island, Georgia: Journal of Parasitology, v. 45, p. 249-252.

Kahn, L.H., 2006, Confronting zoonoses, linking human and veterinary medicine: Emerging Infectious Diseases, v. 12, p. 556-561.

Kahn, L.H., Kaplan, B., and Steele, J.H., 2007, Confronting zoonoses through closer collaboration between medicine and veterinary medicine (as 'one medicine'): Veterinaria Italiana, v. 43, p. 5-19.
Kawanaka, M., Sakamoto, K., and Sugiyama, H., 2001, Raccoon and raccoon roundworm (Baylisascaris procyonis) surveillance in Japan: Clinical Parasitology, v. 12, p. 121-125. [In Japanese.]

Kawanaka, M., Sakamoto, K., Sugiyama, H., and Morishima, Y., 2002, Detection and elimination of Baylisascaris procyonis eggs at zoological gardens exhibiting raccoons in Japan, 2000: Infectious Agents Surveillance Report, v. 23, p. 202-203. [In Japanese.]

Kazacos, E.A., and Kazacos, K.R., 1988, Pathogenesis and pathology of experimental baylisascariasis in ferrets: Proceedings of the American Society of Parasitologists, v. 63, p. 60 .

Kazacos, K.R., 1981, Animal and public health implications of the nematode genus Baylisascaris: Proceedings of the American Association of Veterinary Parasitologists, v. 26, p. 21.

Kazacos, K.R., 1982, Contaminative ability of Baylisascaris procyonis infected raccoons in an outbreak of cerebrospinal nematodiasis: Proceedings of the Helminthological Society of Washington, v. 49, p. 155-157.

Kazacos, K.R., 1983a, Raccoon roundworms (Baylisascaris procyonis). A cause of animal and human disease: West Lafayette, In., Purdue University Agricultural Experiment Station Bulletin 422, 25 p.

Kazacos, K.R., 1983b, Life cycle studies on Baylisascaris procyonis in raccoons: Proceedings of the Conference of Research Workers in Animal Diseases, v. 64, p. 24.

Kazacos, K.R., 1983c, Improved method for recovering ascarid and other helminth eggs from soil associated with epizootics and during survey studies: American Journal of Veterinary Research, v. 44, p. 896-900.

Kazacos, K.R., 1984, Baylisascaris infection of human beings: West Lafayette, Indiana, Letter to state and territorial public health laboratory directors, October 10, 1984.

Kazacos, K.R., 1986, Raccoon ascarids as a cause of larva migrans: Parasitology Today, v. 2, p. 253-255.

Kazacos, K.R., 1991, Visceral and ocular larva migrans: Seminars in Veterinary Medicine and Surgery (Small Animal), v. 6, p. 227-235.

Kazacos, K.R., 1995, Baylisascariasis, in Farris, R., Mahlow, J., Newman, E., Nix, B., eds., Health Hazards in Veterinary Practice, $3^{\text {rd }}$ ed.: Austin, Texas Department of Health, p. 13-14. 
Kazacos, K.R., 1996a, Baylisascaris procyonis and other helminth larvae as causes of ocular larva migrans and DUSN: Proceedings of the International Society of Ophthalmic Pathology and the American Association of Ophthalmic Pathology, Chicago, p. 20.

Kazacos, K.R., 1996b, Baylisascariasis, in Rudolph, A.M., Hoffman, J.I.E., and Rudolph, C.D., eds., Rudolph's pediatrics, 20th ed.: Stamford, Connecticut, Appleton \& Lange, p. 716-717.

Kazacos, K.R., 1997, Visceral, ocular, and neural larva migrans, in Connor, D.H., Chandler, F.W., Schwartz, D.A., Manz, H.J., and Lack, E.E., eds., Pathology of infectious diseases, vol. II: Stamford, Connecticut, Appleton \& Lange, p. 1459-1473.

Kazacos, K.R., 2000, Protecting children from helminthic zoonoses: Contemporary Pediatrics, v. 17 (suppl.), p. 1-24.

Kazacos, K.R., 2001, Baylisascaris and related species, in Samuel, W.M., Pybus, M.J., and Kocan, A.A., eds., Parasitic diseases of wild mammals, $2^{\text {nd }}$ ed.: Ames, Iowa State University Press, p. 301-341.

Kazacos, K.R., 2006, Unusual fecal parasite in a dog: NAVC Clinician's Brief, v. 4, p. 37-39.

Kazacos, K.R., Appel, G.O., and Thacker, H.L., 1981, Cerebrospinal nematodiasis in a woodchuck suspected of having rabies: Journal of the American Veterinary Medical Association, v. 179, p. 1102-1104.

Kazacos, K.R., and Boyce, W.M., 1989, Baylisascaris larva migrans: Journal of the American Veterinary Medical Association, v. 195, p. 894-903. Addendum, 1995, in Zoonosis updates from the Journal of the American Veterinary Medical Association, 2nd ed.: Schaumburg, Illinois, American Veterinary Medical Association, p. 29-30.

Kazacos, K.R., Fitzgerald, S.D., and Reed, W.M., 1991, Baylisascaris procyonis as a cause of cerebrospinal nematodiasis in ratites: Journal of Zoo and Wildlife Medicine, v. 22, p. 460-465.

Kazacos, K.R., Gavin, P.J., Shulman, S.T., Tan, T.Q., Gerber, S.I., Kennedy, W.A., Murray, W.J., and Mascola, L., 2002, Raccoon roundworm encephalitis-Chicago, Illinois, and Los Angeles, California: Morbidity and Mortality Weekly Report, v. 50, p. 1153-1155.

Kazacos, K.R., Jelicks, L.A., and Tanowitz, H.B., 2013, Baylisascaris larva migrans, in Garcia, H.H., Tanowitz, H.B., and Del Brutto, O.H., eds., Handbook of clinical neurology, Vol. 114 ( $3^{\text {rd }}$ series), Neuroparasitology and tropical neurology: Amsterdam, Elsevier B.V., p. 251-262.
Kazacos, K.R., and Kazacos, E.A., 1984, Experimental infection of domestic swine with Baylisascaris procyonis from raccoons: American Journal of Veterinary Research, v. 45, p. 1114-1121.

Kazacos, K.R., and Kazacos, E.A., 1988, Diagnostic exercise: Neuromuscular condition in rabbits: Laboratory Animal Science, v. 38, p. 187-189.

Kazacos, K.R., Kazacos, E.A., Render, J.A., and Thacker, H.L., 1982, Cerebrospinal nematodiasis and visceral larva migrans in an Australian (Latham's) brush turkey: Journal of the American Veterinary Medical Association, v. 181, p. 1295-1298.

Kazacos, K.R., Kazacos, E.A., and Vestre, W.A., 1984, Experimental ocular larva migrans in mice, hamsters, gray squirrels and woodchucks infected with Baylisascaris procyonis: Proceedings of the American Association of Veterinary Parasitologists, v. 29, p. 27-28.

Kazacos, K.R., Kilbane, T.P., Zimmerman, K.D., Chavez-Lindell, T., Parman, B., Lane, T., Carpenter, L.R., Green, A.L., Mann, P.M., Murphy, T.W., Bertucci, B., Gray, A.C., Goldsmith, T.L., Cunningham, M., Stanek, D.R., Blackmore, C., Yabsley, M.J., Montgomery, S.P., and Bosserman, E., 2011, Raccoon roundworms in pet kinkajous_-Three states, 1999 and 2010: Morbidity and Mortality Weekly Report, v. 60, p. 302-305.

Kazacos, K.R., Raymond, L.A., Kazacos, E.A., and Vestre, W.A., 1985, The raccoon ascarid. A probable cause of human ocular larva migrans: Ophthalmology, v. 92, p. 1735-1743.

Kazacos, K.R., Reed, W.M., Kazacos, E.A., and Thacker, H.L., 1983, Fatal cerebrospinal disease caused by Baylisascaris procyonis in domestic rabbits: Journal of the American Veterinary Medical Association, v. 183, p. 967-971.

Kazacos, K.R., Reed, W.M., and Thacker, H.L., 1986, Cerebrospinal nematodiasis in pheasants: Journal of the American Veterinary Medical Association, v. 189, p. 1353-1354.

Kazacos, K.R., and Turek, J.J., 1983, Scanning electron microscopy of the eggs of Baylisascaris procyonis, $B$. transfuga, and Parascaris equorum, and their comparison with Toxocara canis and Ascaris suum: Proceedings of the Helminthological Society of Washington, v. 50, p. 36-42.

Kazacos, K.R., Vestre, W.A., and Kazacos, E.A., 1984, Raccoon ascarid larvae (Baylisascaris procyonis) as a cause of ocular larva migrans: Investigative Ophthalmology and Visual Science, v. 25, p. 1177-1183.

Kazacos, K.R., Vestre, W.A., Kazacos, E.A., and Raymond, L.A., 1984, Diffuse unilateral subacute neuroretinitis syndrome: Probable cause: Archives of Ophthalmology, v. 102, p. 967-968. 
Kazacos, K.R., Winterfield, R.W., and Thacker, H.L., 1982, Etiology and epidemiology of verminous encephalitis in an emu: Avian Diseases, v. 26, p. 389-391.

Kazacos, K.R., and Wirtz, W.L., 1983, Experimental cerebrospinal nematodiasis due to Baylisascaris procyonis in chickens: Avian Diseases, v. 27, p. 55-65.

Kazacos, K.R., Wirtz, W.L., Burger, P.P., and Christmas, C.S., 1981, Raccoon ascarid larvae as a cause of fatal central nervous system disease in subhuman primates: Journal of the American Veterinary Medical Association, v. 179, p. 1089-1094.

Kellner, K.F., Page, L.K., Downey, M., and McCord, S.E., 2012, Effects of urbanization on prevalence of Baylisascaris procyonis in intermediate host populations: Journal of Wildlife Diseases, v. 48, p. 1083-1087.

Kelly, W.R., and Innes, J.R.M., 1966, Cerebrospinal nematodiasis with focal encephalomalacia as a cause of paralysis of beavers (Castor canadensis) in the Dublin Zoological Gardens: British Veterinary Journal, v. 122, p. 285-287.

Kelly, T.G., Madhavan, V.L., Peters, J.M., Kazacos, K.R., and Silvera, V.M., 2012, Spinal cord involvement in a child with raccoon roundworm (Baylisascaris procyonis) meningoencephalitis: Pediatric Radiology, v. 42, p. 369-373.

Kelly, T.G., Silvera, V.M., Madhavan, V.L., Bastos, M.D., Kazacos, K.R., Husson, R.N., and Dangoudoubiyam, S., 2009, Case report: Spinal cord involvement in an infant with raccoon roundworm (Baylisascaris procyonis) encephalitis: Proceedings of the $47^{\text {th }}$ Annual Meeting of the American Society of Neuroradiology, Vancouver British Columbia, May 21, 2009, Paper 436.

Kerr, C.L., Henke, S.E., and Pence, D.B., 1997, Baylisascariasis in raccoons from southern coastal Texas: Journal of Wildlife Diseases, v. 33, p. 653-655.

Kidder, J.D., 1990, Density and distribution of an urban/suburban raccoon population and the prevalence of patent Baylisascaris procyonis infection: Ithaca, New York, Cornell University, M.S. Thesis, 81 p.

Kidder, J.D., Wade, S.E., Richmond, M.E., and Schwager, S.J., 1989, Prevalence of patent Baylisascaris procyonis infection in raccoons (Procyon lotor) in Ithaca, New York: Journal of Parasitology, v. 75, p. 870-874.

Kimball, V.P., Young, D., Keith, R., Kazacos, K.R., and Sakanari, J., 2003, Occurrence of Baylisascaris procyonis in Marin, Sonoma, and Alameda counties in northern California: California Fish and Game, v. 89, p. 46-50.
Koch, F., and Rapp, J., 1981, Zerebrale Nematodiasis bei Sumpfbibern (Myocastor coypus) — verursacht durch Larven von Baylisascaris (Nematoda): Berliner und Münchener Tierärztliche Wochenschrift, v. 94, p. 111-114. [In German.]

Kresta, A.E., Henke, S.E., and Pence, D.B., 2009, Gastrointestinal helminths in raccoons in Texas: Journal of Wildlife Diseases, v. 45, p. 1-13.

Kresta, A.E., Henke, S.E., and Pence, D.B., 2010, Baylisascaris procyonis in raccoons in Texas and its relationship to habitat characteristics: Journal of Wildlife Diseases, v. 46, p. 843-853.

Küchle, M., Knorr, H.L.J., Medenblik-Frysch, S., Weber, A., Bauer, C., and Naumann, G.O.H., 1993, Diffuse unilateral subacute neuroretinitis syndrome in a German most likely caused by the raccoon roundworm, Baylisascaris procyonis: Graefe's Archive for Clinical and Experimental Ophthalmology, v. 231, p. 48-51.

Kwiecien, J.M., Smith, D.A., Key, D.W., Swinton, J., and Smith-Maxie, L., 1993, Encephalitis attributed to larval migration of Baylisascaris species in emus: Canadian Veterinary Journal, v. 34, p. 176-178.

Larson, D.J., and Greve, J.H., 1983, Encephalitis caused by Baylisascaris migration in a silver fox: Journal of the American Veterinary Medical Association, v. 183, p. 1274-1275.

Larson, O.R., and Scharf, W.C., 1975, New helminth records from Minnesota mammals: Proceedings of the Helminthological Society of Washington, v. 42, p. 174-175.

Lee, A.C.Y., Schantz, P.M., Kazacos, K.R., Montgomery, S.P., and Bowman, D.D., 2010, Epidemiologic and zoonotic aspects of ascarid infections in dogs and cats: Trends in Parasitology, v. 26, p. 155-161.

Leigh, W.H., 1940, Preliminary studies on parasites of upland game birds and fur-bearing mammals in Illinois: Bulletin of the Illinois Natural History Survey, v. 21, p. 185-194.

Lennox, A.M., Hanika, C., Popielarczyk, M.M., and Kazacos, K.R., 2015, Fatal Baylisascaris procyonis infection in a household psittacine flock: Proceedings of the Association of Exotic Mammal Veterinarians Annual Conference, San Antonio, Texas, v. 14, Session \#114.

Lewis, R.A., 1985, Discussion (of The raccoon ascarid. A probable cause of human ocular larva migrans): Ophthalmology, v. 92, p. 1743-1744.

Lindquist, W.D., 1978, Baylisascaris procyonis for testing anthelmintics against migratory ascarids: American Journal of Veterinary Research, v. 39, p. 1868-1869. 
Liu, G., Fennelly, G., Kazacos, K.R., Grose, C., Dobroszycki, J., Saffra, N., Coyle, C.M., Weiss, L.M., Szlechter, M.M., and Tanowitz, H.B., 2015, Case report: Baylisascaris procyonis and Herpes simplex Virus 2 co-infection presenting as ocular larva migrans with granuloma formation in a child: American Journal of Tropical Medicine and Hygiene, v. 93 , p. 612-614.

LoGiudice, K., 1995, Control of Baylisascaris procyonis (Nematoda) in raccoons (Procyon lotor) through the use of anthelmintic baits: A potential method for reducing mortality in the Allegheny woodrat (Neotoma floridana magister): New Brunswick, New Jersey, Rutgers University, M.S. Thesis, $78 \mathrm{p}$.

LoGiudice, K., 2001, Latrine foraging strategies of two small mammals: Implications for the transmission of Baylisascaris procyonis: American Midland Naturalist, v. 146, p. 369-378.

LoGiudice, K., 2003, Trophically transmitted parasites and the conservation of small populations: Raccoon roundworm and the imperiled Allegheny woodrat: Conservation Biology, v. 17 , p. 258-266.

LoGiudice, K., 2006, Toward a synthetic view of extinction: A history lesson from a North American rodent: BioScience, v. 56, p. 687-693.

Long, D.B., Campbell, T.A., and Henke, S.E., 2006, Baylisascaris procyonis (Nematoda: Ascaridoidea) in raccoons (Procyon lotor) from Duval County, Texas: Texas Journal of Science, v. 58, p. 281-285.

Loretti, A.P., Dangoudoubiyam, S., Koobs, J., Gai, J.J., and Kazacos, K.R., 2008, Cases of cerebral nematodiasis in canaries and emus due to Baylisascaris procyonis larval migration (neural larva migrans) diagnosed in the State of California, year 2007: Proceedings of the American Association of Veterinary Laboratory Diagnosticians, v. 51, p. 103.

Lotze, J-H., and Anderson, S., 1979, Procyon lotor: Mammalian Species, v. 119, p. 1-8.

Lutz, W., 1984, Die Verbreitung des Waschbären im mittleuropäischen Raum: Zeitshcrift fur Jagdwissenschaft, v. 30, p. 218-228. [In German.]

Lutz, W., 1996, The introduced raccoon Procyon lotor population in Germany: Wildlife Biology, v. 2, p. 228.

Lux, E., and Priemer, J., 1995, Zur Parasitierung wildlebender Waschbären unter dem Aspekt ihrer nordamerikanischen: Verhandlungsbericht Erkrankungen der Zootiere, v. 37, p. 429-434. [In German.]
Lyons, E.T., Swerczek, T.W., and Tolliver, S.C., 2001, Central nervous system disorder in a woodchuck (Marmota monax) in central Kentucky caused by a nematode in the genus Baylisascaris: Journal of the Kentucky Academy of Science, v. 62, p. 142-144.

Mackay, A., Robitaille, J., Messier, S., and Villeneuve, A., 1995, Baylisascaris chez le raton laveur au Québec: possibilité de zoonose: Le Médecin Vétérinaire du Québec, v. 25, p. 102-105. [In French.]

Matoba, Y., Yamada, D., Asano, M., Oku, Y., Kitaura, K., Yagi, K., Tenora, F., and Asakawa, M., 2006, Parasitic helminths from feral raccoons (Procyon lotor) in Japan: Helminthologia, v. 43, p. 139-146.

Matoff, K., and Komandarev, S., 1965, Comparative studies on the migration of the larvae of Toxascaris leonina and Toxascaris transfuga: Zeitschrift fur Parasitenkunde, v. 25, p. 538-555.

McCleery, R.A., Foster, G.W., Lopez, R.R., Peterson, M.J., Forrester, D.J., and Silvy, N.J., 2005, Survey of raccoons on Key Largo, Florida, USA, for Baylisascaris procyonis: Journal of Wildlife Diseases, v. 41, p. 250-252.

McClure, G.W., 1933, Nematode parasites of mammals. From specimens collected in the New York Zoological Park, 1931: Zoologica (New York), v. 15, p. 29-47.

McFadden, K.W., Wade, S.E., Dubovi, E.J., and Gompper, M.E., 2005, A serological and fecal parasitologic survey of the critically endangered pygmy raccoon (Procyon pygmaeus): Journal of Wildlife Diseases, v. 41, p. 615-617.

McGowan, E.M., 1993, Experimental release and fate study of the Allegheny woodrat (Neotoma magister): Albany, New York Federal Aid Project W-166-E; E-1, Job No. VIII-7, New York State Department of Environmental Conservation, $15 \mathrm{p}$.

McNeil, C.W., and Krogsdale, J.T., 1953, Parasites of raccoons in southwest Washington: Journal of Mammalogy, v. 34, p. 123-124.

Medway, W., Skand, D.L., and Sarver, C.F., 1989, Neurologic signs in American porcupines (Erethizon dorsatum) infected with Baylisascaris and Toxoplasma: Journal of Zoo and Wildlife Medicine, v. 20, p. 207-211.

Mehta, P., Boyd, Z., and Cully, B., 2010, Raccoon roundworm encephalitis: Pediatric Radiology, v. 40, p. 1834-1836.

Mets, M.B., Noble, A.G., Basti, S., Gavin, P., Davis, A.T., Shulman, S.T., and Kazacos, K.R., 2003, Eye findings of diffuse unilateral subacute neuroretinitis and multiple choroidal infiltrates associated with neural larva migrans due to Baylisascaris procyonis: American Journal of Ophthalmology, v. 135, p. 888-890. 
Mitchell, M.A., Hungerford, L.L., Nixon, C., Sullivan, J., Esker, T., and Koerkenmeier, R., 1998, Prevalence patterns of patent Baylisascaris procyonis infections in raccoons (Procyon lotor) in west-central Illinois: Proceedings of the American Association of Zoo Veterinarians and American Association of Wildlife Veterinarians Joint Conference, p. 230-233.

Miyashita, M., 1993, Prevalence of Baylisascaris procyonis in raccoons in Japan and experimental infections of the worm to laboratory animals: Seikatsu Eisei (Journal of Urban Living and Health Association), v. 37, p. 137-151. [In Japanese with English summary.]

Moertel, C.L., Kazacos, K.R., Butterfield, J.H., Kita, H., Watterson, J., and Gleich, G.J., 2001, Eosinophil-associated inflammation and elaboration of eosinophil-derived proteins in 2 children with raccoon roundworm (Baylisascaris procyonis) encephalitis: Pediatrics, v. 108, p. e93-e99, accessed July 30, 2014, at http://www.pediatrics.org/cgi/content/ full/108/5/e93.

Moore, B.E., 2009, A case of cerebral baylisascariasis: Neuropathology Blog, September 28, 2009, accessed July 30, 2014, at http://neuropathologyblog.blogspot.com/2009/09/ case-of-cerebral-baylisascariasis.html.

Moore, L., Ash, L., Sorvillo, F., and Berlin, O.G.W., 2004, Baylisascaris procyonis in California: Emerging Infectious Diseases, v. 10, p. 1693-1694.

Morgan, B.B., and Waller, E.F., 1940, Severe parasitism in a raccoon, (Procyon lotor lotor Linnaeus): Transactions of the American Microscopical Society, v. 59, p. 523-527.

Müller-Using, D., 1959, Die Ausbreitung des Waschbären in Westdeutschland: Z. Jagdwiss, v. 5, p. 108-109.

[In German.]

Murray, M., Nelson, G., and Smith, M., 2005, Raccoon roundworm (Baylisascaris procyonis) survey: Reno, Nevada, Washoe County District Health Department Vector-Borne Diseases and Nevada Department of Agriculture Animal Disease and Food Safety Laboratory, accessed September 10, 2014, at https://www.washoecounty.us/health/programsand-services/vector-borne-diseases/surveillance_activities/ raccoon-roundworm-survey.php

Murray, W.J., 2004, Raccoon roundworm infection (Baylisascariasis): A zoonosis of pediatric and public health concern, in Scheld, W.M., Murray, B.E., and Hughes, J.M., eds., Emerging Infections 6: Washington, D.C., ASM Press, p. 159-175.

Murray, W.J., and Kazacos, K.R., 2004, Raccoon roundworm encephalitis: Clinical Infectious Diseases, v. 39, p. $1484-1492$.
Myers, R.K., Monroe, W.E., and Greve, J.H., 1983, Cerebrospinal nematodiasis in a cockatiel: Journal of the American Veterinary Medical Association, v. 183, p. 1089-1090.

Nadler, S.A., and Hudspeth, D.S.S., 2000, Phylogeny of the Ascaridoidea (Nematoda: Ascaridida) based on three genes and morphology: Hypotheses of structural and sequence evolution: Journal of Parasitology, v. 86, p. 380-393.

Nadler, S., Bieberich, A., Pagan, C., Naem, S., and Richardson, D., 2010, Evolutionary genetics and geographic variation of Baylisascaris species in North America: Proceedings of the American Society of Parasitologists, v. 85, p. 84.

Nelson, G.S., 1983, Teaching medical parasitology, in Warren, K.S. and Bowers, J.Z., eds., Parasitology—a global perspective: New York, New York, Springer-Verlag, p. 158-168.

Nettles, V.F., Davidson, W.R., Fisk, S.K., and Jacobson, H.A., 1975, An epizootic of cerebrospinal nematodiasis in cottontail rabbits: Journal of the American Veterinary Medical Association, v. 167, p. 600-602.

Nichols, R.L., 1956, The etiology of visceral larva migrans. I. Diagnostic morphology of infective second-stage Toxocara larvae: Journal of Parasitology, v. 42, p. 349-362.

Noce, S.M., Ayebo, A., Kazacos, K., Humphreys, J., and Brenneman, W.M., 2007, Prevalence and intensity of Baylisascaris procyonis (raccoon roundworm) in Indiana county, Pennsylvania: Journal of the Pennsylvania Academy of Science, v. 80, p. 57-60.

Nupp, T.E., and Swihart, R.K., 2000, Landscape-level correlates of small-mammal assemblages in forest fragments of farmland: Journal of Mammalogy, v. 81, p. 512-526.

Ochiai, K., Ishii, M., and Furukawa, T., 2002, Invasion and distribution of the raccoon, Procyon lotor, in Chiba Prefecture, central Japan: Journal of the Natural History Museum and Institute, Chiba, v. 7, p. 21-27. [In Japanese.]

Olsen, O.W., and Fenstermacher, R., 1938, The raccoon, a new host of Ascaris columnaris Leidy, 1856 (Nematoda:Ascaridae): Proceedings of the Helminthological Society of Washington, v. 5, p. 20.

Overstreet, R.M., 1970, Baylisascaris procyonis (Stefanski and Zarnowski, 1951) from the kinkajou, Potos flavus, in Colombia: Proceedings of the Helminthological Society of Washington, v. 37, p. 192-195.

Owen, S.F., Edwards, J.W., Ford, W.M., Crum, J.M., and Wood, P.B., 2004, Raccoon roundworm in raccoons in central West Virginia: Northeastern Naturalist, v. 11, p. 137-142.

Page, L.K., 1998, Ecology and transmission dynamics of Baylisascaris procyonis: West Lafayette, Indiana, Purdue University, Ph.D. Thesis, 138 p. 
Page, L.K., 2013, Parasites and the conservation of small populations: The case of Baylisascaris procyonis: International Journal for Parasitology: Parasites and Wildlife, v. 2, p. 203-210.

Page, L.K., Anchor, C., Luy, E., Kron, S., Larson, G., Madsen, L., Kellner, K., and Smyser, T.J., 2009, Backyard raccoon latrines and risk for Baylisascaris procyonis transmission to humans: Emerging Infectious Diseases, v. 15, p. $1530-1531$.

Page, L.K., Beasley, J.C., Olson, Z.H., Smyser, T.J., Downey, M., Kellner, K.F., McCord, S.E., Egan, T.S., II, and Rhodes, O.E., Jr., 2011, Reducing Baylisascaris procyonis roundworm larvae in raccoon latrines: Emerging Infectious Diseases, v. 17, p. 90-93.

Page, L.K., Delzell, D.A.P., Gehrt, S.D., Dunkerton, E., Hiben, M., Walter, E., and Kazacos, K.R., 2016, The structure and seasonality of Baylisascaris procyonis populations in raccoons: Journal of Wildlife Diseases, v. 52, at http://www. jwildlifedis.org/doi/pdf/10.7589/2015-06-153.

Page, L.K., Gehrt, S.D., Cascione, A., and Kellner, K.F., 2009, The relationship between Baylisascaris procyonis prevalence and raccoon population structure: Journal of Parasitology, v. 95, p. 1314-1320.

Page, L.K., Gehrt, S.D., and Robinson, N.P., 2008, Land-use effects on prevalence of raccoon roundworm (Baylisascaris procyonis): Journal of Wildlife Diseases, v. 44, p. 594-599.

Page, L.K., Gehrt, S.D., Titcombe, K.K., and Robinson, N.P., 2005, Measuring prevalence of raccoon roundworm (Baylisascaris procyonis): A comparison of common techniques: Wildlife Society Bulletin, v. 33, p. 1406-1412.

Page, L.K., Johnson, S.A., Swihart, R.K., and Kazacos, K.R., 2012, Prevalence of Baylisascaris procyonis in habitat associated with Allegheny woodrat (Neotoma magister) populations in Indiana: Journal of Wildlife Diseases, v. 48, p. 503-507.

Page, L.K., Swihart, R.K., and Kazacos, K.R., 1998, Raccoon latrine structure and its potential role in transmission of Baylisascaris procyonis to vertebrates: American Midland Naturalist, v. 140, p. 180-185.

Page, L.K., Swihart, R.K., and Kazacos, K.R., 1999, Implications of raccoon latrines in the epizootiology of baylisascariasis: Journal of Wildlife Diseases, v. 35, p. 474-480.

Page, L.K., Swihart, R.K., and Kazacos, K.R., 2001a, Seed preferences and foraging by granivores at raccoon latrines in the transmission dynamics of the raccoon roundworm (Baylisascaris procyonis): Canadian Journal of Zoology, v. 79 , p. 616-622.
Page, L.K., Swihart, R.K., and Kazacos, K.R., 2001b, Foraging among feces: Food availability affects parasitism of Peromyscus leucopus by Baylisascaris procyonis: Journal of Mammalogy, v. 82, p. 993-1002.

Page, L.K., Swihart, and R.K., Kazacos, K.R., 2001c, Changes in transmission of Baylisascaris procyonis to intermediate hosts as a function of spatial scale: Oikos, v. 93, p. 213-220.

Pai, P.J., Blackburn, B.G., Kazacos, K.R., Warrier, R.P. and Bégué, R.E., 2007, Full recovery from Baylisascaris procyonis eosinophilic meningitis: Emerging Infectious Diseases, v. 13, p. 928-930.

Papini, R., and Casarosa, L., 1994, A report on the pathology of Baylisascaris transfuga (Ascarididae, Nematoda) for mice: Revue de Médecine Vétérinaire, v. 145, p. 949-952.

Papini, R., Cavicchio, P., and Casarosa, L., 1993, Experimental infection in chickens with larvae of Baylisascaris transfuga (Nematoda: Ascaridoidea): Folia Parasitologica, v. 40, p. 141-143.

Papini, R., Demi, S., and Della Croce, G., 1996, Observations on the migratory behaviour of Baylisascaris transfuga larvae in rabbits: Revue de Médecine Vétérinaire, v. 147, p. 893-896.

Papini, R., Renzoni, G., Lo Piccolo, S., and Casarosa, L., 1996, Ocular larva migrans and histopathological lesions in mice experimentally infected with Baylisascaris transfuga embryonated eggs: Veterinary Parasitology, v. 61, p. 315-320.

Papini, R., Renzoni, G., Malloggi, M., and Casarosa, L., 1994, Visceral larva migrans in mice experimentally infected with Baylisascaris transfuga (Ascarididae: Nematoda): Parasitologia, v. 36, p. 321-329.

Park, C., Levee, D.J., Gilbreath, S., Parman, R., Frazer, L., Kaufman, R., and Murray, W.J., 1998, A survey of the prevalence of the raccoon ascarid, Baylisascaris procyonis, in a geographically defined population of suburban and urban raccoons: Proceedings of the American Society for Microbiology, v. 98, p. 547.

Park, S.Y., Glaser, C., Murray, W.J., Kazacos, K.R., Rowley, H.A., Fredrick, D.R., and Bass, N., 2000, Raccoon roundworm (Baylisascaris procyonis) encephalitis: Case report and field investigation: Pediatrics, v. 106, p. e56-e60, accessed July 30, 2014, at http://www.pediatrics.org/cgi/ content/full/106/4/e56.

Parkanzky, M.C., 2015, Baylisascaris spp. in non-raccoon procyonid hosts and assessment of potential risk of human exposure: West Lafayette, Indiana, Purdue University, M.S. Thesis, $61 \mathrm{p}$. 
Parsons, H.E., 1952, Nematode chorioretinitis. Report of a case, with photographs of a viable worm: Archives of Ophthalmology, v. 47, p. 799-800.

Pegg, E.J., 1977, A new approach to the control of Toxocara canis and other parasitic ova on concrete-floored kennel runs: British Veterinary Journal, v. 133, p. 427-431.

Perlman, J.E., Kazacos, K.R., Imperato, G.H., Desai, R.U., Schulman, S.K., Edwards, J., Pontrelli, L.R., Machado, F.S., Tanowitz, H.B., and Saffra, N.A., 2010, Baylisascaris procyonis neural larva migrans in an infant in New York City: Journal of Neuroparasitology, v. 1, 5 p.

Pessier, A.P., Stringfield, C., Tragle, J., Holshuh, H.J., Nichols, D.K., and Montali, R.J., 1997, Cerebrospinal nematodiasis due to Baylisascaris sp. in golden-headed lion tamarins (Leontopithecus chrysomelas): implications for management: Proceedings of the American Association of Zoo Veterinarians, p. 245-247.

Peters, J.M., Madhavan, V.L., Kazacos, K.R., Husson, R.N., Dangoudoubiyam, S., and Soul, J.S., 2012, Good outcome with early empiric treatment of neural larva migrans due to Baylisascaris procyonis: Pediatrics, v. 129, p. e806-e811, accessed July 30, 2014, at http://www.pediatrics.org/cgi/ content/full/129/3/e806.

Peterson, R.T., 1980, A field guide to the birds ( $4^{\text {th }}$ ed.): New York, Houghton Mifflin Co., 384 p.

Peterson, R.T., 1990, A field guide to western birds (3rd ed.): New York, Houghton Mifflin Co., 432 p.

Pigage, J.C., Pigage, H.K., and Todd, K.S., Jr., 1983, Intestinal parasites of mammals from Willowbrook Wildlife Haven: A survey with implications for management: Proceedings of the National Wildlife Rehabilitation Association, v. 2, p. 174-184.

Pipas, M.J., Page, L.K., and Kazacos, K.R., 2014, Surveillance for Baylisascaris procyonis in raccoons (Procyon lotor) from Wyoming, USA: Journal of Wildlife Diseases, v. 50, p. $777-783$.

Popiotek, M., Szczęsna-Staśkiewicz, J., Bartoszewicz, M., Okarma, H., Smalec, B., and Zalewski, A., 2011, Helminth parasites of an introduced invasive carnivore species, the raccoon (Procyon lotor L.), from the Warta Mouth National Park (Poland): Journal of Parasitology, v. 97, p. 357-360.

Prange, S., Gehrt, S.D., and Wiggers, E.P., 2003, Demographic factors contributing to high raccoon densities in urban landscapes: Journal of Wildlife Management, v. 67, p. 324-333.

Prange, S., Gehrt, S.D., and Wiggers, E.P., 2004, Influences of anthropogenic resources on raccoon movements and spatial distribution in urbanized systems: Journal of Mammalogy, v. 85 , p. $483-490$.
Price, R.L., and Harman, D.M., 1983, Helminths from the raccoon, Procyon lotor litoreus Nelson and Goldman 1930, on St. Catherines Island, Georgia: Proceedings of the Helminthological Society of Washington, v. 50, p. 343-344.

Rascoe, L.N., Santamaria, C., Handali, S., Dangoudoubiyam, S., Kazacos, K.R., Wilkins, P.P., and Ndao, M., 2013, Interlaboratory optimization and evaluation of a serological assay for diagnosis of human baylisascariasis: Clinical and Vaccine Immunology, v. 20, p. 1758-1763.

Rausch, R., 1946, The raccoon, a new host for Microphallus sp., with additional notes on $M$. ovatus from turtles: Journal of Parasitology, v. 32, p. 208-209.

Raymond, L.A., Gutierrez, Y., Strong, L.E., Wander, A.H., Buten, R., and Cordan, D., 1978, Living retinal nematode (filarial-like) destroyed with photocoagulation: Ophthalmology, v. 85, p. 944-949.

Reed, C., Henke, S.E., and Kresta, A.E., 2012, Frequency of deposition and location of Baylisascaris procyonis eggs in raccoon feces: Journal of Wildlife Diseases, v. 48, p. 190-194.

Reed, W.M., Kazacos, K.R., Dhillon, A.S., Winterfield, R.W., and Thacker, H.L., 1981, Cerebrospinal nematodiasis in bobwhite quail: Avian Diseases, v. 25, p. 1039-1046.

Reilly, E., 2008, 'No family deserves this'. Raccoon roundworm robs toddler of sight, mobility: The Hamilton Spectator, Saturday, October 4, 2008, A16.

Reinemeyer, C.R., Berthelin-Baker, C., Alva, R., Erwin, J., Larsen, D., Romano, D., Pettyjohn, M., Ulrich, M.E., Manthei, D., and Kazacos, K.R., 2008, A controlled evaluation of the efficacy of HEARTGARD PLUS ${ }^{\circledR}$ against induced Baylisascaris procyonis infection in dogs: Proceedings of the American Association of Veterinary Parasitologists, v. 53, p. 36.

Richardson, D.J., Owen, W.B., and Snyder, D.E., 1992, Helminth parasites of the raccoon (Procyon lotor) from northcentral Arkansas: Journal of Parasitology, v. 78, p. 163-166.

Richardson, J.A., Kazacos, K.R., Thacker, H.L., Dhillon, A.S., and Winterfield, R.W., 1980, Verminous encephalitis in commercial chickens: Avian Diseases, v. 24, p. 498-503.

Richter, C.B., and Kradel, D.C., 1964, Cerebrospinal nematodosis in Pennsylvania groundhogs (Marmota monax): American Journal of Veterinary Research, v. 25, p. $1230-1235$.

Riley, S.P.D., Hadidian, J., and Manski, D.A., 1998, Population density, survival, and rabies in raccoons in an urban national park: Canadian Journal of Zoology, v. 76, p. 1153-1164. 
Robel, R.J., Barnes, N.A., and Upton, S.J., 1989, Gastrointestinal helminths and protozoa from two raccoon populations in Kansas: Journal of Parasitology, v. 75, p. 1000-1003.

Robinson, V.B., Newberne, J.W., and Brooks, D.M., 1957, Distemper in the American raccoon (Procyon lotor): Journal of the American Veterinary Medical Association, v. 131, p. 276-278.

Rosatte, R.C., Powers, M.J., and MacInnes, C.D., 1991, Ecology of urban skunks, raccoons and foxes in metropolitan Toronto, in Adams, L.W., and Leedy, D.L., eds., Wildlife conservation in metropolitan environments: Columbia, Maryland, National Institute of Urban Wildlife, p. 31-38.

Roth, L., Georgi, M.E., King, J.M., and Tennant, B.C., 1982, Parasitic encephalitis due to Baylisascaris sp. in wild and captive woodchucks (Marmota monax): Veterinary Pathology, v. 19, p. 658-662.

Roussere, G.P., Murray, W.J., Raudenbush, C.B., Kutilek, M.J., Levee, D.J., and Kazacos, K.R., 2003, Raccoon roundworm eggs near homes and risk for larva migrans disease, California communities: Emerging Infectious Diseases, v. 9, p. $1516-1522$.

Rowley, H.A., Uht, R.M., Kazacos, K.R., Sakanari, J., Wheaton, W.V., Barkovich, A.J., and Bollen, A.W., 2000, Radiologic-pathologic findings in raccoon roundworm (Baylisascaris procyonis) encephalitis: American Journal of Neuroradiology, v. 21, p. 415-420.

Rudmann, D.G., Kazacos, K.R., Storandt, S.T., Harris, D.L., and Janovitz, E.B., 1996, Baylisascaris procyonis larva migrans in a puppy: A case report and update for the veterinarian: Journal of the American Animal Hospital Association, v. 32, p. 73-76.

Russell, D.J., 2006, Avian neural larva migrans due to Baylisascaris procyonis: Natural and experimental infection in psittacine birds: Guelph, Ontario, University of Guelph, DVSc Thesis, 284 p.

Russell, D.J., Smith, D.A., Crawshaw, G., Dutton, C.J., ArneOlberg, R., Bertelsen, M.F., and Rose, K., 2005, Neural larva migrans due to Baylisascaris procyonis in captive lovebirds and lorikeets: A case series: Proceedings of the Association of Zoo Veterinarians, p. 135.

Saffra, N.A., Perlman, J.E., Desai, R.U., Kazacos, K.R., Coyle, C.M., Machado, F.S., Kedhar, S.R., Engelbert, M., and Tanowitz, H.B., 2010, Baylisascaris procyonis induced diffuse unilateral subacute neuroretinitis in New York City: Journal of Neuroparasitology, v. 1, 4 p.
Sakla, A.A., Donnelly, J.J., Khatami, M., and Rockey, J.H., 1989, Baylisascaris procyonis (Stefanski and Zarnowski, 1951) Ascarididae: Nematoda. I. Embryonic development and morphogenesis of second stage larvae: Assiut Veterinary Medical Journal, v. 21, p. 68-76.

Samson, A., Dubay, S.A., Huspeni, T.C., and Cyr, A., 2012, Influence of environmental variables on Baylisascaris procyonis infection in raccoons: Journal of Parasitology, v. 98, p. 1279-1282.

Sanders, M.P., 2015, The worm conqueror: Veterinary Heritage, v. 38, p.36-45.

Sanford, S.E., 1991, Cerebrospinal nematodiasis caused by Baylisascaris procyonis in chinchillas: Journal of Veterinary Diagnostic Investigation, v. 3, p. 77-79.

Sass, B., and Gorgacz, E.J., 1978, Cerebral nematodiasis in a chukar partridge: Journal of the American Veterinary Medical Association, v. 173, p. 1248-1249.

Sato, H., Furuoka, H., and Kamiya, H., 2002, First outbreak of Baylisascaris procyonis larva migrans in rabbits in Japan: Parasitology International, v. 51, p. 105-108.

Sato, H., Kamiya, H., and Furuoka, H., 2003, Epidemiological aspects of the first outbreak of Baylisascaris procyonis larva migrans in rabbits in Japan: Journal of Veterinary Medical Science, v. 65, p. 453-457.

Sato, H., Matsuo, K., Osanai, A., Kamiya, H., Akao, N., Owaki, S., and Furuoka, H., 2004, Larva migrans by Baylisascaris transfuga: Fatal neurological diseases in Mongolian jirds, but not mice: Journal of Parasitology, v. 90 , p. $774-781$.

Sato, H., and Suzuki, K., 2006, Gastrointestinal helminths of feral raccoons (Procyon lotor) in Wakayama Prefecture, Japan: Journal of Veterinary Medical Science, v. 68, p. 311-318.

Sato, H., Une, Y., Kawakami, S., Saito, E., Kamiya, H., Akao, N., and Furuoka, H., 2005, Fatal Baylisascaris larva migrans in a colony of Japanese macaques kept by a safari-style zoo in Japan: Journal of Parasitology, v. 91, p. 716-719.

Schaffer, G.D., Davidson, W.R., Nettles, V.F., and Rollor, E.A., III, 1981, Helminth parasites of translocated raccoons (Procyon lotor) in the southeastern United States: Journal of Wildlife Diseases, v. 17, p. 217-227.

Schrott, E.R., 1961, Parasitäre Netzhauterkrankung durch Askaris: Verhandlungen der Österreichischen Ophthalmologischen Gesellschaft, v. 6, p. 160-165. [In German.] 
Schueler, R.L., 1973, Cerebral nematodiasis in a red squirrel: Journal of Wildlife Diseases, v. 9, p. 58-60.

Schultz, A.L., 1962, A survey of parasites of the raccoon (Procyon lotor) in southeastern Michigan: Ann Arbor, The University of Michigan, M.S. Thesis, $42 \mathrm{p}$.

Schultz, T., 2002, 'Raccoon roundworm' infection confirmed: Santa Barbara, CA: Santa Barbara News-Press, May 8, 2002.

Senger, C.M., and Neiland, K.A., 1955, Helminth parasites of some fur-bearers of Oregon: Journal of Parasitology, v. 41, p. 637-638.

Sexsmith, J.L., Whiting, T.L., Green, C., Orvis, S., Berezanski, D.J., and Thompson, A.B., 2009, Prevalence and distribution of Baylisascaris procyonis in urban raccoons (Procyon lotor) in Winnipeg, Manitoba: Canadian Veterinary Journal, v. 50 , p. $846-850$.

Shafir, S.C., Sorvillo, F.J., Sorvillo, T., and Eberhard, M.L., 2011, Viability of Baylisascaris procyonis eggs: Emerging Infectious Diseases, v. 17, p. 1293-1295.

Shafir, S.C., Wang, W., Sorvillo, F.J., Wise, M.E., Moore, L., Sorvillo, T., and Eberhard, M.L., 2007, Thermal death point of Baylisascaris procyonis eggs: Emerging Infectious Diseases, v. 13, p. 172-173.

Shafir, S.C., Wise, M.E., Sorvillo, F.J., and Ash, L.R., 2006, Central nervous system and eye manifestations of infection with Baylisascaris procyonis: Current Infectious Disease Reports, v. 8, p. 307-313.

Sheppard, C.H., 1995, Susceptibility of Peromyscus leucopus (white-footed mouse) and Mus musculus (albino mouse) to infection with Baylisascaris procyonis: West Lafayette, Indiana, Purdue University, M.S. Thesis, 108 p.

Sheppard, C.H., 1996, Verhalten und Pathogenität der Larven von Baylisascaris procyonis Stefanski und Zarnowski 1951 (Ascarididae) in verschiedenen Mäusearten: Hannover, Germany, Tierärztliche Hochschule Hannover, Dissertation, Doctor Medicinae Veterinariae, 100 p. [In German.]

Sheppard, C.H., and Kazacos, K.R., 1997, Susceptibility of Peromyscus leucopus and Mus musculus to infection with Baylisascaris procyonis: Journal of Parasitology, v. 83, p. 1104-1111.

Shoieb, A., and Radi, Z.A., 2014, Cerebral Baylisascaris larva migrans in a cynomolgus macaque (Macaca fascicularis): Experimental and Toxicologic Pathology, v. 66, p. 263-265.
Singaravelu, K., Coyle, C.M., Martins, Y.C., Weiss, L.M., Machado, F.S., Tanowitz, H.B., and Kazacos, K.R., 2016, Nematode larva migrans, in Singh, S.K., ed., Human emerging and re-emerging infections ( $1^{\text {st }}$ ed.): Viral \& parasitic infections: Hoboken, New Jersey, John Wiley \& Sons, v. 1, p. 453-480.

Sivalingam, A., Goldberg, R.E., Augsburger, J., and Frank, P., 1991, Diffuse unilateral subacute neuroretinitis: Archives of Ophthalmology, v. 109, p. 1028.

Smiley, D., 1977a, Research report—Raccoon: New Paltz, New York, Mohonk Preserve, Daniel Smiley Research Center, $19 \mathrm{p}$.

Smiley, D., 1977b, Research report-Cave (Wood) Rat: New Paltz, New York, Mohonk Preserve, Daniel Smiley Research Center, 5 p.

Smiley, D., and Huth, P.C., 1986, "Crazy" animals: New Paltz, New York, Mohonk Preserve, Daniel Smiley Research Center, Natural Science Note 115, 2 p.

Smith, D.A., Kwiecien, J.M., and Smith-Maxie, L., 1993, Encephalitis in emus resulting from migration of Baylisascaris sp: Proceedings of the Association of Avian Veterinarians, p. 301-303.

Smith, H.T., and Engeman, R.M., 2002, An extraordinary raccoon, Procyon lotor, density at an urban park: Canadian Field-Naturalist, v. 116, p. 636-639.

Smith, R.A., Kennedy, M.L., and Wilhelm, W.E., 1985, Helminth parasites of the raccoon (Procyon lotor) from Tennessee and Kentucky: Journal of Parasitology, v. 71, p. 599-603.

Smith, S.L., 1992, The presence of the raccoon roundworm, Baylisascaris procyonis in Procyon lotor in Nova Scotia: Wolfville, Nova Scotia, Acadia University, Senior Honors Thesis, $12 \mathrm{p}$.

Smyser, T.J., Johnson, S.A., Page, L.K., Hudson, C.M., and Rhodes, O.E., Jr., 2013, Use of experimental translocations of Allegheny woodrat to decipher causal agents of decline: Conservation Biology, v. 27, p. 752-762.

Smyser, T.J., Johnson, S.R., Stallard, M.D., McGrew, A.K., Page, L.K., Crider, N., Ballweber, L.R., Swihart, R.K., and VerCauteren, K.C., 2015, Evaluation of anthelmintic fishmeal polymer baits for the control of Baylisascaris procyonis in free-ranging raccoons (Procyon lotor): Journal of Wildlife Diseases, v. 51, p. 640-650. 
Smyser, T.J., Page, L.K., Johnson, S.A., Hudson, C.M., Kellner, K.F., Swihart, R.K., and Rhodes, O.E., Jr., 2013, Management of raccoon roundworm in free-ranging raccoon populations via anthelmintic baiting: Journal of Wildlife Management, v. 77, p. 1372-1379.

Smyser, T.J., Page, L.K., and Rhodes, O.E., Jr., 2010, Optimization of raccoon latrine surveys for quantifying exposure to Baylisascaris procyonis: Journal of Wildlife Diseases, v. 46, p. 929-933.

Smyser, T.J., Redding, J.V., Jr., Bevis, C.M., Page, L.K., and Swihart, R.K., 2015, Development of an automated dispenser for the delivery of medicinal or vaccine-laden baits to raccoons (Procyon lotor): Journal of Wildlife Diseases, v. 51, p. 513-518.

Snyder, D.E., 1983, The prevalence, cross-transmissibility to domestic animals and adult structure of Baylisascaris procyonis (Nematoda) from Illinois raccoons (Procyon lotor): Urbana, University of Illinois at Urbana-Champaign, Ph.D. Thesis, $233 \mathrm{p}$.

Snyder, D.E., and Fitzgerald, P.R., 1985, The relationship of Baylisascaris procyonis to Illinois raccoons (Procyon lotor): Journal of Parasitology, v. 71, p. 596-598.

Snyder, D.E., and Fitzgerald, P.R., 1987, Contaminative potential, egg prevalence, and intensity of Baylisascaris procyonis-infected raccoons (Procyon lotor) from Illinois, with a comparison to worm intensity: Proceedings of the Helminthological Society of Washington, v. 54, p. 141-145.

Sorvillo, F., Ash, L.R., Berlin, O.G.W., Yatabe, J., Degiorgio, C., and Morse, S.A., 2002, Baylisascaris procyonis: An emerging helminthic zoonosis: Emerging Infectious Diseases, v. 8, p. 355-359.

Souza, M.J., Ramsay, E.C., Patton, S., and New, J.C., 2009, Baylisascaris procyonis in raccoons (Procyon lotor) in eastern Tennessee: Journal of Wildlife Diseases, v. 45, p. 1231-1234.

Sprent, J.F.A., 1951, On the migratory behavior of the larvae of various Ascaris species in mice: Journal of Parasitology, v. 37 (suppl.), p. 21.

Sprent, J.F.A., 1952a, On the migratory behavior of the larvae of various Ascaris species in white mice. I. Distribution of larvae in tissues: Journal of Infectious Diseases, v. 90, p. 165-176.

Sprent, J.F.A., 1952b, On an Ascaris parasite of the fisher and marten, Ascaris devosi sp. nov.: Proceedings of the Helminthological Society of Washington, v. 19, p. 27-37.
Sprent, J.F.A., 1953a, On the migratory behavior of the larvae of various Ascaris species in white mice. II. Longevity of encapsulated larvae and their resistance to freezing and putrefaction: Journal of Infectious Diseases, v. 92, p. 114-117.

Sprent, J.F.A., 1953b, On the life history of Ascaris devosi and its development in the white mouse and the domestic ferret: Parasitology, v. 42, p. 244-258.

Sprent, J.F.A., 1955, On the invasion of the central nervous system by nematodes. II. Invasion of the nervous system in ascariasis: Parasitology, v. 45, p. 41-55.

Sprent, J.F.A., 1968, Notes on Ascaris and Toxascaris, with a definition of Baylisascaris gen.nov.: Parasitology, v. 58, p. 185-198.

Sprent, J.F.A., 1970, Baylisascaris tasmaniensis sp.nov. in marsupial carnivores: heirloom or souvenir?: Parasitology, v. 61, p. $75-86$.

Sprent, J.F.A., Lamina, J., and McKeown, A., 1973, Observations on migratory behaviour and development of Baylisascaris tasmaniensis: Parasitology, v. 67, p. 67-83.

Stains, H.J., 1956, The raccoon in Kansas: Lawrence, University of Kansas, Miscellaneous Publications of the Museum of Natural History, v. 10, p. 1-76.

Stefański, W., and Žarnowski, E., 1951, Ascaris procyonis n. sp. z jelita szopa (Procyon lotor L.) Ascaris procyonis n. sp. provenant de l'intestin de Procyon lotor L: Annales Musei Zoologici Polonici, v. 14, p. 199-202.

Stone, W.B., 1983, Intestinal obstruction in raccoons caused by the ascarid Baylisascaris procyonis: New York Fish and Game Journal, v. 30, p. 117-118.

Stringfield, C.E., and Sedgwick, C.J., 1997, Baylisascaris: A zoo-wide experience: Proceedings of the American Association of Zoo Veterinarians, p. 73-77.

Stubbe, M., 1990, Der Status des Waschbären Procyon lotor (L.) in der DDR (1975-1984): Beiträge zur Jagd- und Wildforschung, v. 17, p. 180-192. [In German.]

Stuewer, F.W., 1943, Raccoons: Their habits and management in Michigan: Ecological Monographs, v. 13, p. 204-257.

Suedmeyer, W.K., Bermudez, A., and Kazacos, K.R., 1996, Cerebellar nematodiasis in an emu (Dromaius novaehollandiae): Journal of Zoo and Wildlife Medicine, v. 27, p. 544-549.

Swerczek, T.W., and Helmboldt, C.F., 1970, Cerebrospinal nematodiasis in groundhogs (Marmota monax): Journal of the American Veterinary Medical Association, v. 157, p. $671-674$. 
Taira, K., Une, Y., Šnábel, V., and Sugiyama, H., 2013, Baylisascaris sp. infection in a pet kinkajou Potos flavus: Helminthologia, v. 50, p. 238-243.

Tarantola, R.M., Elkins, K.A., Kay, C.N., and Folk, J.C., 2011, Photoreceptor recovery following laser photocoagulation and albendazole in diffuse unilateral subacute neuroretinitis: Archives of Ophthalmology, v. 129, p. 669-671.

Taylor, M.R.H., Keane, C.T., O’Connor, P., Girdwood, R.W.A., and Smith, H., 1987, Clinical features of covert toxocariasis: Scandinavian Journal of Infectious Diseases, v. 19, p. 693-696.

Tecec, T.G., 1987, Occurrence of Baylisascaris procyonis in raccoon populations on military installations in the Washington, D.C. area: Military Medicine, v. 152, p. 83-84.

Tenora, F., and Stanek, M., 1990, Scanning electron microscopy of Toxascaris procyonis Stefanski et Zarnowski, 1951 (Nematoda): Helminthologia, v. 27, p. 73-77.

Tenora, F., Hönigová, M., and Stanek, M., 1991, Interesting findings of two species of Ascaridata (Nematoda) - parasites of carnivora in Czech and Slovak Federative Republic: Helminthologia, v. 28, p. 131-135.

Thomas, J.S., 1988, Encephalomyelitis in a dog caused by Baylisascaris infection: Veterinary Pathology 25: 94-95.

Thompson, A.B., Glover, G.J., Postey, R.C., Sexsmith, J.L., Hutchison, T.W.S., and Kazacos, K.R., 2008, Baylisascaris procyonis encephalitis in Patagonian conures (Cyanoliseus patagonus), crested screamers (Chauna torquata), and a western Canadian porcupine (Erethizon dorsatum epixanthus) in a Manitoba zoo: Canadian Veterinary Journal, v. 49, p. 885-888.

Tiner, J.D., 1949, Preliminary observations on the life history of Ascaris columnaris: Journal of Parasitology, v. 35 (suppl.), p. 13.

Tiner, J.D., 1951, Observations on larval carnivore ascarids in rodents: Journal of Parasitology, v. 37 (suppl.), p. 21-22.

Tiner, J.D., 1952a, A study of the epidemiology of ascarid nematodes in carnivores and rodents: Urbana, University of Illinois, Ph.D. Thesis, 130 p.

Tiner, J.D., 1952b, Speciation in the genus Ascaris: Additional experimental and morphological data: Journal of Parasitology, v. 38 (suppl.), p. 27.

Tiner, J.D., 1953a, Fatalities in rodents caused by larval Ascaris in the central nervous system: Journal of Mammalogy, v. 34, p. 153-167.

Tiner, J.D., 1953b, The migration, distribution in the brain, and growth of ascarid larvae in rodents: Journal of Infectious Diseases, v. 92, p. 105-113.
Tiner, J.D., 1954, The fraction of Peromyscus leucopus fatalities caused by raccoon ascarid larvae: Journal of Mammalogy, v. 35, p. 589-592.

Tokiwa, T., Nakamura, S., Taira, K., and Une, Y., 2014, Baylisascaris potosis $\mathrm{n}$. sp., a new ascarid nematode isolated from captive kinkajou, Potos flavus, from the Cooperative Republic of Guyana: Parasitology International, v. 63, p. 591-596.

Tokiwa, T., Tsugo, K., Nakamura, S., Taira, K., and Une, Y., 2015, Larva migrans in squirrel monkeys experimentally infected with Baylisascaris potosis: Parasitology International, v. 64, p. 284-287.

Tseng, F.S., 1997, Baylisascaris in squirrels: Proceedings of the North American Veterinary Conference, p. 817-818.

U.S. Department of Agriculture-Animal and Plant Health Inspection Service, 2015, Import live animals: accessed September 10, 2015, at https://www.aphis.usda.gov/.

Van Andel, R.A., Franklin, C.L., Besch-Williford, C., Riley, L.K., Hook, R.R., Jr., and Kazacos, K.R., 1995, Cerebrospinal larva migrans due to Baylisascaris procyonis in a guinea pig colony: Laboratory Animal Science, v. 45, p. 27-30.

Vieira, F.M., Luque, J.L., and Muniz-Pereira, L.C., 2008, Checklist of helminth parasites in wild carnivore mammals from Brazil: Zootaxa, v. 1721, p. 1-23.

Voge, M., 1956, A list of nematode parasites from California mammals: American Midland Naturalist, v. 56, p. 423-429.

Waller, E.F., 1940, Infectious gastroenteritis in raccoons (Procyon lotor): Journal of the American Veterinary Medical Association, v. 96, p. 266-268.

Wang, T., He, G., Yang, G., Fei, Y., Zhang, Z., Wang, C., Yang, Z., Lan, J., Luo, L., and Liu, L., 2008, Cloning, expression and evaluation of the efficacy of a recombinant Baylisascaris schroederi Bs-Ag3 antigen in mice: Vaccine, v. 26, p. 6919-6924.

Wilder, H.C., 1950, Nematode endophthalmitis: Transactions of the American Academy of Ophthalmology, v. 55, p. 99-109.

Williams, C.K., McKown, R.D., Veatch, J.K., and Applegate, R.D., 1997, Baylisascaris sp. found in a wild northern bobwhite (Colinus virginianus): Journal of Wildlife Diseases, v. 33, p. $158-160$.

Williams, G.A., Aaberg, T.M., and Dudley, S.S., 1988, Perimacular photocoagulation of presumed Baylisascaris procyonis in diffuse unilateral subacute neuroretinitis, in Gitter, K.A., Schatz, H., Yannuzzi, L.A., and McDonald, H.R., eds., Laser photocoagulation of retinal disease: San Francisco, California, Pacific Medical Press, p. 275-280. 
Wilson, D.E., and Reeder, D.M., eds., 1993, Mammal species of the world: A taxonomic and geographic reference (2nd ed.): Washington, D.C., Smithsonian Institution Press, $1206 \mathrm{p}$.

Windsor, R.C., Sturges, B.K., Vernau, K.M., and Vernau, W., 2009, Cerebrospinal fluid eosinophilia in dogs: Journal of Veterinary Internal Medicine, v. 23, p. 275-281.

Winter, M., 2006, Procyon lotor: DAISIE, Delivering Alien Invasive Species Inventories for Europe, 4 p., Accessed May 25, 2014 at http://www.europe-aliens.org.

Winter, M., Stubbe, M., and Heidecke, D., 2005, Zur Ökologie des Waschbären (Procyon lotor L., 1758) in SachsenAnhalt: Beiträge zur Jagd- und Wildforschung, v. 30, p. 303-322. [In German.]

Winterfield, R.W., and Thacker, H.L., 1978, Verminous encephalitis in the emu: Avian Diseases, v. 22, p. 336-339.

Wirtz, W.L., 1981, Host range for cerebrospinal nematodiasis and visceral larva migrans due to Baylisascaris procyonis: Proceedings of the Annual Midwestern Conference of Parasitologists, v. 33, p. 7.

Wirtz, W.L., 1982, Cerebrospinal nematodiasis due to the raccoon ascarid, Baylisascaris procyonis: West Lafayette, Indiana, Purdue University, M.S. Thesis, 90 p.

Wise, M.E., Sorvillo, F.J., Shafir, S.C., Ash, L.R., Berlin, O.G., 2005, Severe and fatal central nervous system disease in humans caused by Baylisascaris procyonis, the common roundworm of raccoons: a review of current literature: Microbes and Infection, v. 7, p. 317-323.

Wolf, K.N., Lock, B., Carpenter, J.W., and Garner, M.M., 2007, Baylisasacaris procyonis infection in a moluccan cockatoo (Cacatua moluccensis): Journal of Avian Medicine and Surgery, v. 21, p. 220-225.

Won, K.Y., Kruszon-Moran, D., Schantz, P.M., and Jones, J.L., 2008, National seroprevalence and risk factors for zoonotic Toxocara spp. infection: American Journal of Tropical Medicine and Hygiene, v. 79, p. 552-557.

Wu, J., He, G., and Hu, H., 1987, Study on a new species, Toxascaris ailuri sp. n. (Nematoda:Ascaridae) from red panda: Sichuan Journal of Zoology, v. 2, p. 1-3.
Wyand-Ouellette, W.K., Kazacos, K.R., and DeNicola, D.B., 1983, Assessment of pulmonary migration of ascarids (Baylisascaris, Ascaris) by bronchopulmonary lavage: Proceedings of the American Association of Veterinary Parasitologists, v. 28, p. 24.

Xie, Y., Zhang, Z., Niu, L., Wang, Q., Wang, C., Lan, J., Deng, J., Fu, Y., Nie, H., Yan, N., Yang, D., Hao, G., Gu, X., Wang, S., Peng, X., and Yang, G., 2011, The mitochondrial genome of Baylisascaris procyonis: PLoS One, v. 6, p. e27066 (10 pages).

Xie, Y., Zhou, X., Li, M., Liu, T., Gu, X., Wang, T., Lai, W., Peng, X., and Yang, G., 2014, Zoonotic Baylisascaris procyonis roundworms in raccoons, China [letter]: Emerging Infectious Diseases, v. 20, p. 2170-2172.

Yabsley, M., 2010, Baylisascaris in Florida raccoons: Athens, University of Georgia School of Veterinary Medicine, SCWDS Briefs, v. 26, p. 2-3.

Yeager, L.E., and Rennels, R.G., 1943, Fur yield and autumn foods of the raccoon in Illinois river bottom lands: Journal of Wildlife Management, v. 7, p. 45-60.

Yeitz, J.L., Gillin, C.M., Bildfell, R.J., and DeBess, E.E., 2009, Prevalence of Baylisascaris procyonis in raccoons (Procyon lotor) in Portland, Oregon, USA: Journal of Wildlife Diseases, v. 45, p. 14-18.

Yoshikawa, M., Nishiofuku, M., Moriya, K., Ouji, Y., Ishizaka, S., Kasahara, K., Mikasa, K., Harai, T., Mizuno, Y., Ogawa, S., Nakamura, T., Maruyama, H., and Akao, N., 2008, A familial case of visceral toxocariasis due to consumption of raw bovine liver: Parasitology International, v. 57 , p. 525-529.

Zhang, J.S., Daszak, P., Huang, H.L., Yang, G.Y., Kilpatrick, A.M., and Zhang, S., 2007, Parasite threat to panda conservation: EcoHealth, v. 5, p. 6-9.

Zimmerman, D., Dangoudoubiyam, S., and Kazacos, K.R., 2010, Human serological testing for Baylisascaris procyonis in nonhuman primates: Proceedings of the Joint Conference of the American Association of Zoo Veterinarians and American Association of Wildlife Veterinarians, South Padre Island, Texas, October 2010, p. 124. 


\section{Glossary}

Terms are defined relative to meanings within this publication.

\section{A}

anthelmintic A drug or other agent that kills or expels worm parasites, especially intestinal worms. See also parasite.

antibodies Proteins formed in the body of a vertebrate that are used by the immune system to identify and neutralize the effects of foreign invading proteins, called antigens, coming from bacteria, viruses, parasites, and their enzymes or other proteins. See also antigens, parasite, vertebrate.

antigens Foreign proteins and other substances that, upon entering the body, stimulate the host's immune system to produce protective antibodies and immune cells as a means of protecting the host from harmful invasion. See also antibodies, host.

ascarid Large roundworms in the taxonomic phylum Nematoda that live in the intestines of vertebrates; order Ascaridida, superfamily Ascaridoidea. Includes Ascaris, Baylisascaris, Toxocara, and others. See also nematode, taxonomy, vertebrate.

asymptomatic Without symptoms, or producing no symptoms. See also symptoms.

ataxia An inability to coordinate muscle activity during voluntary movement; may involve the limbs, head, or trunk.

\section{B}

Baermann funnel A funnel apparatus used to isolate parasite larvae from animal tissues or soil, based on the principle of continued activity and penetration through mesh in a warm solution (saline or water). See also larva, parasite.

baylisascariasis Infection or disease caused by nematodes in the genus Baylisascaris; usually involves larval infection (visceral, ocular, neural larva migrans). See also genus, larva, nematode, viscera, neural larva migrans (NLM), ocular larva migrans (OLM).

bear Any of the carnivorous or omnivorous mammals of the family Ursidae, having massive bodies, coarse heavy fur, relatively short limbs, almost rudimentary tails, and walking with the entire sole and heel of the foot on the ground. See also carnivorous, mammals, omnivorous, taxonomy.

birds Warm-blooded vertebrates with wings and feathers, belonging to the class Aves. The wings are poorly developed for some species of flightless birds. See also vertebrate.

\section{C}

cache, caching To hoard, stockpile, store up, collect. Used to refer to the behavior of rodents such as the Allegheny woodrat and other packrats that habitually collect items and store them in their middens. See also midden, rodent, woodrat. cacomistle A carnivorous procyonid mammal, similar in appearance to the ringtail and found from southern Mexico to western Panama. See also carnivorous, mammals, procyonid, ringtail.

canids Carnivorous mammals within the family Canidae (for example, wolves, coyotes, foxes, and other doglike animals). See also carnivorous, taxonomy.

carnivore, carnivorous A flesh-eating mammal of the order Carnivora, comprising the wolves, bears, raccoons, cats, weasels, etc. Their teeth are adapted for feeding on flesh. See also bear, canids, mammals, raccoon.

central nervous system (CNS) The part of the nervous system comprising the brain and spinal cord.

cerebrospinal Relating to the brain and the spinal cord.

cerebrospinal fluid (CSF) The fluid in the ventricles of the brain and surrounding the spinal cord. See also cerebrospinal.

cerebrospinal nematodiasis Invasion of the brain and (or) spinal cord by nematode larvae. An older term referring only to nematodes, this has been replaced by the broader classification called neural larva migrans. See also cerebrospinal, larva, nematode, neural larva migrans.

\section{clinical Readily observable.}

clinical sign Objective evidence of disease or injury that can be perceived by an examiner. See also clinical.

coati A tropical American carnivore of the genus Nasua, related to the raccoon, having an elongated body, long, ringed tail, and a slender, flexible snout. See also carnivore, genus, raccoon, taxonomy.

coma, comatose A state of deep unconsciousness from which a person or animal cannot be aroused. Such individuals cannot react to events in their environment.

communicable disease An illness caused by a specific infectious agent or its toxic products, arising through transmission of that agent or its products from an infected person, animal, or inanimate reservoir directly or indirectly (via intermediate plant or animal host) to a susceptible host. See also host, intermediate host.

companion animals Animals maintained by humans as pets (such as dogs, cats, captive wildlife, horses, etc.).

computed tomography (CT) Also known as computerized axial tomography, an imaging process that demonstrates various bodily structures based on their ability to block an x-ray beam, using a computer to manipulate ("window") the volume of data that is generated by the scanner.

conure Any of several small, long-tailed New World parrots, especially of the genus Aratinga, certain species of which are often kept as pets. Also referred to as large parakeets. See also genus, taxonomy.

cortical Relating to the outer layer of the cerebrum, the part of the brain which coordinates the body's sensory and motor information. 
covert Something that is concealed, hidden, secret, or disguised. A covert infection is one that is present but with nonspecific clinical signs that cannot be specifically diagnosed. Covert infections may be detected by isolating the agent or its antigens or by detecting specific antibodies in the serum. See also antibodies, antigens, clinical sign, serum.

\section{D}

definitive host A host in which a parasite reaches the adult stage or undergoes sexual reproduction. See also host, parasite.

dementia A pattern of mental decline caused by different diseases or conditions, such as brain injury, infection, degenerative diseases, adverse drug reactions, etc.

developmental delay The developmental condition wherein a child does not demonstrate abilities and skills commonly found in other children in the same age group. Developmental delays may involve physical abilities (gross or fine motor skills), language, or personal or social skills.

diffuse unilateral subacute neuroretinitis (DUSN) A type of ocular larva migrans resulting in inflammatory and degenerative changes to the retina, retinal vessels, and optic nerve head, caused by larvae of Baylisascaris, Toxocara, Ancylostoma, Alaria, and probably other parasites. See also inflammation, ocular larva migrans, parasite.

DNA Deoxyribonucleic acid, a nucleic acid found mainly in the chromosomes of an organism that contains the hereditary information of that organism.

\section{E}

emaciated Abnormally thin, caused by lack of nutrition or by disease.

encephalitis Inflammation of the substance of the brain.

enzootic Occurring commonly within an animal population or a geographical area.

enzyme-linked immunosorbent assay (ELISA) A laboratory test used to detect the presence of either antigen or antibody in a sample using an enzyme reagent that generates a color reaction.

eosinophil A white blood cell involved in combating parasitic and certain other infections and also involved in allergic reactions. See also eosinophilia, helminth, parasite.

eosinophilia An abnormally increased number of eosinophils, a type of white blood cell, in the blood. See also eosinophil.

eosinophilic meningitis or meningoencephalitis A type of inflammation of the brain and its coverings in which white blood cells called eosinophils are the predominant cell type; eosinophils usually increase in response to specific antigens produced by helminth larvae, fungi, or other agents. See also antigen, eosinophil, helminth, inflammation, parasite. epidemiology The study of the causes, occurrence, and control of disease in populations.

excretory-secretory (ES) antigens Metabolic antigens (proteins) excreted or secreted by living parasites such as helminth larvae during migration or feeding. These antigens include digestive enzymes, nitrogenous and other waste products, proteins shed from the surface, and other substances. Immune responses of the host are often directed against ES antigens produced by migrating larvae. See also antigens, helminth, host, larva, parasite.

exotic pet A pet of foreign origin or character; not a native species, but introduced from abroad.

$\mathbf{F}$

fecal examination Examination of samples of feces for infectious and parasitic agents. Usually refers to examination for parasite eggs, larvae, cysts, or other stages. See also feces, larvae, parasite.

fecal flotation A method of examining samples of feces in which parasite stages (eggs, larvae, cysts) are isolated from feces by using flotation on high density solutions, usually various salts or sugar. See also feces, larvae, parasite.

feces Waste matter discharged from the intestines through the anus; excrement.

\section{G}

general practitioner A medical professional, such as a physician or veterinarian, whose practice is not limited to any specific branch of medicine or class of diseases.

genus, genera A taxonomic group of similar species; similar genera are grouped into families. See also species, taxonomy.

geophagia Eating earthy matter, especially soil or sand.

granuloma An inflammatory nodule, tumor or growth composed of connective tissue and other cells, often forming around helminth (worm) larvae or other organisms in body tissues. See also helminth, larva.

H

helminth A worm or wormlike organism. In a medical context, refers to worm parasites, including nematodes (roundworms), cestodes (tapeworms), trematodes (flukes), and acanthocephalans (thorny-headed worms). See also parasite.

hemorrhage A profuse discharge of blood, as from a ruptured blood vessel; bleeding.

histology, histological The study of the microscopic structure of tissues.

histopathology The science dealing with the histological structure of abnormal or diseased tissue; pathological histology. See also histology, pathological. 
host A living plant or animal that harbors and (or) nourishes microbes, viruses, or parasites. See also definitive host, paratenic host, parasite.

\section{I}

indirect immunofluorescence A diagnostic method using a fluorescence microscope to detect specific antigens (proteins, etc.) in tissues based on their binding of antibodies carrying fluorescent dyes. See also antibodies, antigens.

infectious disease A disease resulting from infection with a pathogenic microbial agent. See also pathogenic.

inflammation Redness, swelling, pain, tenderness, heat, and disturbed function of an area of the body, especially as a reaction of tissues to injurious agents.

intermediate host A host in which a parasite undergoes essential development of intermediate or larval stages but not to sexual maturity. See also host, parasite.

invertebrates Animals lacking a spinal column, for example, insects and helminth (worm) parasites; vertebrates, in contrast, possess a spinal column. See also helminth.

isolate, isolation To separate something of interest from surrounding material in order to facilitate further study and identification.

\section{$\mathbf{J}$}

\section{K}

kinkajou An arboreal carnivore with a prehensile tail, Potos flavus, of Central and South America, related to the raccoon and coati. See also carnivore, coati, raccoon.

L

larva, larvae, larval An immature stage of an organism that is fundamentally different from the adult.

larva migrans (LM) The prolonged migration and persistence of helminth larvae in the organs and tissues of humans and animals. See also helminth, larva, parasite.

larvicidal Pertaining to an agent, such as an anthelmintic drug, with the ability to kill larvae. See also anthelmintic.

lesion An abnormal change in the appearance of tissue or loss of normal function due to pathogens, injury, or other causes. See also pathogen.

\section{M}

magnetic resonance imaging (MRI) An imaging method that detects various bodily structures in great detail by using powerful magnetic fields to align the magnetization of atomic nuclei in cells in the tissues.

mammals Warm-blooded vertebrate animals that possess hair during some part of their life and suckle their young. See also vertebrate.

midden A dunghill, debris, or garbage pile, or a pile of refuse. Rodents such as ground squirrels and woodrats may use burrows or other areas for food storage, and in the case of woodrats, also known as packrats, various items, including food material, animal bones, fecal material, and disparate shiny or interesting objects, may be cached in these large debris piles. See also cache, rodent, woodrat.

\section{N}

necropsy Examination and dissection of an animal after death, usually to determine a cause of death; postmortem examination.

nematode Unsegmented, cylindrical parasitic worm of the class Nematoda; roundworm.

neural larva migrans (NLM) Invasion of the brain and (or) spinal cord by helminth larvae, such as nematodes in the genera Baylisascaris and Toxocara. The raccoon ascarid, B. procyonis, is a well-known cause of NLM in humans and animals. See also ascarid, genus, helminth, nematode, parasite, raccoon. neurologic disease A disease affecting the nervous system (brain, spinal cord, etc.).

neurologist A medical professional, such as a physician or a veterinarian, who specializes in diseases and conditions of the nervous system.

neurotropic Having a predilection for the nervous system or nervous tissue.

\section{0}

ocular larva migrans (OLM) Invasion of the eye by helminth larvae, such as nematodes in the genera Baylisascaris and Toxocara. See also genus, helminth, larvae, nematode, parasite.

omnivorous Having a diet of both plants and animals.

ophthalmologist A medical professional, such as a physician or a veterinarian, who specializes in diseases of the eye.

\section{$\mathbf{P}$}

parasite, parasitic An organism that lives at least part of its life cycle on or within another organism (the host) upon which it is physiologically dependent and to which it causes harm in some way. In a parasitologic or medical context, it usually refers to animal agents, that is, protozoa, helminths, and arthropods. See also helminth, host.

paratenic host A host in which a parasite survives without undergoing required or essential development. A paratenic host accumulates and maintains intermediate or larval stages of a parasite which may undergo growth, but is not essential or required in the parasite's life cycle. Also known as a transport host. See also host, parasite, paratenesis.

patent Refers to a mature parasitic infection that results in the appearance of parasite eggs or larvae in or from the host. See also host, larva, parasitic, prepatent period.

pathogen, pathogenic Any organism capable of producing disease; typically refers to microorganisms (bacteria, viruses, 
protozoa), but broadly includes all disease-producing agents, including worm parasites. See also parasite.

pathogenicity The ability of an organism to cause disease.

pathology The study of the structural and functional effects of disease.

pathological Pertaining to pathology. See also clinical sign, histopathology, pathology, symptoms.

pediatrician A physician who specializes in the diseases of children.

peridomestic Around or in the vicinity of human habitation.

pheasant Long-tailed and often brightly colored Old World gallinaceous birds of the family Phasianidae. See also birds.

pharmacokinetics The absorption, movement, and other characteristics of distribution and elimination of drugs from the body.

phylogenetics The study of evolutionary relatedness among groups of organisms (such as species and populations) using molecular sequencing and morphological data, useful in biological systematics and taxonomy.

pica An eating disorder characterized by compulsive craving and eating of nonnutritive substances that may include clay, dirt, sand, chalk, paper, etc.

polymerase chain reaction (PCR) A molecular biologic technique that uses an enzyme (deoxyribonucleic acid [DNA] polymerase) and short specific DNA fragments (primers) to enable selective and repeated amplification of a single or a few copies of a piece of DNA across many orders of magnitude, generating thousands to millions of copies of a particular DNA sequence, which can then be detected using gel electrophoresis. The method has become very important and widespread for the detection and diagnosis of pathogens in bodily tissues, fluids and other samples. See also DNA.

population A group of organisms inhabiting a specific area or possessing a specific trait.

poultry A general term for farmed domestic birds, including chickens, turkeys, ducks, and geese. See also birds.

predator An animal that captures, kills, and eats other animals for food.

prepatent period The period of time from initial infection with a parasite until one can demonstrate that the host is infected by finding stages of the parasite (eggs, larvae, etc.) in or from the host; also known as the biological incubation period. The patent period is the period of time from first demonstration of a parasitic infection (by finding eggs, larvae, etc.) until one can no longer demonstrate that the host is infected. See also host, larvae, parasite, patent.

prevalence The total number of cases of a disease in a population at a given time. Also, the proportion of individuals found to be positive (infected) for a pathogen or parasite of those individuals tested or examined. See also pathogen, parasite, population.

primate Any of various omnivorous mammals of the order Primates, comprising humans, the apes, Old and New World monkeys, lemurs, and tarsiers, that are especially distinguished by the use of hands, varied locomotion, and complex social behavior. See also omnivore, taxonomy.

procyonid A mammal within the taxonomic family Procyonidae. They are relatively small, omnivorous New World mammals including raccoons, coatis, kinkajous, olingos, and ringtails. Most procyonids have distinct masklike facial markings and banded tails. See also coati, mammals, omnivorous, raccoon, ringtail, taxonomy.

pseudoparasite From a diagnostic standpoint, nonparasite material or artifacts (for example, pollen, spores, plant hairs, etc.) that are mistaken for parasite stages.

\section{$\mathbf{0}$}

quail Various small, short-tailed gallinaceous birds of the family Phasianidae. See also birds, taxonomy.

\section{$\mathbf{R}$}

rabbit Small, long-eared mammals in the family Leporidae (rabbits and hares) of the order Lagomorpha (rabbits, hares, and pikas). See also mammals, taxonomy.

raccoon A nocturnal carnivore, Procyon lotor, in the family Procyonidae, having a masklike black stripe across the eyes, a sharp snout, and a bushy, ringed tail, native to North and Central America. See also carnivore, procyonid, taxonomy.

raccoon latrine An area of communal defecation by raccoons, where their feces accumulate, sometimes in substantial amounts. Often found on logs, large rocks, at the bases of trees, in barns and other outbuildings, and on rooftops.

raptor A predatory bird such as a hawk, eagle, and owl, with bill and claws adapted for seizing prey. See also birds.

ratite A member of a diverse group of large, flightless birds, including ostrich, emu, rhea, cassowary, and kiwi.

recombinant antigen A protein produced using recombinant DNA technology. See also antigens, recombinant DNA.

recombinant DNA DNA produced by combining genetic material from two or more sources by means of genetic engineering. Often used to express diagnostic or other proteins encoded by DNA sequences by cloning them into bacteria or yeasts. See also DNA.

ringtail A carnivorous procyonid mammal, Bassariscus astutus, of Mexico and the southwestern United States, related to the raccoon but smaller, with a sharper snout and longer, bushy ringed tail. See also carnivorous, mammals, procyonid.

rodent A diverse group of mammals characterized by incisor teeth that grow throughout life. Species within the order Rodentia include mice, rats, squirrels, chipmunks, voles, 
gophers, marmots, beavers, porcupines, and many others. See also mammals, mice, species, taxonomy, vole.

\section{S}

scavenger An animal, such as a vulture, crow, hyena, and jackal, that feeds on carcasses, other carrion, and refuse.

serology Laboratory evaluations of the serum portion of the blood for the purpose of detecting and measuring host antibody levels and responses to infectious agents and other antigens. See also antibodies, host, serum.

seropositive The presence of an antibody specific to an infectious agent or other antigen in the blood as determined by a laboratory test. See also antibodies, antigens, serum.

serum The pale fluid that remains after blood has clotted. It contains a large amount and variety of proteins including antibodies and other substances. See also antibodies, seropositive.

shrew A small molelike omnivorous mammal in the order Soricomorpha, family Soricidae, possessing sharp, spikelike teeth, poor eyesight, and excellent senses of hearing and smell. They are very active, with voracious appetites and unusually high metabolic rates. See also mammals, omnivorous, taxonomy.

skunk Several species of carnivores within the family Mephitidae well-known for their pungent anal glands; specifically, the striped, hooded, spotted, and hog-nosed skunk. See also carnivore, species.

somatic (tissues, migration) Pertaining to the body wall proper (muscles, connective tissue, etc.) as opposed to the viscera. See also viscera.

species A population of organisms whose members are able to breed among themselves and produce fertile offspring. More precise determinations of species are based on similarity of deoxyribonucleic acid (DNA). See also DNA, population, taxonomy.

specificity The restriction of a parasite to one or more species of hosts, that is, the degree to which a parasite is able to develop in more than one host species. See also host, parasite, species.

squirrel Small to medium-sized arboreal rodents in the family Sciuridae, having long, bushy tails and strong hind legs.

stage Any particular form in the life cycle of a parasite that can be distinguished from all of its other forms. See also parasite.

stupor, stuporous A state of impaired consciousness in which the patient shows a marked diminution in reactivity to environmental stimuli and can be aroused only by continual stimulation.

subclinical A condition without overt clinical manifestations, yet sometimes able to be detected using specialized equipment or procedures. See also clinical. symptoms Subjective indications of a disorder or disease, experienced by an individual as a change from normal function, sensation, or appearance.

\section{$\mathbf{T}$}

taxonomic, taxonomy The systematic principles and procedures of grouping and arranging organisms into a hierarchical framework (below).

\begin{tabular}{l}
\hline $\begin{array}{c}\text { Taxonomic hierarchy, } \\
\text { from general to specific }\end{array}$ \\
\hline Kingdom \\
Phylum \\
Class \\
Order \\
Family \\
Subfamily \\
Genus \\
Species \\
\hline
\end{tabular}

Toxocara A genus of large roundworms or ascarids (nematodes) that includes species infecting dogs, cats, foxes, and other carnivores. See also ascarid, carnivore, nematode, taxonomy, toxocariasais, toxocaral.

toxocaral Relating to infection or disease caused by Toxocara roundworms. See also Toxocara.

translocation Human capture of wildlife at one geographic area and their transportation and release at a different geographic area.

transplacental Transmitted across the placenta. Some infectious agents and parasites are transmitted from mother to offspring in utero across the placenta. See also parasite.

U

ungulate A hoofed, grazing mammal.

V

viscera, visceral The organs in the cavities of the body, especially those in the abdominal cavity; pertaining to those organs.

visceral larva migrans (VLM) Invasion of the viscera (liver, lungs, etc.) by helminth larvae, such as nematodes in the genera Baylisascaris and Toxocara. See also helminth, larvae, nematode, parasite, viscera, Toxocara.

voles Small rodents of the genus Microtus and related genera that typically have a stout body, rather blunt nose (compared to mice), and small ears. See also genus, mice, rodent.

W

waterfowl Birds within the family Anatidae, including species of ducks, geese, and swans. See also birds, taxonomy. 
Western blotting A laboratory diagnostic format used to detect reactivity to specific proteins in a tissue homogenate, extract, or complex mixture by separating the native proteins by gel electrophoresis, transferring them to a membrane, reacting the separated proteins with serum (that is, antibodies), and detecting resultant antigen-antibody reactions using a secondary antibody linked to a reporter enzyme that drives a colorimetric reaction. See also antibody, antigen, serum.

woodrat Medium to large rodents (order Rodentia) in the genus Neotoma, also known as packrats. Have a ratlike appearance with long tails, large ears, and large black eyes, and a characteristic behavior of gathering food material, bones, feces, and other objects and caching them in middens in or near their den. See also cache, feces, genus, midden, rodent, taxonomy.

\section{$\mathbf{X}$}

\section{Y}

Z

zoonosis An infection or disease of animals that can be transmitted to humans.

zoonotic Of or relating to or constituting a zoonosis. See also zoonosis. 



\section{Appendixes}

Appendix 1. Common and scientific names of animals cited.

Appendix 2. Cases of Baylisascaris neural larva migrans in pets.

Appendix 3. Cases of Baylisascaris neural larval migrans in animal facilities. 
Appendix 1. Common and scientific names of animals cited.

\begin{tabular}{|c|c|}
\hline Common name & Scientific name \\
\hline \multicolumn{2}{|r|}{ Mammals } \\
\hline Allegheny woodrat & Neotoma magister \\
\hline American badger & Taxidea taxus \\
\hline American beaver & Castor canadensis \\
\hline American red squirrel & Tamiasciurus hudsonicus \\
\hline Bennett's wallaby & Macropus rufogriseus rufogriseus \\
\hline Black-and-white ruffed lemur & Varecia variegata \\
\hline Black-mantled tamarin & Saguinus nigricollis \\
\hline Black-tailed prairie dog & Cynomys ludovicianus \\
\hline Bornean orangutan & Pongo pygmaeus \\
\hline Botta’s pocket gopher & Thomomys bottae \\
\hline Brazilian porcupine & Coendou prehensilis \\
\hline Brown rat (or laboratory rat) & Rattus norvegicus \\
\hline Cacomistle & Bassariscus sumichrasti \\
\hline California ground squirrel & Otospermophilus beecheyi \\
\hline California pocket mouse & Chaetodipus californicus \\
\hline Capybara & Hydrochoerus hydrochaeris \\
\hline Coati & Nasua narica, N. nasua \\
\hline Common squirrel monkey & Saimiri sciureus \\
\hline Coquerel's giant mouse lemur & Mirza coquereli \\
\hline Cottontop tamarin & Saguinus oedipus \\
\hline Coyote & Canis latrans \\
\hline Cozumel raccoon & Procyon pygmaeus \\
\hline Crab-eating macaque & Macaca fascicularis \\
\hline Crab-eating raccoon & Procyon cancrivorus \\
\hline De Brazza’s monkey & Cercopithecus neglectus \\
\hline Deer mouse & Peromyscus maniculatus \\
\hline Desert cottontail & Sylvilagus audubonii \\
\hline Diana monkey & Cercopithecus diana \\
\hline Domestic cat & Felis catus \\
\hline Domestic cow & Bos taurus \\
\hline Domestic dog & Canis lupus familiaris \\
\hline
\end{tabular}


Appendix 1. Common and scientific names of animals cited.-Continued

\begin{tabular}{|c|c|}
\hline Common name & Scientific name \\
\hline \multicolumn{2}{|c|}{ Mammals-Continued } \\
\hline Domestic ferret (domesticated European polecat) & Mustela putorius furo \\
\hline Domestic pig & Sus scrofa domesticus \\
\hline Domestic sheep & Ovis aries \\
\hline Douglas squirrel & Tamiasciurus douglasii \\
\hline Dusky-footed woodrat & Neotoma fuscipes \\
\hline Eastern chipmunk & Tamias striatus \\
\hline Eastern cottontail & Sylvilagus floridanus \\
\hline Eastern fox squirrel & Sciurus niger \\
\hline Eastern gray squirrel & Sciurus carolinensis \\
\hline Emperor tamarin & Saguinus imperator \\
\hline European rabbit (domesticated) & Oryctolagus cuniculus \\
\hline Fisher & Martes pennati \\
\hline Francois’ langur & Trachypithecus francoisi \\
\hline Giant panda & Ailuropoda melanoleuca \\
\hline Golden hamster & Mesocricetus auratus \\
\hline Golden-headed lion tamarin & Leontopithecus chrysomelas \\
\hline Guinea pig (domesticated) & Cavia porcellus \\
\hline Hamadryas baboon & Papio hamadryas \\
\hline Hispid cotton rat & Sigmodon hispidus \\
\hline House mouse (or laboratory mouse) & Mus musculus \\
\hline Human & Homo sapiens \\
\hline Japanese macaque & Macaca fuscata fuscata \\
\hline Kinkajou & Potos flavus \\
\hline Least weasel & Mustela nivalis \\
\hline Lion-tailed macaque & Macaca silenus \\
\hline Long-nosed potoroo & Potorous tridactylus \\
\hline Long-tailed chinchilla & Chinchilla lanigera \\
\hline Long-tailed weasel & Mustela frenata \\
\hline Mantled guereza & Colobus guereza kikuyuensis \\
\hline Marten & Martes americana \\
\hline Meadow jumping mouse & Zapus hudsonius \\
\hline Meadow vole & Microtus pennsylvanicus \\
\hline
\end{tabular}


Appendix 1. Common and scientific names of animals cited. - Continued

\begin{tabular}{|c|c|}
\hline Common name & Scientific name \\
\hline \multicolumn{2}{|c|}{ Mammals-Continued } \\
\hline Mohol bushbaby & Galago moholi \\
\hline Mongolian gerbil & Meriones unguiculatus \\
\hline Mountain beaver & Aplodontia rufa \\
\hline Muskrat & Ondatra zibethicus \\
\hline North American porcupine & Erethizon dorsatum \\
\hline Northern olingo & Bassaricyon gabbii \\
\hline Northern short-tailed shrew & Blarina brevicauda \\
\hline Northern white-cheeked gibbon & Nomascus leucogenys \\
\hline Nutria & Myocastor coypus \\
\hline Olive baboon & Papio anubis \\
\hline Patagonian mara & Dolichotis patagonum \\
\hline Prairie vole & Microtus ochrogaster \\
\hline Prevost’s squirrel & Callosciurus prevostii \\
\hline Quoll & Dasyurus spp. \\
\hline Raccoon & Procyon lotor \\
\hline Red fox & Vulpes vulpes \\
\hline Red kangaroo & Macropus rufus \\
\hline Red ruffed lemur & Varecia rubra \\
\hline Red-handed or Midas tamarin & Saguinus midas \\
\hline Red-tailed squirrel & Sciurus granatensis \\
\hline Rhesus macaque & Macaca mulatta \\
\hline Ringtail & Bassariscus astutus \\
\hline Ring-tailed lemur & Lemur catta \\
\hline Rodrigues flying fox & Pteropus rodricensis \\
\hline Siamang & Symphalangus syndactylus \\
\hline Southern flying squirrel & Glaucomys volans \\
\hline Southern sea otter & Enhydra lutris nereis \\
\hline Spider monkey & Ateles spp. \\
\hline Striped skunk & Mephitis mephitis \\
\hline Sumatran orangutan & Pongo abelii \\
\hline Tasmanian devil & Sarcophilus harrisii \\
\hline Thirteen-lined ground squirrel & Ictidomys tridecemlineatus \\
\hline
\end{tabular}


Appendix 1. Common and scientific names of animals cited.-Continued

\begin{tabular}{|c|c|}
\hline Common name & Scientific name \\
\hline \multicolumn{2}{|c|}{ Mammals-Continued } \\
\hline Tiger quoll & Dasyurus maculatus \\
\hline Townsend's mole & Scapanus townsendii \\
\hline Virginia opossum & Didelphis virginiana \\
\hline Western gray squirrel & Sciurus griseus \\
\hline Western harvest mouse & Reithrodontomys megalotis \\
\hline Western lowland gorilla & Gorilla gorilla gorilla \\
\hline Western pocket gopher & Thomomys mazama \\
\hline White-eared titi monkey & Callicebus donacophilus \\
\hline White-footed mouse & Peromyscus leucopus \\
\hline White-handed gibbon & Hylobates lar \\
\hline White-headed lemur & Eulemur albifrons \\
\hline White-headed or Geoffroy's marmoset & Callithrix geoffroyi \\
\hline White-tailed deer & Odocoileus virginianus \\
\hline Wolf & Canis lupus \\
\hline Woodchuck & Marmota monax \\
\hline Woylie (brush-tailed bettong) & Bettongia penicillata \\
\hline Yellow-footed rock wallaby & Petrogale xanthopus \\
\hline \multicolumn{2}{|r|}{ Birds } \\
\hline African grey parrot & Psittacus erithacus \\
\hline American crow & Corvus brachyrhynchos \\
\hline American robin & Turdus migratorius \\
\hline Australian brushturkey & Alectura lathami \\
\hline Barn owl & Tyto alba \\
\hline Black-capped chickadee & Parus atricapillus \\
\hline Black-crowned night heron & Nycticorax nycticorax \\
\hline Blue jay & Cyanocitta cristata \\
\hline Blue-and-yellow or blue-and-gold macaw & Ara ararauna \\
\hline Blue-crowned parakeet or conure & Aratinga acuticaudata \\
\hline Blue-fronted Amazon & Amazona aestiva \\
\hline Blue-naped mousebird & Urocolius macrourus \\
\hline Brown thrasher & Toxostoma rufum \\
\hline Budgerigar & Melopsittacus undulatus \\
\hline
\end{tabular}


Appendix 1. Common and scientific names of animals cited.-Continued

\begin{tabular}{|c|c|}
\hline Common name & Scientific name \\
\hline \multicolumn{2}{|c|}{ Birds-Continued } \\
\hline Burrowing parrot & Cyanoliseus patagonus \\
\hline Bushtit & Psaltriparus minimus \\
\hline California quail & Callipepla californica \\
\hline California thrasher & Toxostoma redivivum \\
\hline Carolina wren & Thryothorus ludovicianus \\
\hline Chukar & Alectoris chukar \\
\hline Cockatiel & Nymphicus hollandicus \\
\hline Common canary & Serinus canaria \\
\hline Common pheasant & Phasianus colchicus \\
\hline Cuban Amazon & Amazona leucocephala \\
\hline Dark-eyed junco & Junco hyemalis \\
\hline Diamond dove & Geopelia cuneata \\
\hline Domestic canary & Serinus canaria domestica \\
\hline Domestic chicken & Gallus gallus domesticus \\
\hline Domestic duck & Anas platyrhynchos domesticus \\
\hline Downy woodpecker & Picoides pubescens \\
\hline Eastern rosella & Platycercus eximius \\
\hline Eastern screech owl & Otus asio \\
\hline Emu & Dromaius novaehollandiae \\
\hline European starling & Sturnus vulgaris \\
\hline Galah & Eolophus roseicapilla \\
\hline Greater rhea & Rhea americana \\
\hline Greater roadrunner & Geococcyx californianus \\
\hline Green-naped lorikeet & Trichoglossus haematodus haematodus \\
\hline Helmeted guineafowl & Numida meleagris \\
\hline Hermit thrush & Catharus guttatus \\
\hline House finch & Carpodacus mexicanus \\
\hline House sparrow & Passer domesticus \\
\hline House wren & Troglodytes aedon \\
\hline $\begin{array}{l}\text { Hybrid blue-and-yellow X Scarlet macaw } \\
\text { (“Catalina” macaw) }\end{array}$ & Ara ararauna X A. macao \\
\hline Inca tern & Larosterna inca \\
\hline Indian peafowl & Pavo cristatus \\
\hline
\end{tabular}


Appendix 1. Common and scientific names of animals cited.-Continued

\begin{tabular}{|c|c|}
\hline Common name & Scientific name \\
\hline \multicolumn{2}{|c|}{ Birds-Continued } \\
\hline Loggerhead shrike & Lanius ludovicianus \\
\hline Lovebirds & Agapornis spp. \\
\hline Mallard X & Anas platyrhynchos $\mathrm{X}$ \\
\hline Marigold (Edward's) lorikeet & Trichoglossus capistratus \\
\hline Military macaw & Ara militaris \\
\hline Mourning dove & Zenaida macroura \\
\hline Northern bobwhite & Colinus virginianus \\
\hline Northern cardinal & Cardinalis cardinalis \\
\hline Northern flicker & Colaptes auratus \\
\hline Northern mockingbird & Mimus polyglottos \\
\hline Northern red-billed hornbill & Tockus erythrorhynchus \\
\hline Orange-fronted parakeet or conure & Aratinga canicularis \\
\hline Ornate lorikeet & Trichoglossus ornatus \\
\hline Ostrich & Struthio camelus \\
\hline Ovenbird & Seiurus aurocapillus \\
\hline Rainbow lorikeet & Trichoglossus haematodus \\
\hline Red-and-green macaw & Ara chloropterus \\
\hline Red-crowned (green-cheeked) Amazon & Amazona viridigenalis \\
\hline Red-tailed black cockatoo & Calyptorhynchus banksii \\
\hline Rock partridge & Alectoris graeca \\
\hline Rock pigeon & Columba livia \\
\hline Rosy-faced lovebird & Agapornis roseicollis \\
\hline Ruffed grouse & Bonasa umbellus \\
\hline Salmon-crested or moluccan cockatoo & Cacatua moluccensis \\
\hline Sanderling & Calidris alba \\
\hline Scarlet macaw & Ara macao \\
\hline Southern screamer & Chauna torquata \\
\hline Speckled mousebird & Colius striatus \\
\hline Spotted towhee & Pipilo maculatus \\
\hline Sun parakeet or conure & Aratinga solstitialis \\
\hline Swainson’s lorikeet & Trichoglossus haematodus moluccanus \\
\hline Swainson's thrush & Catharus ustulatus \\
\hline
\end{tabular}


Appendix 1. Common and scientific names of animals cited.-Continued

\begin{tabular}{|c|c|}
\hline Common name & Scientific name \\
\hline \multicolumn{2}{|c|}{ Birds-Continued } \\
\hline Thick-billed parrot & Rhynchopsitta pachyrhyncha \\
\hline Tufted titmouse & Baeolophus bicolor \\
\hline Western scrub jay & Aphelocoma californica \\
\hline White (umbrella) cockatoo & Cacatua alba \\
\hline White-breasted nuthatch & Sitta carolinensis \\
\hline Wild turkey & Meleagris gallopavo \\
\hline Wood thrush & Hylocichla mustelina \\
\hline Yellow-backed lorikeet & Lorius garrulus flavopalliatus \\
\hline Yellow-headed Amazon or yellow-headed parrot & Amazona oratrix \\
\hline Yellow-naped Amazon & Amazona auropalliata \\
\hline Yellow-rumped warbler & Dendroica coronata \\
\hline \multicolumn{2}{|c|}{ Roundworms (nematodes) } \\
\hline Dog roundworm & Toxocara canis \\
\hline Raccoon roundworm & Baylisascaris procyonis \\
\hline \multicolumn{2}{|c|}{ Hookworms (nematodes) } \\
\hline Dog and cat hookworms & Genus Ancylostoma \\
\hline \multicolumn{2}{|c|}{ Flatworms or flukes (trematodes) } \\
\hline Intestinal flukes of carnivores & Genus Alaria \\
\hline & Insects \\
\hline Bed bugs & Genus Cimex \\
\hline
\end{tabular}


Appendix 2. Cases of Baylisascaris neural larva migrans in pets.

[NR, not reported or details unavailable; >,greater than]

\begin{tabular}{|c|c|c|c|c|}
\hline Animal(s) & Location & $\begin{array}{c}\text { Deaths or } \\
\text { animals } \\
\text { affected per } \\
\text { total number } \\
\text { of animals }\end{array}$ & Source of infection & Reference \\
\hline Dog & Michigan & 1 of 1 & $\begin{array}{l}\text { The owner also had a raccoon that shed roundworms } \\
\text { in its feces. A puppy was exposed to the raccoon } \\
\text { and its environment. }\end{array}$ & Thomas (1988). \\
\hline Dog & California & 1 of 1 & $\begin{array}{l}\text { A dog had access to a small property known to } \\
\text { contain raccoon latrines. }\end{array}$ & $\begin{array}{l}\text { H.R. Galano and others, } \\
\text { unpub. data (2005). }\end{array}$ \\
\hline Rabbit & Indiana & 1 & $\begin{array}{l}\text { A pet rabbit was placed in a cage that } 2 \text { years previ- } \\
\text { ously had housed two juvenile raccoons for reha- } \\
\text { bilitation. At no time did the raccoons receive } \\
\text { any treatments for parasites. }\end{array}$ & $\begin{array}{l}\text { J.A. Engelhardt, } \\
\text { unpub. data (1987). }\end{array}$ \\
\hline Rabbits & Washington & 4 of 4 & $\begin{array}{l}\text { Rabbits were kept by two owners and had access to } \\
\text { an outdoor enclosure and a yard. Raccoons were } \\
\text { common in the area and often were seen by the } \\
\text { owners. }\end{array}$ & Deeb and DiGiacomo (1994). \\
\hline Rabbits & Illinois & 2 of 2 & $\begin{array}{l}\text { House rabbits were let out in the backyard in } \\
\text { Chicago where raccoons were common. }\end{array}$ & $\begin{array}{l}\text { K.R. Kazacos, unpub. data } \\
\text { (1996). }\end{array}$ \\
\hline Cockatiels & Iowa & 3 of 3 & $\begin{array}{l}\text { The birds were briefly housed in a cage previously } \\
\text { used for two young raccoons. }\end{array}$ & Myers and others (1983). \\
\hline Canaries & California & 12 of 22 & $\begin{array}{l}\text { Twenty-two canaries were housed in an outdoor } \\
\text { aviary. Raccoons were commonly seen near the } \\
\text { aviary. }\end{array}$ & Loretti and others (2008). \\
\hline Cockatoo & Kansas & 1 of 1 & $\begin{array}{l}\text { A cockatoo owned by a wildlife rehabilitator was } \\
\text { intermittently exposed to a cage previously used } \\
\text { to house juvenile raccoons. }\end{array}$ & Wolf and others (2007). \\
\hline $\begin{array}{l}\text { Spider } \\
\text { monkey }\end{array}$ & Massachusetts & 1 of 1 & $\begin{array}{l}\text { A spider monkey was housed in an area where } \\
\text { raccoons had been kept previously. }\end{array}$ & Garlick and others (1996). \\
\hline $\begin{array}{l}\text { Parrots and } \\
\text { parakeets }\end{array}$ & Indiana & 10 of 10 & $\begin{array}{l}\text { The birds were fed a seed mixture that was stored in } \\
\text { a person's garage and became contaminated } \\
\text { by wild raccoons that had access to the area. }\end{array}$ & $\begin{array}{l}\text { A.M. Lennox and others, } \\
\text { unpub. data (1996); } \\
\text { Lennox and others (2015). }\end{array}$ \\
\hline $\begin{array}{l}\text { Scarlet } \\
\text { macaws }\end{array}$ & Iowa & 2 of 2 & NR & $\begin{array}{l}\text { M.A. Nieves and others, } \\
\text { unpub. data (1989). }\end{array}$ \\
\hline Pigeons & Nebraska & $>15$ of 200 & $\begin{array}{l}\text { The birds were fed a seed mixture containing sor- } \\
\text { ghum that was contaminated with raccoon feces. }\end{array}$ & $\begin{array}{l}\text { E.N. Pendleton and V.W. Rinne, } \\
\text { unpub. data (1992). }\end{array}$ \\
\hline
\end{tabular}


Appendix 3. Cases of Baylisascaris neural larval migrans in animal facilities.

[CNS, central nervous system; NR, not reported; >, greater than]

\begin{tabular}{|c|c|c|c|c|c|}
\hline Animal(s) & Location & Facility type & $\begin{array}{l}\text { Number of } \\
\text { deaths or } \\
\text { animals } \\
\text { affected }\end{array}$ & Source of infection & Reference \\
\hline Rabbits & Michigan & $\begin{array}{l}\text { Commercial } \\
\text { rabbitry }\end{array}$ & 80 & $\begin{array}{l}\text { Although the source was not determined, hay and } \\
\text { straw bedding used for the rabbits were stored in } \\
\text { a barn loft that was accessible by wild birds and } \\
\text { mammals; raccoons or skunks were suspected. }\end{array}$ & $\begin{array}{l}\text { Dade and others } \\
\text { (1975). }\end{array}$ \\
\hline Rabbits & Indiana & $\begin{array}{l}\text { Private } \\
\quad \text { rabbitry }\end{array}$ & 20 & $\begin{array}{l}\text { Raccoons were common on the farm where the } \\
\text { rabbits were kept and had access to the rabbit } \\
\text { feed. A raccoon had been kept in one of the rabbit } \\
\text { cages approximately } 2 \text { months prior. }\end{array}$ & $\begin{array}{l}\text { D.D. Harrington, } \\
\text { unpub. data } \\
\text { (1982). }\end{array}$ \\
\hline Bobwhites & Indiana & Farm & 85 & $\begin{array}{l}\text { Eighty-five bobwhite quail had access to a dirt run } \\
\text { that had previously housed three young raccoons. } \\
\text { Huge numbers of infective } B \text {. procyonis eggs were } \\
\text { found in soil samples from the pen, and feces of } \\
\text { the raccoons were positive. }\end{array}$ & $\begin{array}{l}\text { Reed and others } \\
\text { (1981); Kaza- } \\
\text { cos and others } \\
\text { (1982). }\end{array}$ \\
\hline Bobwhites & Illinois & Farm & 640 & $\begin{array}{l}\text { A flock of } 712 \text { bobwhite quail were exposed to pens } \\
\text { and straw contaminated by wild raccoons. }\end{array}$ & $\begin{array}{l}\text { K.R. Kazacos and } \\
\text { others, unpub. } \\
\text { data (2002). }\end{array}$ \\
\hline $\begin{array}{l}\text { Long-tailed } \\
\text { chinchillas }\end{array}$ & Minnesota & Farm & 17 & $\begin{array}{l}\text { At a farm where 1,400 chinchillas were housed, } \\
\text { low-level exposure to B. procyonis eggs through } \\
\text { contaminated hay was suspected in the deaths. }\end{array}$ & $\begin{array}{l}\text { A. Wuenschmann } \\
\text { and others, un- } \\
\text { pub. data (2007). }\end{array}$ \\
\hline Emus & Ontario & Farm & $\begin{array}{l}9 \text { chicks } \\
2 \text { adults }\end{array}$ & $\begin{array}{l}\text { Breeder birds and } 35 \text { emu chicks were housed in } \\
\text { indoor or outdoor pens with straw bedding from a } \\
\text { barn. Raccoons were seen frequently on the farm. } \\
\text { It was suspected that this straw bedding had been } \\
\text { contaminated by raccoons, which had frequently } \\
\text { been seen on the farm. }\end{array}$ & $\begin{array}{l}\text { Kwiecen and others } \\
\text { (1993). }\end{array}$ \\
\hline Domestic sheep & Idaho & Ranch & 1 & $\begin{array}{l}\text { A 3-day-old lamb had been moribund since birth and } \\
\text { had Baylisascaris NLM. The pregnant ewe must } \\
\text { have ingested infective eggs, and larvae migrated } \\
\text { transplacentally into the developing lamb. }\end{array}$ & Anderson (1999). \\
\hline
\end{tabular}


Appendix 3. Cases of Baylisascaris neural larval migrans in animal facilities.-Continued

[CNS, central nervous system; NR, not reported; >, greater than]

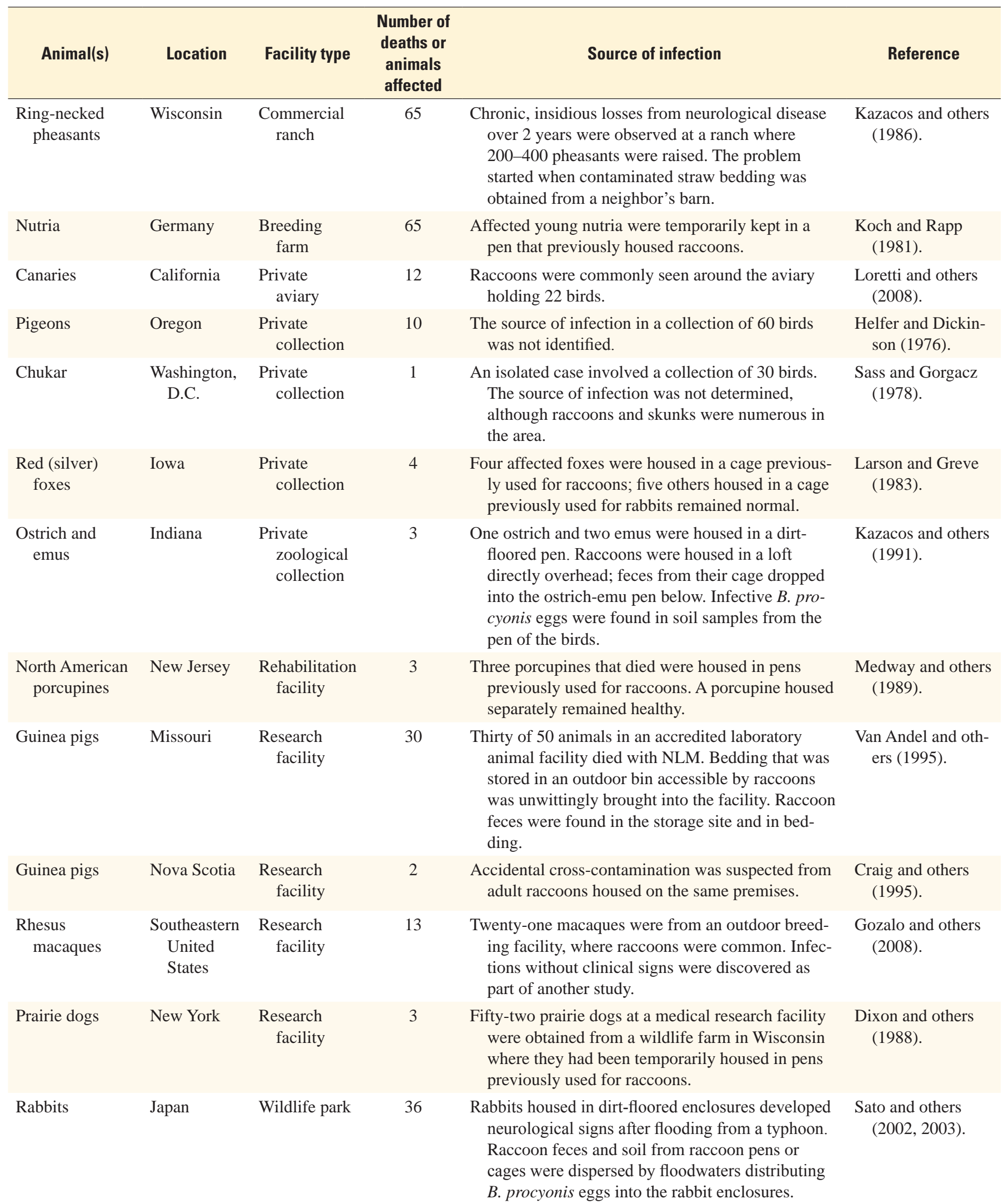


Appendix 3. Cases of Baylisascaris neural larval migrans in animal facilities.-Continued

[CNS, central nervous system; NR, not reported; >, greater than]

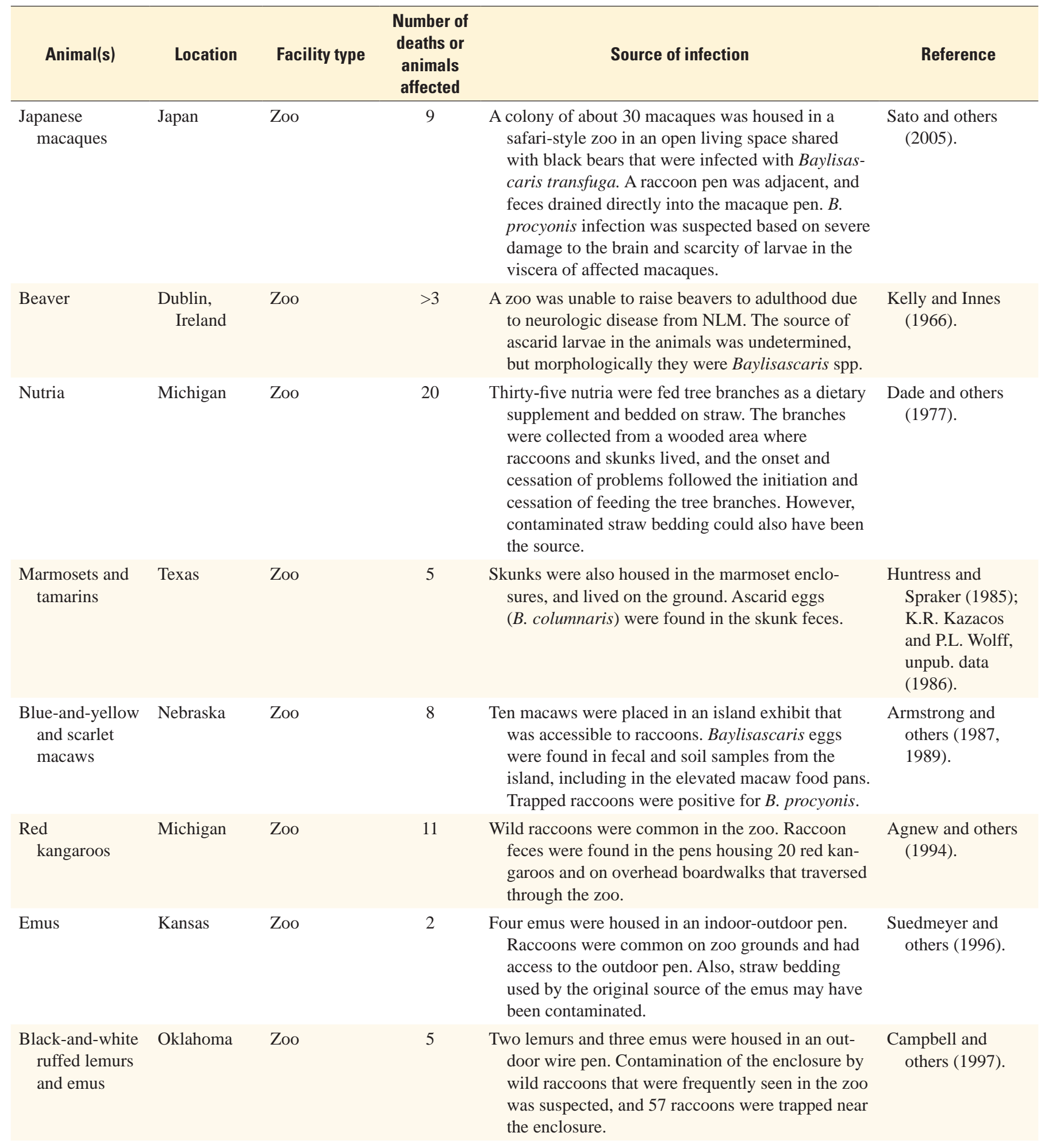


Appendix 3. Cases of Baylisascaris neural larval migrans in animal facilities.-Continued

[CNS, central nervous system; NR, not reported; >, greater than]

\begin{tabular}{|c|c|c|c|c|c|}
\hline Animal(s) & Location & Facility type & $\begin{array}{l}\text { Number of } \\
\text { deaths or } \\
\text { animals } \\
\text { affected }\end{array}$ & Source of infection & Reference \\
\hline $\begin{array}{l}\text { Indian fruit bat, } \\
\text { yellow-footed } \\
\text { rock wal- } \\
\text { labies, lion } \\
\text { tamarins, red- } \\
\text { tailed black } \\
\text { cockatoo, } \\
\text { thick-billed } \\
\text { parrot, galah }\end{array}$ & California & Zoo & $>15$ & $\begin{array}{l}\text { Raccoons and skunks had free-run of the zoo, with } \\
\text { widespread contamination. Roundhouse exhibits } \\
\text { with wire tops allowed feces to fall into pens. } \\
\text { Large wire mesh and overhanging foliage allowed } \\
\text { animal access to the zoo and exhibits. A major } \\
\text { control effort reduced the problem. }\end{array}$ & $\begin{array}{l}\text { Stringfield and } \\
\quad \text { Sedgwick } \\
\text { (1997). }\end{array}$ \\
\hline $\begin{array}{l}\text { White-handed } \\
\text { gibbon }\end{array}$ & Kansas & Zoo & 1 & $\begin{array}{l}\text { A gibbon developed CNS signs after being placed } \\
\text { in an island exhibit in which wild raccoons had } \\
\text { established latrines. The gibbon spent time under } \\
\text { its shelter, where raccoon feces with infective } \\
\text { Baylisascaris eggs were found. }\end{array}$ & $\begin{array}{l}\text { Ball and others } \\
\text { (1988). }\end{array}$ \\
\hline Orangutan & Wisconsin & Zoo & 1 & $\begin{array}{l}\text { A 32.5-year-old orangutan developed worsening } \\
\text { CNS disease and was euthanized. It had long-term } \\
\text { exposure to an enclosure with raccoon latrines } \\
\text { and had exhibited geophagia. }\end{array}$ & $\begin{array}{l}\text { Hanley and others } \\
\text { (2006). }\end{array}$ \\
\hline Titi monkey & Maryland & Zoo & 2 & $\begin{array}{l}\text { Two titi monkeys developed progressive CNS } \\
\text { disease, and one responded to treatment. Raccoon } \\
\text { latrines were found near their indoor and outdoor } \\
\text { display enclosures. }\end{array}$ & $\begin{array}{l}\text { Beck and others } \\
\text { (2010). }\end{array}$ \\
\hline $\begin{array}{l}\text { Burrowing } \\
\text { parrots, } \\
\text { crested } \\
\text { screamers, } \\
\text { porcupine }\end{array}$ & Manitoba & Zoo & 7 & $\begin{array}{l}\text { The animals were housed in chainlink mesh } \\
\text { enclosures; raccoons had access to the tops of } \\
\text { the enclosures and were observed on them. One } \\
\text { porcupine, two screamers, and four of five parrots } \\
\text { died. }\end{array}$ & $\begin{array}{l}\text { Thompson and oth- } \\
\text { ers (2008). }\end{array}$ \\
\hline $\begin{array}{l}\text { Amazon and } \\
\text { Cuban parrots, } \\
\text { rosy-faced } \\
\text { lovebirds, } \\
\text { rainbow and } \\
\text { Swainson's } \\
\text { lorikeets }\end{array}$ & $\begin{array}{l}\text { Ontario } \\
\text { (Toronto) }\end{array}$ & Zoo & 29 & $\begin{array}{l}\text { Raccoons and raccoon fecal contamination were } \\
\text { both common on zoo grounds, especially around } \\
\text { the aviary. Latrines were found on the tops of wire } \\
\text { enclosures. }\end{array}$ & $\begin{array}{l}\text { Russell and others } \\
\text { (2005); Russell } \\
\text { (2006). }\end{array}$ \\
\hline
\end{tabular}


Appendix 3. Cases of Baylisascaris neural larval migrans in animal facilities.-Continued

[CNS, central nervous system; NR, not reported; >, greater than]

\begin{tabular}{|c|c|c|c|c|c|}
\hline Animal(s) & Location & Facility type & $\begin{array}{l}\text { Number of } \\
\text { deaths or } \\
\text { animals } \\
\text { affected }\end{array}$ & Source of infection & Reference \\
\hline $\begin{array}{c}\text { De Brazza’s } \\
\text { monkeys }\end{array}$ & Indiana & Zoo & 2 & $\begin{array}{l}\text { The monkeys had subtle CNS disease following } \\
\text { exposure to a contaminated roundhouse enclosure. } \\
\text { Raccoon latrines were found on the top of the } \\
\text { enclosure. }\end{array}$ & $\begin{array}{l}\text { C.L. Eng and } \\
\text { K.R. Kazacos, } \\
\text { unpub. data } \\
\text { (1997). }\end{array}$ \\
\hline $\begin{array}{l}\text { Patagonian } \\
\text { maras and } \\
\text { capybara }\end{array}$ & Illinois & Zoo & 5 & $\begin{array}{l}\text { All animals were exposed to raccoon fecal contami- } \\
\text { nation in their enclosures from wild raccoons on } \\
\text { zoo grounds; four maras and one capybara died. }\end{array}$ & $\begin{array}{l}\text { K.R. Kazacos and } \\
\text { others, unpub. } \\
\text { data (1987 } \\
\text { [capybara] and } \\
1989 \text { [maras]). }\end{array}$ \\
\hline
\end{tabular}


For more information concerning this report, contact:

Director

U.S. Geological Survey

National Wildlife Health Center

6006 Schroeder Road

Madison, WI 53711-6223

jsleeman@usgs.gov

or visit our Web site at:

http://www.nwhc.usgs.gov/ 
